Roberto dos Santos Rocha

\title{
Linha de Produto para Gestão de Processos de Negócio incluindo Aspectos Dinâmicos
}

São Paulo

Novembro 2012 
Roberto dos Santos Rocha

\title{
Linha de Produto para Gestão de Processos de Negócio incluindo Aspectos Dinâmicos
}

\author{
Dissertação apresentada como parte da \\ avaliação do programa de mestrado em \\ Sistemas de Informação da EACH - Escola de \\ Artes, Ciências e Humanidades.
}

Orientador: Prof. Dr. Marcelo Fantinato

Versão corrigida. Resolução CoPGr 6018, de 13 de outubro de 2011.

A versão original está disponível na Biblioteca da EACH | USP

São Paulo

Novembro 2012 
Autorizo a reprodução e divulgação total ou parcial deste trabalho, por qualquer meio convencional ou eletrônico, para fins de estudo e pesquisa, desde que citada a fonte.

\section{CATALOGAÇÃO-NA-PUBLICAÇÃO \\ Biblioteca}

Escola de Artes, Ciências e Humanidades da Universidade de São Paulo

Rocha, Roberto dos Santos

Linha de produto para gestão de processos de negócio incluindo aspectos dinâmicos / Roberto dos Santos Rocha ; orientador, Marcelo Fantinato. - São Paulo, 2012.

116 f. : il.

Dissertação (Mestrado em Ciências) - Programa de PósGraduação em Sistema de Informação, Escola de Artes, Ciências e Humanidades da Universidade de São Paulo.

1. Engenharia de software. 2. Linhas de produtos de software. 3. Sistemas de informação gerencial. I. Fantinato, Marcelo, orient. II. Título.

CDD 22.ed. - 005.1 
Dissertação de mestrado sob o título "Linha de Produto para Gestão de Processos de Negócio incluindo Aspectos Dinâmicos", defendida por Roberto dos Santos Rocha e aprovada em 01 de novembro de 2012, em São Paulo, Estado de São Paulo, pela banca examinadora constituída pelos doutores:

Prof. Dr. Marcelo Fantinato

Orientador

\author{
Prof $^{\mathrm{a}}$. Dr ${ }^{\mathrm{a}}$. Lucinéia Heloisa Thom \\ Universidade Federal do Rio Grande do Sul
}

Prof. Dr. Marcos Lordello Chaim

Universidade de São Paulo 
Com todo meu amor e eterna gratidão, dedico este trabalho ao meu pai Manoel (em memória). 
Agradeço a Deus pela vida e pela oportunidade de ter participado deste programa de pós-graduação.

Ao meu orientador, Prof. Dr. Marcelo Fantinato, por ter me apresentado o fascinante mundo da pesquisa e pelo direcionamento cuidadoso, sempre mostrando os caminhos mais adequados a serem seguidos. Ainda, pelas valiosas contribuições à minha formação pessoal $e$ profissional.

Com atenção especial à minha família. Ao meu pai Manoel (em memória) a quem serei eternamente grato. À minha querida mãe, Enivalda, pelo carinho e apoio em todos os momentos da minha vida: amo-te muito! Agradeço também a minha irmã, Renata, $e$ sobrinhas - Manu e Nanda - pelo carinho, paciência e compreensão.

Aos meus tios - Renato e Reni - e primos pelo apoio à fase inicial de adaptação à cidade de São Paulo.

Aos "Cavaleiros da Ordem da Nutella" - Eric Ostroski, Fernando Henrique, Higor Amario, Jadson Castro, Leila Bergamasco, Renata Madeo e Rosiane Correia - pelos poucos, porém marcantes, encontros para o café da tarde com Nutella. Agradeço a todos pela generosidade com que me trataram durante esse período de convivência.

Aos professores do PPgSI, especialmente aqueles com quem tive a oportunidade de trabalhar diretamente disciplinas, período em que fui representante discente e/ou eventos científicos: Prof ${ }^{a}$. Ariane Machado, Prof ${ }^{a}$. Claudia Inés Garcia, Profa. Fátima Nunes, Profa. Kátia Honório, Prof ${ }^{a}$. Sarajane Peres, Prof. Edmir Prado, Prof. Ivandré Paraboni, Prof. Luciano Digiampietri, Prof. Marcelo Lauretto, Prof. Marcelo Morandini e Prof. Marcos Chaim.

Aos amigos do Núcleo de Apoio Acadêmico do IMS/CAT UFBA que muito torceram e contribuíram para tornar possível este sonho.

À Universidade Federal da Bahia (UFBA) e aos órgãos de fomento - Coordenação de Aperfeiçoamento de Pessoal de Nível Superior (Capes) e Fundação de Amparo à Pesquisa do Estado de São Paulo (Fapesp) - responsáveis por parte do financiamento à esta pesquisa. 
"Academic organizations in computer science seem to prefer to work on new theories. However, some of the most successful academic work is a fusion and formalization of successful techniques".

(James M. Neighbors, 1989) 


\section{Resumo}

Linha de Produto de Software (LP) é uma forma sistemática de promover a geração de produtos de software específicos baseados no reúso de uma infraestrutura bem definida. Conceitos de LP aplicados ao domínio de Gestão de Processos de Negócio (BPM - Business Process Management) já apresentaram resultados significativos, entretanto, o escopo de aplicação e os benefícios ainda são limitados. Essas limitações ocorrem, pois as abordagens de LP já existentes para BPM normalmente não cobrem todo o ciclo de vida de processos de negócio e não oferecem o devido tratamento aos aspectos dinâmicos que as organizações demandam para esse domínio. Linha de Produto de Software Dinâmica (LPD) é uma evolução das LPs tradicionais que tem proporcionado uma forma eficiente para lidar com adaptações de produtos em tempo de execução. LPDs podem ser aplicadas, por exemplo, no contexto de arquiteturas SOA (Service-oriented Architecture), que por sua vez podem ser usadas como base tecnológica para viabilizar BPM nas organizações. Dentro desse contexto, este trabalho propõe uma abordagem de LPD para atender as necessidades de organizações interessadas em realizar processos de negócio, por meio de um alinhamento entre conceitos de BPM e SOA. A abordagem proposta aqui, denominada Dynamic Product Line for Business Process Management (DynPL4BPM), visa ser abrangente o suficiente para cobrir todo o ciclo de vida de BPM, sendo previsto o tratamento de aspectos dinâmicos que o domínio de BPM requer. Uma avaliação sistemática e comparativa demonstrou que a abordagem proposta é bem sucedida em apresentar processos bem mais abrangentes que outras soluções similares já propostas na literatura para o mesmo fim.

Palavras-chave: Gestão de Processos de Negócio; BPM; Computação Orientada a Serviços; SOA; Linha de Produto de Software; Linha de Produto Dinâmica. 


\section{Abstract}

Software Product Line (PL) is a systematic way to promote the generation of specific software products based on the reuse of a well-defined infrastructure. Concepts of PL applied to Business Process Management (BPM) have already presented significant results; however, the application scope and benefits are still limited. These limitations occur because the existing approaches of LP for BPM usually do not cover the entire lifecycle of business processes and do not provide proper treatment to the dynamic aspects that organizations demand for this domain. Dynamic Software Product Line (DPL) is an evolution of traditional PLs that has provided an efficient way to deal with adaptations of products at runtime. DPLs can be applied, for example, in the SOA (Service-oriented Architecture) context, which in turn can be used as technological basis to enable BPM within organizations. Within this context, this dissertation proposes a DPL approach to meet the needs of organizations interested in carrying out business processes by means of an alignment between BPM and SOA concepts. The approach proposed here, called Dynamic Product Line for Business Process Management (DynPL4BPM), aims to be comprehensive enough to cover the entire BPM lifecycle, including the treatment of dynamic aspects that the BPM domain requires. A systematic and comparative assessment showed that the proposed approach is successful in presenting processes much more comprehensive than other similar solutions already proposed in the literature for the same purpose.

Keywords: BPM; SOA; Service-oriented Computing; Business Process Management; Software Product Line; Dynamic Product Line. 


\section{Sumário}

Lista de Figuras

Lista de Abreviaturas e Siglas ..xii

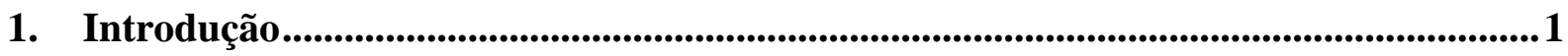

1.1. Exemplo Motivacional .......................................................................................... 3

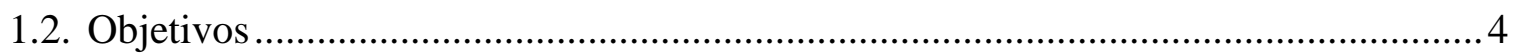

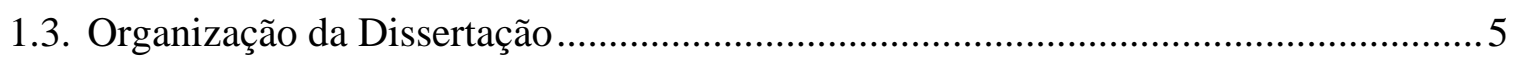

2. Gestão de Processos de Negócio - BPM ...............................................................6

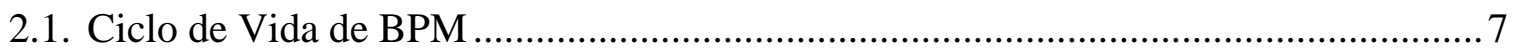

2.2. Notação e Modelo de Processos de Negócio - BPMN .................................................9

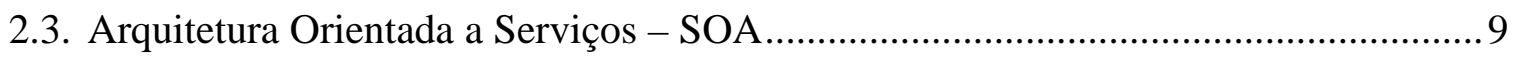

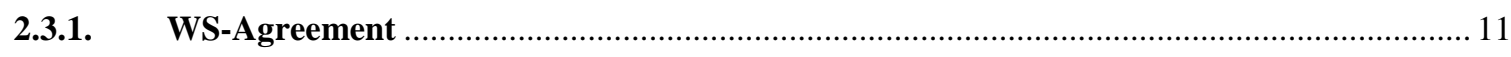

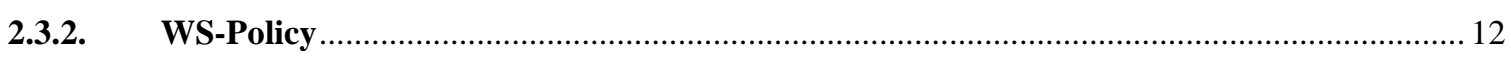

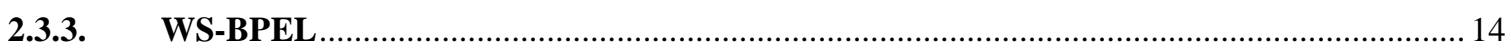

2.4. Processos de Negócio Dinâmicos e Adaptáveis ........................................................ 15

2.5. Considerações Finais ........................................................................................ 17

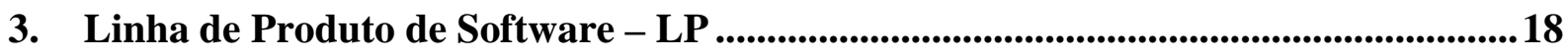

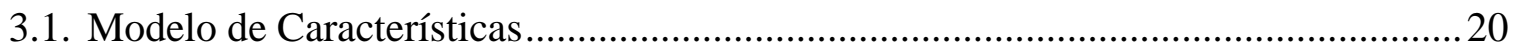

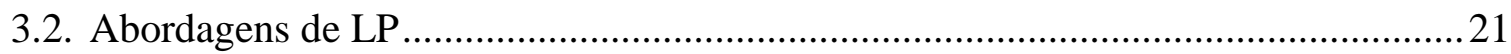

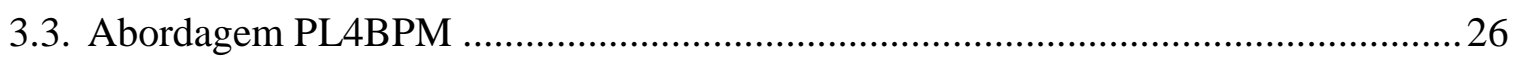

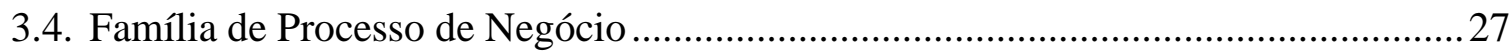

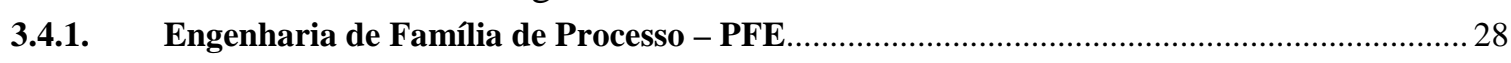

3.4.2. Engenharia de Família de Negócios - BFE …………………………………………...... 30

3.5. Linha de Produto de Software Dinâmica - LPD .......................................................... 33

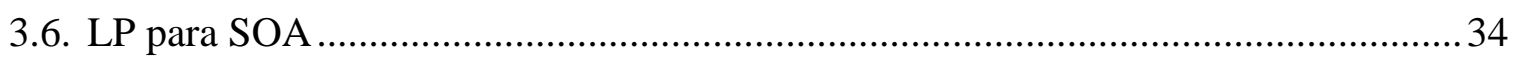

3.6.1. Definição de Serviços com Base em Características.............................................................. 35

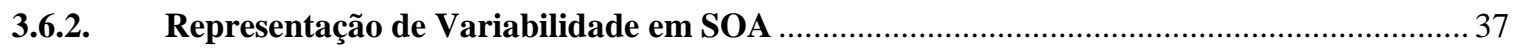

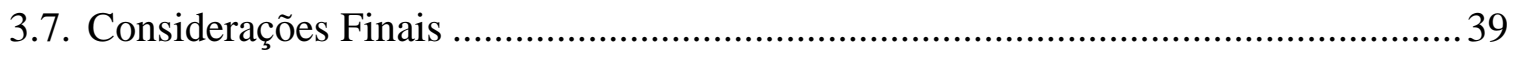

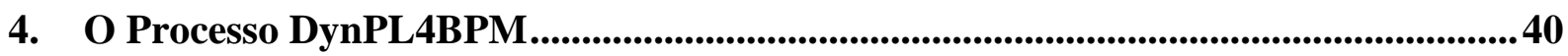

4.1. Visão Geral do Processo DynPL4BPM .................................................................... 40

4.2. Tratamento de Aspectos Dinâmicos na DynPL4BPM ............................................ 48 


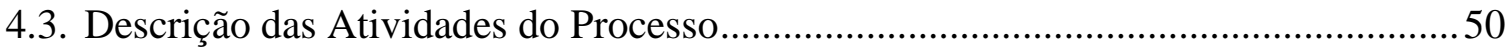

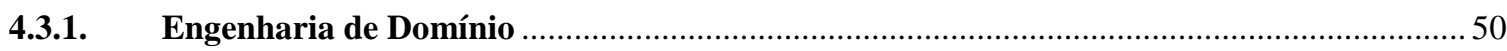

4.3.1.1. Atividade "1.A - Análise de Domínio do PN" ........................................................................... 50

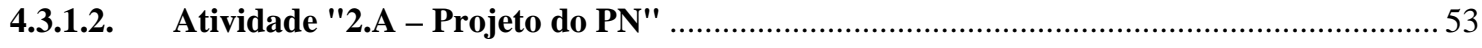

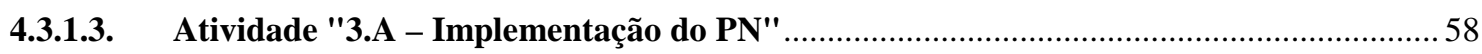

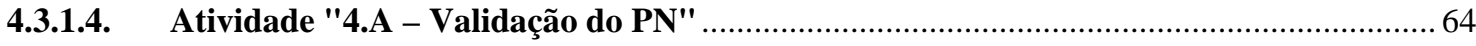

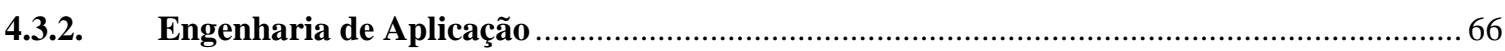

4.3.2.1. Atividade "1.B - Refinamento do Modelo de Domínio do PN" .......................................... 66

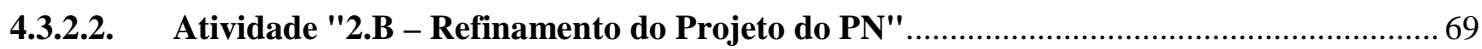

4.3.2.3. Atividade "3.B - Refinamento da Implementação do PN" .............................................. 71

4.3.2.4. Atividade "4.B - Refinamento da Validação do PN" ......................................................... 74

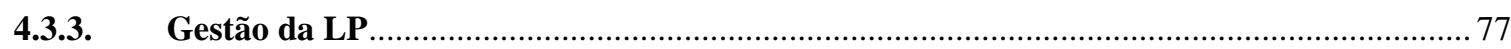

4.3.3.1. Atividade "5 - Execução e Administração da IPN" ................................................................ 77

4.3.3.2. Atividade "6 - Monitoramento da IPN".......................................................................... 78

4.3.3.3. Atividade "7 - Seleção Dinâmica de Serviços Web" .............................................................. 79

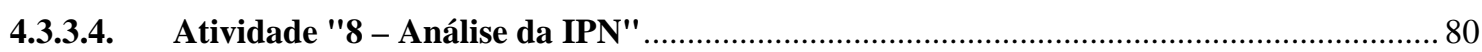

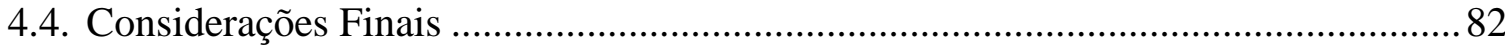

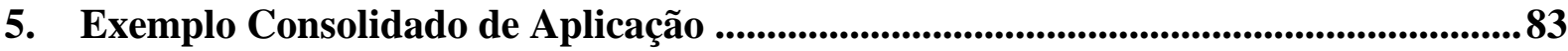

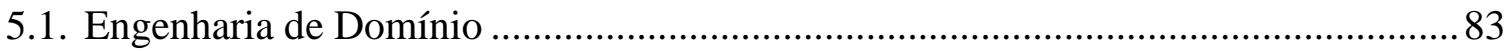

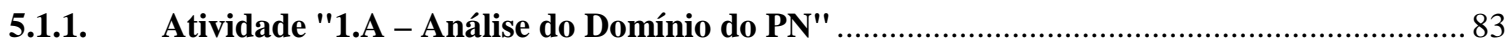

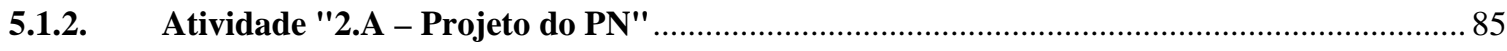

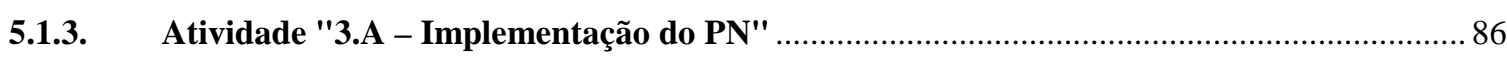

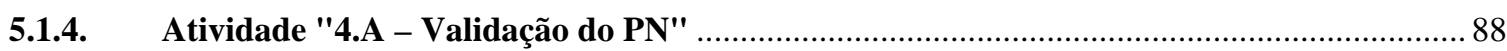

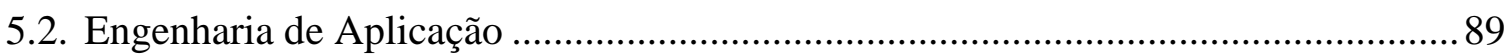

5.2.1. Atividade "1.B - Refinamento do Modelo de Domínio do PN" ................................................. 89

5.2.2. Atividade "2.B - Refinamento do Projeto do PN" ................................................................... 91

5.2.3. Atividade "3.B - Refinamento da Implementação do PN" .................................................. 92

5.2.4. Atividade "4.B - Refinamento da Validação do PN".............................................................. 93

6. Comparação da Abordagem DynPL4BPM ..................................................................94

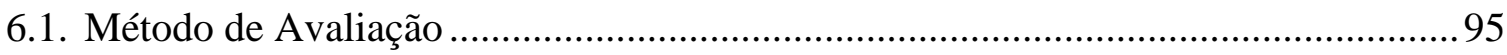

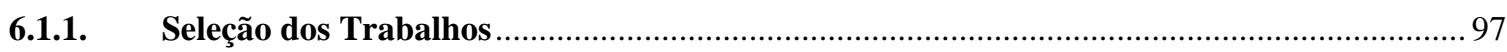

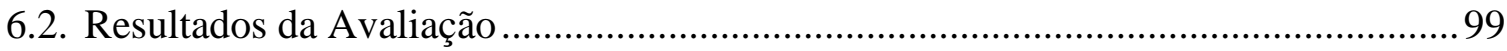

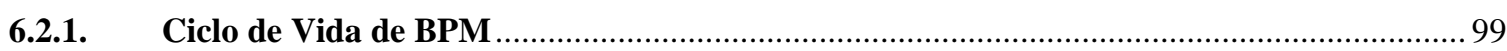

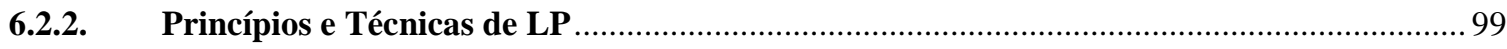

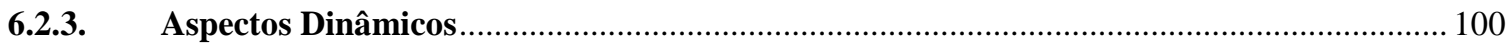

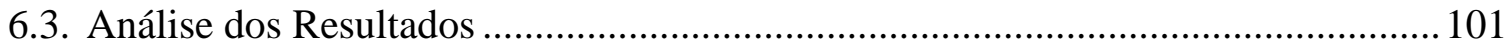

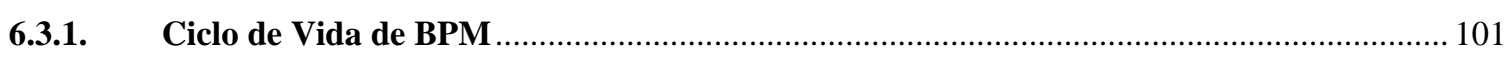

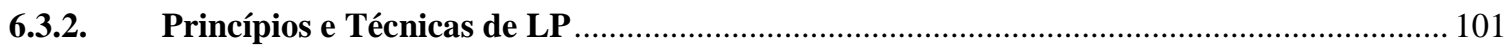




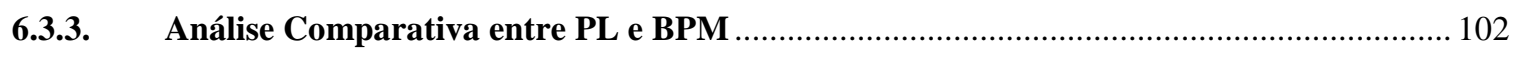

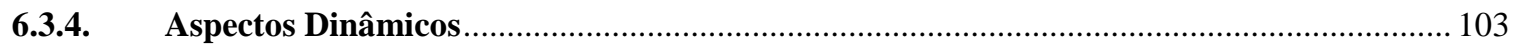

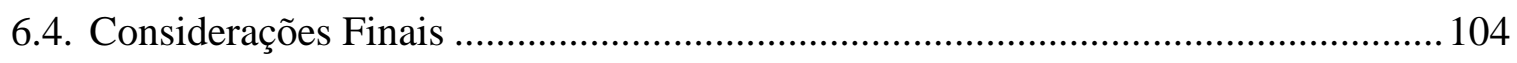

7. Conclusõ

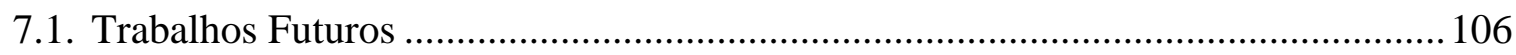

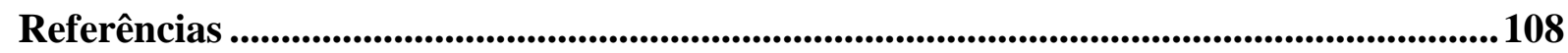

ANEXO A - Artigos Publicados e em Avaliação............................................................ 116 


\section{Lista de Figuras}

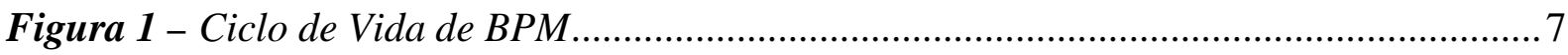

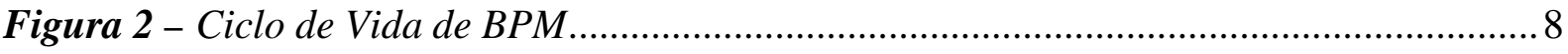

Figura 3 - Elementos básicos da notação BPMN ............................................................... 10

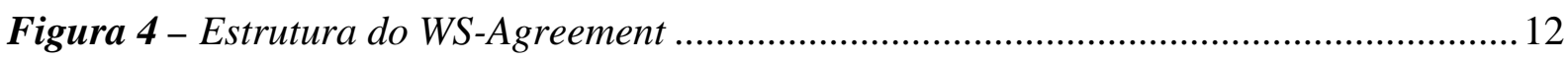

Figura 5 - Exemplo de política de segurança ..................................................................... 13

Figura 6 - Processo de Desenvolvimento de uma LP - Método FORM. .................................19

Figura 7 - Modelo de Características de uma Loja Virtual...................................................20

Figura 8 - Modelo de Características Configurado de uma Loja Virtual ...............................21

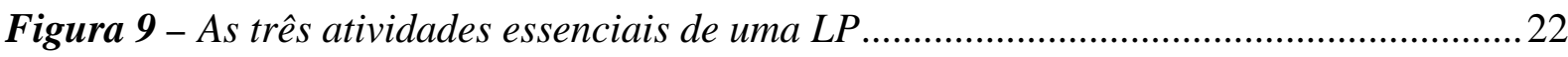

Figura 10 - Relacionamento entre as Áreas de Práticas ........................................................ 23

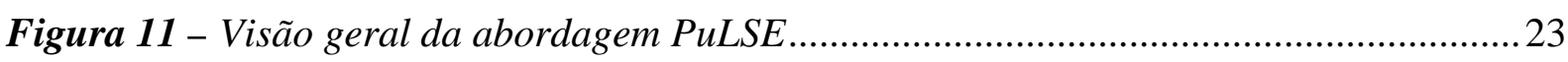

Figura 12 - Modelo de Processo Evolucionário para LP .................................................... 24

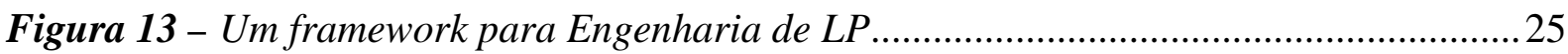

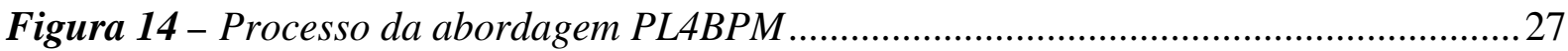

Figura 15 - Aspectos de variabilidade definido pela abordagem PFE ................................. 30

Figura 16 - Equivalência entre cada um dos MEFs e sua representação usando BPMN...... 32

Figura 17 - Um Modelo de Características refinado baseado em duas categorias de serviços

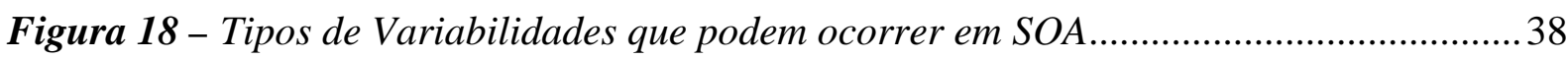

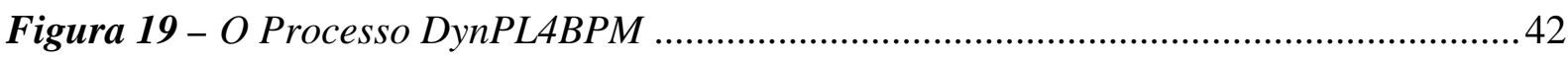

Figura 20 - Exemplo do Modelo de Características do Domínio de Marketing ..................... 52

Figura 21 - Exemplo do Modelo de Características do Domínio de Marketing usando a Técnica de Lee, Muthig e Naab (2010) ................................................................................. 53

Figura 22 - Modelo de Processo de Negócio gerado a partir da aplicação da técnica proposta na abordagem BFE ....

Figura 23 - Modelo de Processo de Negócio gerado a partir da aplicação da técnica proposta na abordagem BFE com adaptações.

Figura 24 - Exemplo de "Ligação Tardia"

Figura 25 - Exemplo de aplicação da técnica "Modelagem Tardia" em partes do processo com restrição 58

Figura 26 - Exemplo de Processo de Negocio Executável em WS-BPEL ...............................59

Figura 27 - Modelo de Composição de Serviços ....................................................................63

Figura 28 - Parte do processo DynPL4BPM relacionado à geração dos artefatos da atividade 1.B - Refinamento do Modelo de Domínio do PN ..... 
Figura 29 - Exemplo do Modelo de Características Configurado para uma organização específica

Figura 30 - Parte do processo DynPL4BPM relacionado à geração dos artefatos da atividade 2.B - Refinamento do Projeto do PN .

Figura 31 - Modelo de Processo de Negócio Configurado

Figura 32 - Parte do processo DynPL4BPM relacionado à geração dos artefatos da atividade 3.B - Refinamento da Implementação do PN.

Figura 33 - Representação gráfica do Processo de Negócio Executável Configurado em WSBPEL para uma organização específica

Figura 34 - Parte do processo DynPL4BPM relacionado à geração dos artefatos da atividade 3.B - Refinamento da Implementação do $P N$.

Figura 35 - Framework Unificado proposto.

Figura 36 - Três atividade de mineração de processos relacionadas ao suporte operacional

Figura 37 - Exemplo do Modelo de Características do Domínio de Marketing

Figura 38 - Exemplo do Modelo de Características do Domínio de Marketing após aplicação da técnica de Lee, Muthig e Naab (2010)

Figura 39 - Modelo de Processo de Negócio gerado a partir da aplicação da técnica proposta na abordagem BFE.

Figura 40 - Modelo de Processo de Negócio gerado a partir da aplicação da técnica proposta na abordagem BFE com adaptações.

Figura 41 - Exemplo de Processo de Negócio Executável em WS-BPEL

Figura 42 - Exemplo do Modelo de Características Configurado para uma organização específica

Figura 43 - Modelo de Processo de Negócio Configurado

Figura 44 - Representação Gráfica do Processo de Negócio Executável Configurado em WSBPEL para uma organização específica

Figura 45 - Fases do ciclo de vida de BPM alcançadas quando princípios e técnicas de LP são aplicados neste domínio nos estudos primários 99

Figura 46 - Princípios e técnicas de LP aplicados ao domínio BPM nos estudos primários

Figura 47 - Aspectos Dinâmicos de LP aplicados ao domínio de BPM nos estudos primários

Figura 48 - Distribuição cruzada entre fases do ciclo de vida de BPM e princípios e técnicas de LP nos estudos primários 


\section{Lista de Abreviaturas e Siglas}

\begin{tabular}{|c|c|}
\hline $\mathrm{BFE}$ & Business Family Engineering \\
\hline BPM & Business Process Management \\
\hline BPMN & Business Process Modeling Notation \\
\hline FPN & Família de Processos de Negócio \\
\hline IFPN & Instância de Família de Processos de Negócio \\
\hline IPN & Instância de Processos de Negócio \\
\hline FSPLP & Framework Software Product Line Practice \\
\hline FORM & Feature-oriented Reuse Method \\
\hline LP & Linha de Produto de Software \\
\hline LPD & Linha de Produto de Software Dinâmica \\
\hline LPOA & Linha de Produto de Software Orientada a Serviços \\
\hline PFE & Process Family Engineering \\
\hline PFA & Process Family Architecture \\
\hline PLUS & Product Line UML-Based Software Engineering \\
\hline PuLSE & Product Line Software Engineering \\
\hline QoS & Quality of Service \\
\hline SOA & Service-oriented Architecture \\
\hline SOAP & Simple Object Access Protocol \\
\hline UDDI & Universal Description Discovery Interface \\
\hline WS-Agreement & Web Service Agreement Specification \\
\hline WS-BPEL & Web Service Business Process Language \\
\hline WSDL & Web Service Definition Language \\
\hline WS-Policy & Web Services Policy \\
\hline
\end{tabular}




\section{Introdução}

O ambiente no qual as organizações estão inseridas atualmente é cada vez mais determinado pela competição intensa, exigindo mudanças significativas na forma de realização de seus negócios. Para competir nesse mercado, as organizações precisam passar por uma transformação de seus processos de negócio, assim como de suas estruturas organizacionais e gerenciais (BURTLER et al., 1997). Organizações precisam de flexibilidade e dinamismo para conseguir, por exemplo, reagir rapidamente a novos requisitos de clientes, a novos produtos oferecidos pelos atuais, a novos concorrentes, e ao avanço da tecnologia.

A Gestão de Processos de Negócio (BPM - Business Process Management) e a Arquitetura Orientada a Serviços (SOA - Service-oriented Architecture) têm oferecido apoio técnico para melhorar a competitividade das organizações (BALDAM et al., 2007). Enquanto que, em BPM, o foco recai em tratar processos que alinhem as diferentes atividades da organização em fluxos transversais (WESKE, 2007); por outro lado, SOA oferece uma plataforma flexível capaz de proporcionar apoio computacional aos processos por meio da combinação dos recursos de TI estruturados com base no paradigma de orientação a serviços (PAPAZOGLOU et al., 2008).

Apesar do uso combinado entre BPM e SOA, de acordo com Adam e Doerr (2008), ainda existem lacunas para que se alcance uma infraestrutura de TI flexível e adaptável. Parte significativa dessa completa flexibilidade organizacional pode ser alcançada com a aplicação de Linha de Produto de Software - ou apenas Linha de Produto (LP) - que promove reúso, redução do tempo de disponibilização do produto para o mercado e redução dos custos de desenvolvimento ao longo do tempo (CLEMENTS; NORTHROP, 2001). Segundo Fantinato, Gimenes e Toledo (2010), BPM é um dos domínios em potencial para o qual conceito e técnicas de LP podem ser aplicados de forma bem-sucedida.

Há abordagens que aplicam LP ao domínio de BPM, em conjunto com SOA, que já apresentaram resultados significativos (ROCHA; FANTINATO; BARROS, 2012). Porém, seus escopos de aplicação e seus benefícios são ainda limitados, visto que se trata de abordagens essencialmente estáticas, nas quais as decisões precisam ser tomadas em tempo de projeto. Assim, em geral, elas não são satisfatórias para o dinamismo do mundo organizacional, já que decisões em relação à gestão de processos precisam ser tomadas também em tempo de execução. Baldam et al. (2007) afirmam que, para fazer diferença, os sistemas de gestão de processos de negócio precisam ser suficientemente flexíveis para se 
adaptarem de forma dinâmica ou pelo menos de forma mais ágil que os atuais. Dessa forma, existem desafios que precisam ser superados para que essas tecnologias realizem corretamente seu papel no ambiente organizacional. Um deles é possibilitar a gestão dinâmica de processos de negócio.

No contexto de BPM, a flexibilidade para composição automática e dinâmica de processos de negócio distribuídos, por exemplo, está longe de ser alcançada (FANTINATO, 2009). A composição de serviços eletrônicos nas abordagens existentes é geralmente estática, ou seja, as interações são antecipadas em tempo de projeto. Existe assim a necessidade de se estabelecer mecanismos dinâmicos não apenas para a composição de serviços, mas também para o ciclo de vida de BPM completo, incluindo as seguintes fases: análise e modelagem; implementação; execução, administração e monitoramento; e otimização.

Com o surgimento de sistemas pervasivos, móveis e orientados a serviços, variações dinâmicas na necessidade do usuário e restrições de recurso estão se tornando cada vez mais generalizadas. Consequentemente, um tipo específico de LP tem sido explorado - as Linhas de Produto Dinâmicas (LPD) (HALLSTEINSEN et al., 2008). Essas LPDs têm proporcionado uma forma eficiente para lidar com adaptações de produtos em tempo de execução. Uma LPD produz software capaz de adaptação às mudanças para atender à necessidade do usuário, levando em consideração as restrições de recursos. Embora LPDs sejam construídas sobre a ideia central de LP típica, existem diferenças importantes entre ambas (HALLSTEINSEN et al., 2008) e que podem ser úteis no domínio de BPM.

Dentro desse amplo contexto, entende-se que organizações que requerem alto grau de flexibilidade e dinamismo para seus negócios possam se beneficiar da adoção de abordagens baseadas em LPD para suas estratégicas de BPM baseadas em SOA. Apesar disso, dada a complexidade em convergir todos esses paradigmas e tecnologias, não foram propostas ainda abordagens de LPD amplas o suficiente para cobrir todo o ciclo de vida de BPM. Ao invés disso, apenas as fases de modelagem e implementação de processos de negócio têm sido tratados sob a perspectiva de LP, e ainda assim sem considerar LPD.

Considerando esse contexto, o restante deste capítulo apresenta nas próximas seções: um exemplo motivacional que visa deixar mais claro esse contexto; os objetivos deste trabalho de forma mais específica; e a estrutura do restante desta dissertação. 


\subsection{Exemplo Motivacional}

Normalmente, os processos de negócio tratados pelas organizações atuais são processos interorganizacionais, ou seja, aqueles que atravessam as fronteiras de uma única organização. Enquanto uma organização foca suas atividades em seus conhecimentos chave, ela terceiriza as atividades das quais ela não domina o conhecimento, envolvendo organizações parceiras em seus processos de negócio - formando os processos de negócio interorganizacionais. Assim, os processos de negócio de uma organização principal envolvem atividades tanto dentro dela própria, podendo passar por diferentes departamentos, por exemplo, quanto à comunicação com seus parceiros externos.

Nesta seção é apresentado um caso real desse tipo de processo de negócio interorganizacional, que foi apresentado por Fuchsloch e Hoyer (2010), e que é usado como exemplo motivacional neste trabalho. O exemplo consiste na estratégia de internacionalização da marca de uma organização de grande porte situada em Hamburgo, Alemanha - AllSport.

Para essa estratégia, os departamentos de marketing e vendas da organização são os responsáveis pela divulgação de um novo produto na Maratona Internacional de Madrid, Espanha. A Maratona de Madrid é considerada uma instância específica e podem existir outras maratonas ou até mesmo outros eventos esportivos que podem despertar interesse da AllSport para a divulgação dos seus produtos.

Para a divulgação do produto naquela instância específica, a AllSport precisa estabelecer parcerias com uma agência de promoção local, pois esta conhece bem os fornecedores e prestadores de serviços, entre outros potenciais parceiros. Esse tipo de parceria tem sido muito comum e fundamental para o sucesso das estratégias de internacionalização, pois agências locais de marketing estão mais aptas a responderem rapidamente às necessidades da estratégia determinada pela contratante. A agência de promoção escolhida, para o caso em questão, foi a PromoBueno - companhia de tamanho médio, localizada em Madrid, Espanha. PromoBueno oferece diferentes serviços aos seus clientes, tais como a organização de atividades de promoção em feiras e eventos, promoção da marca e campanhas de marketing.

O exemplo apresentado é um caso típico em que a aplicação de reúso sistemático - por meio de princípios de LP - pode auxiliar a estratégia organizacional da AllSport e as seguintes características típicas de cenários dinâmicos podem ocorrer: 
- Fornecedores de serviços podem não cumprir com os requisitos não funcionais estabelecidos como, por exemplo, os atributos de QoS contratados, o que pode implicar a seleção de outros fornecedores de serviços em tempo de execução;

- A legislação de determinados países impõe uma série de restrições às operações das empresas externas, o que requer flexibilidade dos processos organizacionais para mudar ou adaptar a essas situações e contextos específicos;

- A organização percebe que estratégia pré-definida para o marketing promocional não está adequada e, portanto, precisa de uma intervenção como, por exemplo, a adição dinâmica de uma nova atividade à instância de processo já em execução;

- Uma lei - nacional ou internacional - é criada e impõe uma série de restrições às organizações. Como consequência, o modelo de processo de negócio não tem como prever todas essas dinâmicas do ambiente externo. Assim, o processo de negócio deve mudar para estar em conformidade com a norma e, além disso, estas mudanças deverão ser propagadas às instâncias dos processos que já estão em execução.

Dessa forma, o caso apresentado nesta seção se mostra pertinente a este propósito, pois deve ser dinâmico e requer flexibilidade nos processos de negócio organizacionais para contratar as agências de promoção que serão responsáveis pela divulgação do produto naquele mercado particular. Além disso, esse caso possui potencial de variabilidades que será explorado na descrição da abordagem proposta neste trabalho, como por exemplo, os eventos esportivos podem variar em relação à modalidade esportiva, local em que ocorre, o que exige maior flexibilidade dos seus processos de negócio para atender as estratégias organizacionais definidas. Pode-se ainda usar de serviços web para identificar eventos esportivos que ocorrem em uma determinada região geográfica.

\subsection{Objetivos}

O principal objetivo deste trabalho é propor uma abordagem para gerenciar os processos de negócio, em todo seu ciclo de vida, que ocorrem em um ambiente de negócio dinâmico, tendo como base os princípios de LPD e o paradigma SOA.

Para isso, os seguintes objetivos específicos são buscados:

1. Definição de uma abordagem de LP para BPM, em alto nível, que contemple todo o ciclo de vida de BPM, considerando que as atuais abordagens de LP para BPM 
contemplam apenas parte do ciclo de vida de BPM. Essa abordagem de LP para BPM deve ser ampla e genérica o suficiente, como um framework, para permitir que aspectos dinâmicos sejam incorporados nela;

2. Identificar técnicas existentes que fazem tratamento de aspectos dinâmicos em diferentes fases do ciclo de vida de BPM considerando principalmente a base tecnológica do paradigma SOA, tais como: seleção dinâmica dos serviços web; composição dinâmica de processos de negócio; e monitoramento dinâmico da execução do processo, considerando os níveis contratados para os atributos de QoS;

3. Propor o uso conjunto e sistemático das técnicas relacionadas a aspectos dinâmicos identificadas de acordo com o "objetivo 2" dentro da abordagem de LP para BPM definido de acordo com o "objetivo 1", visando a definição de um processo amplo, comum e único de LPD para BPM - chamado de DynPL4BPM (Dynamic Product Line for Business Process Management);

4. Avaliar sistematicamente a abordagem DynPL4BPM a partir de um procedimento de classificação criado por meio de uma série de atributos específicos, que possibilitam a categorização e a comparação da abordagem proposta com os trabalhos relacionados que foram selecionados por meio de uma Revisão Sistemática da Literatura.

Em relação aos aspectos dinâmicos da abordagem de LPD para BPM sendo proposta, não faz parte do escopo deste trabalho propor novas técnicas específicas a serem usadas dentro do processo sendo definido. Ao invés disso, o objetivo deste trabalho é, por meio da identificação de técnicas já existentes, propor seus usos de forma integrada dentro de um processo sistemático e uniforme. Portanto, a contribuição deste trabalho é em um nível conceitual mais alto do que os demais trabalhos em que são apresentados e usados aqui.

\subsection{Organização da Dissertação}

Esta dissertação de mestrado está organizada da seguinte forma: no Capítulo 2 são apresentados os conceitos básicos relacionados a BPM; no Capítulo 3 são apresentados os conceitos básicos relacionados a LP; no Capítulo 4 é apresentada a abordagem proposta DynPL4BPM; no Capítulo 5 é apresentado o exemplo consolidado de aplicação; no Capítulo 6 é apresentada a avaliação da abordagem proposta e, por fim, no Capítulo 7, é apresentada a conclusão deste trabalho. Além disso, no Anexo A é apresentado um resumo do estado atual das publicações geradas a partir deste trabalho de mestrado. 


\section{Gestão de Processos de Negócio - BPM $M^{1}$}

BPM tem sido apresentada como elemento chave para o sucesso de uma infraestrutura de TI preparada para as demandas das organizações atuais (BALDAM et al., 2007). Além disso, BPM pode ser vista como uma vantagem competitiva das organizações, uma vez que revela o nível de maturidade das mesmas (FANTINATO; GIMENES; TOLEDO, 2010).

De acordo com van der Aalst et al. (2003), BPM inclui métodos, técnicas e ferramentas para apoiar a concepção, a representação, a gestão e a análise de processos de negócio operacionais. BPM pode ser considerada uma extensão de sistemas e abordagens clássicas de gerenciamento de workflows (Workflow Management).

Segundo Weske (2007), um processo de negócio consiste em um conjunto de tarefas realizadas em uma sequência específica para alcançar um objetivo comum de negócio. O ciclo de vida de processos de negócio no domínio de BPM envolve várias atividades, incluindo (WESKE, 2007): (a) modelagem de processo de negócio; (b) instanciação do modelo de processo de negócio; (c) apoio à execução de processos de negócio; (d) monitoramento e auditoria de execução de processos de negócio; e, (e) análise do processo de negócio em execução. Nessa última etapa, o histórico de execução é analisado para identificação de problemas, o que pode levar à remodelagem de processos, começando todo ciclo novamente de forma rápida devido aos ambientes dinâmicos do mercado e das organizações em que BPM é usada.

Para viabilizar a gestão e a integração dos processos de negócio, do ponto de vista técnico, diferentes tecnologias já foram apresentadas, incluindo mais recentemente os frameworks de middleware tais como CORBA, DCOM e Java-RMI (ALONSO et al., 2004). À medida que a necessidade de interoperabilidade evoluiu para as cooperações interorganizacionais, as soluções existentes deixaram de atender seus objetivos, até que SOA e os serviços web surgiram oferecendo novas perspectivas para essa necessidade e proporcionado, como por exemplo, a composição de serviços por meio da linguagem WS-BPEL (OASIS, 2007), linguagem que permite a execução de processos de negócio.

O restante deste capítulo tem o objetivo de apresentar uma visão geral dos principais conceitos relacionados à BPM necessários para a abordagem sendo proposta no Capítulo 4. Para isso, as seções a seguir apresentam os seguintes assuntos: Ciclo de Vida de BPM;

\footnotetext{
${ }^{1}$ Acrônimo em inglês de: Business Process Management
} 
Notação e Modelo de Processos de Negócio; Arquitetura SOA; e Processos de Negócio Dinâmicos e Adaptáveis.

\subsection{Ciclo de Vida de BPM}

O ciclo de vida de BPM consiste em fases que se relacionam entre si. Além disso, as fases são organizadas em uma estrutura cíclica que mostra a dependência lógica entre elas (WESKE, 2007). Há diversas propostas para definir e representar o ciclo de vida de BPM, embora sejam todas bastante similares. Como exemplo, a Figura 2 apresenta o ciclo de vida de BPM proposto por van der Aalst (2003).

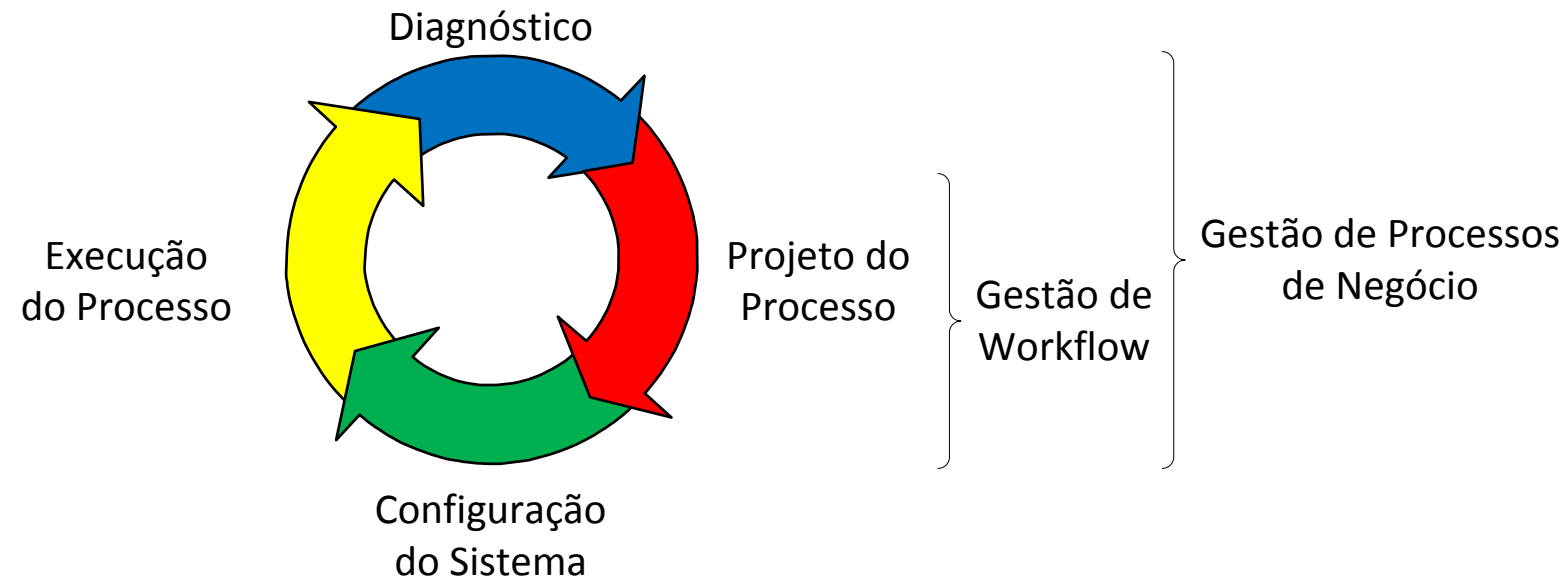

Figura 1 - Ciclo de Vida de BPM

Fonte: Traduzido de van der Aalst (2003)

O ciclo de vida de BPM apresentado na Figura 1 descreve as várias fases de apoio à operação dos processos de negócio. Na fase Projeto do Processo, os processos são criados ou recriados. Na fase de Configuração do Sistema, os projetos são implementados. Após a configuração, a fase Execução do Processo é iniciada e os processos operacionais de negócios são executados usando o sistema configurado. Na fase Diagnóstico, os processos operacionais são analisados para identificar problemas e também o que pode ser melhorado. De acordo com van der Aalst (2003), a diferença entre BPM e Gestão de Workflow (WFM Workflow Management) é em relação às fases do ciclo de vida (van der Aalst, 2003): BPM amplia a abordagem tradicional WFM pelo apoio à fase de Diagnóstico.

Tendo em vista a complexidade envolvida em cada uma das fases do ciclo de vida apresentado na Figura 1, Weske (2007) propõe um ciclo de vida de BPM, composto por 
subfases, que por ser mais completo em descrição é o adotado na abordagem de LP para BPM sendo apresentada no Capítulo 4 desta Dissertação. A Figura 2 apresenta uma visão geral deste ciclo de vida, que é composto também por quatro grandes fases: Projeto e Análise, Configuração, Execução e Avaliação. Cada uma dessas fases é explicada com mais informações na sequência.

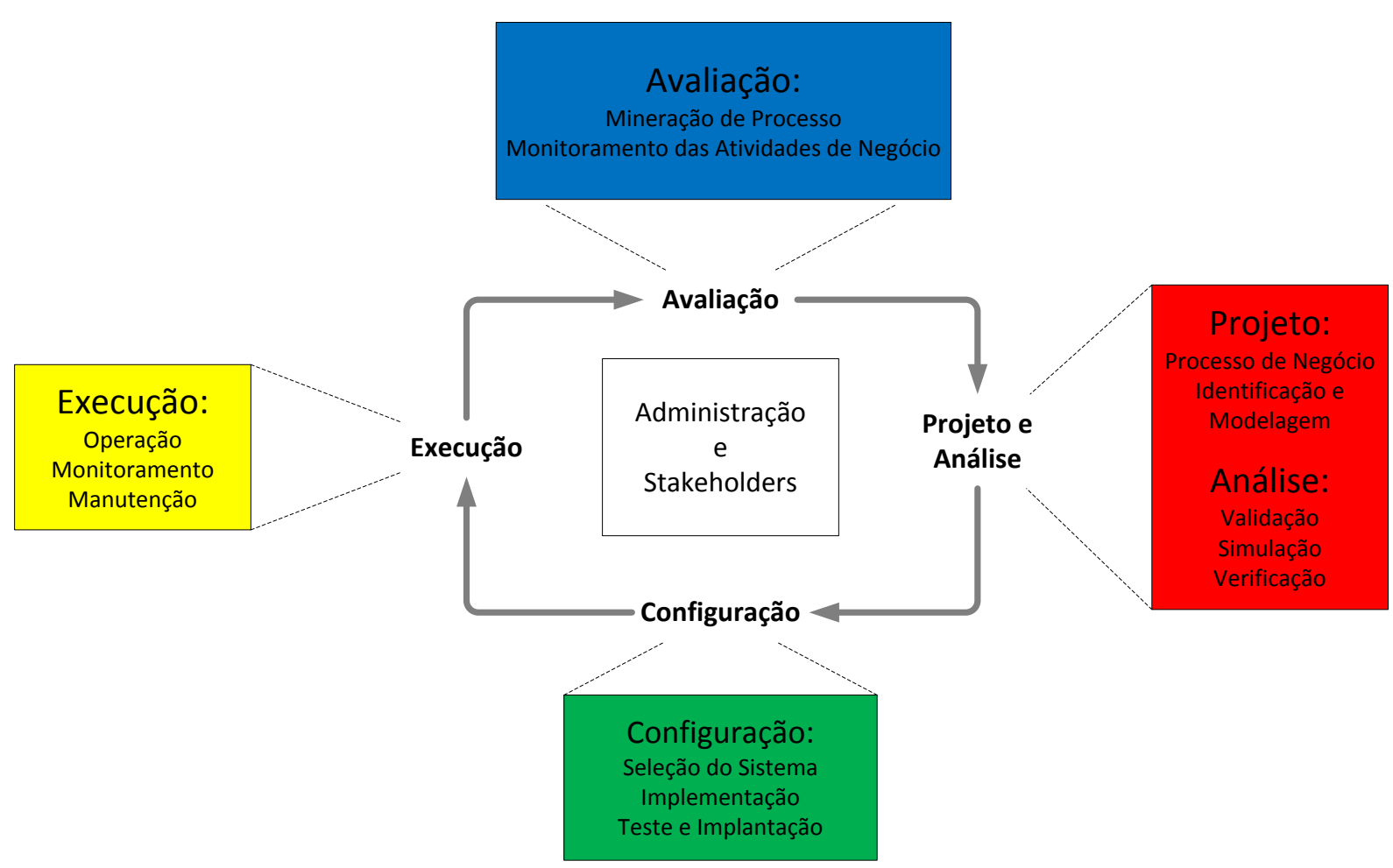

Figura 2 - Ciclo de Vida de BPM

Fonte: Traduzido de Weske (2007)

Na fase de Projeto e Análise é realizado um levantamento, de como o trabalho é realizado na organização, a fim de identificar, revisar e validar os processos de negócio. Umas das principais atividades desta etapa é a modelagem de processos de negócio, em que as práticas organizacionais são definidas, estipuladas e formalizadas em modelos de processos, isto é, artefatos gráficos que por meio de alguma notação - BPMN, UML ou EPC, por exemplo - definem o fluxo das tarefas envolvidas no processo. Além disso, técnicas de validação, simulação e verificação também são usadas nesta fase.

Após a definição e validação dos processos, a fase seguinte consiste na Configuração, ou seja, usam-se as definições dos processos de negócio para realizar a implementação dos processos. Nessa fase, plataformas e ferramentas de software são usadas para dar apoio à implantação dos processos (ou seja, à seleção do sistema). Em alguns casos, pode-se realizar a 
implementação do software que apoia a execução dos processos. É também nessa fase que são realizados testes e implantação.

A fase seguinte consiste na Execução dos processos, na qual a ênfase está em acompanhar e monitorar a realização dos processos em tempo real ou em tempo de execução. Além disso, há também preocupação com a manutenção dos processos de negócio em execução.

As informações geradas pela execução dos processos de negócio são base para a última etapa do ciclo de vida de BPM: a Avaliação, que inclui a mineração dos processos e monitoramento das atividades. O objetivo dessa atividade é coletar os dados gerados da execução das atividades dos processos e analisar se os objetivos organizacionais estão sendo atingidos de maneira satisfatória, identificando eventuais ineficiências no processo de forma a permitir propor melhorias nos processos de negócio.

\subsection{Notação e Modelo de Processos de Negócio - BPMN}

Atualmente, BPMN (Business Process Model and Notation) (OMG, 2011) é a notação mais abrangente para modelagem de processos (JURIC; PANT, 2008).

A notação BPMN baseia-se na representação dos fluxos de atividades e permite representar diferentes níveis de detalhes para diferentes propostas. A Figura 3 (página 10) mostra os elementos mais comuns usados em BPMN e suas respectivas notações gráficas. Em BPMN, os papéis que participam de um processo são representados por Divisão e Compartimentos. Em termos de semântica organizacional, Divisões costumam representar organizações e Compartimentos costumam representar os participantes ou departamentos/setores de uma organização. O processo é composto por subprocessos e tarefas, conectados por meio de fluxos de comunicação. Há elementos que representam os eventos que iniciam o processo (Eventos de Início), que terminam o processo (Eventos de Fim) ou que acontecem durante a execução do processo, ou seja, Eventos Intermediários (JURIC; PANT, 2008; THOM; ICHOPE, 2010).

\subsection{Arquitetura Orientada a Serviços - SOA}

SOA é um paradigma da Engenharia de Software, considerado um assunto de grande interesse, pois especialistas preveem que em poucos anos, a maioria dos aplicativos de 
negócio em organizações será desenvolvido de uma forma orientada a serviços eletrônicos (YE et al., 2007).

Um serviço eletrônico significa uma função encapsulada com granularidade adequada ao desenvolvimento de aplicações, e fornece um modo uniforme paro reúso, independentemente de plataforma ou localização (YE et al., 2007). Como serviços são independentes e flexíveis, processos flexíveis podem ser desenvolvidos a partir da composição de serviços (YE et al., 2007). SOA decompõe o software em serviços e trata da integração entre diferentes sistemas, via fornecimento e consumo de serviços, em um escopo interorganizacional (PAPAZOGLOU et al., 2008). Os serviços podem ser definidos, invocados, e compostos por meio de interfaces bem definidas e independentes da aplicação (PAPAZOGLOU et al., 2008).

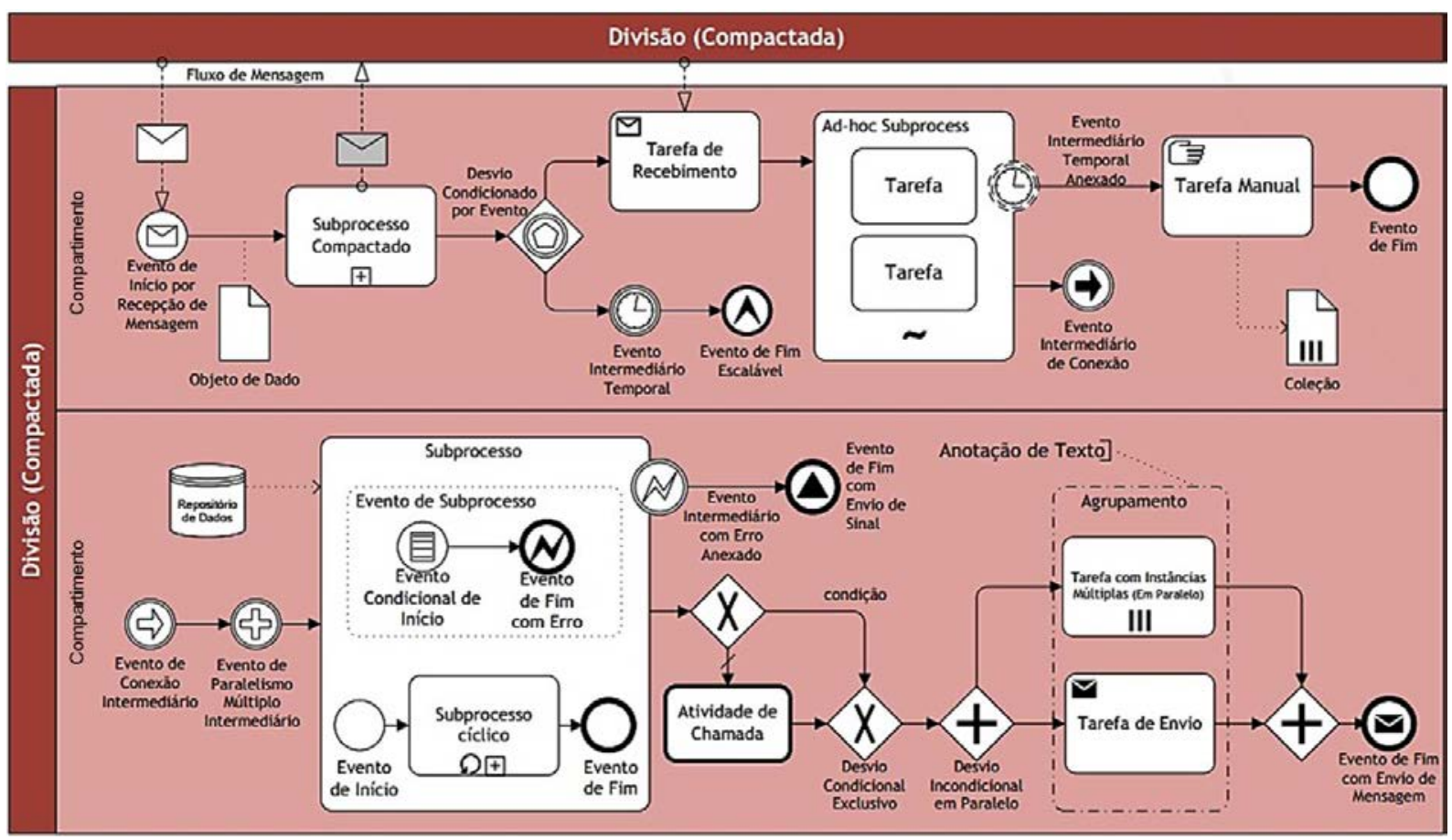

Figura 3 - Elementos básicos da notação BPMN

Fonte: Adaptado de Thom e Ichope (2010)

A principal forma de se implementar SOA atualmente é por meio da tecnologia de serviços web (BALDAM et al., 2007; WEERAWARANA et al., 2005): um tipo específico de serviço eletrônico que usa padrões abertos da internet para sua descrição, busca e requisição de operações (MCCABE et. al., 2004). Serviços web podem ser vistos como aplicações, disponíveis via internet, que podem ser usadas para executar determinados serviços. Eles podem ser desde simples serviços como a realização de verificações de números de cartões de 
crédito, até serviços complexos, muitas vezes compostos por serviços mais simples, como manipulação de aplicações de hipotecas.

Serviços web usam padrões já consolidados, abertos e baseados em XML (eXtendible Markup Language) para executar suas funcionalidades. Os padrões básicos que caracterizam serviços web são: SOAP, WSDL e UDDI. SOAP (Simple Object Access Protocol) define o formato das mensagens que são trocadas entre consumidores, fornecedores e diretórios de serviços (GUDGIN et al., 2007). WSDL (Web Service Description Language) é usada para descrever as características "funcionais" de um serviço web, ou seja, quais as ações o serviço realiza em termos de mensagens que o serviço recebe e retorna (WEERAWARANA et al., 2005). UDDI (Universal Description Discovery Interface) define a estrutura e o conteúdo dos diretórios que contém descrições de serviços oferecidos (WEERAWARANA et al., 2005).

Além desses três padrões básicos, há vários outros para a descrição de outros aspectos relacionados a serviços web. Linguagens tais como WS-Agreement (Web Services Agreement Specification) (ANDRIEUX et al., 2007) e WS-Policy (Web Services Policy Framework) (VEDAMUTHU et al., 2006) podem ser usadas, por exemplo, para especificar atributos de Qualidade de Serviço (QoS) ou atributos não funcionais relacionados a serviços web. Além disso, a composição de serviços web, para formar processos de negócio, pode ser especificada usando a linguagem WS-BPEL (Web Services Business Process Execution Language) (OASIS, 2007). Nas subseções a seguir, breves descrições dessas três linguagens são apresentadas.

\subsubsection{WS-Agreement}

Em relação ao estabelecimento de requisitos não funcionais, WS-Agreement (ANDRIEUX et al., 2007) é uma das alternativas, tendo em vista que é uma linguagem projetada para a especificação formal das capacidades de provedores de serviços web (em particular aqueles relacionados a atributos de QoS) (FANTINATO, 2007).

Como representado na Figura 4, um documento WS-Agreement consiste de três seções principais: (i) Nome: seção opcional que inclui um nome para o acordo WS-Agreement; (ii) Contexto: seção que descreve as partes envolvidas no acordo WS-Agreement e alguns metadados relacionados com o acordo, como, por exemplo, seu tempo de vida;

(iii) Termos: seção que define o conteúdo do acordo WS-Agreement propriamente dito.

Ainda em relação aos Termos, a especificação define dois tipos, que são (ANDRIEUX et al., 2007): (i) Termos de Serviço (TS): contém informação para instanciar 
ou identificar o serviço. É composto de descrição, referência e propriedades; Termos de Garantia (TG): subseção que define um conjunto de garantias de QoS (relacionadas tanto aos compromissos quanto às penalidades). TGs podem ser usados para o monitoramento do serviço e garantir os termos do acordo.

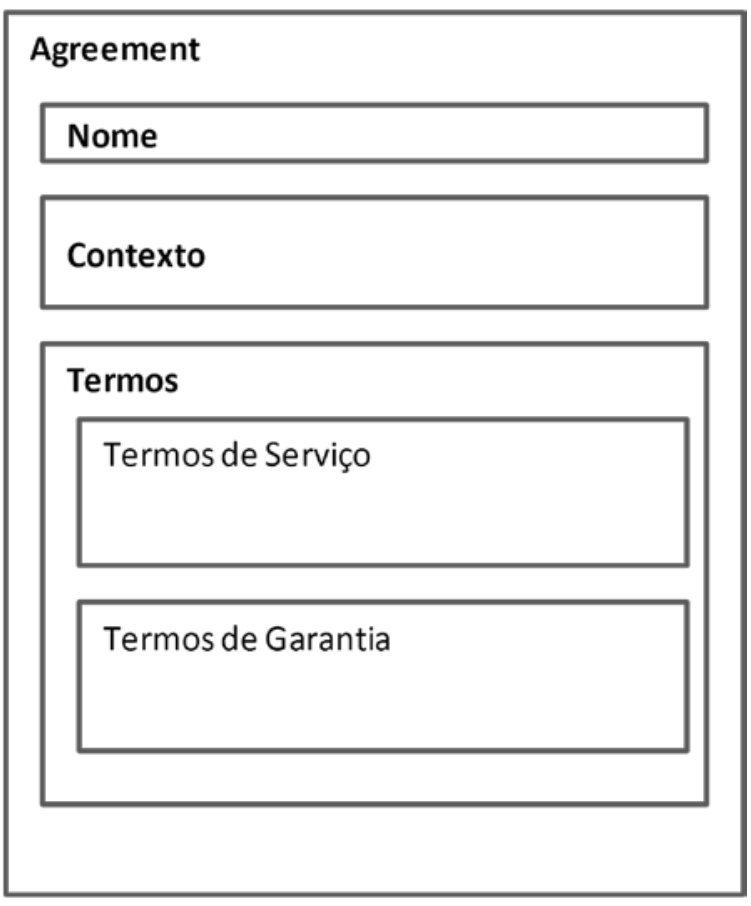

Figura 4 - Estrutura do WS-Agreement

Fonte: Traduzido de Andrieux et al. (2007)

\subsubsection{WS-Policy}

WS-Policy surgiu como a finalidade de descrever as propriedades que caracterizam um serviço web. Por meio dessa especificação, a descrição funcional de um serviço pode ser vinculada a um conjunto de asserções que descrevem como o serviço da web deve funcionar em termos de aspectos como transacionalidade, segurança e mensagem confiável (BARESI; GUINEA; PLEBANI, 2006).

O Web Services Policy Framework (WS-Policy) fornece sintaxe e modelos gerais para descrever as políticas de um serviço web. Este framework define um conjunto de construtores que podem ser usados e estendidos por outras especificações dos serviços web, para descrever vários requisitos e capacidades de um serviço (SILVA; SANTOS, AZEVEDO, 2011).

WS-Policy define uma política (policy) como uma coleção de alternativas de política, em que cada alternativa é uma coleção de asserções da política (policy assertions). As asserções da política especificam requisitos tradicionais e capacidades que, em última 
instância, se manifestarão na ligação (wire), como por exemplo, no esquema de autenticação ou na seleção do protocolo de transporte.

O exemplo da Figura 5 ilustra uma política de segurança usando asserções definidas em WS-SecurityPolicy. As linhas (01-06) representam uma política para um conjunto de algoritmos necessários à execução de operações criptográficas simétricas ou assimétricas, com símbolos baseados em chave de segurança.

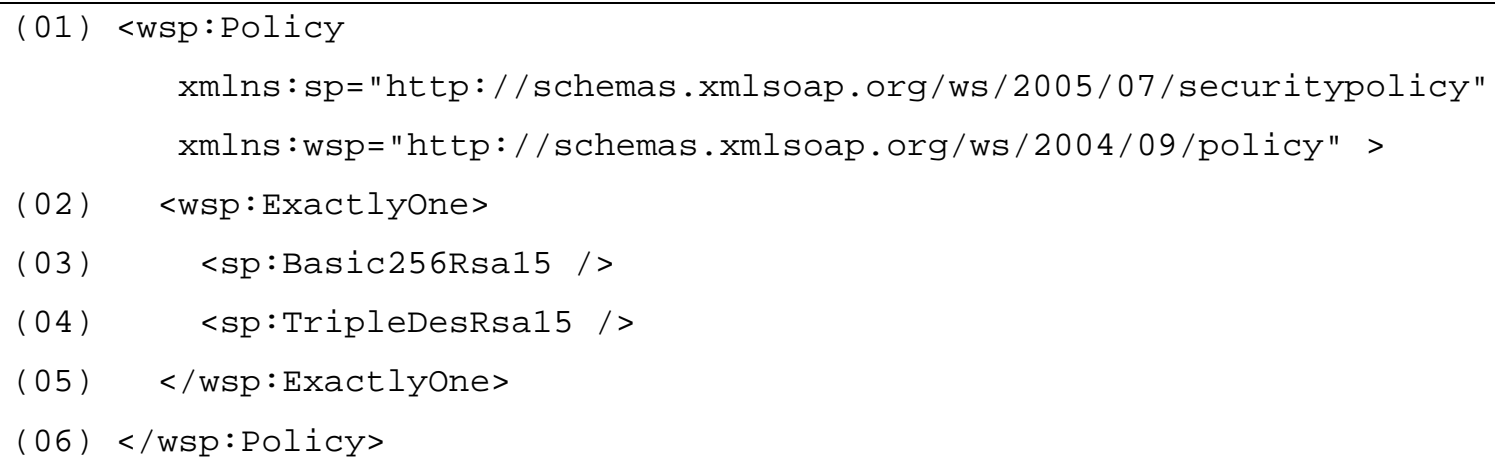

Figura 5 - Exemplo de política de segurança

Fonte: Vedamuthu et al. (2006)

As linhas (02-05) ilustram o operador ExactlyOne. Operadores de política agrupam asserções de políticas em alternativas de políticas. Uma interpretação válida da política acima seria que uma invocação de um serviço da web usa exatamente uma das afirmações do conjunto de algoritmos (Linhas 03-04) especificados.

A especificação do WS-Policy usa uma sintaxe baseada em XML. Os principais termos apresentados são (VEDAMUTHU et al., 2006):

- Política (policy): é um conjunto de alternativas de políticas;

- Alternativa de política (policy alternative): é uma coleção de asserções de política;

- Asserção de política (policy assertion): identifica o comportamento que é um requisito individual ou uma capacidade de um assunto de política (policy subject);

- Tipo de asserções de política (policy assertion type): representa uma classe de asserções de políticas e implica em um esquema para instâncias da asserção e uma semântica específica da asserção;

- Vocabulário de política (policy vocabulary): é um conjunto de todos os tipos de asserções usados em uma política; 
- Expressão de política (policy expression): é uma representação de uma política por meio de um infoset XML, de uma forma normal ou de uma forma compacta equivalente;

- Assunto de política (policy subject): é uma entidade com a qual uma política pode ser associada;

- Escopo da política (policy scope): é uma coleção de assuntos de política para a qual a política se aplica;

- Anexo da política (policy attachment): é o mecanismo para associar políticas a um ou mais escopos de política.

\subsubsection{WS-BPEL}

Tornar os processos executáveis com a possibilidade de usar parte de processos de outras organizações, com objetivo de atingir metas ainda maiores, tornou-se uma necessidade fundamental para as organizações. Com isso as principais motivações para o uso de WSBPEL são (MOREIRA et al., 2011): (i) simplificar a integração entre parceiros de negócio; (ii) incentivar as organizações a definir melhor seus processos; e, (iii) facilitar a exposição das funcionalidades da organização por meio de serviços eletrônicos. Assim, WS-BPEL (OASIS, 2007) tem sido adotada como o padrão "de facto" para o desenvolvimento de processos de negócio executáveis.

O principal objetivo de WS-BPEL é padronizar a automação dos processos entre serviços (JURIC; PANT, 2008). Por meio de WS-BPEL, é possível descrever os processos de negócio em duas maneiras distintas: (i) especificar os detalhes reais dos processos de negócio; (ii) especificar a troca pública de mensagens entre as partes envolvidas na realização dos processos de negócio (JURIC; PANT, 2008). Os processos formados a partir de uma descrição detalhada são chamados de processos de negócio executáveis e podem ser executados por um motor de workflow (workflow engine). Aqueles que apenas especificam a troca pública de mensagens entre as partes envolvidas são chamados de processos de negócio abstratos (JURIC; PANT, 2008), ou seja, não incluem os detalhes internos dos fluxos de processos e, portanto, não são executáveis.

Existem alguns elementos fundamentais da linguagem WS-BPEL que podem ser usados tanto para a especificação de processos de negócio quanto para a especificação de protocolos de interação de negócio. Além desses conceitos, existem algumas extensões requeridas para cada um desses dois usos específicos. A estrutura geral de um processo de 
negócio especificado em WS-BPEL é formada por quatro seções: PartnerLinks, Variables, FaultHandlers e Activities, conforme descritas a seguir (OASIS, 2007):

- PartnerLinks: seção que define os diferentes parceiros (ou seja, as partes envolvidas) que interagem com o processo de negócio durante toda sua execução. Eles são usados para identificar a funcionalidade que deve ser oferecida por cada serviço parceiro;

- Variables: seção que define as variáveis de dados usadas pelo processo de negócio. As definições são feitas em termos de tipos de mensagem WSDL, elementos ou tipos simples de esquemas XML. Elas são usadas para manter os dados de estado e o histórico do processo com base nas mensagens trocadas;

- FaultHandlers: seção que contém os tratadores de falhas que definem as atividades a serem executadas em resposta às falhas resultantes da invocação de serviços de avaliação e de aprovação;

- Activities: seção que contém a descrição do comportamento normal para a execução do processo de negócio.

\subsection{Processos de Negócio Dinâmicos e Adaptáveis}

A complexidade do mundo corporativo tem exigido grande dinamismo da infraestrutura de TI no oferecimento de soluções técnicas à condução de negócios. BPM e tecnologias relacionadas têm oferecido apoio técnico para melhorar a competitividade das organizações, como, por exemplo, o auxílio à obtenção do alinhamento estratégico entre negócio e TI (ADAM; DOERR, 2008). No entanto, estas tecnologias não tiveram ainda uma adoção generalizada como era esperado pela academia e indústria (WEBER, SADIQ; REICHERT, 2009). Apesar de existir um elevado número de trabalhos que chamam a atenção sobre este aspecto, ainda é limitado o suporte técnico às mudanças dinâmicas, principalmente nos processos de negócio (FANTINATO, 2009), o que acaba inibindo a capacidade de uma organização em responder tais mudanças de forma ágil.

Em ambientes dinâmicos, é necessário definir rapidamente novos processos de negócio ou então adaptá-los para atender às necessidades das organizações (NUNES et al., 2011). Assim, flexibilidade tornou-se um requisito importante para a gestão de processos de negócio.

Um processo de negócio dinâmico pode ser definido como personalização ou adaptação de um processo a uma situação em particular, tornando possível a realização deste processo no tempo em que ocorre tal situação (NUNES et al., 2011). 
Para classificar as abordagens que tratam de adaptação dinâmica de processos de negócio, Nunes et. al., (2011) consideram quatro aspectos específicos inter-relacionados: (i) notações; (ii) técnicas para gestão de variabilidades em processo; (iii) infraestrutura tecnológica para apoio à adaptação dinâmica dos processos; (iv) identificação alternativa e seleção de apoio.

Abordagens que lidam com as notações e técnicas para a realização de adaptação ao processo dinâmico devem apoiar a padronização de modelagem das partes comuns e variáveis dos processos, para que se possa identificar o que varia (e quais são as regras de adaptação entre as partes do processo) e permitir o reúso de partes do processo. Nesse cenário, Rosemann e Aalst (2007) propõem uma extensão da notação de modelagem do EPC (Eventdriven Process Chain), chamado C-EPC (Configurable Event-driven Process Chain). A abordagem PFE (acrônimo em inglês de Engenharia de Família de Processos) (BAYER et al., 2005) estabelece o conceito de rich-variant em modelo de processo de negócio, na qual a representação do modelo de processo é estendida com o uso de notações e estereótipos, de modo a introduzir variabilidade no modelo. E, por fim, outra forma de representar flexibilidade nos processos é por meio de regras de negócio (MEJIA BERNAL et al., 2010).

Técnicas para gestão de variabilidades em processo estão relacionadas aos métodos e infraestrutura que permitem a criação do processo com variabilidades (NUNES et al., 2011). A abordagem PFE (BAYER et al., 2005) e a BFE (acrônimo em inglês de Engenharia de Família de Negócios) são exemplos de tais técnicas. Ambas as abordagens serão detalhadas no Capítulo 3, por ser o mais adequado considerando os objetivos apresentados nesta dissertação.

Em relação à infraestrutura tecnológica de apoio à adaptação dinâmica de processos, tem-se o framework PAIS (Process-Aware Information Sytem), que significa "sistema de software que gerencia e executa os processos operacionais envolvendo pessoas, aplicações e/ou fontes com base em modelos de processos" (AALST, 2009; WEBER; SADIQ; REICHERT, 2009).

Por fim, para a identificação alternativa e seleção de apoio de processos de negócio, CBR (Case-Based Reasoning) e Engenharia de Resiliência são usadas neste contexto (NUNES et al., 2011). 


\subsection{Considerações Finais}

Neste capítulo foram apresentados os conceitos relacionados à BPM, e também à SOA, a arquitetura de tecnológica amplamente usada para apoiar a realização de BPM. Nesse contexto, BPM e SOA podem fornecer apoio para melhorar a competitividade das organizações. A combinação BPM e SOA é importante para apoiar as estratégias organizacionais. Porém, ainda existem lacunas entre TI e negócios, sendo necessárias novas abordagens para que BPM e SOA forneçam uma infraestrutura de TI flexível e adaptável.

BPM e tecnologias relacionadas ainda não tiveram a adoção generalizada que era esperada (WEBER; SADIQ; REICHERT, 2009). A principal razão para isso é o apoio limitado às mudanças dinâmicas, que inibe a capacidade de uma organização em responder às mudanças do negócio de forma ágil. Assim, flexibilidade tornou-se um requisito importante na modelagem de processos de negócio.

Para apoiar a adaptação dinâmica de processos de negócio várias abordagens são propostas, inclusive o reúso sistemático, por meio dos princípios e técnicas de LP e LPD. LP tem proporcionado redução de tempo e aumento da qualidade dos produtos. Quando aplicada no domínio de BPM torna possível, para alguns domínios de aplicação, a tão almejada flexibilidade na realização dos processos organizacionais. Conceitos e abordagens de LP de maneira geral e, mais especificamente, aplicadas ao domínio de BPM são apresentados a seguir no Capítulo 3 desta dissertação. 


\section{Linha de Produto de Software - LP}

LP é um conjunto de sistemas que usam software intensivamente, que compartilham um conjunto de características comuns, que são gerenciadas para satisfazer as necessidades de um segmento particular de mercado ou objetivo, e que são desenvolvidos a partir de um conjunto comum de artefatos principais e de uma forma preestabelecida, seguindo um processo bem definido (CLEMENTS; NORTHROP, 2001). Como parte desse processo, uma técnica para capturar e gerenciar os pontos comuns e variáveis das propriedades existentes na família de produtos deve ser usada (GIMENES; TRAVASSOS, 2002).

Uma LP envolve um conjunto de aplicações similares dentro de um domínio a serem desenvolvidas a partir de uma arquitetura genérica comum (a arquitetura da LP) e um conjunto de componentes que povoam a arquitetura. De acordo com Gimenes e Travassos (2002), essa abordagem busca identificar aspectos comuns e diferenças entre os artefatos de software durante o desenvolvimento da LP, para identificar os pontos de decisão em que a adaptação dos componentes para a geração de produtos específicos possa ser realizada.

A Figura 6 apresenta uma das abordagens propostas para LP, o método FORM (Feature-oriented Reuse Method) (KANG et al., 1998). Uma propriedade comum em abordagens de LP, também presente no método FORM, é a existência de dois processos "Engenharia de Domínio" e "Engenharia de Aplicação". "Engenharia de Domínio" representa o desenvolvimento do núcleo de artefatos, que engloba atividades tais como a análise de domínio, o desenvolvimento da arquitetura e o desenvolvimento de componentes (KANG et al., 1998). "Engenharia de Aplicação" representa o desenvolvimento de produtos específicos, englobando atividades tais como a análise baseada no modelo do domínio, a criação de uma instância para a arquitetura da LP e o desenvolvimento e teste da aplicação por meio da integração dos componentes reusáveis (KANG et al., 1998).

A arquitetura da LP é o artefato mais importante dos processos da LP, pois representa sua infraestrutura central (GIMENES; TRAVASSOS, 2002). Ela engloba a definição de suas estruturas gerais, descrevendo os elementos que compõem os sistemas e as interações entre eles, além de questões importantes de projeto, tais como (GIMENES; TRAVASSOS, 2002): organização do sistema como a composição de componentes, as estruturas de controle globais, os protocolos de comunicação, a composição dos elementos do projeto, e o projeto da funcionalidade dos componentes. 


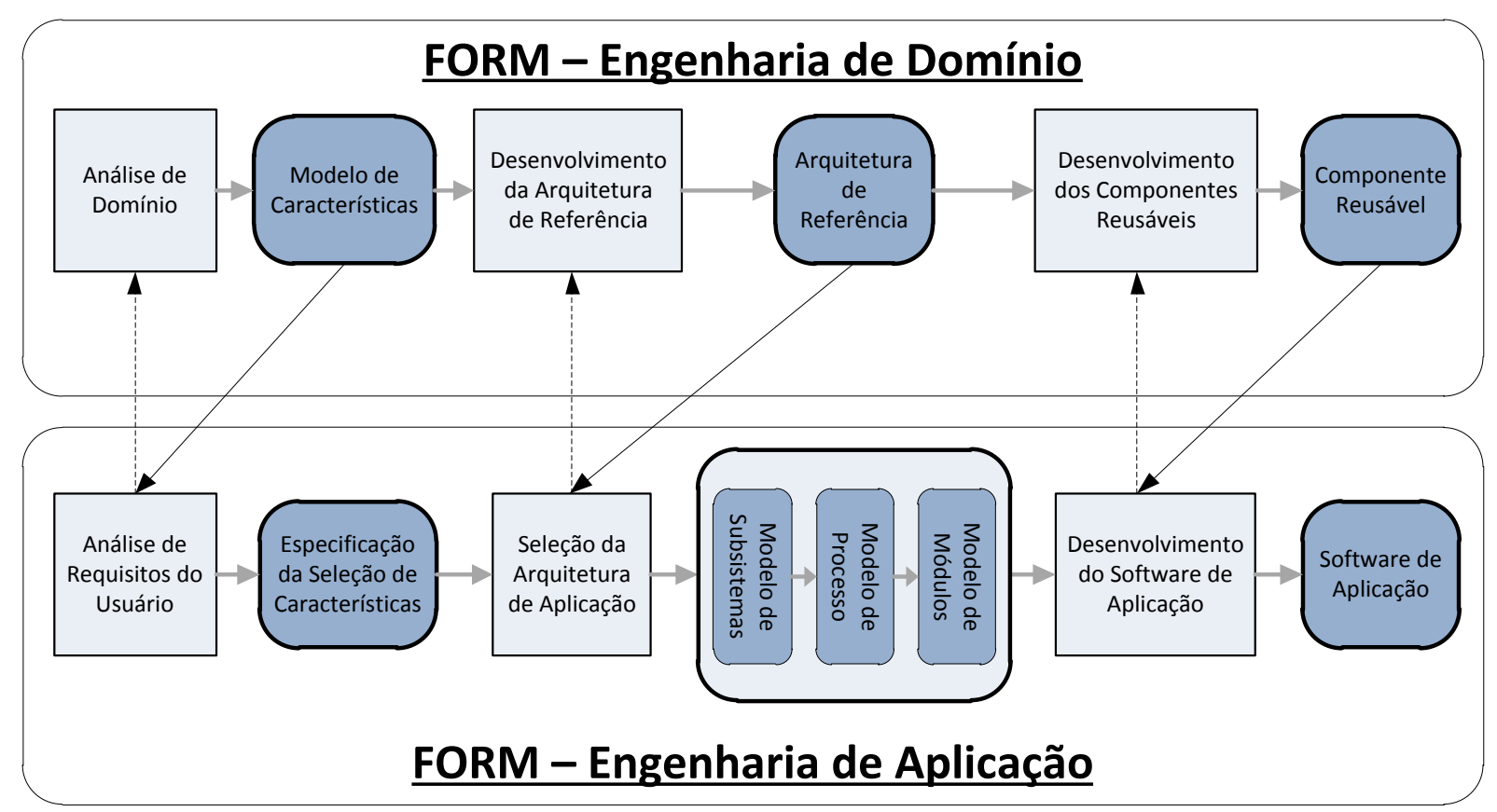

Figura 6 - Processo de Desenvolvimento de uma LP - Método FORM.

Fonte: Traduzido de Kang et al. (1998)

Um conceito central em LP são variabilidades: diferenças tangíveis, entre produtos, que podem ser reveladas e distribuídas entre todos os artefatos da LP de forma rastreável (GIMENES; TRAVASSOS, 2002). As variações podem ser reveladas em qualquer passo do desenvolvimento de uma LP, a começar pela análise de requisitos (GIMENES; TRAVASSOS, 2002). Há dois conceitos relacionados a variabilidades: (i) pontos de variação - são posições em que a variação pode ocorrer; (ii) variantes - são as diferentes possibilidades que existem para satisfazer um determinado ponto de variação (BACHMANN; BASS, 2001).

O restante deste capítulo tem o objetivo de apresentar uma visão geral dos principais conceitos relacionados à LP necessários para a abordagem sendo proposta no Capítulo 4. Para isso, as seções a seguir apresentam os seguintes assuntos: Modelo de Características; Abordagens de LP; uma abordagem específica base de LP para BPM usada como base para este trabalho; processos de negócio; Linha de Produto de Software Dinâmica - LPD; e LP para SOA. 


\subsection{Modelo de Características}

Uma das técnicas mais usadas para a gestão de variabilidades em LP são os modelos

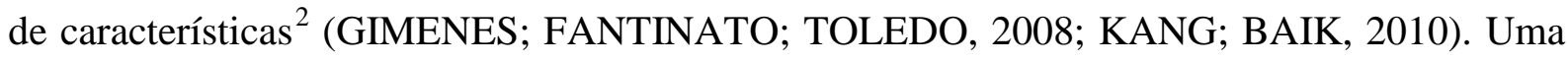
característica pode ser definida como uma propriedade de um sistema que é relevante para alguma entidade envolvida em seu desenvolvimento ou uso. Ela é usada para capturar pontos comuns ou estabelecer uma discriminação entre sistemas em uma família de sistemas. Uma característica pode denotar qualquer propriedade funcional ou não funcional em relação a requisitos, arquitetura, componentes ou plataformas computacionais (KANG, et al., 1998).

A representação gráfica mais comum é por meio de árvore, o que constitui o diagrama de característica (feature diagram) como apresentado na Figura 7. Nesses diagramas, características podem ser representadas como: 'AND', 'Alternativa', 'OR', 'Obrigatória’ e 'Opcional'. O modelo a seguir foi elaborado com o uso da ferramenta SPLOT (acrônimo em inglês de Software Product Line Online Tools) (MENDONCA; BRANCO; COWAN, 2009).

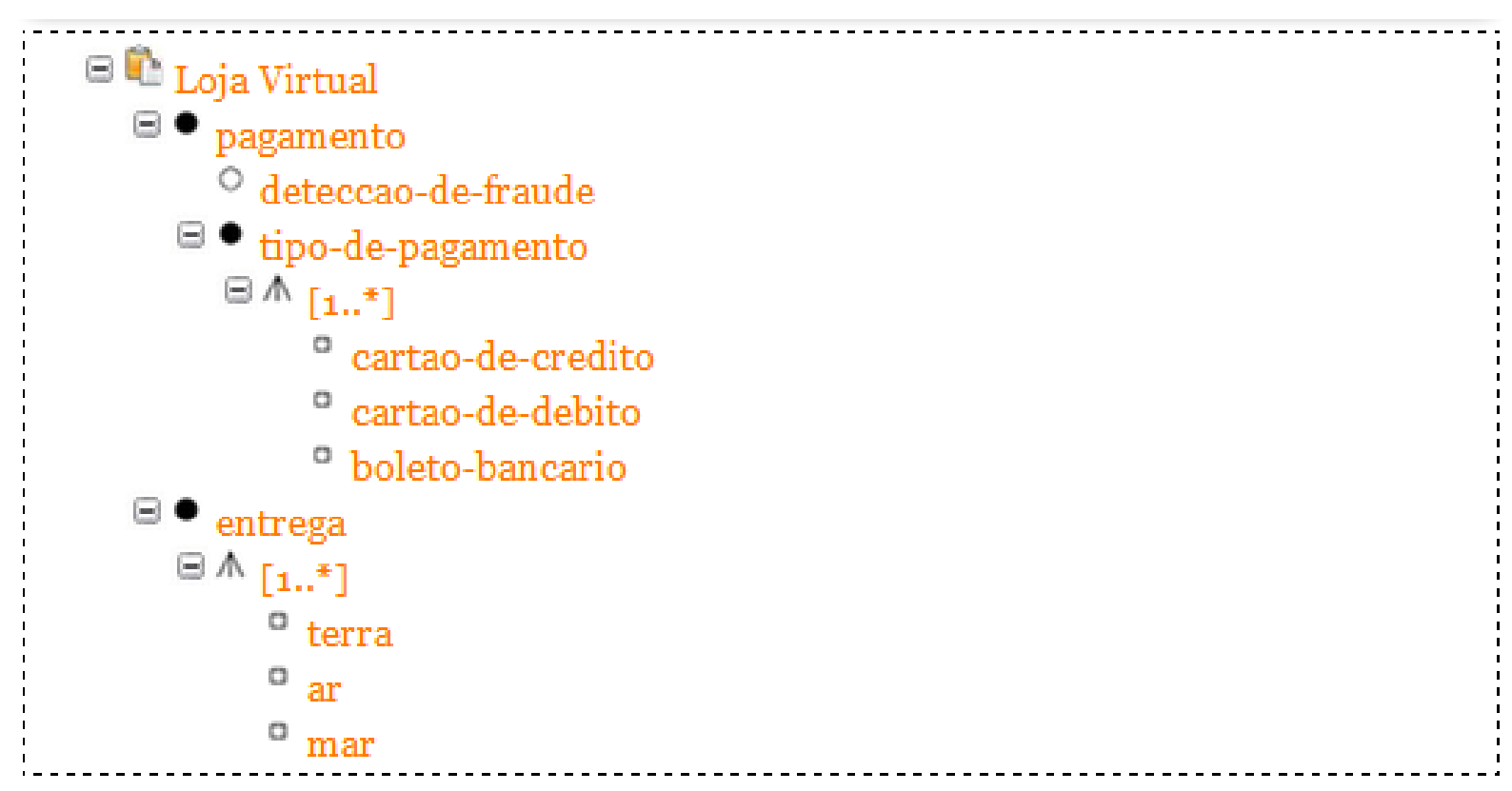

Figura 7 - Modelo de Características de uma Loja Virtual

Um modelo de características pode descrever o espaço de configuração de uma família de sistemas (FANTINATO, 2007). Um membro da família pode ser especificado por meio da seleção das características desejadas a partir do modelo de características, considerando as restrições de variabilidades definida pelo modelo. O conjunto de características selecionadas é chamado de configuração (GRÖNER et al., 2011) Um exemplo de configuração para o modelo apresentado na Figura 7 é escolher as seguintes características: o "tipo de pagamento"

\footnotetext{
${ }^{2}$ Do inglês: feature models
} 
deve ser apenas por "boleto bancário" sem a característica "detecção de fraude", e a "entrega" apenas por "mar", conforme apresentado na Figura 8:

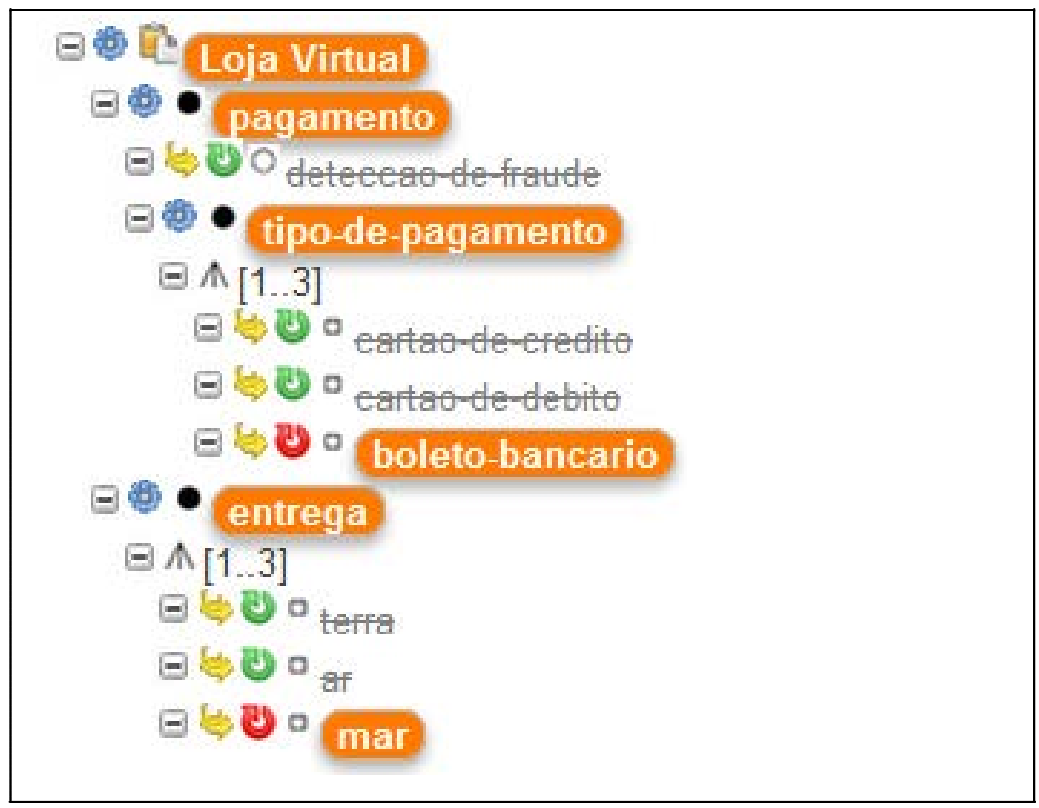

Figura 8 - Modelo de Características Configurado de uma Loja Virtual

\subsection{Abordagens de LP}

Existem diversas abordagens de LP e seus respectivos processos. Considerando os objetivos deste trabalho, a escolha de uma abordagem de LP base, que mais bem se adapta ao domínio de BPM, é um passo essencial para a definição de um processo completo que contemple todo o ciclo de vida de BPM, incluindo a evolução da LP, crítico à natureza do ciclo de vida de BPM. Dentro desse contexto, essa seção apresenta as seguintes abordagens de LP que foram avaliadas dentro deste projeto por serem consideradas completas o suficiente: Framework Software Product Line Practice (CLEMENTS; NORTHROP, 2001); Product Line Software Engineering (PuLSE) (BAYER et al., 1999); Product Line UML-Based Software Engineering (PLUS) (GOMAA; SALEH, 2005); e, Framework para Engenharia de LP (POHL; BLÖCKLE; LINDEN, 2005).

Por meio do Framework Software Product Line Practice (FSPLP), o Instituto de Engenharia de Software (SEI - Software Engineering Institute) estabeleceu as atividades essenciais de uma LP, que são: o Desenvolvimento do Núcleo de Artefatos (Core Asset Development), também conhecida como "Engenharia de Domínio"; o Desenvolvimento do Produto (Product Develepment), também conhecida como "Engenharia de Aplicação"; e a "Gestão da LP" (Management) (CLEMENTS; NORTHROP et al., 2001). Essas três 
atividades, apresentadas na Figura 9, estão intrinsecamente relacionadas de tal forma que a alteração de uma implica analisar o impacto nas demais.

Para realização dessas três atividades essenciais, o Framework PLP define Áreas de Práticas (Practice Areas), que representam uma coleção de atividades que uma organização deve conhecer para realizar o trabalho essencial de uma LP (NORTHROP et al., 2012). As Áreas de Práticas são classificadas em três categorias:

- Área de Práticas de Engenharia de Software: é constituída pelas atividades necessárias para aplicar a tecnologia apropriada para a criação e evolução do núcleo de artefatos dos produtos instanciados;

- Área de Práticas de Gerenciamento Técnico: é constituída pelas atividades necessárias para gerenciar a criação e evolução do núcleo de artefatos dos produtos instanciados;

- Área de Práticas de Gerenciamento Organizacional: é constituída pelas atividades ou itens necessários para coordenar os esforços para o desenvolvimento da LP inteira.

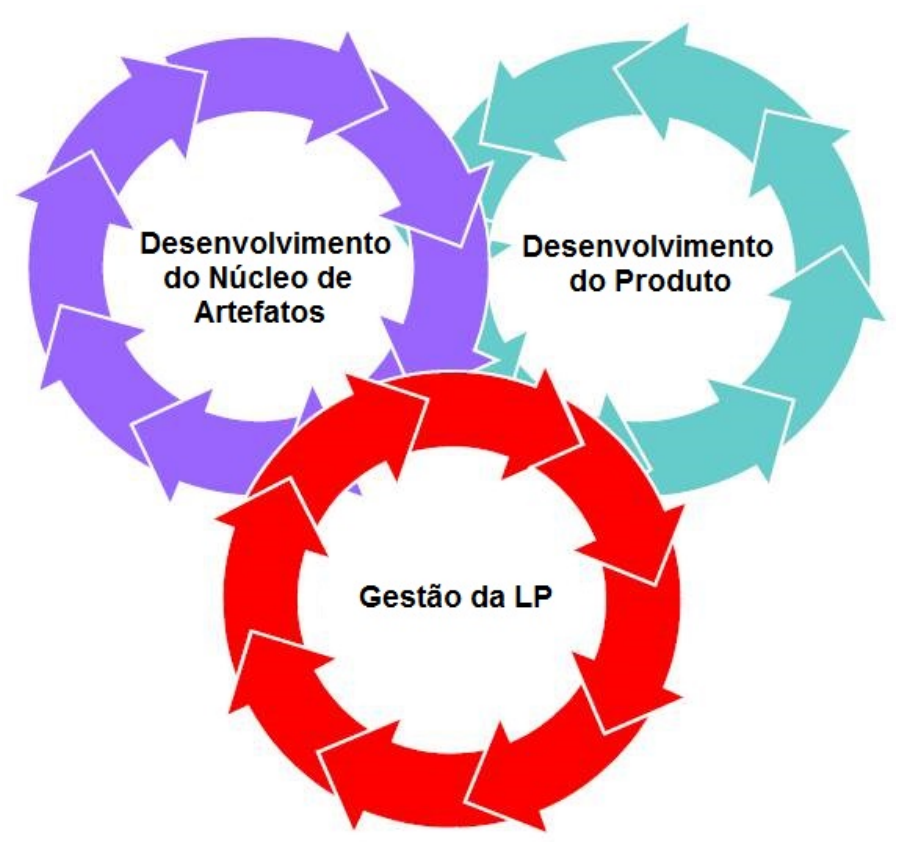

Figura 9 - As três atividades essenciais de uma $L P$ Fonte: Traduzido de Clements e Northrop (2001)

A Figura 10 apresenta como essas três Áreas de Práticas estão relacionadas: a Área de Práticas de Gerenciamento Organizacional habilita e orquestra as áreas de Gerenciamento Técnico e de Engenharia de Software. Estas, por sua vez, oferecem mecanismos de gestão e suporte à LP. 


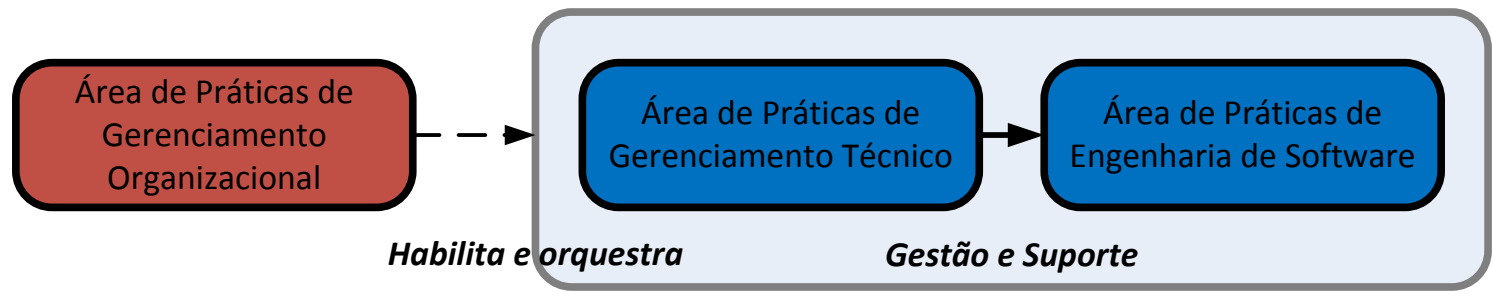

Figura 10 - Relacionamento entre as Áreas de Práticas Fonte: Traduzido de Northrop et al. (2012)

PuLSE é uma metodologia para construção e uso de LP articulada em torno de três eixos principais, conforme apresentado na Figura 11: Fases de Implantação; Componentes Técnicos; e Componentes de Apoio (BAYER et al., 1999). As Fases de Implantação são: Iniciação; Construção da Infraestrutura da LP; Uso da Infraestrutura da LP; e, Evolução e Gestão da Infraestrutura da LP. Os Componentes Técnicos fornecem conhecimento para operacionalizar o desenvolvimento da LP, sendo relacionados com: Customização; Escopo; Modelagem; Desenvolvimento da Arquitetura; Instanciação; e, Evolução \& Gestão. Os Componentes de Apoio são pacotes de informação, que auxiliam na melhor adaptação, evolução e implantação de LP, estando relacionados com os componentes de apoio: Pontos de Entrada no Projeto; Escala de Maturidade; e, as Questões de Organização.

Fases de Implantação

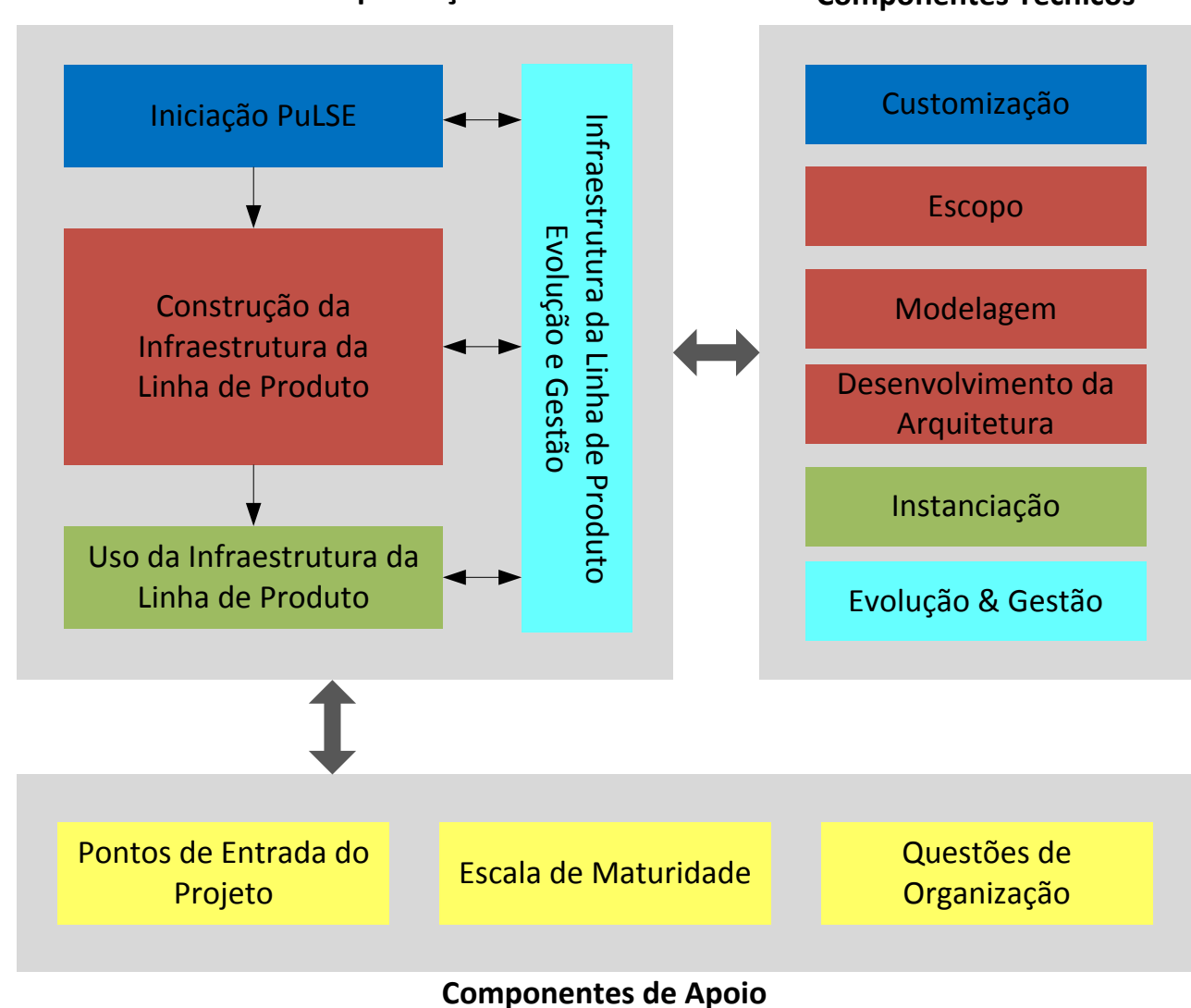

Figura 11 - Visão geral da abordagem PuLSE

Fonte: Traduzido de Bayer et al. (1999) 
A abordagem PLUS (GOMAA; SALEH, 2005) estende os métodos de modelagem de sistemas baseados em UML para tratar LP. Ela é baseada no Processo Unificado da Rational (RUP - Rational Unified Process), em que cada fase da PLUS corresponde a um workflow do RUP com o mesmo nome. A abordagem PLUS tem como principal objetivo modelar explicitamente as características comuns e variáveis de uma LP. O processo evolucionário da LP consiste em dois principais processos como mostrado na Figura 12 (GOMAA; SALEH, 2005): (i) Engenharia de LP - um modelo de LP, que oferece múltiplas visões da LP; (ii) Configuração do Sistema Alvo - um sistema alvo é um membro da LP, e a múltipla visão do modelo para um sistema alvo é configurado a partir do modelo de múltiplas visões da Engenharia de LP.

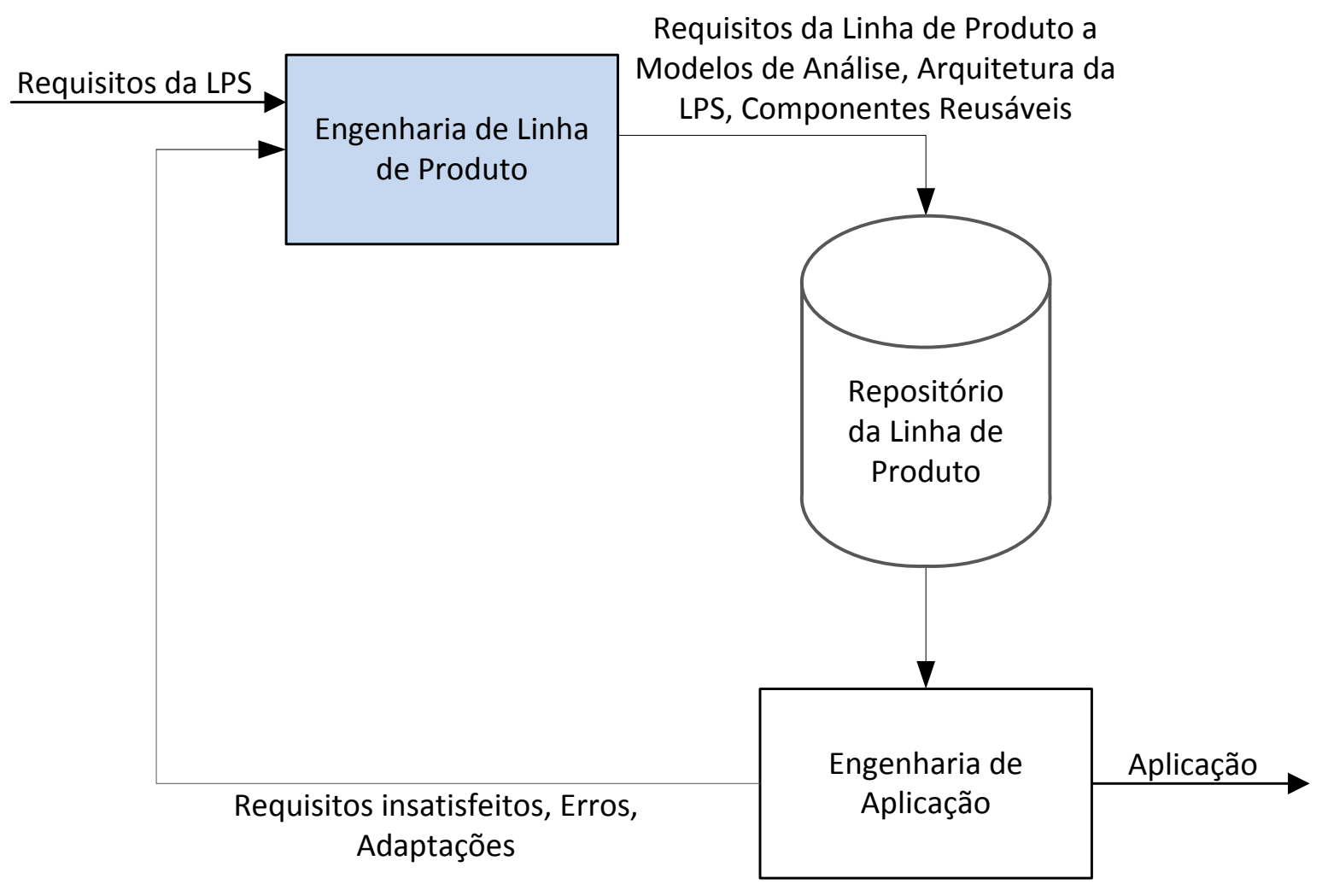

Figura 12 - Modelo de Processo Evolucionário para LP

Fonte: Traduzido de Gomaa e Saleh (2005)

O Framework para Engenharia de LP (POHL; BLÖCKLE; LINDEN, 2005) também é dividido em dois processos - "Engenharia de Domínio" e "Engenharia de Aplicação", conforme apresentado na Figura 13. A "Engenharia de Domínio" contempla: (i) Gestão do Produto - que define o escopo da LP; (ii) Engenharia de Requisitos do Domínio - que identifica o escopo do domínio e os principais artefatos da LP; (iii) Projeto do Domínio - que desenvolve uma arquitetura de referência da LP e define um plano de 
produção; (iv) Realização do Domínio - que implementa os principais artefatos; e, (v) Teste do Domínio - que valida e verifica os artefatos. A "Engenharia de Aplicação" contempla: (i) Engenharia de Requisitos da Aplicação - que produz a especificação dos requisitos da aplicação; (ii) Projeto da Aplicação - que corresponde as atividades para produzir uma arquitetura da aplicação, usando a arquitetura de referência da fase de "Engenharia de Domínio" e as adaptações específicas da aplicação; (iii) Realização da Aplicação - que instancia a aplicação, usando a arquitetura definida na etapa imediatamente anterior e os artefatos implementados na "Engenharia de Domínio"; e, (iv) Teste da Aplicação - que valida e verifica o produto instanciado de acordo com a especificação.

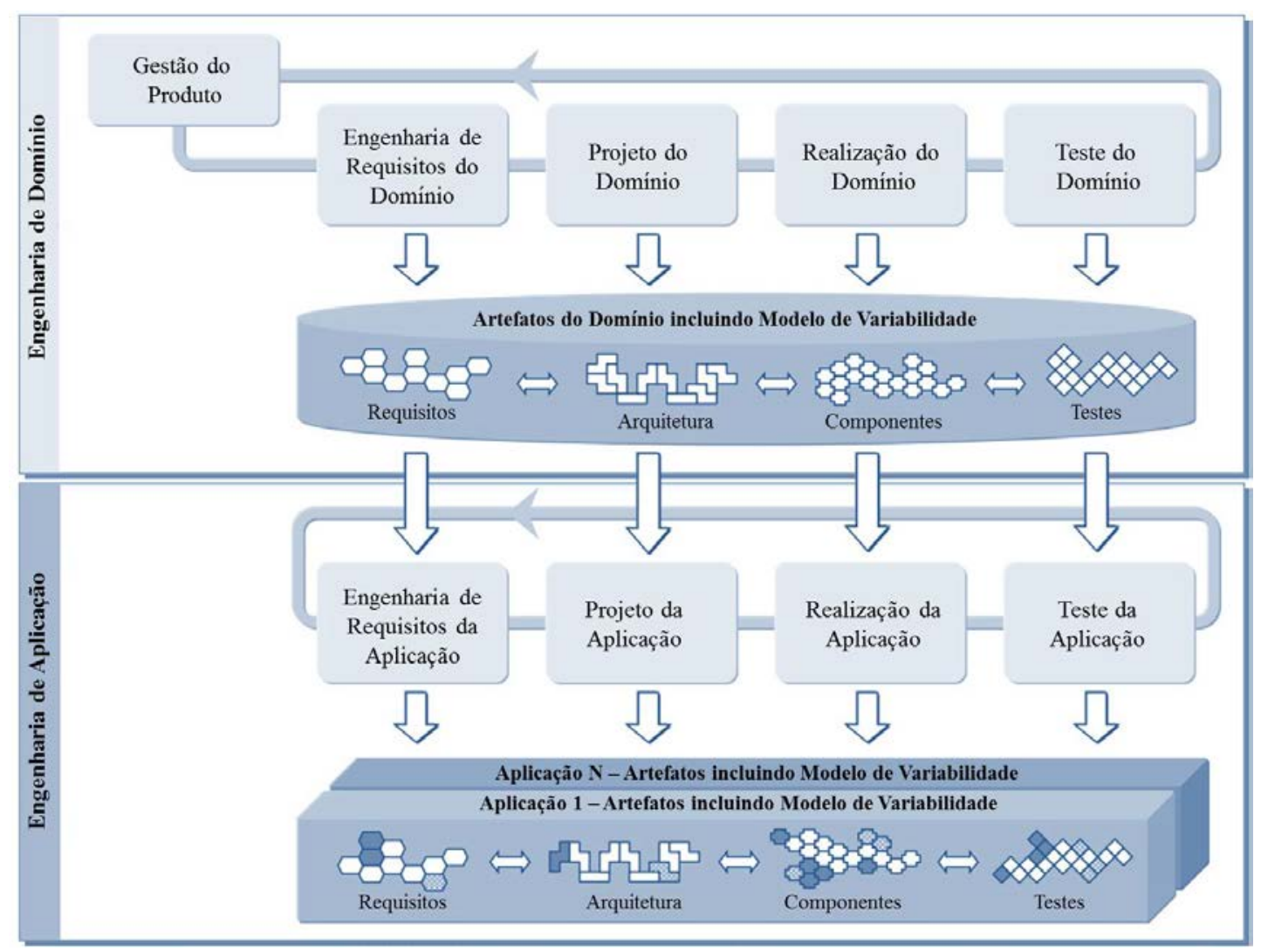

Figura 13 - Um framework para Engenharia de LP

Fonte: Traduzido de Pohl, Böckle e Linden (2005)

Nesta seção foi apresentada uma visão geral dos vários processos para o desenvolvimento de LP, cada um com as suas especificidades, como por exemplo, alguns enfatizam mais o processo "Engenharia de Domínio", enquanto outras dão ênfase ao processo da "Engenharia de Aplicação", como é o caso da abordagem PLUS. Outro aspecto percebido é que alguns processos, como as abordagens PLP e PuLSE, lançam a preocupação em ter uma 
boa gestão da LP devido às implicações deste processo para a geração da família de produto e sua evolução.

\subsection{Abordagem PL4BPM}

Considerando que BPM é um domínio no qual conceitos de LP podem ser aplicados, já que uma mesma organização pode realizar processos de negócio similares com diferentes organizações parceiras, ou mesmo instâncias de processo com uma mesma organização em momentos diferentes, Fantinato, Gimenes e Toledo (2010) propuseram uma abordagem de estabelecimento de contratos eletrônicos para BPM baseada em modelos de características e em conceitos de LP. Essa abordagem, chamada de PL4BPM (Product Line for Business Process Management), é usada como abordagem base para esta proposta, embora não se trate de uma extensão direta.

O processo da abordagem PL4BPM consiste em cinco atividades agrupadas em dois processos - Desenvolvimento do Molde e Desenvolvimento do Contrato - conforme apresentado na Figura 14. O processo "Desenvolvimento do Molde" consiste no desenvolvimento de novos moldes de contrato ou a atualização dos contratos pré-existente. $\mathrm{O}$ ciclo é composto pelas seguintes atividades: Elaboração dos Modelos de Características para Serviços Eletrônicos; Criação do Molde de Contrato Eletrônico para Serviços Web; Desenvolvimento e Publicação de Serviços Web.

O processo "Desenvolvimento do Contrato" consiste na criação de novas instâncias de contratos baseados no molde do contrato. Este ciclo é composto pelas seguintes atividades: Configuração dos Modelos de Características para Serviços Eletrônicos; Criação da Instância do Contrato Eletrônico para Serviços Web.

As atividades dos dois processos são baseadas no método FORM (KANG et al., 1998). Na abordagem PL4BPM, os modelos de características são usados para a representação genérica de serviços eletrônicos e níveis de atributos de QoS, e essa representação permite a derivação de um molde de contrato eletrônico.

PL4BPM pode ser considerada uma das primeiras abordagens a relacionar LP ao domínio de BPM, cujos primeiros resultados foram apresentados em 2006 (FANTINATO; TOLEDO; GIMENES, 2006). Apesar dos benefícios para a área de BPM, a abordagem PL4BPM original bem como os refinamentos posteriores, assim como outras abordagens propostas posteriormente, não cobre todo o ciclo de vida de processos de negócio e também não trata aspectos dinâmicos do gerenciamento de processos e do paradigma de apoio SOA. 


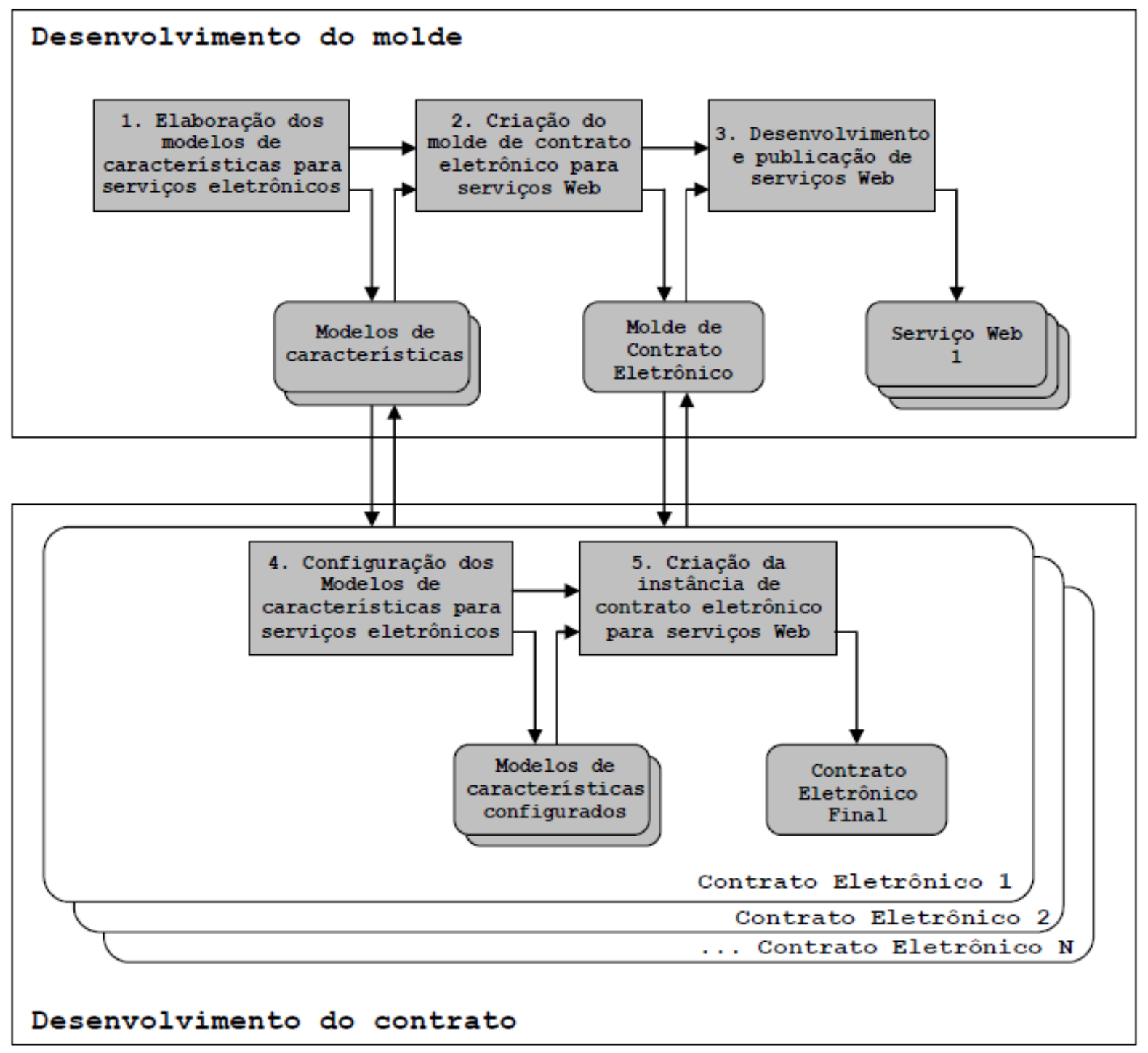

Figura 14 - Processo da abordagem PL4BPM

Fonte: Fantinato, Gimenes e Toledo (2010)

\subsection{Família de Processo de Negócio}

A Engenharia de LP pode também ser aplicada ao domínio de processos de negócio. Aplicando princípios e técnica de LP nesse domínio pode-se gerar um conjunto de processos de negócios relacionados, formando assim uma família de processos de negócio (YE et al., 2007).

Nesse contexto, a abordagem Engenharia de Família de Processo (BAYER et al., 2005) foi uma das primeiras a usar técnicas de LP em processos de negócio (MONTERO; PEÑA; RUIZ-CORTÉS, 2008b), ao aplicar modelos de características para a gestão de variabilidades e a representação de tais variabilidades nos modelos de processos de negócio. 
Assim, a abordagem é relevante para a definição dos objetivos desta dissertação e será apresentada na Subseção 3.4.1. Além disso, na Subseção 3.4.2 é apresentada outra abordagem - denominada de Engenharia de Família de Negócios - que propõe alternativas aos problemas identificados na PFE.

\subsubsection{Engenharia de Família de Processo - $\mathbf{P F E}^{3}$}

A Engenharia de Família de Processo (PFE - Process Family Engineering) foi definida no contexto do projeto PESOA ${ }^{4}$ - acrônimo de Engenharia de Família de Processos em Aplicações Orientadas a Serviços (BAYER et al., 2005).

A principal diferença entre abordagem de LP tradicional e a PFE é que LP proporciona um conjunto de diferentes produtos que compartilham características comuns e a abordagem PFE provê apenas um produto, o qual representa um processo de negócio que evolui em tempo de execução; além disso, cada configuração possível do negócio é gerenciada como um produto que contém um subconjunto de processos que serão habilitados em um algum momento da execução (MONTERO, 2009).

Gestão de variabilidade no contexto da PFE é realizada por meio dos mecanismos de variabilidade. Estes representam técnicas para derivação de variantes de um modelo de processo já existente (SCHNIEDERS; PUHLMANN, 2006). A seleção adequada destes é crucial para o projeto de uma família de processos de negócio, devido aos impactos que podem gerar nas propriedades funcionais e não funcionais da família. Além disso, uma seleção adequada dos mecanismos de variabilidade assegura uma derivação rápida e de qualidade dos membros da família de processos.

Na abordagem PFE, os modelos de características são usados para representar o conjunto de processos contidos em um negócio. Além disso, uma notação de diagrama de processos de negócio, tal como BPMN, é usada para representar um processo específico. No entanto, a sintaxe dessa notação precisa ser redefinida para dar apoio à representação das variantes dos modelos de processos de negócio (SCHNIEDERS; PUHLMANN, 2006; PUHLMANN, et al. 2005).

Os mecanismos são definidos por meio de duas categorias de variabilidade, conforme ilustrados na Figura 15 (PUHLMANN, et al. 2005):

\footnotetext{
${ }^{3}$ Acrônimo em inglês de: Process Family Engineering

${ }^{4}$ Do ingles: Process Family Engineering in Service-Oriented Applications
} 
- Mecanismos básicos de variabilidade: são mecanismos independentes, que não necessitam de quaisquer outros mecanismos de variabilidade. Quatro tipos de mecanismos básicos de variabilidade foram identificados: (i) encapsulamento de diferentes subprocessos, (ii) parametrização, (iii) adição/omissão/substituição de elementos individuais e variabilidade de tipo de dados;

- Mecanismos derivados de variabilidade: são derivados dos mecanismos básicos de variabilidade. Essa categoria é dividida em mecanismos de variabilidade derivados por restrição e por mecanismos de variabilidade por combinação. Herança e extensão são exemplos de mecanismos de variabilidade derivado por restrição e Padrões de Projeto é um exemplo de um mecanismo de variabilidade por combinação.

Ainda de acordo com o ilustrado na Figura 15, uma variante do diagrama de processos de negócio deve conter mais três padrões (SCHNIEDERS; PUHLMANN, 2006): (i) marcação dos pontos onde a variabilidade ocorre (ou seja, pontos de variação); (ii) as resoluções possíveis (chamadas de variantes) deverão ser mostradas no diagrama; e, (iii) o mecanismo de variabilidade usado para derivar a resolução.

Para a identificação dos pontos de variação, Schnieders e Puhlmann (2006) adaptaram o conceito de estereótipo da especificação da Unified Modeling Language 2.0 - UML2 (OMG, 2005) para BPMN. Assim, cada atividade, associação e/ou artefato pode ter um estereótipo associado. A Figura 14 corresponde aos principais exemplos de mecanismos de variabilidade para BPMN, que são:

- Comportamento Opcional: define quando existem várias formas diferentes para realizar uma atividade em um Modelo de Processo de Negócio. Figura 15. A mostra um exemplo de um refinamento do processo de negócio do exemplo motivacional;

- Parametrização: define que cada atributo BPMN pode ser parametrizado para apoiar um intervalo de valores (conforme Figura 15.B);

- Herança: define uma modificação de um subprocesso existente, adicionando ou removendo elementos relativos a regras específicas. Isto permite a realização pontos de variação alternativos (conforme Figura 15.C);

- Pontos de Extensão: define um comportamento alternativo, como por exemplo, na Figura 15.D a atividade pode ser configurada com um requisito de qualidade (garantia de qualidade). 


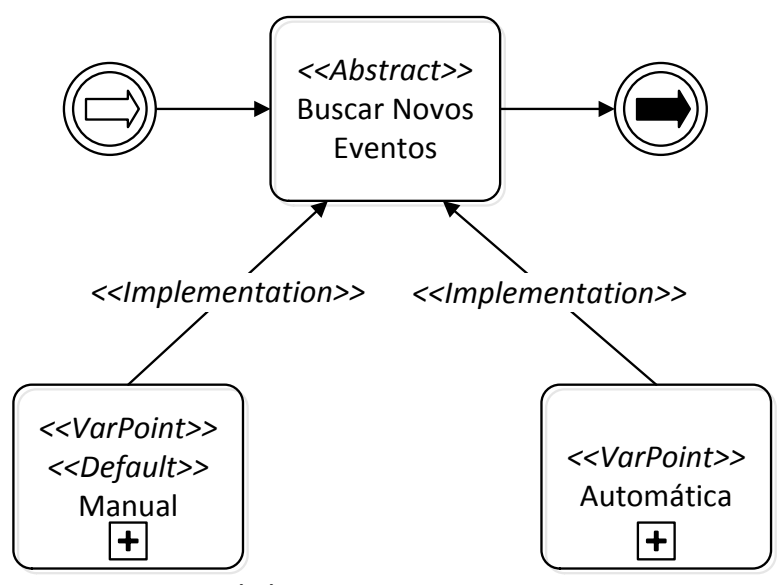

(A) Comportamento Opcional

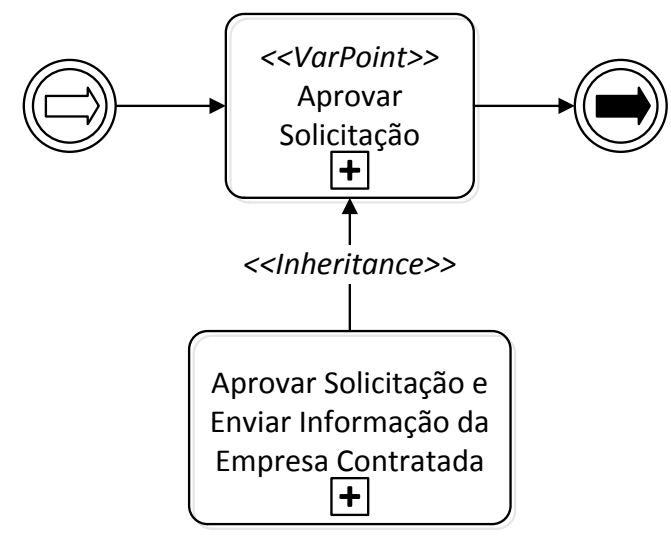

(C) Herança

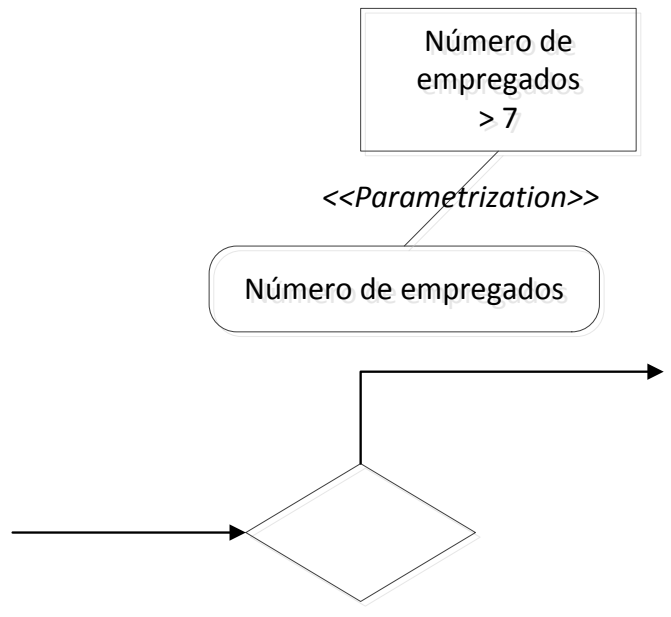

(B) Parametrização

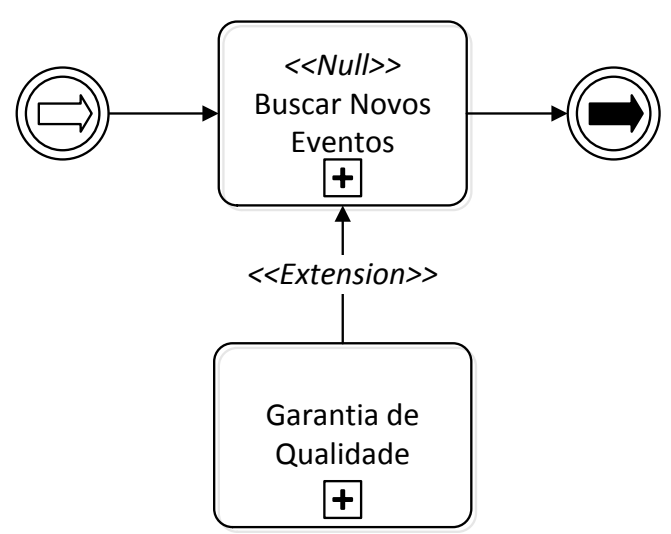

(D) Extensão

Figura 15 - Aspectos de variabilidade definido pela abordagem PFE

\subsubsection{Engenharia de Família de Negócios $-\mathbf{B F E}^{5}$}

A motivação principal da abordagem BFE é propor alternativas aos problemas identificados na PFE, principalmente na fase de projeto. Os problemas identificados foram agrupados em três categorias (MONTERO; PEÑA; RUIZ-CORTÉS, 2008b):

- Ambiguidade: a PFE redefine implicitamente a semântica dos modelos de características, sem fornecer uma definição clara para gerar os modelos de processos de negócio a partir dos modelos de características;

- Manutenção: a PFE estende a notação BPMN e adiciona informação sobre variabilidades. Esta informação também está presente nos modelos de

\footnotetext{
${ }^{5}$ Acrônimo em ingles de: Business Family Engineering
} 
características e, assim, a informação está duplicada o que pode acarretar em problemas de manutenção;

- Derivação Manual: o relacionamento entre o modelo de característica e o processo de negócio associado não é rigorosamente definido, e o desenvolvimento dos modelos de processos de negócios é realizado manualmente usando como entrada apenas o modelo de característica.

Para contornar tais problemas a abordagem BFE propõe: (i) definição de uma nova semântica para os modelos de características e (ii) mapeamento de um modelo de característica para uma estrutura BPMN.

Para definir a nova semântica, foi proposta uma nova gramática, levando em consideração que em LPs tradicionais não é necessário estabelecer a ordem de apresentação das características da família de produtos, mas no contexto de família de processos, é extremamente essencial (MONTERO; PEÑA; RUIZ-CORTÉS, 2008b). Além disso, para a definição deste mapeamento entre modelo de características e processos de negócio deve-se considerar que: (i) características pai (que representam os pontos de variação) no modelo de características, são considerados processos complexos; (ii) características filhas (que representam as variantes), são consideradas subprocessos.

Para o mapeamento entre um modelo de características e uma estrutura do BPMN, Montero, Peña e Ruiz-Cortés (2008b) consideram que BPMN pode representar o comportamento de uma Máquina de Estados Finito (MEF). Assim, os gateways em BPMN são viáveis para serem usados na implementação do comportamento de uma MEF, como mostrado na Figura 16, que apresenta um catálogo de equivalência entre MEFs e sua representação usando BPMN. 


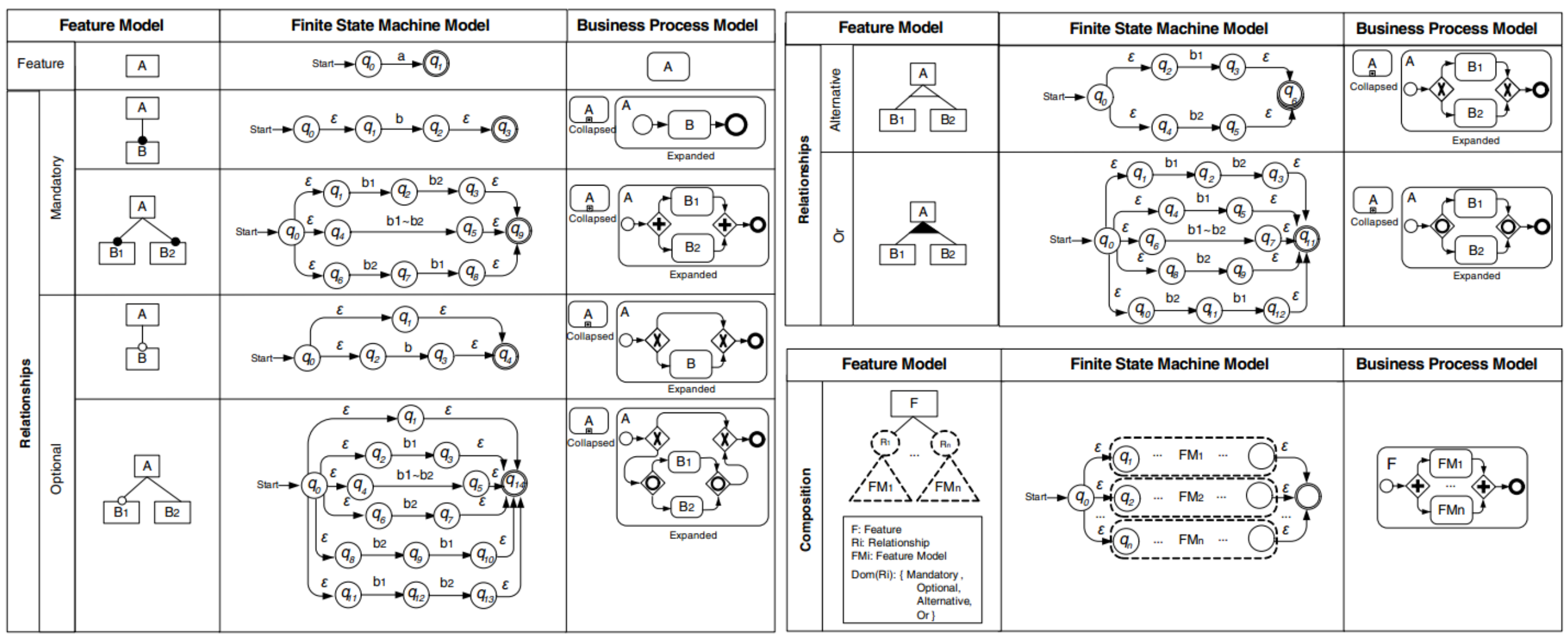

Figura 16 - Equivalência entre cada um dos MEFs e sua representação usando BPMN Fonte: Montero, Peña e Ruiz-Cortés (2008b) 


\subsection{Linha de Produto de Software Dinâmica - LPD}

Nos últimos anos, experimentos práticos têm demonstrado que técnicas de LP contribuíram para a derivação de produtos com alta qualidade, baixo custo e tempo reduzido de desenvolvimento. Entretanto, abordagens típicas de LP não focam em aspectos dinâmicos do processo e dos produtos derivados (BURÉGIO; MEIRA; ALMEIDA, 2010). Como alternativa, a abordagem LPD foi recentemente identificada como uma estratégia para lidar com adaptações de produtos em tempo de execução, mais especificamente, em aplicações dos seguintes domínios: sistemas embarcados, sensíveis ao contexto e orientados a serviços (BURÉGIO; MEIRA; ALMEIDA, 2010).

Uma LPD produz software capaz de adaptação às mudanças para atender a necessidade do usuário, levando em consideração as restrições de recursos. Embora LPD seja construída na ideia central de LP típica, existem diferenças entre ambas, visto que uma LPD possui a maioria das seguintes propriedades (HALLSTEINSEN et al., 2008):

1) Variabilidade dinâmica - configuração e vínculo em tempo de execução;

2) Mudanças de vínculos várias vezes durante o tempo de vida;

3) Mudança de pontos de variação durante tempo de execução - adição de pontos de variação;

4) Tratamento de mudanças inesperadas (em algum caminho limitado);

5) Tratamento de mudanças dos usuários (requisitos funcionais ou de qualidade);

6) Sensibilidade ao contexto e percepção da situação;

7) Propriedades autônomas ou autoadaptativas;

8) Tomada de decisão automática;

9) Ambiente individual/situação de contexto em vez de um "mercado".

Um mapeamento de estudo sistemático da área de LPD foi proposto por Burégio, Meira e Almeida (2010). Foi realizado um levantamento dos principais artigos com o objetivo de construir um esquema de classificação preliminar para estruturar o campo de LPD em termos de três facetas: (a) foco de pesquisa; (b) tipo de contribuição; e, (c) tipo de pesquisa. Em "foco de pesquisa", identificou-se que grande parte das pesquisas (45,5\% dos artigos) trata dos aspectos de derivação dinâmica, relacionada principalmente a: derivação de produto em tempo de execução; modelos de decisão para sistema de reconfiguração dinâmica; seleção autônoma de variantes; e, gestão de adaptações de característica em tempo de execução. Em 
"tipo de contribuição" mostra que o campo de pesquisa ainda está em estágio de formação, pois poucos trabalhos propõem ferramentas que suportam aspectos de variabilidade e/ou adaptação dinâmica, já que a maioria das contribuições apresentadas refere-se a propostas de solução (mais de 50\%), sendo a maior parte relacionada ao desenvolvimento de metodologias e outra parte focada em abordagens para representação dos aspectos dinâmicos (modelagem).

Esse levantamento preliminar realizado por Burégio, Meira e Almeida (2010) não identifica a aplicação de LPD no domínio de BPM, foco desta proposta. No entanto, o estudo realizado cobre apenas artigos publicados nos dois fóruns de pesquisa mais importante da área: a International Software Product Line Conference (SPLC) e o International Workshop on Dynamic Software Product Line (DSPL).

\subsection{LP para SOA}

Apesar de poucas LPD já terem sido propostas especificamente para o domínio de BPM, já existem diversas propostas de LPD associadas ao paradigma SOA, que é o paradigma mais usado atualmente como base tecnológica para a implementação de BPM (ADAM; DOERR, 2008). As abordagens existentes de LPD para SOA, embora não sejam diretamente aplicáveis ao objetivo desta proposta, são úteis para sua definição.

De fato, LP e SOA satisfazem uma meta comum da Engenharia de Software - reúso, visando à aplicação de uma mesma parte de software em diferentes contextos. A união de ambas resulta em LP Orientada a Serviços (LPSOA), formadas por um conjunto de sistemas orientados a serviços similares em um domínio específico que pode ser desenvolvido a partir de um núcleo comum de artefatos reusáveis (TRUJILLO; KASTNER; APEL, 2007; YE et al. 2007).

LPD e LPSOA relacionam-se entre si conceitualmente. De acordo com Lee e Kotonya (2010), toda LPSOA é uma LPD por definição, considerando que, ao aplicar os princípios de SOA em uma LP, arquiteturas genéricas para sistemas adaptativos em ambiente heterogêneos são desenvolvidas naturalmente, permitindo ajustes em tempo de execução, de forma que a LP pode ser considerada uma LPD. A seguir, nesta seção, são apresentados alguns trabalhos considerados relevantes no âmbito de LPSOA, que pelo entendimento de Lee e Kotonya (2010) podem ser consideradas LPD para SOA.

Segura, Benavides e Ruiz-Cortés (2007) apresentaram questões que devem ser tratadas para esclarecer a conexão entre LP e SOA. Uma questão importante é como conceitos de LP podem ser usados para apoiar aplicações orientadas a serviços. Nesse sentido, é proposta uma 
visão geral dos principais pontos de variabilidade na composição de serviços web, em que a "identificação" e a "gestão de pontos de variabilidades" são consideradas como um passo essencial para tornar possível a integração entre ambos os campos.

De acordo com Kang e Baik (2010), a forma de identificar serviços é o desafio mais relevante a ser resolvido para desenvolvimento de LPSOA. Assim, é proposta uma abordagem para identificação de serviços que une modelos de características de uma LP e modelos de processos de negócio, no domínio de SOA, para obter os benefícios do reúso de software. Em relação à modelagem de processos, o método usa um modelo de workflow baseado nas regras de BPMN para receber o fluxo dos requisitos de negócios dos processos de negócio.

Por fim, observa-se que a maioria dos trabalhos atuais trata de variabilidades em LP em termos de recursos, ativo (assets) ou decisões, focando apenas nos aspectos de modelagem.

Nas próximas subseções são apresentadas algumas abordagens de LPSOA agrupadas pela maior contribuição que está sendo proposta. Dessa forma, a Subseção 3.6.1 apresenta abordagens que usam modelos de características no contexto de LPSOA. Da mesma maneira, a Subseção 3.6.2 apresenta o tratamento de variabilidades no contexto de LPSOA.

\subsubsection{Definição de Serviços com Base em Características}

Uma abordagem para desenvolvimento de LPSOA foi apresentada por Lee, Muthig e Naab (2008) e Lee e Kotonya (2010). Nesses trabalhos, é proposto um método para identificar e compor serviços usando modelos de característica. Em Lee e Kotonya (2010) são apresentados também os desafios encontrados no desenvolvimento de LPSOA, e é descrita uma possível solução. A abordagem de identificação de serviços foi refinada, pela incorporação de ontologias, que facilita a descrição dos serviços e contratos de serviços em termos de atributos (funcionais) e qualidades (não funcionais).

O método propõe diretrizes que auxiliam desenvolvedores na identificação de serviços em um nível correto de granularidade. De posse do Modelo de Características do domínio, é realizada uma análise por meio de feature biding analysis, que consistem em duas atividades (LEE; MUTHIG; NAAB, 2010): (i) feature biding unit identification - que possibilita a identificação das características dos serviços; (ii) feature binding time determination - que, por meio das análises das características dos serviços, identifica quais serviços compartilham o mesmo tempo de ligação (biding time) para agrupá-los em um único produto/pacote. Então o Modelo de Características é refinado e reestruturado por meio da separação entre duas 
categorias: behavioral (workflow) e características de serviços computacionais (tasks). A Figura 17 ilustra esses dois conceitos.

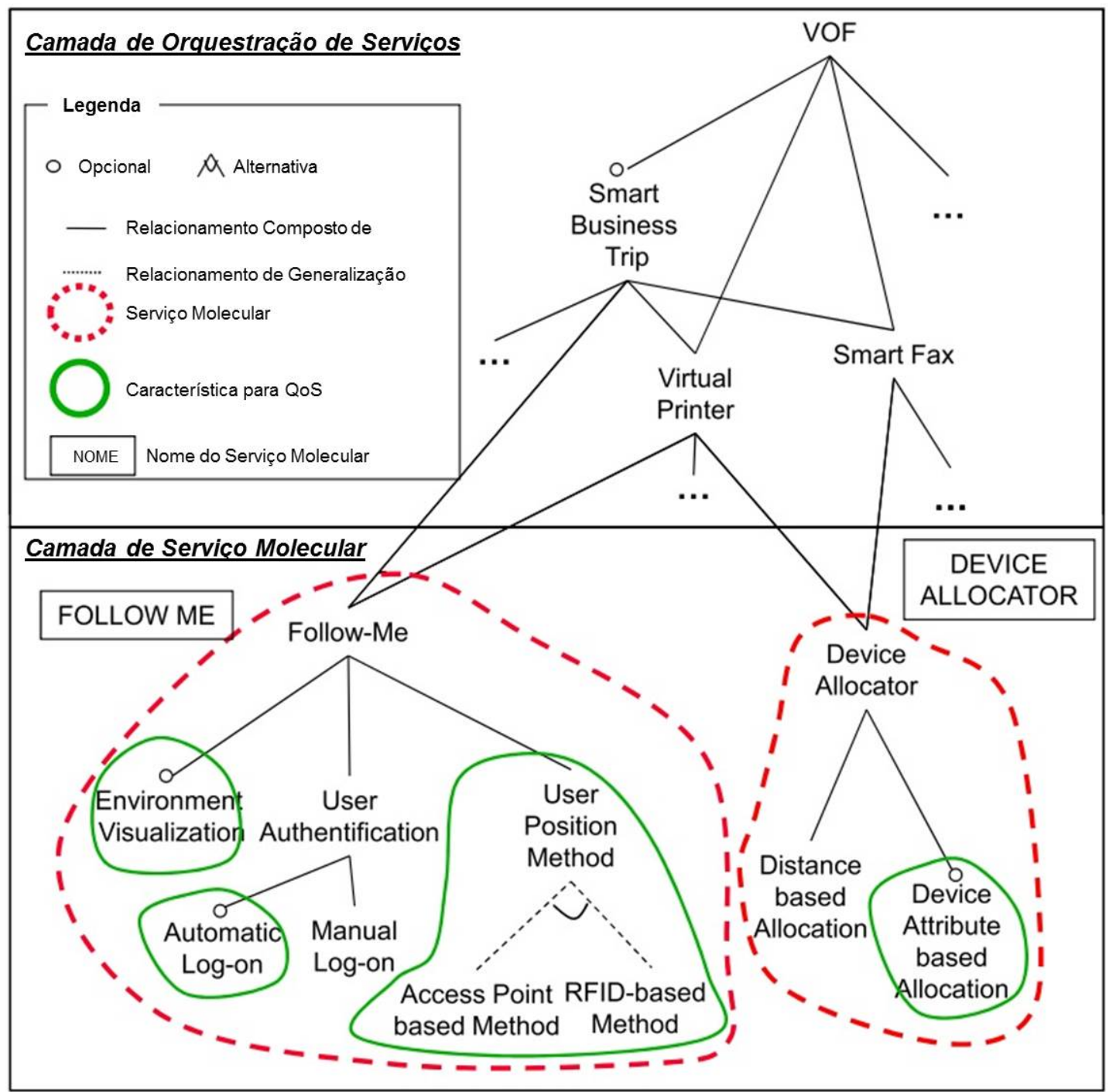

Figura 17 - Um Modelo de Características refinado baseado em duas categorias de serviços Fonte: Lee, Muthig e Naab (2010)

Na Camada de Orquestração de Serviços (Orchestrating Service Layer) são definidos, principalmente, quais serviços realizam cada tarefa e a sequência destas, ou seja, aqueles que possuem comportamento de workflow. Serviços nessa categoria são chamados de serviços de orquestração. A Camada de Serviço Molecular (Molecular Service Layer) fornece saídas computacionais (tarefas predefinidas a serem executadas por sistemas computacionais ou pessoas). Os serviços dessa categoria são chamados de serviços moleculares. A identificação dos serviços moleculares com granularidade correta é o fator chave para aumentar a capacidade de reúso do desenvolvimento do sistema orientada a serviços (LEE; MUTHIG; NAAB, 2010). 
SOPLE-DE é outra abordagem para identificar serviços candidatos, usando modelos de características (MEDEIROS; ALMEIDA; MEIRA, 2010). A abordagem proposta usa uma combinação de LP, SOA, processos de negócio, casos de uso e cenários de atributo de qualidade. Essa é uma abordagem orientada a serviços, para a identificação sistemática, projeto e documentação de ativos principais, que serve de apoio para o reúso não sistemático do desenvolvimento orientado a serviço (SOD - Service-Oriented Development). Um estudo experimental foi realizado para validar e refinar a abordagem proposta.

Em outra linha, Nguyen e Colman (2010) propõem uma abordagem orientada a características para adaptação de serviços web que pretende resolver, pelo menos em parte, três grandes desafios: redução da complexidade; validação automática; e, desenvolvimento dinâmico. O uso de características em tempo de execução permite o desenvolvimento dinâmico de processos de negócio para a adaptação do serviço. Assim, é estabelecido o uso de modelos de características como artefato para descrição do serviço no intuito de facilitar a adaptação dos serviços web. Além disso, Nguyen et al. (2011) apresentaram uma revisão de trabalhos relacionados sobre a gestão de variabilidades e os desafios encontrados e propuseram também uma abordagem, porém ainda em busca de maturidade, para resolver os principais desafios da gestão de variabilidades.

\subsubsection{Representação de Variabilidade em SOA}

O objetivo principal da abordagem apresentada por Galster (2010) é melhorar a variabilidade dinâmica em LPSOA, pois existem poucas pesquisas sendo desenvolvidas que tentam resolver a variabilidade em qualquer etapa do ciclo de vida do software. Sua proposta alcança seu objetivo pela combinação de conceitos de SOA e LP, fornecendo abordagens de Engenharia de Software que maximizam os benefícios de ambos os domínios. Baseado nos princípios de SOA, Galster (2010) argumenta ser possível desenvolver arquiteturas genéricas para sistemas autoadaptativos em ambientes heterogêneos. Além disso, para o mesmo sistema, princípios de LP ajudam a desenvolver arquiteturas que podem ser reusadas em múltiplas instâncias.

Galster (2010) sugere uma forma de representar a variabilidade em SOA pela formalização da noção de variabilidade. De acordo com sua proposta, o conjunto de variabilidades que podem ocorrer em aplicações orientadas a serviços são: (a) variabilidade em sistemas baseados em serviços podem ocorrer em diferentes níveis de abstração; (b) variabilidade precisa considerar a integração de serviços, aplicações de terceira parte; 
sistemas de diferentes organizações e sistemas legados; e, (c) variabilidade em tempo de execução dinâmica deve ser apoiada.

A partir de uma comparação entre formas de reúso obtidas por meio de LPSOA, Chang e Kim (2007) procuram aplicar elementos de LP para tratar variabilidades em SOA. Esse trabalho apresenta uma classificação das variabilidades em SOA e um método de modelagem de variabilidades. Primeiro, compara-se as variabilidades em aplicações convencionais e as variabilidades em SOA. A partir desse ponto foram identificadas quatro tipos de variabilidade, conforme ilustrado na Figura 18, que podem ocorrer em processos de negócio: (i) Workflow, (ii) Composição, (iii) Interface, e (iv) Variabilidade Lógica.

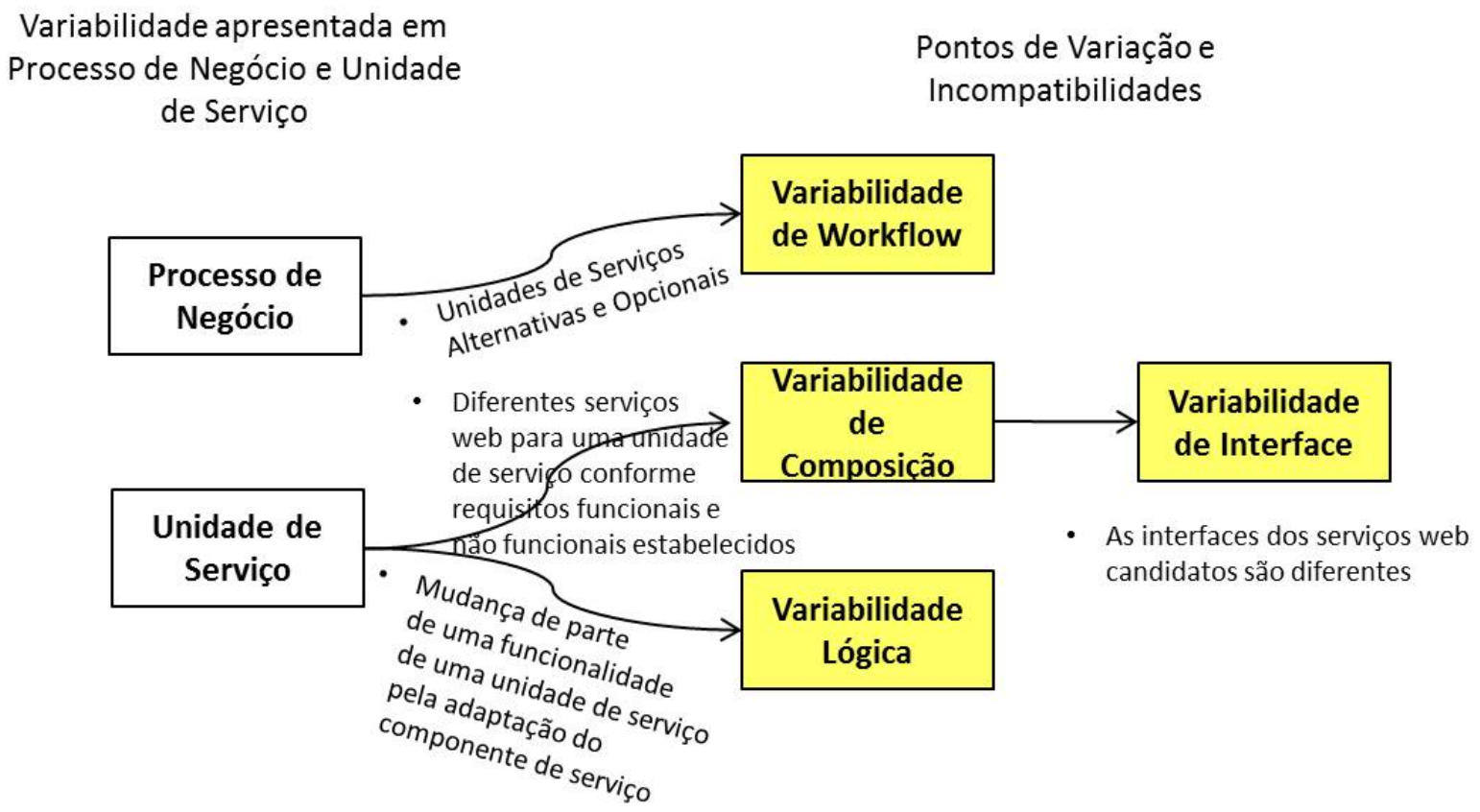

Figura 18 - Tipos de Variabilidades que podem ocorrer em SOA

Fonte: Traduzido de Chang e Kim (2007)

- Variabilidade de Workflow: em um workflow, algumas unidades de serviços podem não ser solicitadas por um usuário de um serviço específico; além disso, parte dessa sequência pode ser realizada de forma diferente para outro usuário específico. Assim, unidades de serviços podem ser alternativas ou de forma opcional ajustadas a determinado workflow dependendo dos usuários específicos dos serviços;

- Variabilidade de Composição: a variação ocorre sobre a seleção da interface de serviço mais adequada, pois para uma unidade de serviço pode existir mais de uma interface de serviço possível, com diferentes lógicas de implementação ou atributos de qualidades; 
- Variabilidade de Interface: ocorre quando as interfaces de unidade de serviço não correspondem às interfaces de serviços publicados em UDDI no registro (service registry);

- Variabilidade Lógica: o componente de serviço deve fornecer lógicas diferentes dependendo dos serviços específicos solicitados.

\subsection{Considerações Finais}

BPM é um dos domínios em potencial para os quais conceitos e técnicas de LP podem ser aplicados de forma bem-sucedida. Entretanto, existem desafios que precisam ser superados para que essas tecnologias realizem corretamente seu papel no ambiente organizacional. Um deles é possibilitar atividades de BPM em tempo de execução (run-time). LPD tem proporcionado uma forma eficiente para lidar com adaptações de produtos em tempo de execução. As abordagens de LPSOA apresentadas neste capítulo servem de apoio ao tratamento dos aspectos dinâmicos que serão incorporados ao processo proposto no Capítulo 4. 


\section{O Processo DynPL4BPM}

Este capítulo apresenta a proposta de processo da abordagem dinâmica de LP para atender às necessidades de organizações interessadas em realizar processos de negócio interorganizacionais baseados no paradigma de orientação a serviços, por meio de um alinhamento entre conceitos de BPM e SOA, com o apoio de uma abordagem de LPD.

A abordagem apresentada neste trabalho, denominada DynPL4BPM - Dynamic Product Line for Business Process Management, é inspirada na abordagem Product Line for Business Process Management (PL4BPM) (FANTINATO; GIMENES; TOLEDO, 2010).

Para uma melhor estruturação da abordagem, esta proposta está dividida em quatro partes: na Seção 4.1 é apresentada a visão geral do processo da DynPL4BPM; na Seção 4.2 é apresentada uma introdução ao tratamento de aspectos dinâmicos cobertos pelo processo proposto; e na Seção 4.3 as atividades do processo da DynPL4BPM são apresentados com mais informações.

\subsection{Visão Geral do Processo DynPL4BPM}

Nesta seção, é apresentada uma visão geral do processo da abordagem DynPL4BPM (chamado a partir desse ponto de apenas "processo DynPL4BM"); neste primeiro momento, sem tratar ainda de aspectos dinâmicos. Trata-se de uma proposta que foi elaborada baseada, principalmente, nas seguintes contribuições: (i) o processo PL4BPM proposto por Fantinato, Gimenes e Toledo (2010); (ii) a abordagem de LP FORM proposto por Kang et al. (1998) e a abordagem de LP PLP proposto por Clements e Northrop (2001); e (iii) o ciclo de vida de BPM proposto por Weske (2007).

Os dois processos de LP propostos na abordagem PL4BPM (FANTINATO; GIMENES; TOLEDO, 2010) foram mapeados, respectivamente, aos dois primeiros processos da abordagem DynPL4BPM, adaptando-os quando necessários. O processo PL4BPM é constituído por cinco atividades, que foram derivadas do método FORM (KANG et al, 1998). Para o mapeamento das atividades da PL4BPM ao processo da DynPL4BPM, adaptações foram realizadas, chegando a um processo com um número maior de estágios, já que todo o ciclo de vida de BPM está sendo agora contemplado.

A abordagem PLP (CLEMENTS; NORTHROP, 2001) contribuiu com conceitos sobre a "Gestão da LP", e como esta pode evoluir em relação ao tempo. Esse processo foi 
importante para a definição do processo relacionado à gestão de instâncias de processos de negócio.

Por fim, como ainda as LPs que serviram de base para a definição do processo da DynPL4BPM não focavam explicitamente o domínio de BPM, exceto a PL4BPM, um ciclo de vida de BPM foi necessário para avaliar quais fases de BPM poderiam ser incorporadas aos processos de LP. O ciclo de vida de BPM apresentado na Figura 2, foi usado como referência para a definição do processo da DynPL4BPM, realizando as devidas adaptações para o contexto de LP, buscando a cobertura total do ciclo de vida de BPM nos processos de LP.

O processo proposto para a abordagem DynPL4BPM está apresentado na Figura 19. Foram usadas cores para sinalizar quais atividades do ciclo de vida de BPM (conforme esquema de cores usado na Figura 2) foram incorporadas as atividades dos processos da LP na abordagem DynPL4BPM. Além disso, as cores dos três processos - "Engenharia de Domínio", "Engenharia de Aplicação" e "Gestão da LP" - representam as três áreas do Framework Software Product Line Practice (FSPLP) (conforme esquema de cores usado na Figura 9). Há dois casos de mapeamento não direto ou completo, em que as cores usadas estão mais claras do que as outras atividades usando as mesmas cores; tais mapeamentos são explicados posteriormente.

De acordo com a Figura 19, o processo DynPL4BPM possui três processos, equivalentes aos processos de uma LP, porém focados em BPM, ou seja, tendo o Processo de Negócio como o "produto" ou a "aplicação" sendo desenvolvida pela LP e posteriormente executado e evoluído. Esses processos são descritos a seguir:

- "Engenharia de Domínio": esse processo é responsável pelo estabelecimento e manutenção da plataforma reusável da LP para BPM, definindo os pontos comuns e as variabilidades do processo de negócio, cujos artefatos produzidos devem servir como templates de processos de negócio para as atividades do processo "Engenharia de Aplicação";

- "Engenharia de Aplicação": esse processo é responsável pelas aplicações das plataformas reusáveis definidas para a LP para BPM em um contexto organizacional ou interorganizacional específico. Isso é feito com base nos artefatos definidos nas atividades do processo "Engenharia de Domínio", por meio da manutenção dos pontos comuns e resolução das variabilidades do processo de negócio. Para cada contexto de aplicação específico desejado a partir de um mesmo domínio, esse processo deve ser executado uma vez; 

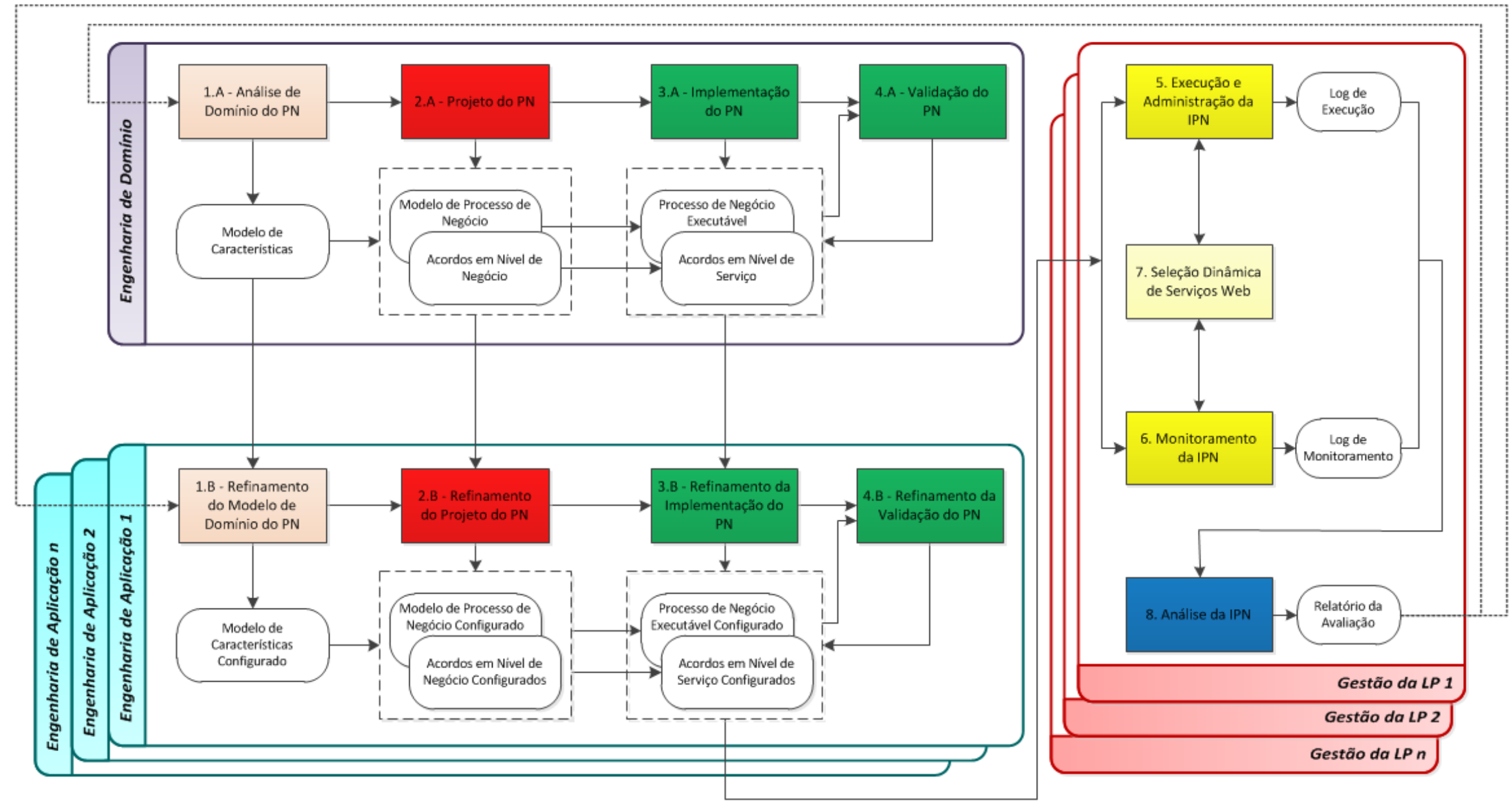

Legenda :

PN - Processo de Negócio

IPN - Instância de Processo de Negócio

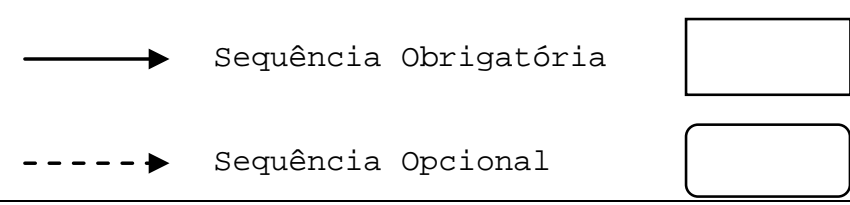

Figura 19 - O Processo DynPL4BPM
Atividade

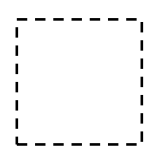

Artefato
Bloco de Artefatos 
- "Gestão da LP": esse processo é responsável pela gestão do conjunto de instâncias de um mesmo processo de negócio a serem executadas, monitoradas e possivelmente avaliadas para otimização a partir dos processos de negócio derivados no processo "Engenharia de Aplicação". O resultado da avaliação pode levar à evolução da LP para BPM, via dois possíveis caminhos: a realização de ajustes nos artefatos da plataforma reusável de uma forma geral, no processo "Engenharia de Domínio"; ou uma nova aplicação da plataforma reusável da LP para BPM, no processo "Engenharia de Aplicação" apenas iniciando com um novo conjunto de configurações.

A seguir, cada um desses três processos é apresentado com mais informações.

O processo "Engenharia de Domínio" é composto pelas seguintes atividades:

1.A) Análise de Domínio $\underline{\text { do }} \underline{\text { PN: }}$ essa atividade consiste na definição do $\underline{\text { Modelo }} \underline{\text { de }}$

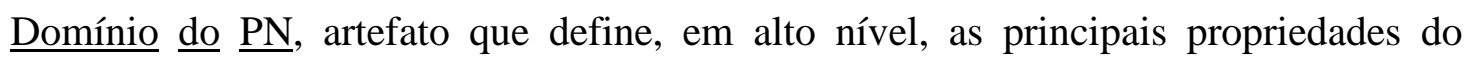
processo de negócio sendo criado, incluindo, por exemplo: organizações ou departamentos envolvidos no processo de negócio, demandas de serviços a serem oferecidos e usados para cada parte envolvida, possíveis requisitos não funcionais atrelados a essas demandas. O artefato a ser usado para essa atividade é um Modelo de Características, que possibilita definir as propriedades obrigatórias, opcionais e alternativas, a partir das quais todos os demais artefatos a serem produzidos nas demais atividades devem estar ligados;

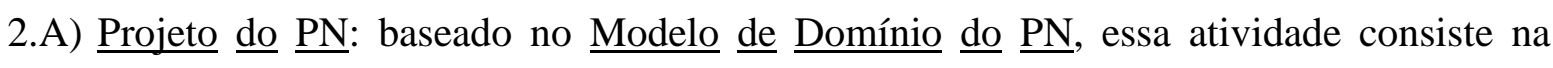

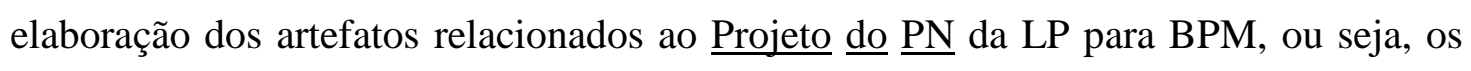

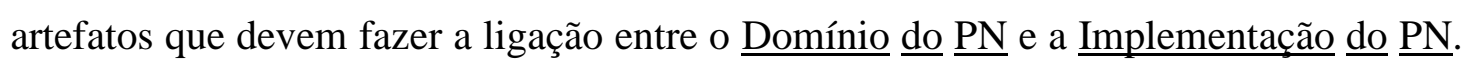
Para isso, dois artefatos inter-relacionados são previstos nessa atividade: Modelo de Processo de Negócio e Acordos em Nível de Negócio - o primeiro, elaborado na notação BPMN (OMG, 2011), define o fluxo de atividades modelado para atender as

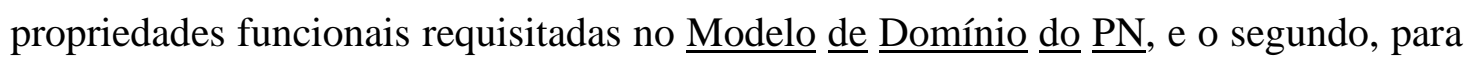
o qual não existe ainda um padrão definido, define as regras de qualidade associadas ao processo de negócio modelado para atender as propriedades não funcionais

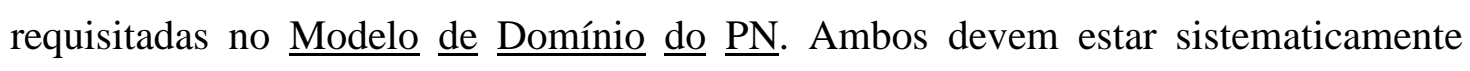
ligados às características do Modelo de Características para que seja possível identificar quais de seus elementos são também, por sua vez, obrigatórios, opcionais e 
alternativos - para que ambos possam servir de templates durante a execução do processo "Engenharia de Aplicação";

3.A) Implementação do $\underline{\mathrm{PN}}$ : baseado no Projeto $\underline{\text { do }} \underline{\mathrm{PN}}$, essa atividade consiste na geração dos artefatos de nível mais técnico do processo de negócio, ou seja, os artefatos no nível de execução dos processos de negócio da LP para BPM. Para isso, dois artefatos inter-relacionados são previstos nessa atividade: Processo de Negócio Executável e Acordos em Nível de Serviço associados - o primeiro, elaborado nas linguagens WSBPEL e WSDL e derivado do Modelo de Processo de Negócio, define a versão executável do fluxo de atividades para atender as propriedades funcionais requisitadas

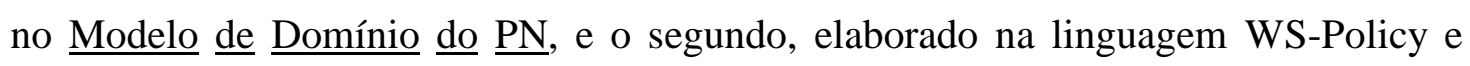
derivado dos Acordos em Nível de Negócio, define as regras de qualidade de serviço associadas ao Processo de Negócio Executável para atender as propriedades não funcionais requisitadas no $\underline{\text { Modelo }} \underline{\text { de }} \underline{\text { Domínio }} \underline{\text { do }} \underline{\text { PN. Ambos devem estar }}$ sistematicamente ligados às respectivas partes dos artefatos que foram usados para suas derivações que, por sua vez, estão ligados às características do Modelo de Características, de modo que seja possível identificar quais de seus elementos são também obrigatórios, opcionais e alternativos - para que ambos possam servir de templates durante a execução do processo "Engenharia de Aplicação";

4.A) Validação do $\underline{\mathrm{PN}}$ : essa atividade consiste na validação dos artefatos gerados durante a atividade Implementação $\underline{\text { do }} \underline{\mathrm{PN}}$, ou seja, os artefatos Processo de Negócio Executável e Acordos em Nível de Serviço, visando garantir que eles estão de acordo com os requisitos da LP para BPM, conforme modelado na atividade Análise de Domínio do

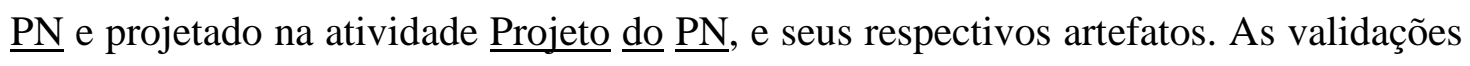
realizadas nessa atividade devem considerar o contexto genérico do processo de negócio, ou seja, as diversas possibilidades de aplicação, em diferentes contextos, que podem ocorrer durante o processo "Engenharia de Aplicação", já que o processo de negócio elaborado aqui não tem o objetivo de ser usado para resolver um problema específico.

O processo "Engenharia de Aplicação" é composto pelas seguintes atividades:

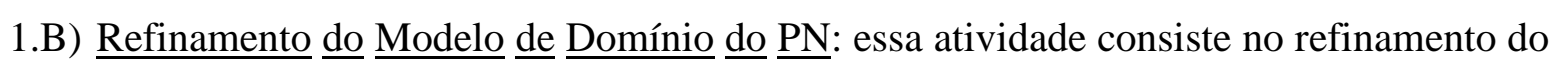

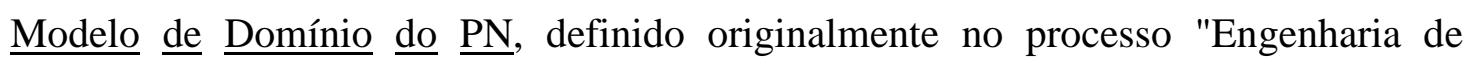
Domínio", para que o mesmo represente, em alto nível, as propriedades específicas do processo de negócio sendo criado para uma necessidade específica, incluindo, por 
exemplo: subconjunto de serviços a serem oferecidos e usados para cada parte envolvida e requisitos não funcionais específicos atrelados a essas demandas. O Modelo de Características criado no processo "Engenharia de Domínio" deve ser agora configurado, para que as propriedades opcionais e alternativas sejam então selecionadas, o que vai definir exatamente como os demais artefatos da LP pra BPM devem ser também derivados para a criação desse processo de negócio específico, já que todos estão sistematicamente ligados às características desse Modelo de Características Configurado;

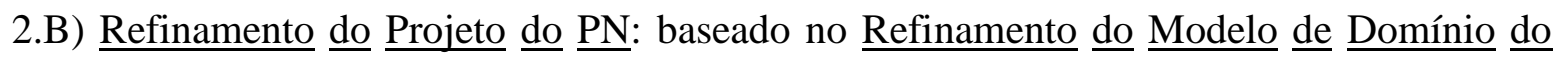
$\underline{\mathrm{PN}}$, essa atividade consiste no refinamento dos artefatos relacionados ao Projeto $\underline{\text { do }}$

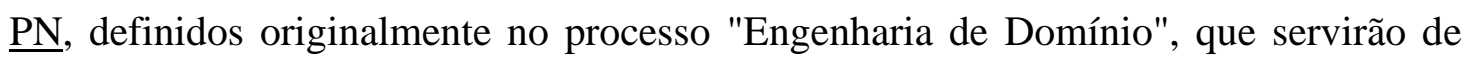
templates para essa atividade. Para isso, os dois artefatos inter-relacionados de projeto da LP para BPM (Modelo de Processo de Negócio Configurado e Acordos em Nível de Negócio Configurados) são derivados considerando o contexto específico do processo de negócio desejado. Para cada processo de negócio específico sendo derivado a partir de um mesmo domínio, diferentes artefatos de Projeto do $\underline{\text { PN }}$ devem ser refinados, dependendo de quais características opcionais e alternativas foram selecionadas

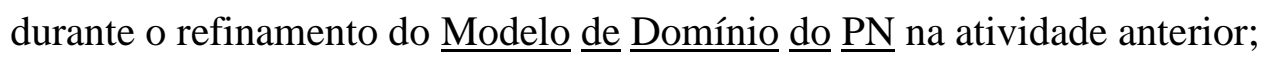

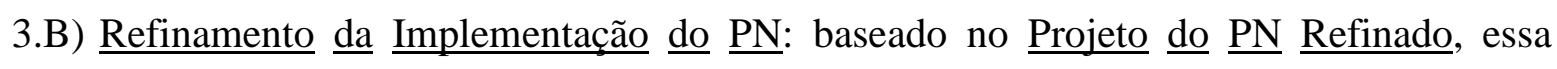
atividade consiste no refinamento dos artefatos relacionados à Implementação $\underline{\text { do }} \underline{\text { PN, }}$ definidos originalmente no processo "Engenharia de Domínio", que servirão de templates para essa atividade. Para isso, os dois artefatos inter-relacionados de projeto da LP para BPM (Processo de Negócio Executável Configurado e Acordos em Nível de Serviço Configurados) são derivados considerando o contexto específico do processo de negócio desejado. Para cada processo de negócio específico sendo derivado a partir de um mesmo domínio, diferentes artefatos de Implementação do $\underline{\text { PN }}$ devem ser refinados, dependendo de como foi refinado o Projeto $\underline{\text { do }} \underline{\text { PN }}$ que, por sua vez, depende de quais características opcionais e alternativas foram selecionadas

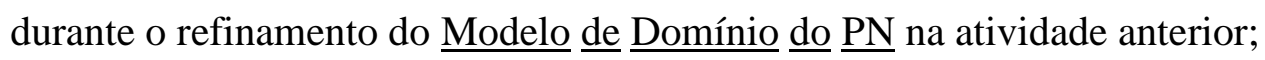

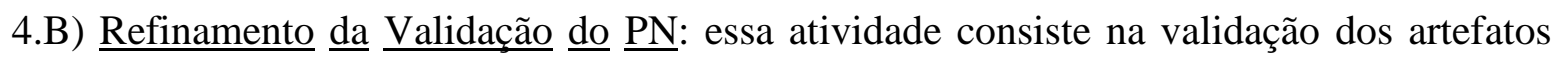

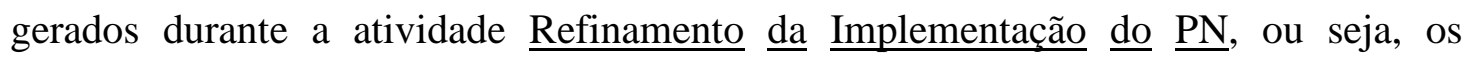
artefatos refinados Processo de Negócio Executável Configurados e Acordos em Nível de Serviço Configurados, visando garantir que eles estão de acordo com os requisitos da LP para BPM considerando essa aplicação do processo de negócio em específico, 
conforme modelado na atividade $\underline{\text { Refinamento }} \underline{\text { do }} \underline{\text { Modelo }} \underline{\text { de Domínio }} \underline{\text { do }} \underline{\text { PN }}$ e

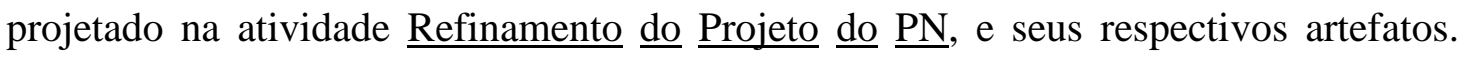
Diferentemente do que deve ocorrer na Validação $\underline{\text { do }} \underline{\mathrm{PN}}$, no processo "Engenharia de Domínio", as validações realizadas nessa atividade devem considerar o contexto específico do processo de negócio refinado, ou seja, a aplicação específica criada durante esse processo "Engenharia de Aplicação", já que o processo de negócio elaborado aqui tem o objetivo de ser usado para resolver um problema em específico.

O processo "Gestão da LP" é composto pelas seguintes atividades:

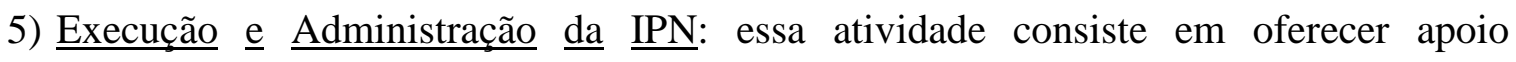
administrativo à execução de IPNs para cada processo de negócio derivado como resultado do processo "Engenharia de Aplicação". Para cada processo de negócio criado, espera-se que ele entre em execução para atender uma determinada demanda organizacional ou mesmo interorganizacional. Considerando a natureza conceitual de processos de negócio, um mesmo processo pode ser executado várias vezes, para um conjunto de dados de entradas diferentes, chamados aqui de instâncias de processo de negócio (IPN), enquanto o processo de negócio usado como base satisfizer as necessidades organizacionais ou o ambiente ser flexível o suficiente para permitir ajustes dinâmicos no processo durante suas execuções. Uma IPN ao ser colocada em execução, em sua versão executável, invoca os serviços web que a compõe. Há duas possibilidades para essa invocação: invocação estática de serviço web, considerando os casos em que o serviço web já foi definido em tempo de projeto, ou seja, durante as atividades Implementação $\underline{\text { do }} \underline{\mathrm{PN}}$ ou Refinamento $\underline{\text { da }} \underline{\text { Implementação }} \underline{\text { do }} \underline{\mathrm{PN}}$; ou invocação dinâmica do serviço web, considerando os casos em que o serviço web não foi definido em tempo de projeto, mas sim houve a indicação de que o mesmo deve ser selecionado em tempo de execução - nesse caso, a atividade Seleção $\underline{\text { Dinâmica de }}$

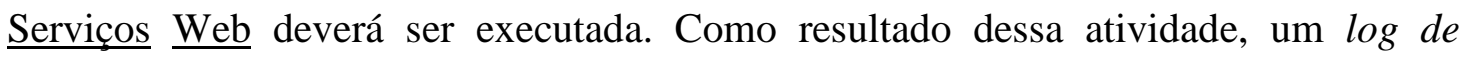
execução deve ser mantido para que a atividade $\underline{\text { Análise }} \underline{\text { da }} \underline{\text { IPN }}$ possa usá-lo posteriormente;

6) Monitoramento da IPN: essa atividade consiste em monitorar a execução de IPNs, também para cada processo de negócio derivado como resultado do processo "Engenharia de Aplicação", visando garantir a conformidade dos Acordos de Nível de Serviço associados ao respectivo processo de negócio. Para cada caso específico, os diferentes atributos de QoS definidos devem ser avaliados durante a execução de uma 
determinada IPN. Em caso de não conformidades detectadas, uma das ações possíveis, caso tenha sido prevista no processo de negócio definido e artefatos relacionados, é a substituição dos serviços web sendo usados para a execução da IPN - nesse caso, a

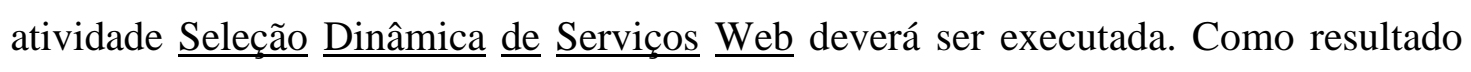
dessa atividade, um log de monitoramento deve ser mantido para que a atividade

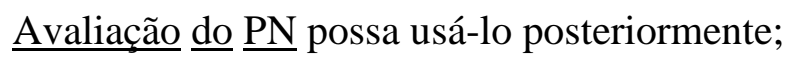

7) Seleção Dinâmica de Serviços Web: essa atividade consiste em buscar e selecionar serviços web em tempo de execução, para os casos em que essa ação tenha sido prevista, que podem ser de dois tipos principalmente: serviços web para que implementem atividades de processo de negócio não definidos em tempo de projeto propositalmente para que as organizações responsáveis possam ter flexibilidade de realizar essa escolha de forma dinâmica em tempo de execução; e serviços web alternativos para substituir outros serviços web que estejam falhando em cumprir os níveis de serviços dos atributos de QoS que foram contratados nos Níveis de Acordo de Serviço definidos entre as organizações envolvidas;

8) Análise da IPN: essa atividade consiste em realizar uma análise de uma IPN em particular, ou de um conjunto de IPNs, visando uma possível otimização do processo de negócio em execução. Para isso, pode se aplicar, por exemplo, técnicas de análise estatística ou mineração de dados em processos, buscando por pontos de gargalo ou outras tendências identificáveis nas IPNs, com base nos logs de execução e de monitoramento. A intenção é que - ao invés de apenas encerrar a execução de uma IPN e iniciar uma nova IPN baseado no mesmo processo de negócio base para um determinado contexto de aplicação, gerado a partir do processo "Engenharia de Aplicação", para um determinado domínio, gerado a partir do processo "Engenharia de Domínio" - se tenha a oportunidade de otimizar ou a plataforma reusável no nível de domínio ou pelo menos o processo de negócio sendo usado como base para a geração de instâncias no nível de aplicação. Assim, o resultado da avaliação pode levar à evolução da LP para BPM, via dois possíveis caminhos: a manutenção e consequente evolução da plataforma reusável de uma forma geral, no processo "Engenharia de Domínio"; ou uma nova aplicação de uma plataforma reusável da LP para BPM, no processo "Engenharia de Aplicação", por meio de um novo conjunto de configurações no Refinamento do Modelo de Domínio do $\underline{\text { PN. }}$. 


\subsection{Tratamento de Aspectos Dinâmicos na DynPL4BPM}

O processo proposto na seção anterior para a abordagem DynPL4BPM não contempla necessariamente os aspectos dinâmicos que são um dos objetivos principais deste trabalho, embora o processo seja proposto de forma adequada para que tais aspectos sejam incorporados apropriadamente. A única exceção é a atividade "7 - Seleção Dinâmica de Serviços Web", em que é prevista explicitamente a possibilidade de seleção dinâmica de serviços web, em tempo de execução, para compor o processo de negócio sendo executado.

Além da seleção dinâmica de serviços web, há diversos aspectos dinâmicos que podem ser tratados dentro de uma abordagem de LP para BPM apoiada pelo paradigma SOA, considerando a natureza e as demandas dinâmicas de cada uma dessas abordagens e tecnologias por si. Portanto, o desafio deste projeto foi identificar exatamente quais aspectos dinâmicos poderiam ser incorporados ao processo apresentado na seção anterior, considerando benefícios e limitações.

Uma importante fonte de análise para essa questão foi considerar que no contexto geral de LP, sendo usado como base nesse trabalho, existem as abordagens de LPD, tendo sido já identificadas como importante estratégia para lidar com adaptações de produtos em tempo de execução, mais especificamente, em aplicações de domínios emergentes, tais como os sistemas orientados a serviços. São, portanto, as LPDs que serviram como fonte principal de técnicas e metodologias a serem incorporadas na abordagem DynPL4BPM, incluindo principalmente as nove propriedades que toda LPD deveria possuir de acordo com Hallsteinsen et al. (2008), apresentadas na Seção 3.5.

Assim, um dos objetivos deste trabalho foi identificar quais dos nove tipos de propriedades associadas à LPDs poderiam ser aplicados no contexto deste trabalho, considerando principalmente o contexto de BPM, mas também o paradigma SOA como sua base tecnológica. O paradigma SOA já apresenta uma série de aspectos dinâmicos, quando avaliado de forma independente, que pode ser levado ao contexto de BPM ao usar SOA para a realização de processos de negócio. O desafio é realizar o tratamento desses aspectos dinâmicos dentro da abordagem de LP em conjunto com BPM, que mesmo sem considerar aspectos dinâmicos já apresentou benefícios anteriormente.

As nove propriedades apresentadas por Hallsteinsen et al. (2008) para LPD foram usadas para auxiliar na identificação de trabalhos inicialmente relacionados ao contexto de LP e SOA. Esse trabalho de busca, realizado como uma Revisão Sistemática, foi apresentado por 
Rocha, Fantinato e Barros (2012). Dos trabalhos encontrados, os mais representativos estão apresentados no Capítulo 3, que são os trabalhos selecionados para auxiliar na definição da abordagem proposta aqui, ou seja, os trabalhos de Chang e Kim (2007); Galster (2010); Gimenes, Fantinato e Toledo (2008); Kang e Baik (2010); Lee e Kotonya (2010) e Lee, Muthig e Naab (2010); Medeiros, Almeida e Meira (2010); Nguyen e Colman (2010) e Nguyen et al. (2011); Segura, Benavides e Ruiz-Cortés (2007); Trujillo; Kastner; Apel (2007); Ye et al. (2008).

Das nove propriedades de LPDs mencionadas, as sete a seguir foram identificadas como candidatas a serem incorporadas à abordagem DynPL4BPM, considerando os trabalhos selecionados na Revisão Sistemática referida acima, pois estes proporcionaram a base teórica para incorporação dos aspectos dinâmicos no processo da DynPL4BPM:

1) Variabilidade dinâmica;

2) Mudanças de vínculos durante o ciclo de vida;

3) Mudança de pontos de variação durante tempo de execução;

4) Tratamento de mudanças inesperadas (ou seja, tolerância a falhas);

5) Tratamento de mudanças dos usuários (requisitos funcionais ou de qualidade);

6) Propriedades autônomas ou autoadaptativas;

7) Tomada de decisão automática.

As outras duas propriedades, "Sensibilidade ao Contexto e Percepção da Situação" e "Ambiente / Situação de Contexto", não foram consideradas tendo em vista que ainda são pouco exploradas mesmo no contexto de LP, de uma maneira geral. Isso requer identificação de trabalhos em outros domínios de aplicação, como por exemplo, sistemas autoadaptativos.

As propriedades "Variabilidade Dinâmica" e "Mudanças de Pontos de Variação Durante Tempo de Execução" estão relacionadas à gestão de variabilidades em LP. Existem várias propostas para tratamento e gestão de variabilidades, no contexto de LPD para SOA, e que podem ser adaptadas para o contexto de LPD para BPM apoiada em SOA. Aspectos relacionados à variabilidade dinâmica são tratados principalmente nas atividades "1.A Análise de Domínio do PN" e "1.B - Refinamento do Modelo de Domínio do PN" do processo DynPL4BPM.

A propriedade "Mudanças de Vínculos Durante o Ciclo de Vida" relaciona-se aos aspectos de seleção e ligação de serviços web em tempo de execução. Essa propriedade é tratada principalmente nas atividades "3.A - Implementação do PN", "3.B - Refinamento da Implementação do PN" e "7 - Seleção Dinâmica de Serviços Web". 
As propriedades "Tratamento de Mudanças Inesperadas", "Propriedades Autônomas ou Autoadaptativas" e "Tomada de Decisão Automática" estão relacionadas ao monitoramento dinâmico, tratadas principalmente nas atividades "4.B - Refinamento da Validação do PN" e "6 - Monitoramento da IPN".

A propriedade "Tratamento de Mudanças dos Usuários" foi tratada nas atividades "2.A - Projeto do PN" e "2.B - Refinamento do Projeto do PN".

\subsection{Descrição das Atividades do Processo}

Esta seção apresenta cada uma das atividades que compõem os três processos do processo DynPL4BPM: "Engenharia de Domínio"; "Engenharia de Aplicação" e "Gestão da LP", já considerando o tratamento de aspectos dinâmicos de BPM por meio da aplicação de técnicas identificadas e já apresentadas no Capítulo 3 sendo incorporadas nos processos.

\subsubsection{Engenharia de Domínio}

Primeiramente são apresentadas informações referentes ao processo "Engenharia de Domínio" do processo DynPL4BPM, nas subseções a seguir.

\subsubsection{Atividade "1.A - Análise de Domínio do PN"}

A análise de domínio, no contexto da Engenharia de Software, é uma tentativa de identificar os objetos, operações e relações entre o que peritos em um determinado domínio percebem como importante (NEIGHBORS, 1992). No contexto da abordagem DynPL4BPM, a atividade "1.A - Análise de Domínio do PN" pode ser considerada equivalente à análise de domínio convencional, no entanto, ela atua em um metanível, por se referir ao processo "Engenharia de Domínio" e as propriedades exploradas, na forma de requisitos - que podem ser tanto requisitos funcionais quanto requisitos não funcionais, dizem respeito especificamente a um processo de negócio de uma determinada área, ou seja, de um determinado domínio.

Embora essa atividade não tenha um correspondente direto com o ciclo de BPM apresentado na Figura 2, o qual foi incorporado e mapeado para dentro dos processos de LP, ela foi mantida de forma adaptada no processo DynPL4BPM por ser um conceito inerente à LPs, considerando sua grande importância. Assim, no processo DynPL4BPM, ela foi representada com um vermelho claro (conforme Figura 19), pois, conceitualmente, ela está 
indiretamente relacionada com a fase Projeto e Análise do ciclo de vida de BPM (conforme Figura 2), já que ela é usada para preparar as informações para a próxima atividade do processo DynPL4BPM. Especificamente para o contexto de BPM, essa atividade e seu artefato correspondente, devem definir, em alto nível, as principais propriedades do processo de negócio sendo criado, incluindo, por exemplo: organizações ou departamentos envolvidos no processo de negócio, demandas de serviços a serem oferecidos e usados para cada parte envolvida, e possíveis propriedades de qualidade atreladas a essas demandas; sendo que em todos esses exemplos podem se configurar propriedades obrigatórias para todas as aplicações específicas da LP ou não.

No contexto de LP, várias técnicas foram propostas para a captura de propriedades de domínio em LP, tais como UML (Unified Modeling Language), Modelo de Variabilidade Ortogonal e Modelo de Características; cada um com suas vantagens e limitações. Neste trabalho, propõe-se o uso de Modelo de Características como técnica para a análise de domínio, considerada a técnica mais comum e genérica para esse fim. Os Modelos de Características, como apresentado no Capítulo 3, permitem definir para um determinado domínio quais são as propriedades obrigatórias, opcionais e alternativas de uma LPS. Assim como em outras LPs, o Modelo de Características é usado no processo DynPL4BPM para nortear a elaboração dos demais artefatos tanto no processo "Engenharia de Domínio" quanto no processo "Engenharia de Aplicação".

Com o objetivo de deixar mais clara a aplicação dessa técnica dentro do processo DynPL4BPM, um exemplo do Modelo de Características é apresentado na Figura 20. Esse exemplo corresponde ao domínio apresentado no exemplo motivacional, denominado "Domínio de Marketing", apresentado no Capítulo 1.

De acordo com esse modelo, "Oportunidade de Negócio" e "Marketing Promocional" são exemplos de características Obrigatórias, ou seja, são características que devem ser incluídas no modelo de característica configurado. "Mídia" é um exemplo de característica Opcional, e não necessariamente precisa aparecer no modelo de característica configurado. Além disso, "Eventos Promocionais" e "Ofertas" são exemplos de característica 'Alternativa' e característica 'Ou', respectivamente. 


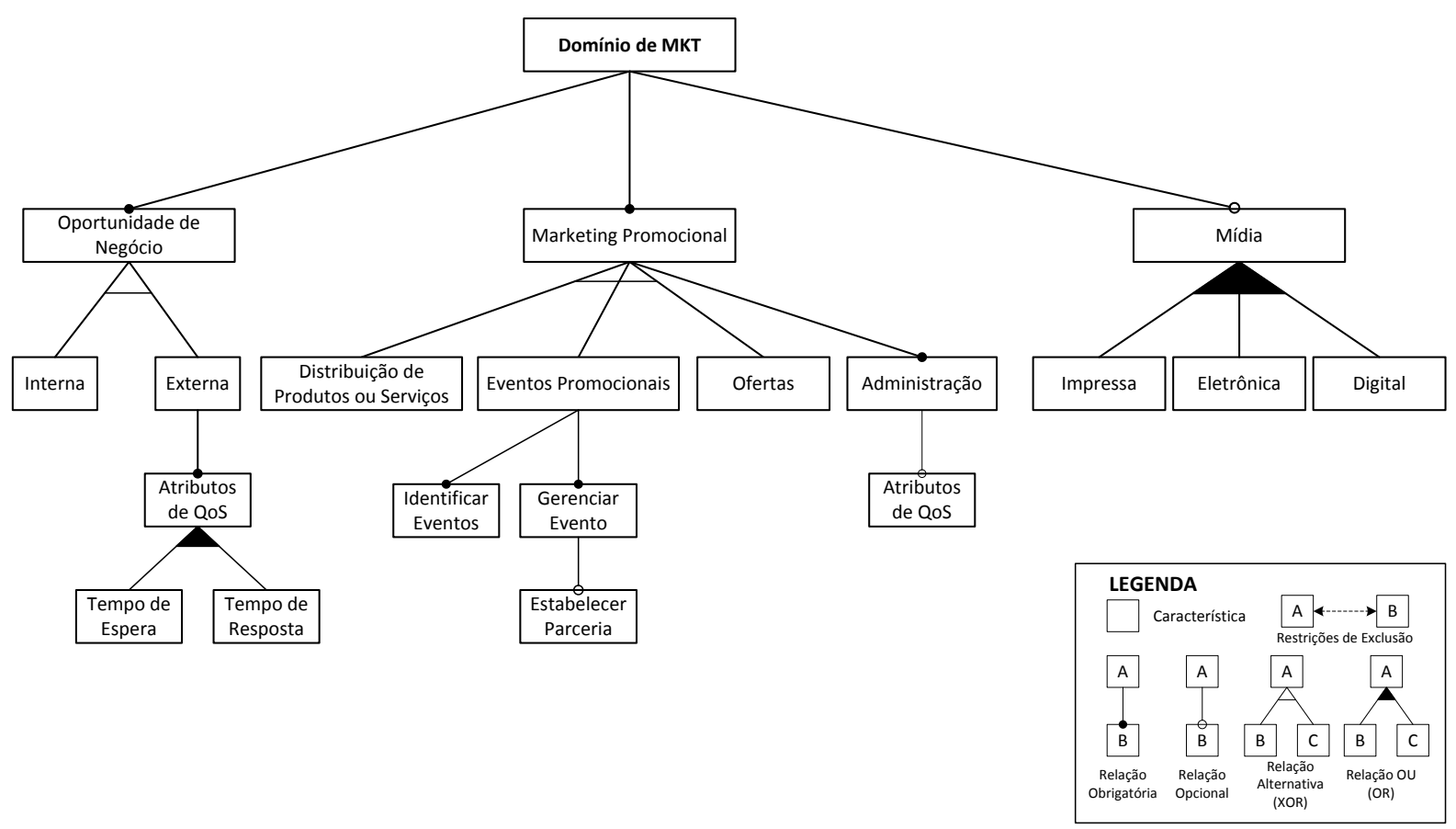

Figura 20 - Exemplo do Modelo de Características do Domínio de Marketing

\section{Tratamento dos Aspectos Dinâmicos}

O Modelo de Características apresentado na Figura 20 define apenas, em alto nível, as principais propriedades do processo de negócio, incluindo, possíveis requisitos não funcionais atrelados a essas demandas. Estabelecer diferenciação entre propriedades funcionais e não funcionais que podem ser realizadas por serviços web das propriedades que apenas definem comportamento do processo de negócio tornou-se uma preocupação dentro desta abordagem e assim precisaria ser tratada. Além disso, levando em consideração que o processo DynPL4BPM não se propõe ao desenvolvimento de serviço web, mas a identificação e seleção de tais serviços, principalmente, em tempo de execução, o Modelo de Característica deve deixar explícito quais as propriedades representam tais serviços e quais serviços compartilham o mesmo tempo de ligação.

Assim sendo, para tratamento dessas preocupações e, principalmente, dos aspectos dinâmicos da LP nessa atividade, propõe-se o uso do método proposto por Lee, Muthig e Naab (2010), apresentado no Capítulo 3. O método propõe diretrizes que auxiliam desenvolvedores na identificação de serviços eletrônicos em um nível correto de granularidade. A Figura 21 apresenta o resultado da aplicação dessa técnica ao Modelo de Características da Figura 20, reestruturando-o por meio da separação entre duas categorias: (i) Molecular Service Layer - que representa as características comportamentais, ou seja, aquelas que definem apenas a sequência do processo de negócio e que não são, 
necessariamente, realizadas por serviços web, como, por exemplo, as atividades manuais realizadas por um determinado setor ou pessoa e (ii) Orchestrating Service Layer - que representam características de serviços computacionais, ou seja, as atividades que podem ser realizadas por meio de serviços web e, portanto, podem ser identificadas e selecionadas em tempo de execução. A área delimitada por uma borda vermelha representa os Serviços Moleculares em um nível adequado de granularidade. No exemplo da Figura 21 há duas características que podem ser realizadas através de serviços web: "Oportunidade de Negócio" e "Eventos Promocionais". O círculo verde representa níveis de QoS que devem ser levados em consideração pelos serviços web a serem selecionados, tanto em tempo de projeto, quanto em tempo de execução.

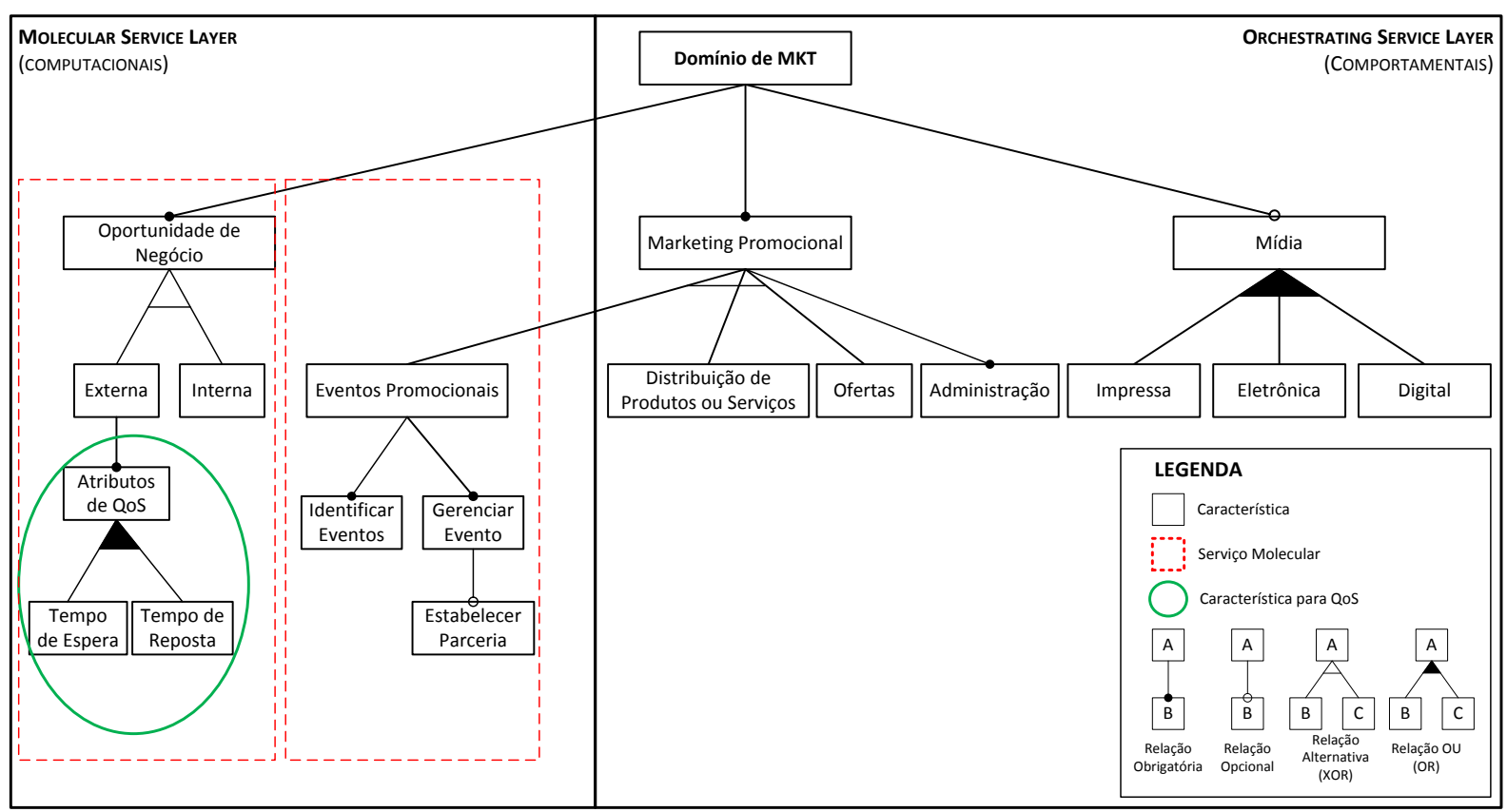

Figura 21 - Exemplo do Modelo de Características do Domínio de Marketing usando a Técnica de Lee, Muthig e Naab (2010)

\subsubsection{Atividade "2.A - Projeto do PN"}

A atividade "2.A - Projeto do PN" consiste na elaboração do Modelo de Processo de Negócio (derivado dos requisitos funcionais) e na especificação do Acordo em Nível de Negócio (derivado dos requisitos não funcionais), tendo como entrada o Modelo de Características produzido na atividade anterior. O objetivo principal dessa atividade é criar um modelo abstrato do processo de negócio, que explora os requisitos funcionais e não funcionais de uma determinada área, de acordo com o $\underline{\text { Modelo }} \underline{\text { de Domínio elaborado na }}$ atividade anterior, e que seja genérico o suficiente para ser usado em diferentes aplicações no 
processo "Engenharia de Aplicação". Essa atividade corresponde à fase Projeto e Análise do ciclo de vida de BPM (conforme Figura 2). Com base no Modelo de Características da atividade anterior, os modelos de processos de negócio são elaborados.

Para a elaboração do Modelo de Processo de Negócio, propõe-se o uso da notação BPMN (OMG, 2011), apresentada no Capítulo 2. Além da notação básica de modelagem de processos - no caso, a BPMN, para apoiar a elaboração do modelo de processos no contexto de LP, é também necessária uma técnica que define como usar as informações do Modelo de Característica para a obtenção da estrutura básica do Modelo de Processo de Negócio. Isto pode ser realizado de diferentes maneiras incluindo o uso dos mecanismos de variabilidades propostos na abordagem PFE (acrônimo em inglês de Process Family Engineering) (PUHLMANN et al., 2005; SCHNIEDERS; PUHLMANN, 2006) ou por meio da abordagem BFE (acrônimo em inglês de Business Family Engineering) (MONTERO, 2009; MONTERO; PEÑA; RUIZ-CORTÉS, 2008b), ambas apresentadas no Capítulo 3. Para o processo DynPL4BPM optou-se pelo uso da abordagem BFE pelos seguintes motivos: (i) a abordagem fornece uma descrição rigorosa para o modelo de característica e (ii) estabelece uma relação de mapeamento que define como usar as informações do modelo de característica para a obtenção da estrutura básica do processo de negócio. Aplicando a técnica de derivação ao Modelo de Característica representado na Figura 21, obteve-se o modelo em BPMN, apresentado na Figura 22. Por definição, características pai do Modelo de Característica, são consideradas os pontos de variação. As características filhas, denominadas variantes, são consideradas subprocessos. Na Figura 21, a característica raiz "Domínio de MKT" da Figura 18 pode ser considerada como um ponto de variação e, assim, foi transformada em um processo complexo aplicando as regras de derivação da abordagem BFE. As características "Mídia", "Oportunidade de Negócio" e "Marketing Promocional" são as variantes e foram representadas como subprocesso na Figura 22. 


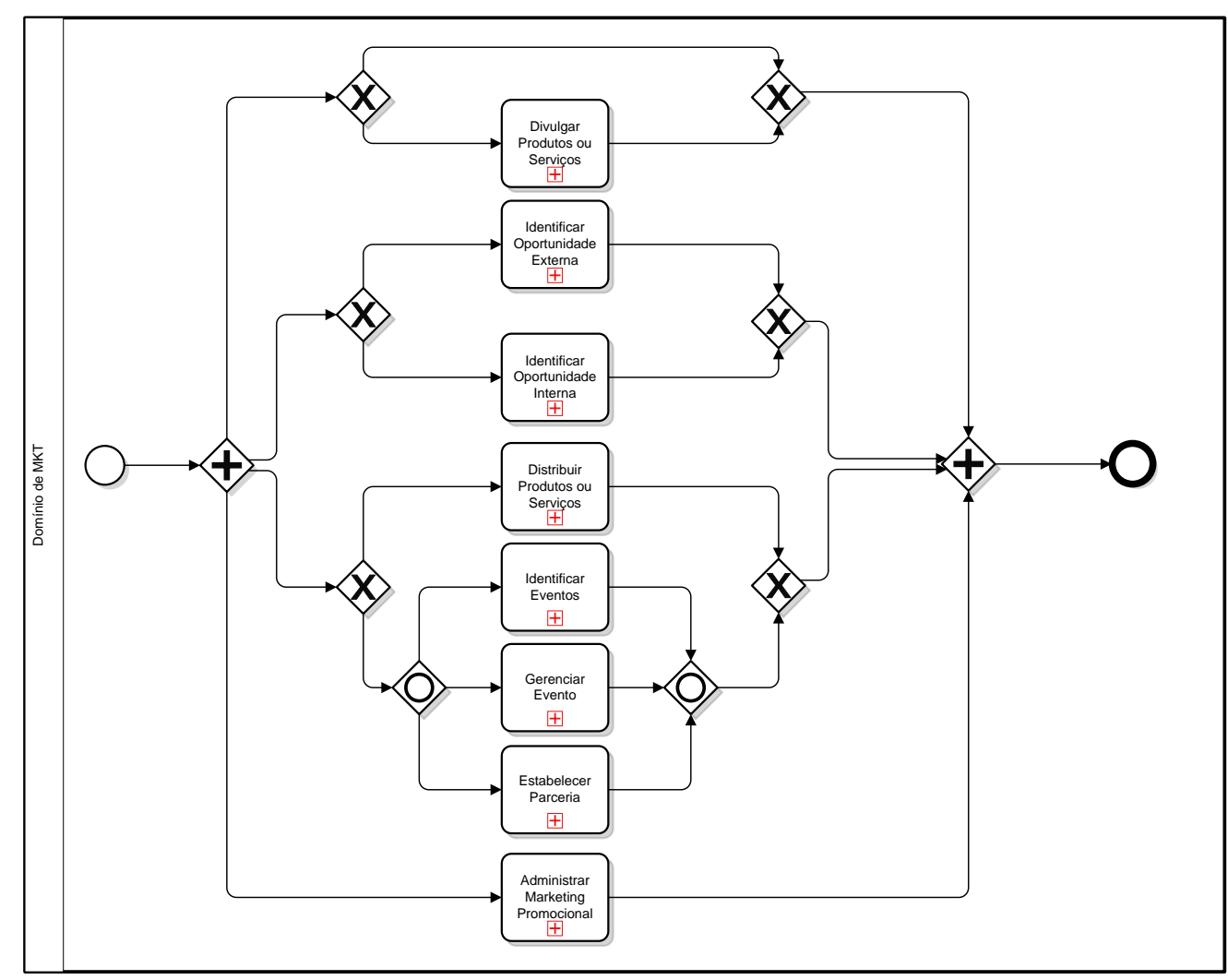

Figura 22 - Modelo de Processo de Negócio gerado a partir da aplicação da técnica proposta na abordagem $B F E$

Por meio da Figura 22, nota-se que a técnica aplicada apenas gera um modelo de "Composição sem Sobreposição" (MONTERO, 2009), ou seja, o modelo de processos de negócio não consome ou fornece artefatos para as atividades e subprocessos gerados e, portanto, podem ser realizados de forma independente. É um avanço derivar modelos a partir de características de uma maneira sistemática, mas para a realidade das organizações isso não é suficiente, pois é preciso representar, para alguns casos, uma sequência de atividades. A abordagem BFE ainda não prevê esse tipo de derivação e ajustes manuais devem ser realizados para que o processo modelado possa representar, de uma forma ampla, os processos organizacionais, considerando que o Projeto $\underline{\text { do }} \underline{\text { PN }}$ está inserido na "Engenharia de Domínio". Assim, o processo apresentado na Figura 22 foi adaptado, considerando àquelas atividades que implicavam em um encadeamento lógico, ou seja, apenas as atividades que deveriam ser realizadas em paralelo e a ordem de execução das atividades era relevante considerando o Modelo de Domínio em questão. O processo adaptado está representado na Figura 23. As características foram agrupadas pelo elemento disponibilizado na linguagem BPMN denominado "Grupo", com o objetivo de facilitar a identificação do mapeamento 
realizado entre o Modelo de Características (Figura 21) e o Modelo de Processo De Negócio em BPM.

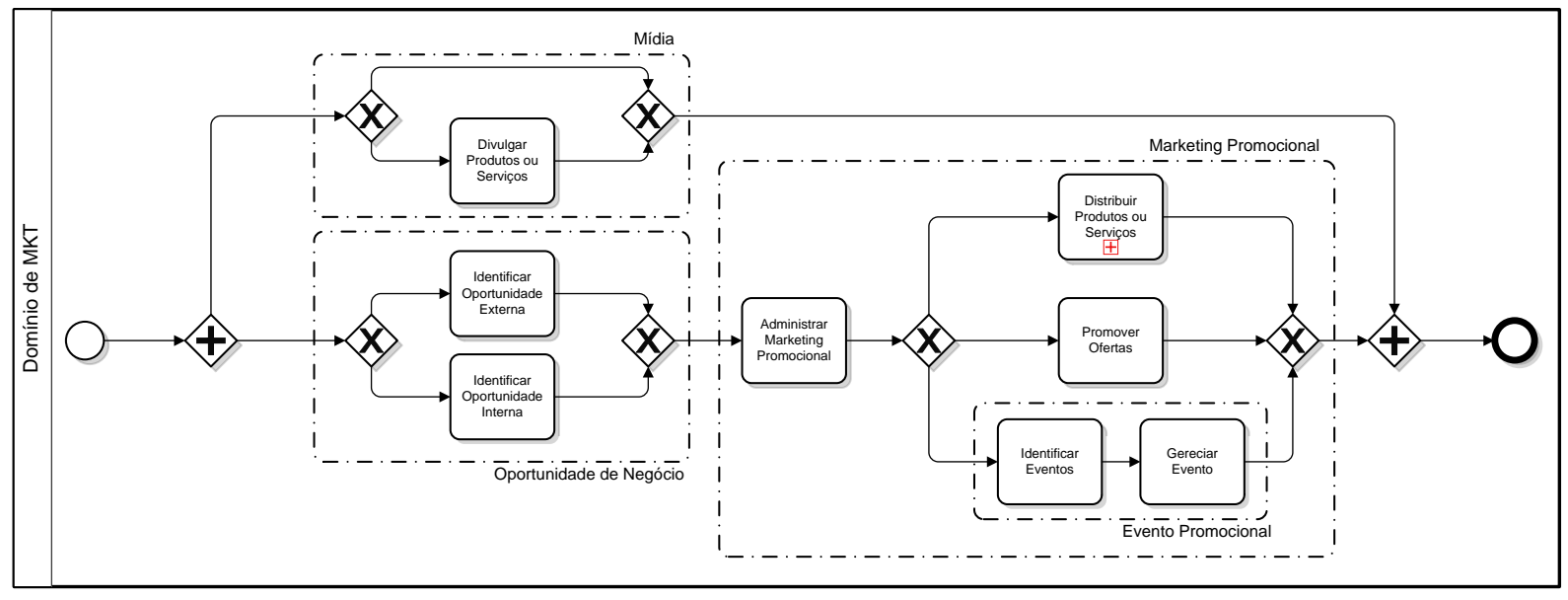

Figura 23 - Modelo de Processo de Negócio gerado a partir da aplicação da técnica proposta na abordagem BFE com adaptações

Como em todo processo de Engenharia de Software, e não apenas de LP, além das propriedades funcionais - aqui representadas pelo Modelo de Processo de Negócio em BPMN - é importante especificar também as propriedades não funcionais. No caso dessa atividade especificamente, é necessário incluir uma subatividade de definição das restrições de operação e a qualidade que o processo de negócio sendo modelado deve considerar - ou seja, os requisitos não funcionais (NFR - Non-Functional Requeriment). O artefato gerado por essa subatividade é chamado de BLA (Business Level Agreement). Apesar de trabalhos apontarem a importância e os benefícios de se associar formalmente atividades e processos aos atributos de NFRs - como tempo, custo e disponibilidade - as linguagens de modelagem de processos de negócio são ainda pobres nessa questão (SALLES; FANTINATO, 2012).

Por meio de uma revisão sistemática da literatura Salles e Fantinato (2012) identificaram iniciativas para a extensão de linguagens de modelagem de processos, tais como BPMN, Diagramas de Atividades da UML e RAD, visando representar requisitos de qualidade ou restrições de execução. As propostas existentes não se aprofundam na discussão sobre derivação desses requisitos para a versão executável do processo de negócio, o que é esperado em um paradigma orientado a modelos como em LP, exceto quando mencionados como propostas de trabalhos futuros. Portanto, considera-se que ainda não há nenhuma técnica adequada para ter seu uso proposto dentro do processo DynPL4BPM, ficando uma lacuna neste ponto do processo, já que não há uma técnica específica de elaboração de BLA a ser usada de forma associada a BPM par ser proposta seu uso dentro desse processo. 


\section{Tratamento dos Aspectos Dinâmicos}

Weber, Sadiq e Reichert (2009) apresentam uma revisão dos desafios e técnicas que existem para a gestão do ciclo de vida de processos dinâmicos. Para a fase de modelagem de tais processos apresentam cinco técnicas, que são: Controle de Granularidade; (ii) Flexibilidade por Enumeração; (iii) Configuração do Processo; (iv) Ligação Tardia; (v) Modelagem Tardia. Na sequência serão apresentadas somente "Ligação Tardia" e "Modelagem Tardia", pois podem ser adaptadas ao contexto de uma LPD.

Por meio da técnica "Ligação Tardia" (do inglês, Late Binding) as atividades são modeladas apenas como espaço reservado ${ }^{6}$, ou seja, como um modelo de processo abstrato e em tempo de execução um serviço adequado é selecionado e ligado a atividade do processo, conforme representado na Figura 24. O processo DynPL4BPM incorpora aspectos da "Ligação Tardia" pois possui um modelo abstrato que é definido em tempo de projeto e os serviços que realizam tais atividades são selecionados em tempo de execução, conforme apresentado na visão geral do processo (Subseção 4.1).

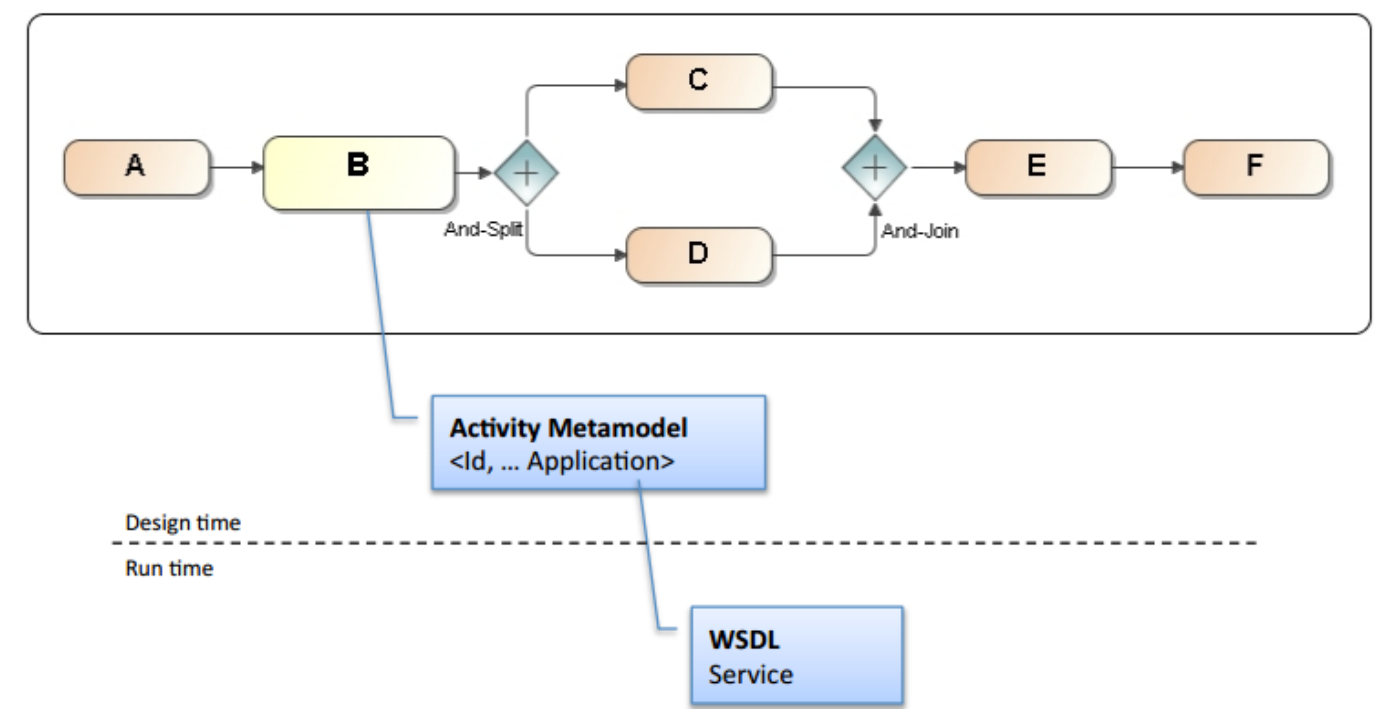

Figura 24 - Exemplo de "Ligação Tardia"

Fonte: Weber, Sadiq e Reichert (2009)

Outra técnica que pode ser incorporada ao processo DynPL4BPM é a "Modelagem Tardia", que consiste na definição (modelagem) de partes do processo ou o processo completo em tempo de execução (WEBER; SADIQ; REICHERT, 2009). O modelo sendo definido em tempo de execução pode ou não ser controlado por diretrizes ou restrições, ambas definidas em tempo de projeto. Basicamente, existem quatro opções para modelagem tardia (WEBER; SADIQ; REICHERT, 2009): (i) o processo inteiro é definido em tempo de execução sem

\footnotetext{
${ }^{6}$ Do inglês: Placeholder
} 
qualquer restrição; (ii) partes do processo são definidas em tempo de execução sem qualquer restrição; (iii) partes do processo são definidas em tempo de execução com restrição; (iv) o processo inteiro definido é com restrição. A Figura 25 ilustra a aplicação da técnica em uma parte de um processo genérico (Atividade B), com algumas restrições previamente definidas:

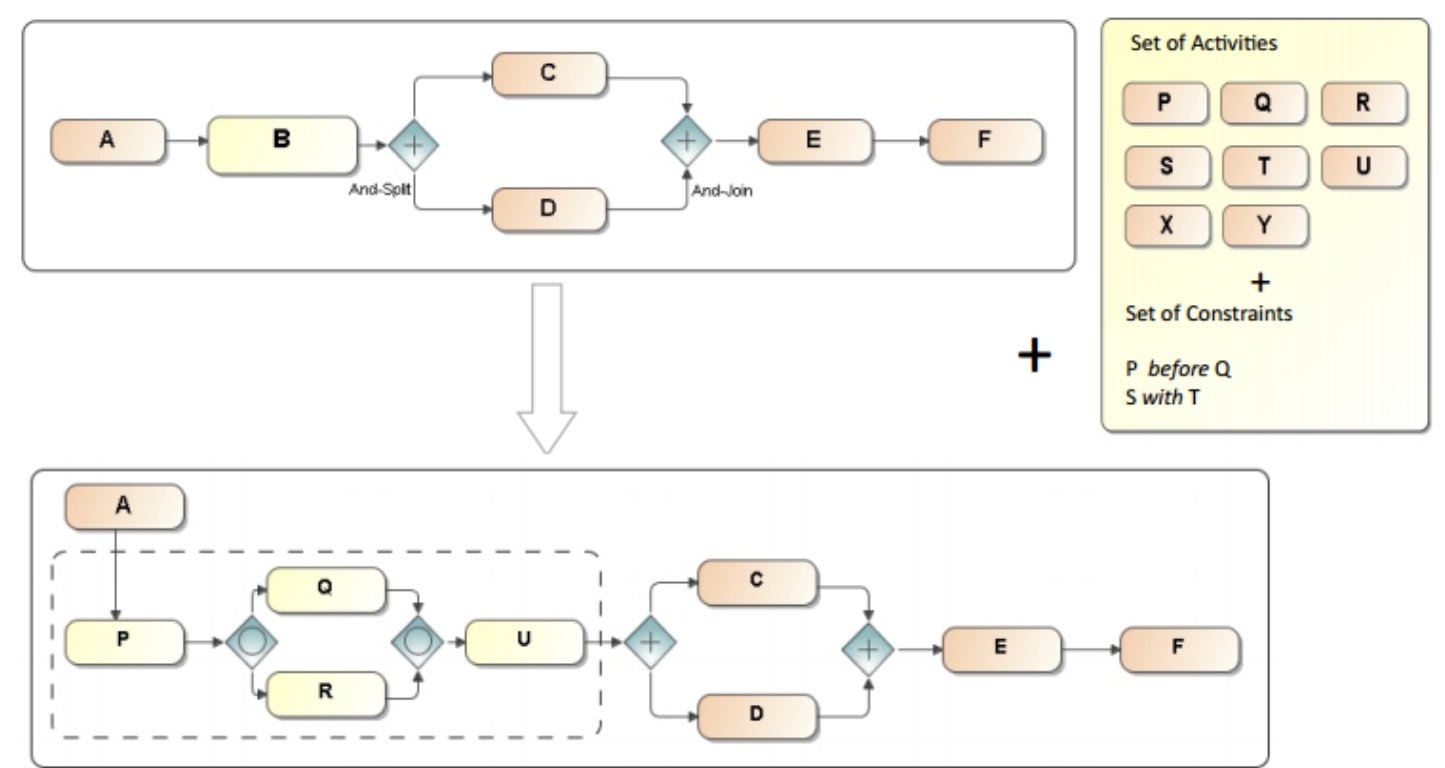

Figura 25 - Exemplo de aplicação da técnica "Modelagem Tardia" em partes do processo com restrição

Fonte: Weber, Sadiq e Reichert (2009)

\subsubsection{Atividade "3.A - Implementação do PN"}

A atividade "3.A - Implementação do PN" corresponde à fase Configuração do ciclo de vida de BPM (conforme Figura 2) e consiste na transformação dos artefatos gerados na atividade anterior, que representam o projeto do processo de negócio, tanto em termos funcionais quanto em termos não funcionais, em artefatos que permitam a execução do processo de negócio. Assim, as especificações Modelo de Processo de Negócio e Acordo em Nível de Negócio devem ser transformadas, respectivamente, em Processo de Negócio Executável e Acordos em Nível de Serviço.

Especificamente para o mapeamento do processo de negócio, partindo de modelo para sua versão executável, alguns métodos já foram propostos para esse fim. Considerando o processo de negócio modelado em BPMN, existem regras de mapeamento partindo de BPMN para a linguagem WS-BPEL (OUYANG et al., 2009; DIKMANS, 2008), incluindo ferramentas que automatizam tal transformação. Assim como os elementos representados no Modelo de Processo de Negócio em BPMN são mapeados para elementos do Processo de 
Negócio Executável em WS-BPEL, as informações de variabilidades dos elementos em BPMN também são herdadas pelos elementos em WS-BPEL, de forma que esses, por sua vez, também acabem ligados sistematicamente, por transitividade, às características do Modelo de Características, mantendo a rastreabilidade entre todos os artefatos, a fim de ser usada na geração de diferentes aplicações durante o processo "Engenharia de Aplicação", quando as variabilidades precisam ser resolvidas.

Para manter a rastreabilidade entre todos os artefatos, anotações são criadas nos dois templates gerados nesta fase - Processo de Negócio Executável e Acordos em Nível de Serviço. As anotações correspondem a comentários na linguagem XML, ligando os elementos gerados por meio de um identificador. Como exemplo, a Figura 26 e o Código 01 apresenta uma parte do Processo de Negócio Executável em WS-BPEL. No Código 01, a anotação <! -- Feature_ID = Oportunidade de Negocio 《<core»> - -> indica que todo o código que está entre o bloco <bpel: if name="If"> </bpel: if > está ligada à característica obrigatória "Oportunidade de Negocio".

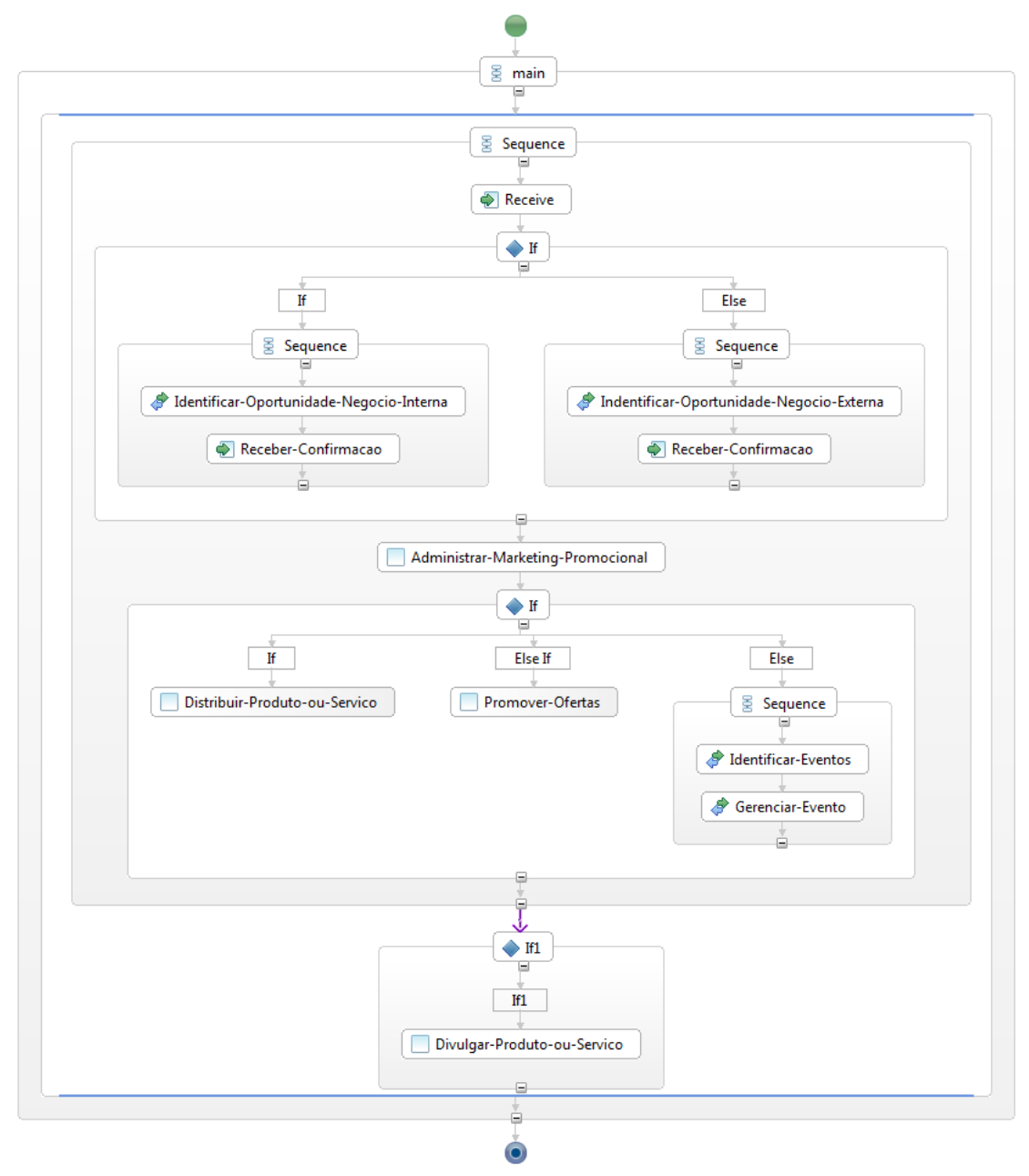

Figura 26 - Exemplo de Processo de Negocio Executável em WS-BPEL 


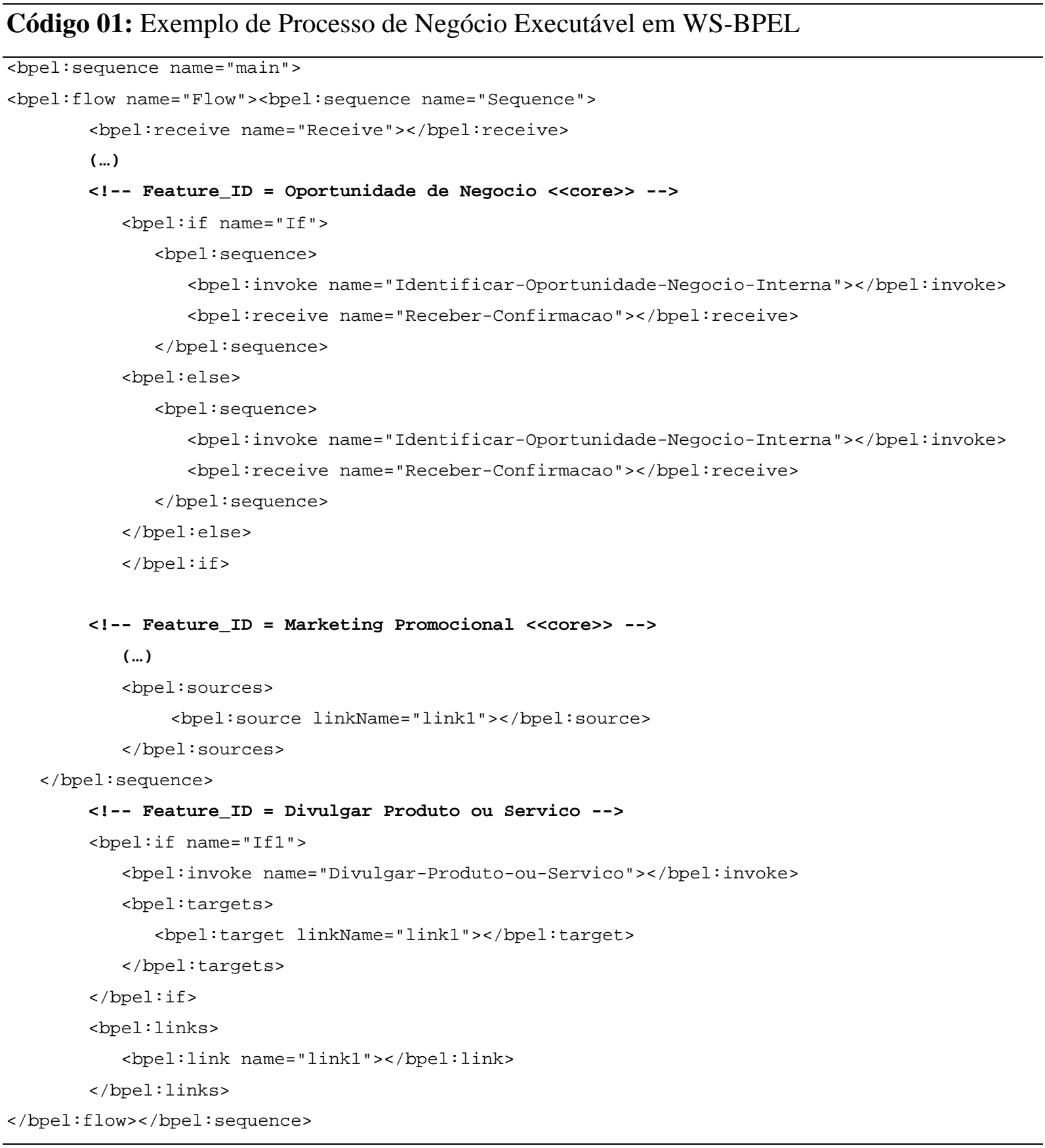

Um aspecto importante a ser considerado sobre os aspectos funcionais é que existem dois conceitos - Acordo em Nível de Negócio (BLA) ${ }^{7}$ e Acordo em Nível de Serviço $(\mathrm{SLA})^{8}$ - que precisam ser esclarecidos para uma melhor compreensão do que está sendo proposto nesta abordagem para os requisitos não funcionais e como estes estão relacionados ao Modelo de Processos de Negócio em BPMN e Modelo de Processos de Negócio Executável em WS-BPEL, respectivamente. Propriedades não funcionais podem se relacionar tanto a BLA quanto a SLA, sendo que BLA visa garantir o cumprimento desses requisitos sob

\footnotetext{
${ }^{7}$ Do inglês: Business Level Agreement

${ }^{8}$ Do inglês: Service Level Agreement
} 
a perspectiva de processos de negócio, enquanto SLA visa garantir qualidade em nível dos serviços. O ideal é que os objetivos de negócio, em termos de qualidade, fossem representados durante a modelagem de processos em BPMN, servindo de insumo para a criação dos SLAs que, por sua vez, estarão associados a processos especificados em WSBPEL e WSDL, na direção top-down. No entanto, como apresentado na Subseção 4.3.1.2 ainda não existe uma solução adequada para a representação de BLAs e a subsequente derivação para SLAs.

Embora não exista esse mecanismo de tradução, os requisitos não funcionais identificados na atividade Projeto $\underline{\text { do }} \underline{\mathrm{PN}}$ devem ser transformados em um SLA. Para tanto, o W3C recomenda as linguagens WS-Agreement e WS-Policy para formalizar as necessidades não funcionais dos serviços web que compõem um processo de negócio. Ambas, inclusive, são as linguagens mais tradicionais para esses fins. O Código 02 apresenta parte de uma especificação Acordo em Nível de Serviço (SLA). A maneira mais simples de especificar uma política é incorporá-la diretamente onde se deseja aplicá-la. Para associar uma política com uma porta específica no contrato WSDL, deve-se especificá-la da seguinte forma:

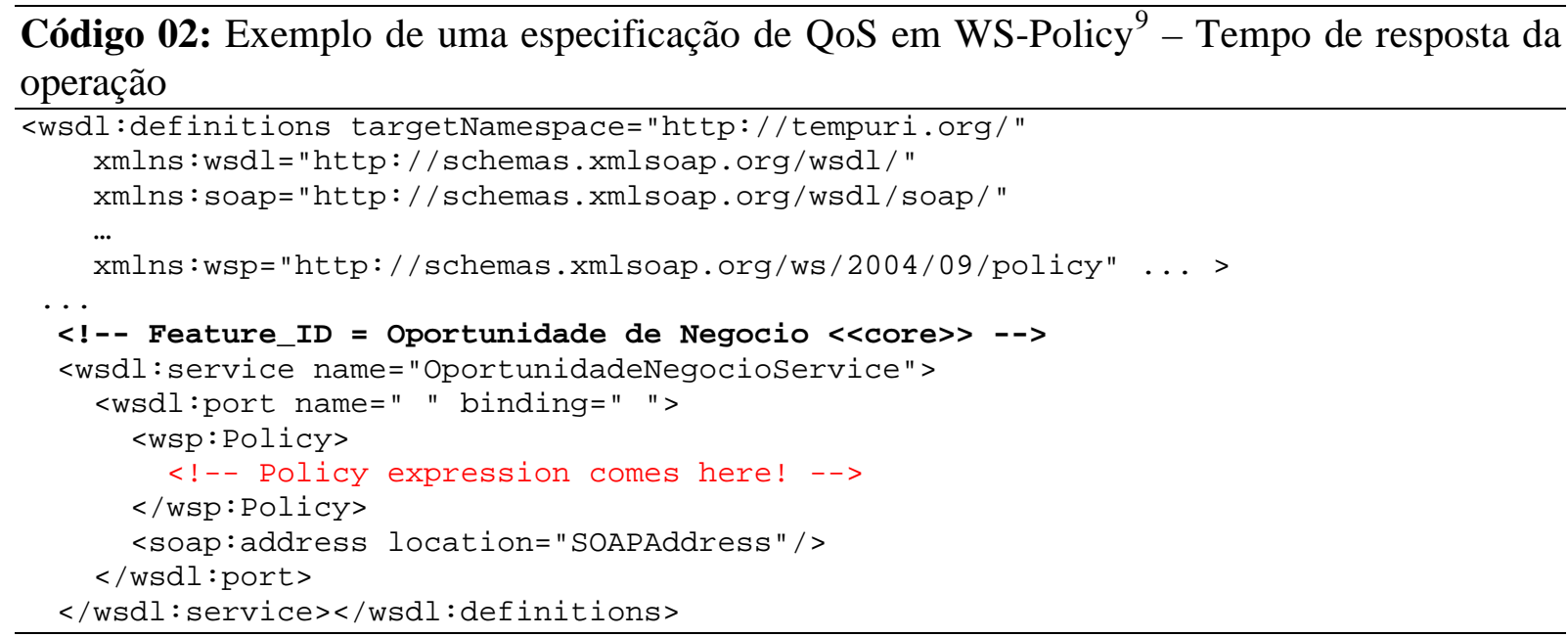

\section{Tratamento dos Aspectos Dinâmicos}

O tratamento dos aspectos dinâmicos na atividade "3.A - Implementação do PN" está relacionado à composição dinâmica dos processos de negócio. Resumidamente, as estratégias de composição são classificadas em dois eixos: criação do serviço abstrato e momento de ligação (FLUEGGE et al., 2006). A criação do serviço abstrato refere-se à criação de um workflow de atividades abstratas, isto é, atividades que não possuem implementação e que, portanto, precisam ser ligadas a serviços concretos para que possam ser executadas. A criação do serviço abstrato pode ser realizada de três formas distintas: manual,

\footnotetext{
${ }^{9}$ Prefixos e Namespaces usados no exemplo foram baseados em Vedamuthu et al. (2006).
} 
semiautomática ou automática. Por sua vez, a ligação entre os serviços abstrato e concreto pode ocorrer em dois momentos distintos: em tempo de projeto ou em tempo de execução (FLUEGGE et al., 2006). Considerando esses critérios, a invocação dinâmica dos serviços constituintes requer um nível suficiente de interoperabilidade que deve ser estabelecida por meio de interfaces fixas ou aplicando técnicas mais sofisticadas de casamento (do inglês matchmaking) e mecanismos de mapeamento (FLUEGGE et al., 2006).

A estratégia de composição usada neste trabalho é baseada em workflow com ligação dinâmica (FLUEGGE et al., 2006). Trata-se de workflow, pois pressupõe um modelo inicial neste caso, um Processo de Negócio Executável e Acordos em Nível de Serviço e ambos agindo como um serviço consumidor - cujas atividades definem os requisitos que precisam ser satisfeitos por serviços reais. Trata-se de ligação dinâmica, pois a composição no processo DynPL4BPM significa buscar e selecionar, para cada atividade abstrata definida nos artefatos Processo de Negócio Executável e Acordos em Nível de Negócio, um serviço concreto capaz de realizá-la em tempo de execução.

Tizzo, Coello, e Cardozo (2011) apresentaram um modelo em WS-BPEL capaz de selecionar serviços web que serão invocados em tempo de execução, segundo os requisitos do usuário. Este modelo é usado no processo DynPL4BPM para definir como será realizada a composição de serviços em tempo de execução. A Figura 27 mostra a lógica de funcionamento do modelo de composição, que, resumidamente, funciona da seguinte forma (TIZZO et al., 2011): o usuário - uma pessoa ou outra aplicação - especifica os requisitos de seleção e envia-os para o Serviço Composto (passo 1). O Seletor de Serviço recebe os requisitos de seleção do Serviço Composto, faz uma transformação interna para obter uma consulta SPARQL ${ }^{10}$; essa consulta é passada para o Seletor de Serviços que buscará os arquivos $\mathrm{RDF}^{11}$ disponíveis (que representam os Perfis de Serviço), e retorna para o Serviço Composto os resultados que correspondem aos requisitos solicitados (passo 2). O Serviço Composto é um processo WS-BPEL que tem pelo menos três atividades que devem ser consideradas: (i) a Atividade 1 que invoca o serviço de seleção; (ii) a Atividade 2 que modifica o partner link para fazer a ligação dinâmica (passo 3); (iii) a Atividade 3 que invoca o serviço selecionado (passo 4).

Na sequência serão apresentados os passos para preparar o código do processo em WS-BPEL para estar apto à realizar a ligação dinâmica. Não serão apresentados os detalhes

\footnotetext{
${ }^{10}$ SPARQL é uma linguagem de consulta e protocolo de acesso de dados para Web Semântica.

${ }^{11} \mathrm{RDF}$ - Resource Description Language
} 
dos passos 1 e 2, pois estes serão tratados na "Atividade 7 - Seleção Dinâmica de Serviços Web”.

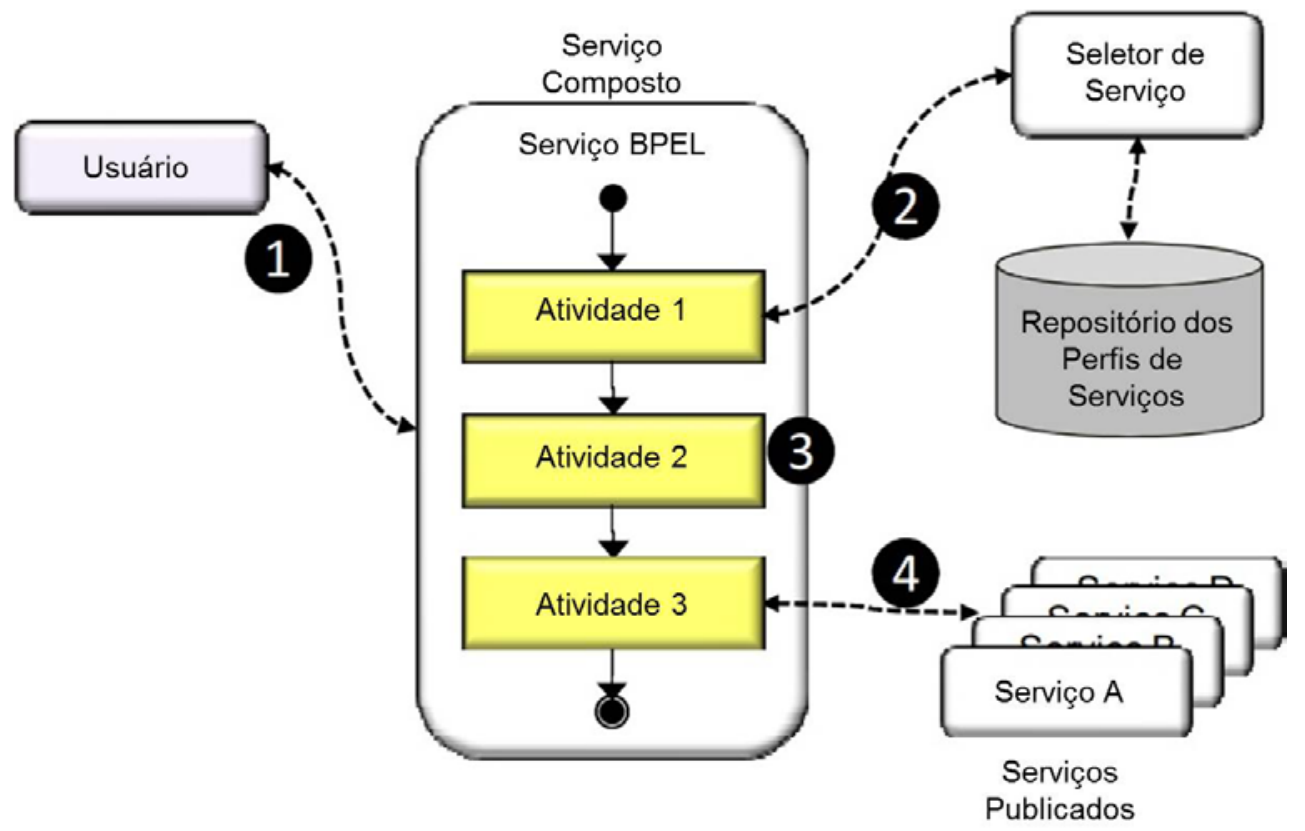

Figura 27 - Modelo de Composição de Serviços Fonte: Traduzido de Tizzo et al. (2011)

Em WS-BPEL, uma ligação dinâmica é feita pela definição de um endpoint dinâmico. O processo é apresentado de forma completa na sequência:

Passo 1) Definir um tipo de variável endpointReference para armazenar o endereço do serviço que será invocado. Esta variável pode ser posteriormente atribuída a um partner link, a fim de modificar o endereço e o nome em tempo de execução. No exemplo isso pode ser realizado da seguinte maneira:

<variable name="partnerReference" element="wsa:EndpointReference"/>

Passo 2) A variável deve seguir o padrão de serviços web de endereçamento, o que significa que ela deve ter o namespace wsa: definido no início do arquivo WS-BPEL como: xmlns:wsa="http://schemas . xmlsoap.org/ws/2003/03/addressing"

Passo 3) Por padrão, um processo WS-BPEL usa strings como entrada e saída. Para modificar isso, é necessário definir ou importar um tipo novo "esquema XML" e usá-lo como parte dos tipos de mensagem. Para este modelo, deve-se importar o esquema XML que define o endereçamento do serviço web. Isso deve ser feito no arquivo WSDL do processo WSBPEL. No exemplo abaixo, 192.168.16.26 e 8888 são, respectivamente, o endereço IP e o número da porta do servidor que hospeda o XML Schema: 


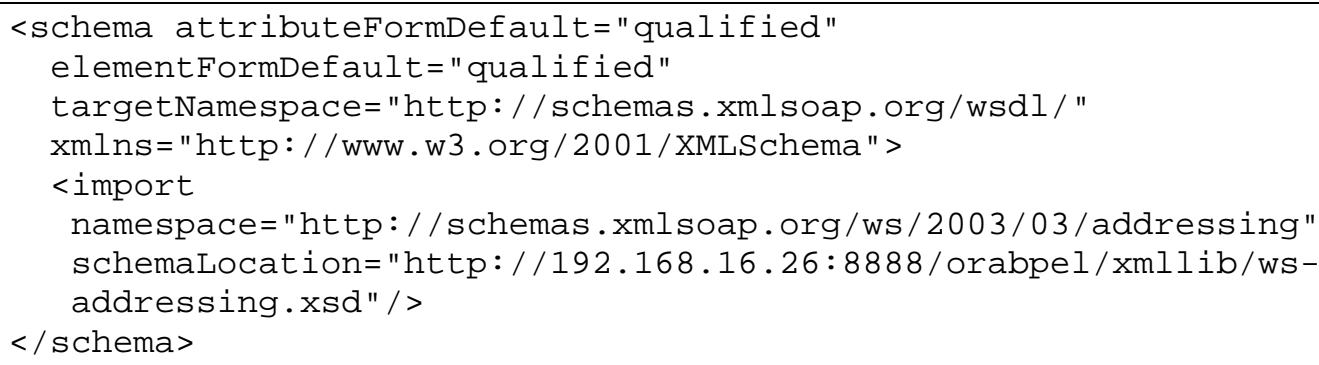

Passo 4) A variável partnerReference é composta por duas partes: o endereço e o nome do serviço. Por agora, o seu conteúdo será uma referência nula. Isso é feito por meio do seguinte fragmento de código XML:

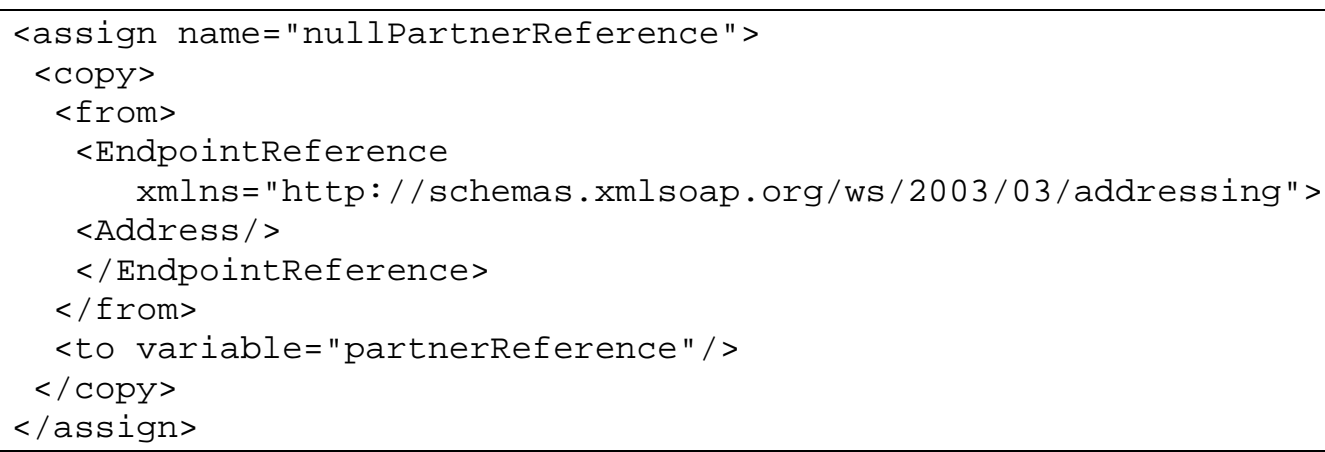

Passo 5) Por fim, deve-se atribuir o endereço do serviço à variável partnerReference. Neste caso, o endereço do serviço a ser invocado é armazenado na variável retornada pelo seletor de serviço, chamado serviceselectoroutputvariable:

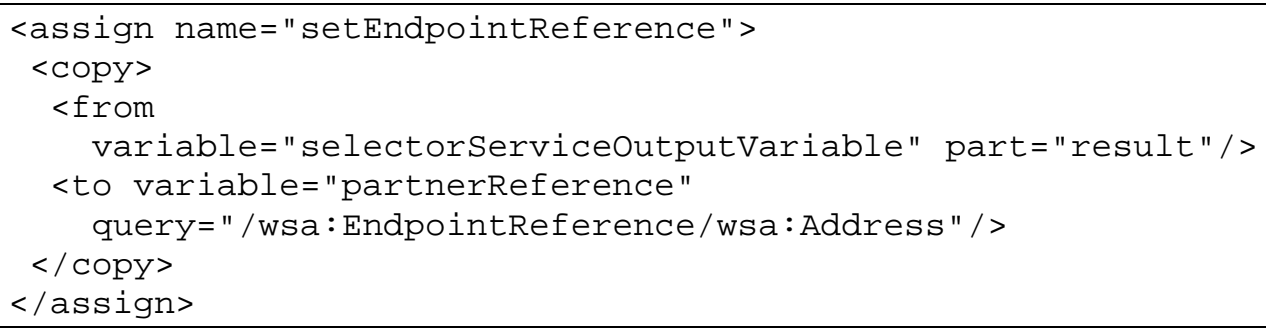

\subsubsection{Atividade "4.A - Validação do PN"}

A atividade "4.A - Validação do PN" consiste em realizar atividades de análises estáticas ou dinâmicas sobre os artefatos de implementação do processo de negócio a fim de garantir que os mesmos atendem seus objetivos de acordo com o contexto e projeto da LP. Assim, os artefatos gerados durante a terceira atividade (3.A - Implementação do PN, ou seja, Processo de Negócio Executável em WS-BPEL e Acordos em Nível de Serviço em WSPolicy) devem ser avaliados em função dos artefatos gerados durante a primeira atividade (1.A - Análise de Domínio do PN, ou seja, Modelo de Domínio como Modelo de 
Características) e a segunda atividade (2.A - Projeto do PN, ou seja, Modelo de Processo de Negócio em BPMN e Acordo em Nível de Negócio em linguagem genérica) do processo.

Em Engenharia de Software tradicional, comumente a validação de implementação de software é realizada por meio de "Teste de Software". Neste ponto, existem vários níveis de testes que tratam de diferentes tipos de erros, que são (LÜBKE, 2007): teste de unidade, teste de integração e teste de sistema. Uma correlação entre teste de software "tradicional" e teste de composição de serviços pode ser estabelecida e assim, esses níveis de teste podem ser aplicados às composições de serviços.

Teste de unidade é o processo que testa um simples componente, denominado de unidade, de forma isolada. Esse tipo de teste tenta detectar falhas que são inerentes ao componente, tais como defeitos de lógica. No contexto de composição de serviços em WSBPEL, teste de unidade implica a substituição por mocks dos serviços web que representam dependência externa. Como esses mocks devem ser implementados, torna-se uma atividade bastante custosa. Deste modo, o recomendado seria automatização desse tipo de teste.

Teste de integração tenta verificar a interação entre vários componentes. Assim, esse tipo de teste tenta disparar todas as comunicações e chamadas entre os componentes. Existem vários desafios para a realização de teste de integração em composição de serviços, um deles é a necessidade de ter todos os serviços necessários disponíveis. Lubke (2007) apresenta duas alternativas quando o ambiente de teste não está disponível para a realização de teste de integração: (i) criar mocks para serviços atômicos externos e (ii) fornecimento de contas para testes pelo provedor do serviço web.

Teste de sistema é o processo de testar o sistema por completo, e consiste na replicação do ambiente em um ambiente de teste, incluindo o servidor WS-BPEL e os serviços web desenvolvidos.

Especificamente para o contexto de LP, o Teste de Software possui variações de técnicas ao considerar os diferentes processos "Engenharia de Domínio" e "Engenharia de Aplicação". Embora haja diferentes abordagens já propostas que direcionem a testar diferentes aspectos em cada um dos processos, o teste de software para o contexto de LP ainda não é uma etapa tão madura quanto às demais etapas de LP (TEVANLINNA; TAINA; KAUPPINEN, 2004).

No caso específico do processo de DynPL4BPM, o teste deve levar em consideração tanto as propriedades funcionais do processo de negócio, representadas pela especificação em WS-BPEL, quanto às propriedades não funcionais, representadas pelas especificações em WS-Policy. Um desafio de teste no contexto de LP, quando aplicado ao processo "Engenharia 
de Domínio", que também se apresenta aqui é testar um artefato genérico, que pode ser usado em diferentes configurações durante a "Engenharia de Aplicação" e, portanto, deve ser testado levando em consideração diversas combinações.

Uma dificuldade encontrada no teste de LP diz respeito ao teste dos componentes básicos criados na "Engenharia de Domínio", visto que os testes de integração e de sistema não são factíveis uma vez que a tentativa de se testar diferentes combinações dos componentes do domínio leva a um crescimento exponencial das configurações de teste (TEVANLINNA; TAINA; KAUPPINEN, 2004).

\section{Tratamento dos Aspectos Dinâmicos}

Para garantir a qualidade dos serviços compostos em tempo de execução, várias técnicas de validação e verificação foram propostas como, por exemplo, Teste de Regressão em LP; Execução de teste por meio de arquitetura mocking (LÜBKE, 2007). No entanto, considerando os custos envolvidos na realização de testes em LP, dado que a tentativa de testar diferentes combinações dos componentes do domínio pode levar a um crescimento exponencial das configurações de testes, é recomendável realizar tais tipos de testes no processo "Engenharia de Aplicação".

\subsubsection{Engenharia de Aplicação}

O processo "Engenharia de Aplicação" é responsável pela criação do produto final por meio da adaptação da arquitetura de referência e artefatos reusáveis, criados no processo "Engenharia de Domínio", com exceção dos requisitos dos usuários de uma organização específica. Nas subseções a seguir, são apresentadas informações referentes ao processo "Engenharia de Aplicação" do processo DynPL4BPM.

\subsubsection{Atividade "1.B - Refinamento do Modelo de Domínio do PN"}

A atividade "1.B - Refinamento do Modelo de Domínio do PN" é responsável pelo

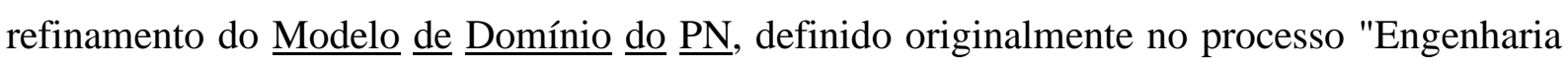
de Domínio", para que o mesmo represente, em alto nível, as propriedades específicas do processo de negócio a ser criado para uma necessidade específica, incluindo, por exemplo: subconjunto de serviços a serem oferecidos e usados para cada parte envolvida e requisitos não funcionais específicos atrelados a essas demandas. 


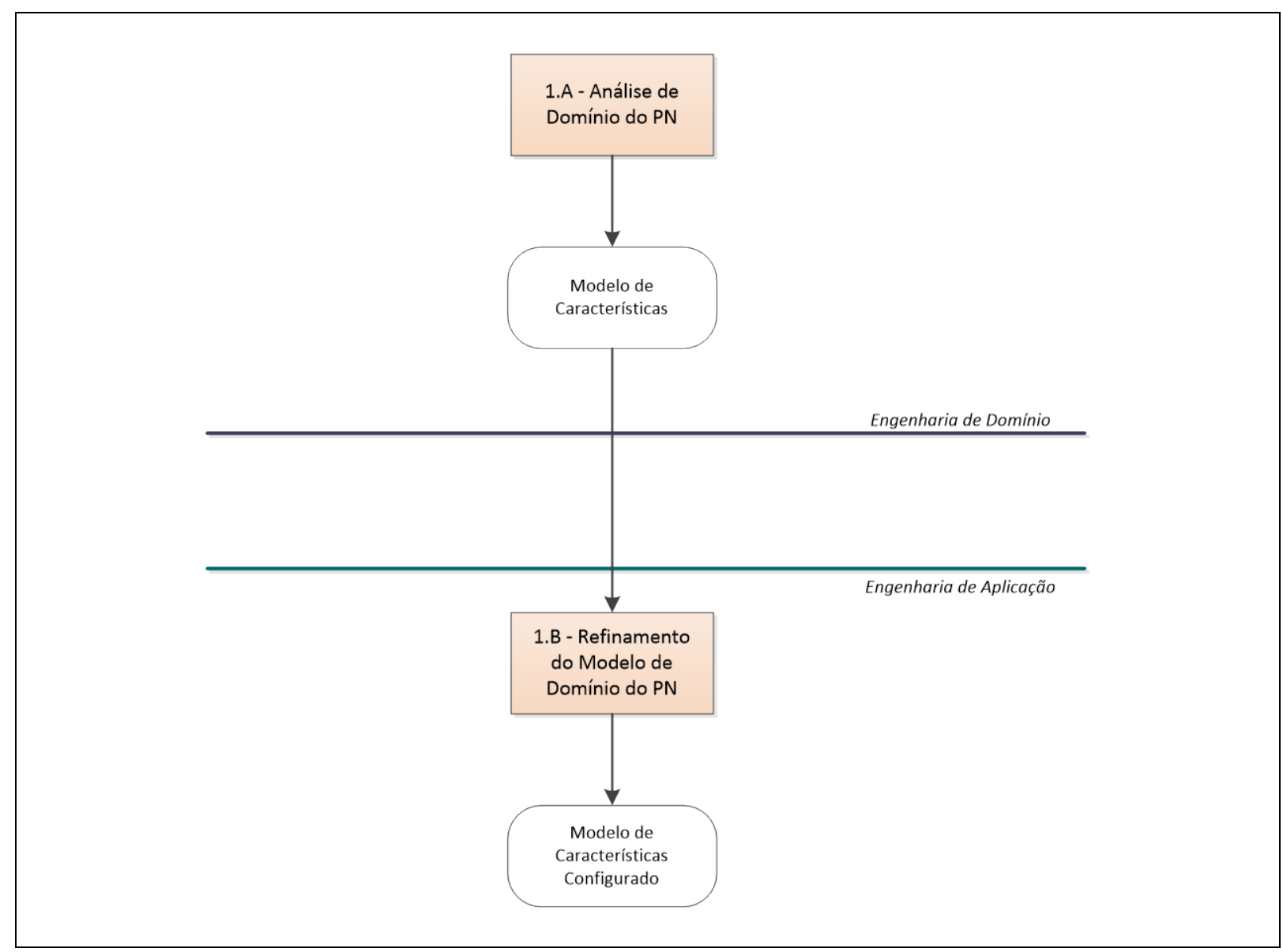

Figura 28 - Parte do processo DynPL4BPM relacionado à geração dos artefatos da atividade 1.B - Refinamento do Modelo de Domínio do PN

Essa atividade coleta os requisitos funcionais e não funcionais de uma organização específica que serão usados para escolher adequadamente as características do $\underline{\text { Modelo }} \underline{\text { de }}$ Domínio criado no processo "Engenharia de Domínio". O foco da atividade $\underline{\text { Refinamento do }}$

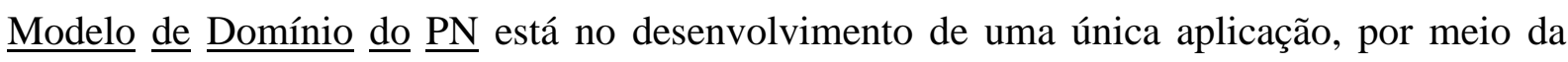
configuração do Modelo de Característica gerado na "Engenharia de Domínio". A Figura 28 apresenta parte do processo DynPLBPM que ilustra, em um nível alto, como é gerado o artefato Modelo de Características Configurado.

Um exemplo do Modelo de Características Configurado é apresentado na Figura 29. A configuração foi realizada no último artefato gerado, representado na Figura 21, na atividade $\underline{\text { Análise de Domínio }} \underline{\text { do }} \underline{\text { PN. }}$. 


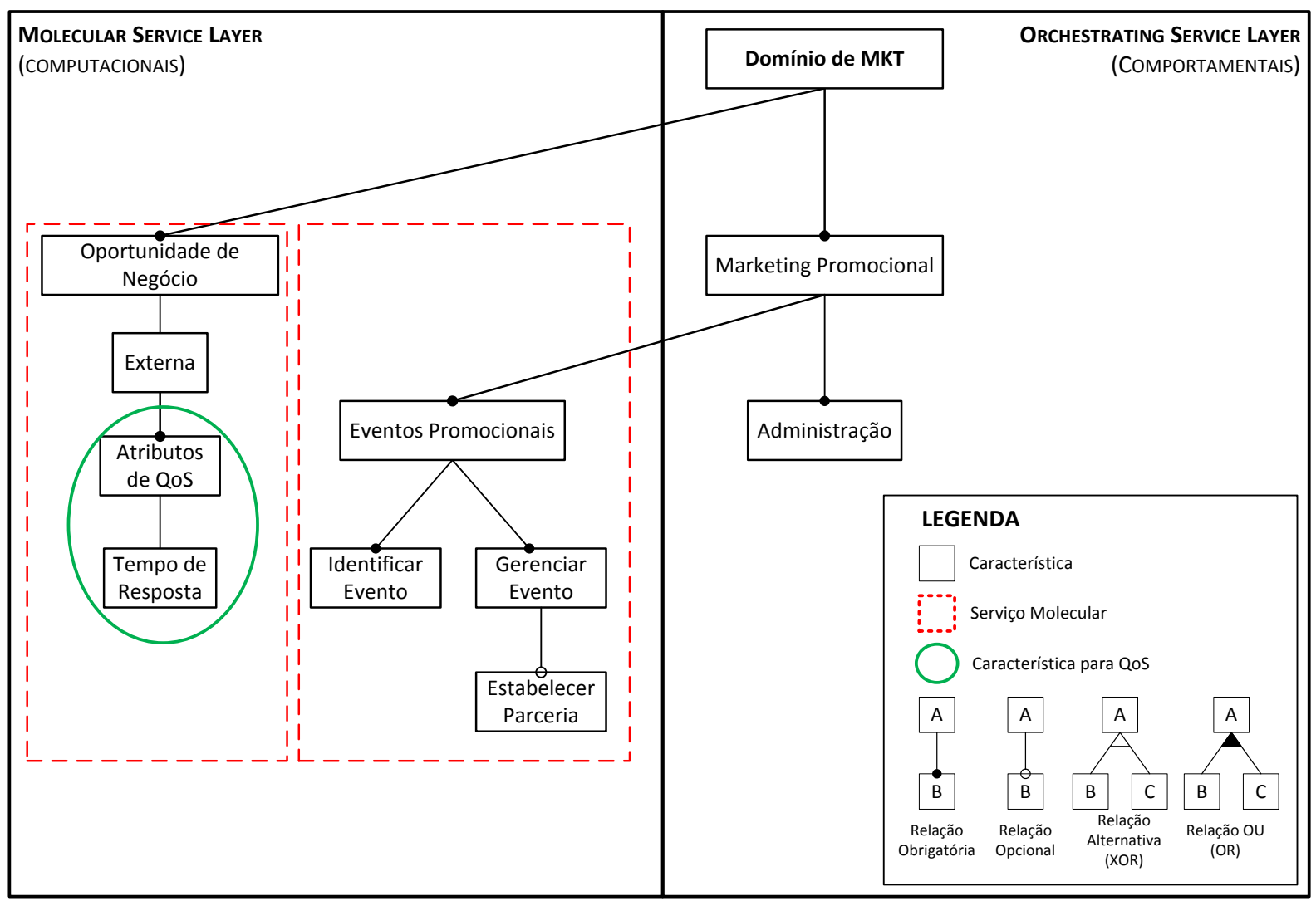

Figura 29 - Exemplo do Modelo de Características Configurado para uma organização específica

Conforme o modelo da Figura 29, as características "Oportunidade de Negócio" e "Marketing Promocional" - exemplos de características obrigatórias na Figura 21 permaneceram no modelo configurado. Em "Marketing Promocional", a característica "Eventos Promocionais" foi a escolhida e como decorrência todas as características filhas obrigatórias também permanecem no modelo configurado, que são: "Identificar Evento" e "Gerenciar Evento". A característica filha opcional "Estabelecer Parceria" pertencente à característica "Gerenciar Evento" foi escolhida e também permanece no Modelo de Características Configurado. A característica "Mídia" da Figura 21 não foi escolhida, tendo em vista que a organização pode subcontratar outra organização para realizar a divulgação dos seus produtos. A empresa específica aqui representada é AllSport, citada no exemplo motivacional (Subseção 1.1).

\section{Tratamento dos Aspectos Dinâmicos}

Para tratamento dos aspectos dinâmicos, o Modelo de Característica Configurado, representado na Figura 29, também foi reestruturado por meio da separação entre duas categorias: (i) Molecular Service Layer e (ii) Orchestrating Service Layer, conforme técnica de Lee, Muthig e Naab (2010) apresentada com mais informações na Subseção 4.3.1.1. 


\subsubsection{Atividade "2.B - Refinamento do Projeto do PN"}

A atividade "2.B - Refinamento do Projeto do PN" consiste no aprimoramento dos artefatos relacionados ao Projeto $\underline{\text { do }} \underline{\mathrm{PN}}$, definidos originalmente no processo "Engenharia de Domínio", que servirão de templates para essa atividade. Para isso, os dois artefatos interrelacionados - Modelo de Processo de Negócio e Acordos em Nível de Negócio - são derivados considerando o contexto específico do processo de negócio desejado representado no artefato Modelo de Características Configurado. Para uma melhor compreensão da atividade $\underline{\text { Refinamento }} \underline{\text { do }} \underline{\text { Projeto }} \underline{\text { do }} \underline{\mathrm{PN}}$, a Figura 30 apresenta a parte do processo DynPL4BPM e os relacionamentos estabelecidos para a geração dos artefatos específicos Modelo de Processo de Negócio Configurado e Acordos em Nível de Serviço Configurados.

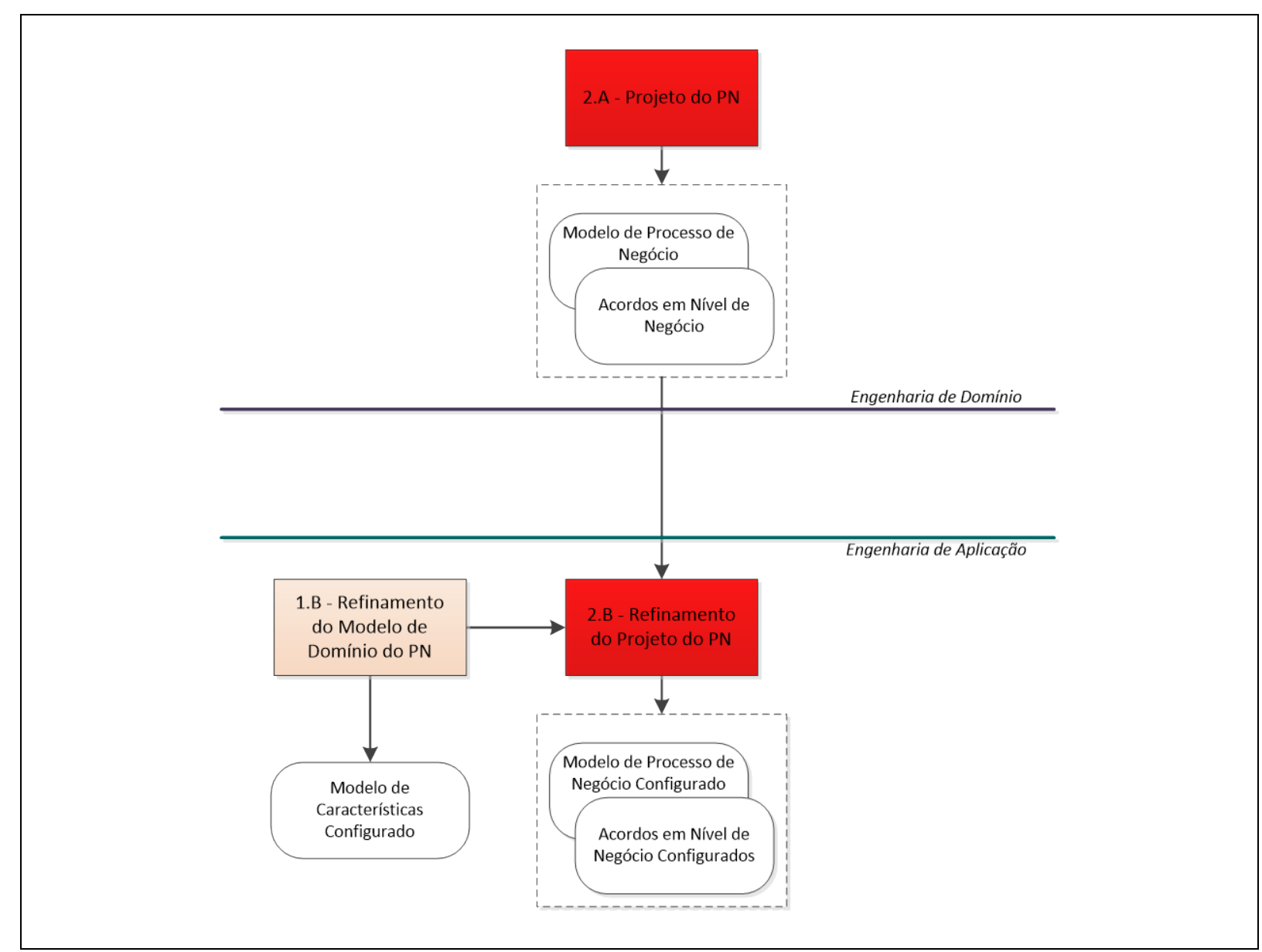

Figura 30 - Parte do processo DynPL4BPM relacionado à geração dos artefatos da atividade 2.B - Refinamento do Projeto do PN

Considerando que os artefatos gerados na "Engenharia de Domínio" estão relacionados direta ou indiretamente aos modelos de características por meio de anotações (comentários), o Modelo de Características Configurado gerado atividade $\underline{\text { Refinamento do }}$

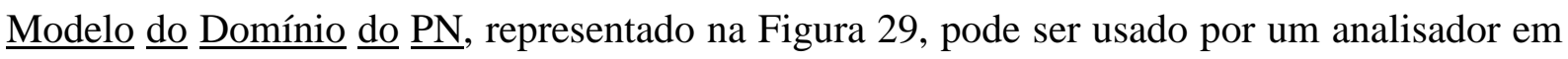


um processo manual ou automático de remoção. Assim, são mantidos no Modelo de Processo de Negócio todos os elementos associados às características obrigatórias ou as características opcionais e/ou alternativas selecionadas durante a configuração do modelo de características. As características opcionais e/ou alternativas não selecionadas no Modelo de Características Configurado devem ser removidas do template. Esse processo resulta no artefato Modelo de Processo de Negócio Configurado. Seguindo os passos descritos anteriormente, chega-se ao exemplo da Figura 31:

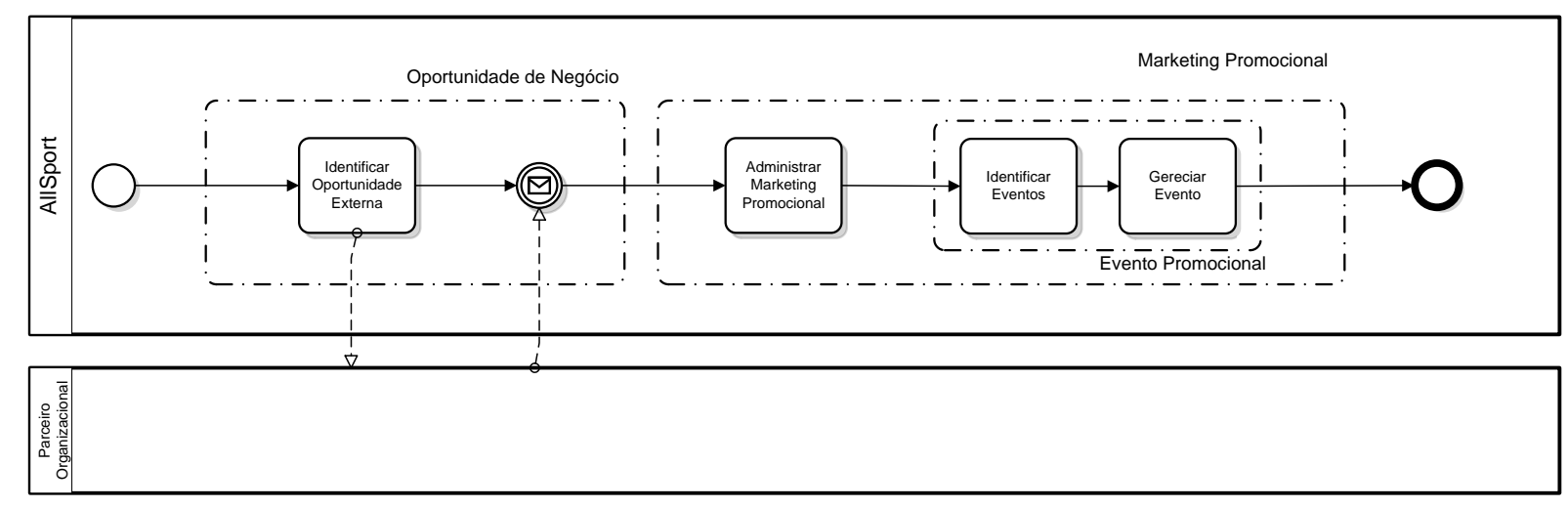

Figura 31 - Modelo de Processo de Negócio Configurado

Durante a criação do Modelo de Característica Configurado, informações não previstas podem ser requeridas como, por exemplo, novas atividades, fluxo de mensagem etc. Assim, algumas adaptações devem ser realizadas no modelo para representar as especificidades de cada negócio, como foi realizado no exemplo da Figura 31 com a adição de fluxo de mensagem para representar uma oportunidade de parceria externa.

Como em todo processo de Engenharia de Software, e não apenas de LP, além das propriedades funcionais - aqui representadas pelo Modelo de Processo de Negócio Configurado em BPMN - é importante especificar também as propriedades não funcionais.

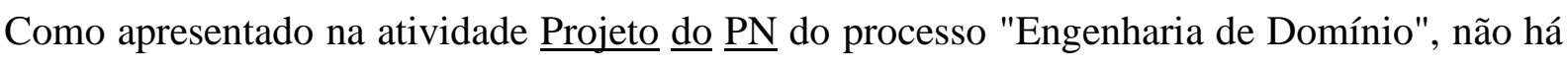
nenhuma técnica adequada para ter seu uso proposto dentro do processo DynPL4BPM, ficando uma lacuna neste ponto do processo.

\section{Tratamento dos Aspectos Dinâmicos}

O tratamento dos aspectos dinâmicos na atividade "2.B - Refinamento do Projeto do PN” está relacionado às técnicas apresentadas na Subseção 4.3.1.2 - Ligação Tardia e Modelagem Tardia. O processo DynPL4BPM incorpora aspectos da "Ligação Tardia" pois possui um modelo abstrato que é definido em tempo de projeto e os serviços que realizam tais 
atividades são selecionados em tempo de execução. Deve-se apenas realizar os ajustes necessários ao contexto de cada organização.

A "Modelagem Tardia" - ainda não explorada no contexto de LP - seria uma relevante contribuição para a propriedade "Tratamento de Mudanças dos Usuários" de LPD.

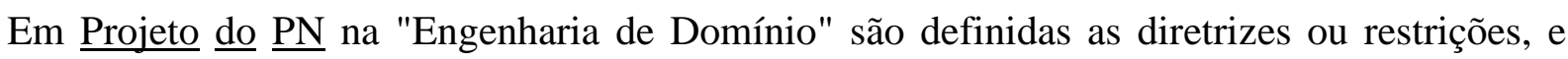
nesta atividade - Refinamento do Projeto do PN - são escolhidas as diretrizes ou restrições que se ajustam às necessidades específicas de uma organização.

\subsubsection{Atividade "3.B - Refinamento da Implementação do PN"}

A atividade "3.B - Refinamento da Implementação do PN" consiste na transformação dos artefatos gerados na atividade anterior em artefatos que permitam a execução do processo de negócio. Essa atividade usa também os artefatos inter-relacionados Processo de Negócio Executável e Acordos em Nível de Serviços - do processo "Engenharia de Domínio" como templates.

Com o objetivo de manter a rastreabilidade entre os artefatos gerados nesta atividade, deve-se manter apenas nos templates as características selecionadas no Modelo de Característica Configurado, realizando os ajustes necessários para que os artefatos derivados

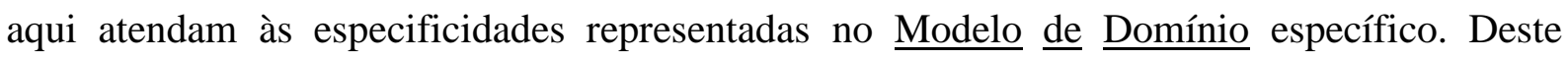

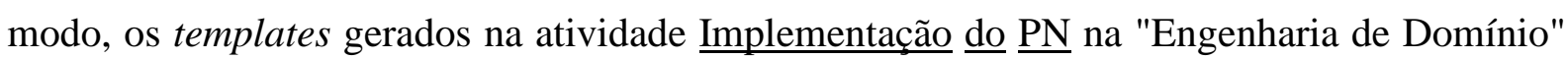
são transformados, respectivamente, em Processo de Negócio Executável Configurado e Acordos em Nível de Serviço Configurados, conforme Figura 32. 


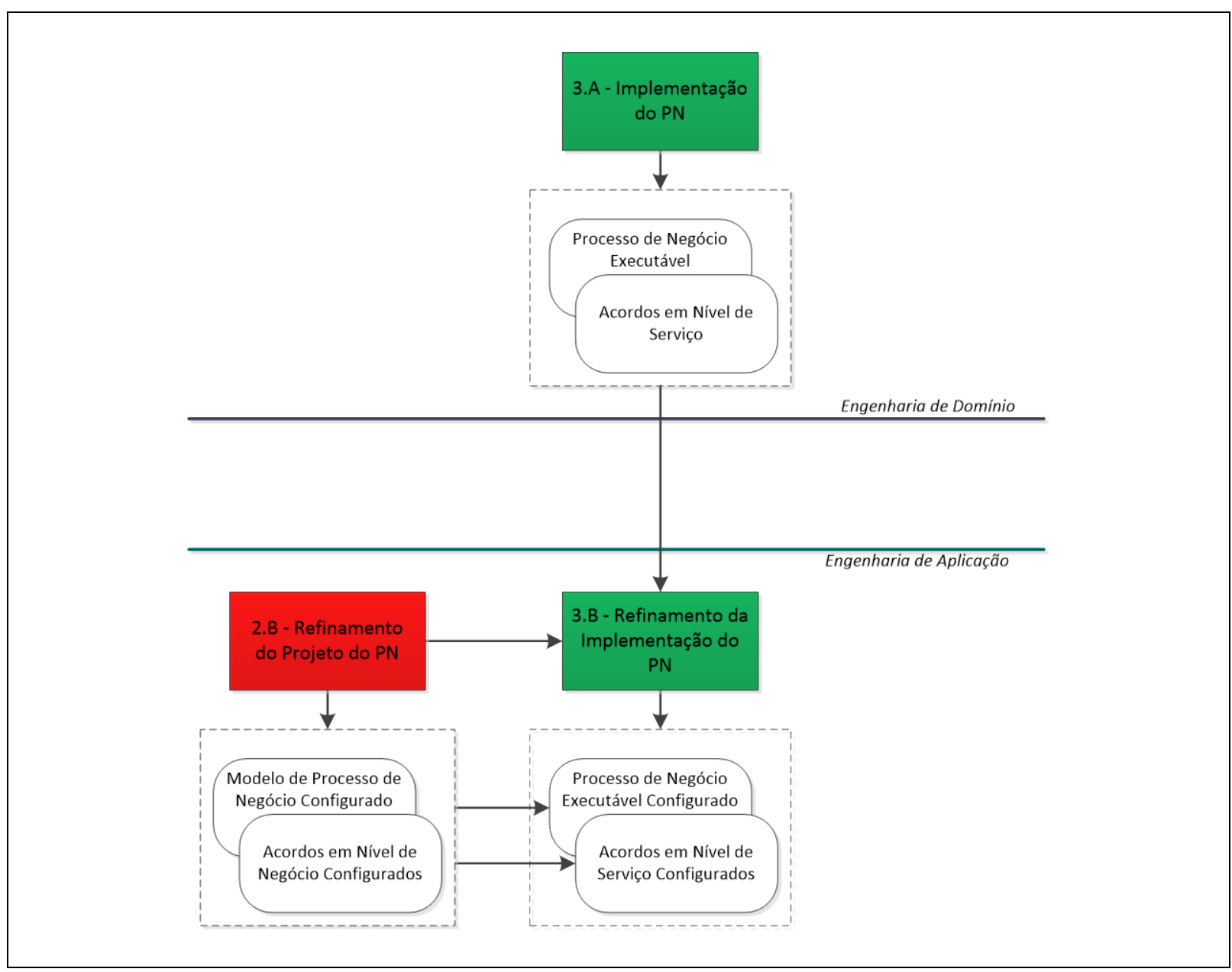

Figura 32 - Parte do processo DynPL4BPM relacionado à geração dos artefatos da atividade 3.B - Refinamento da Implementação do PN

Como exemplo, Figura 33 e Código 02 apresenta uma parte do Processo de Negócio Executável Configurado em WS-BPEL, referente ao processo de negócio da AllSport.

Código 02: Exemplo de Processo de Negocio Executável Configurado em WS-BPEL

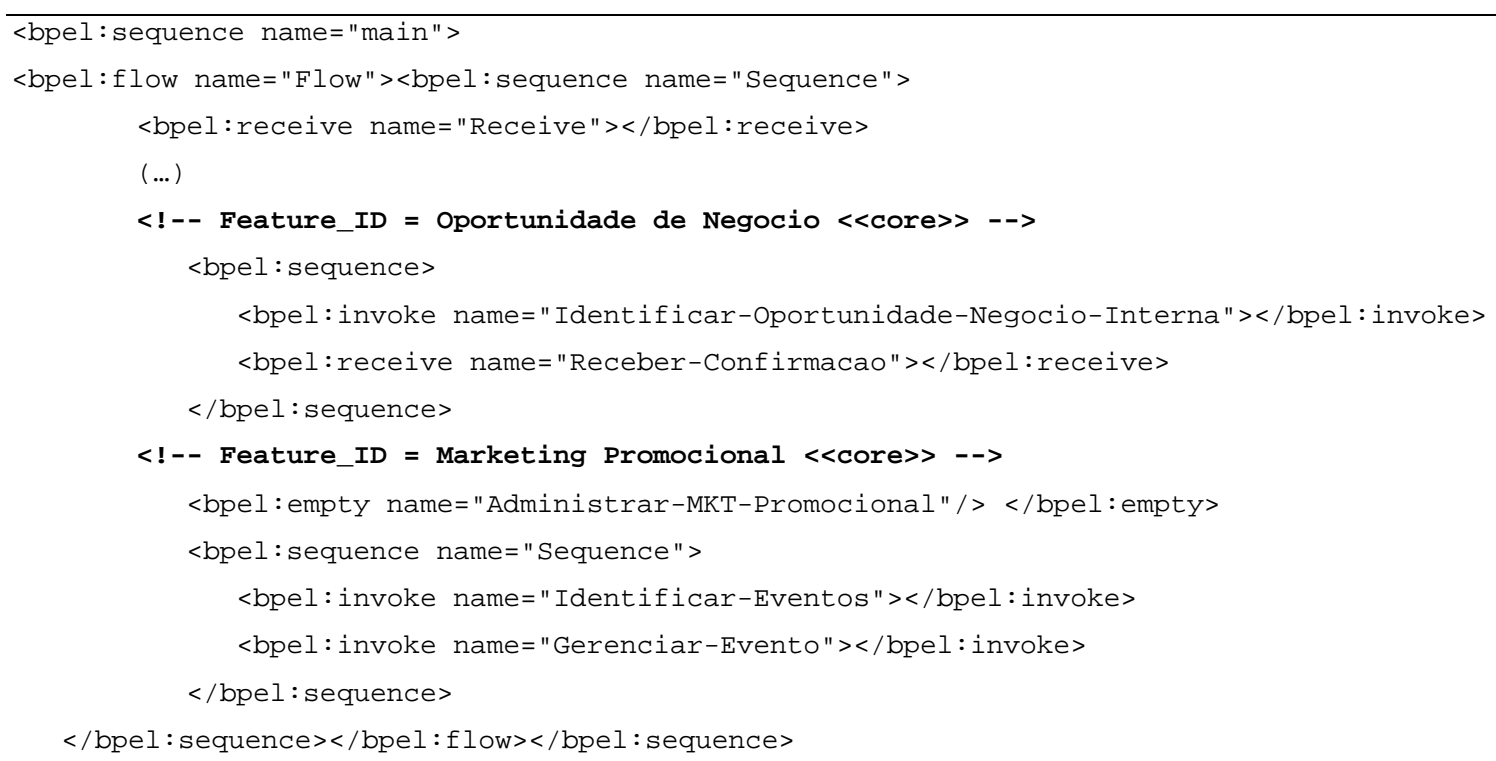




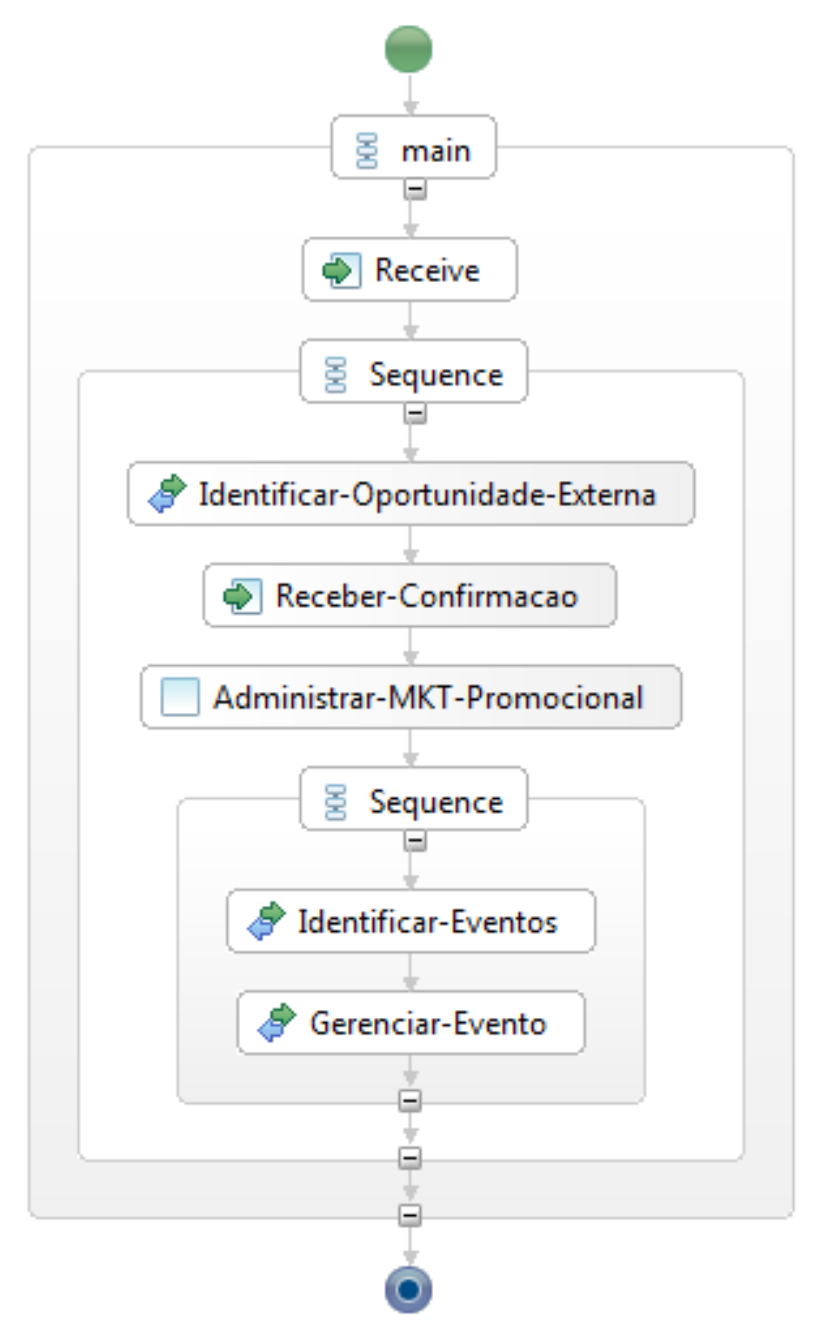

Figura 33 - Representação gráfica do Processo de Negócio Executável Configurado em WSBPEL para uma organização específica

Em relação aos requisitos não funcionais específicos identificados na atividade Refinamento do Projeto do PN, estes devem ser transformados em um SLA. Para tanto, recomenda-se a especificação WS-Policy para formalizar os NFRs dos serviços web que compõem um processo de negócio. O Código 03 apresenta uma especificação de política em WS-Policy. O exemplo ilustra uma política para atributos de qualidade utilizando uma asserção que define o tempo de resposta oferecido por um serviço web. Este exemplo está relacionado à característica selecionada "Tempo de Resposta" no Modelo de Características Configurado da Figura 29. 


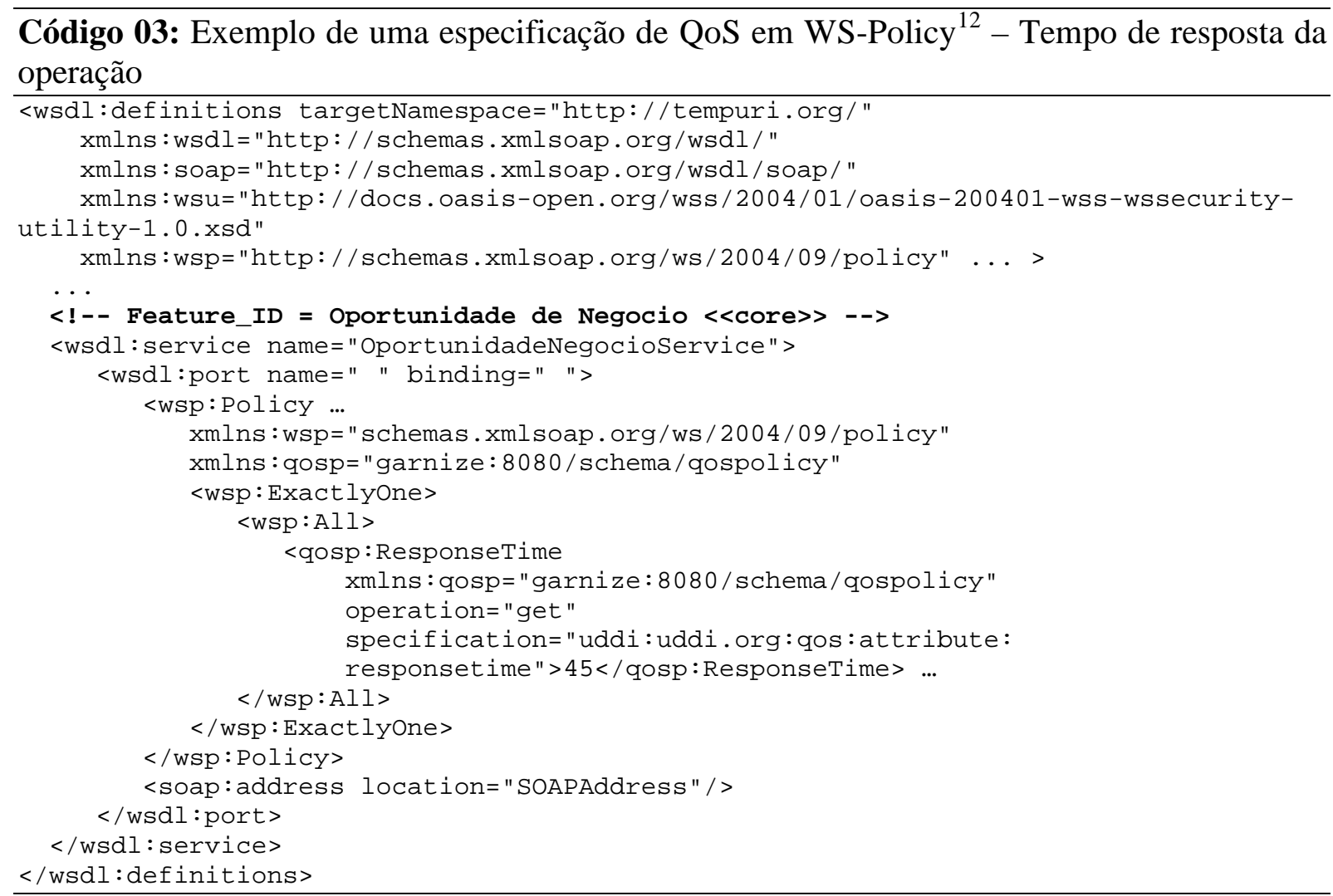

\section{Tratamento dos Aspectos Dinâmicos}

O tratamento dos aspectos dinâmicos na atividade “3.B - Refinamento da Implementação do PN” está relacionado à composição dinâmica dos processos de negócio. A estratégia de composição usada neste trabalho é baseada em workflow com ligação dinâmica. A partir do template gerado na atividade "Implementação do PN", que já está preparado para a ligação dos serviços em tempo de execução, deve-se apenas realizar os ajustes necessários adaptando os requisitos - funcionais e não funcionais - às necessidades especificas para cada organização.

\subsubsection{Atividade "4.B - Refinamento da Validação do PN"}

A atividade "4.B - Refinamento da Validação do PN" consiste na validação dos artefatos Processo de Negócio Executável Configurados e Acordos em Nível de Serviço Configurados, visando garantir que eles estão de acordo com os requisitos da LP para BPM considerando essa aplicação do processo de negócio em específico, conforme projetado na atividade $\underline{\text { Refinamento do }} \underline{\text { Projeto }} \underline{\text { do }} \underline{\mathrm{PN}}$, e seus respectivos artefatos, conforme representado na Figura 34.

\footnotetext{
${ }^{12}$ Prefixos e Namespaces usados no exemplo foram baseados em Vedamuthu et al. (2006).
} 


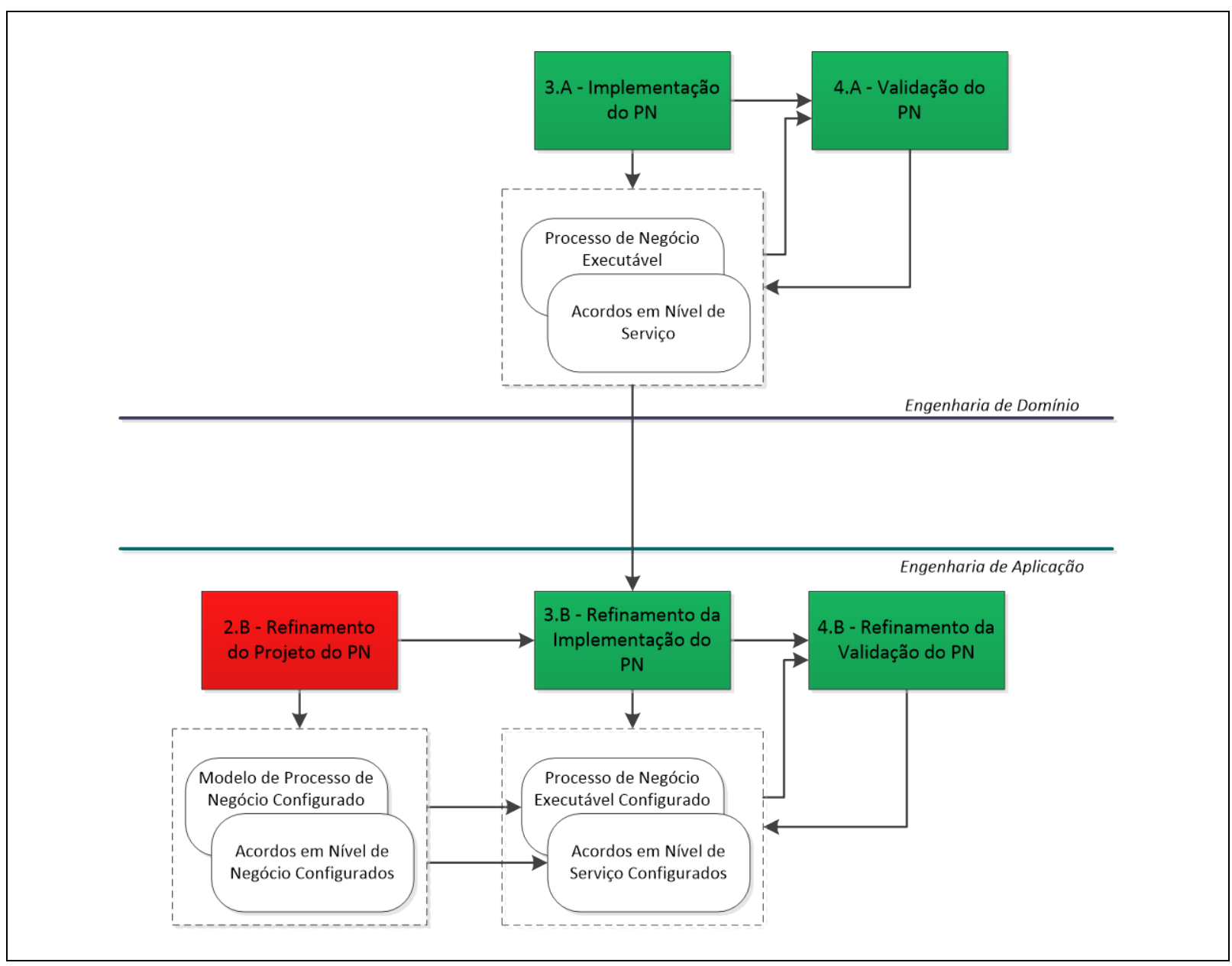

Figura 34 - Parte do processo DynPL4BPM relacionado à geração dos artefatos da atividade 3.B - Refinamento da Implementação do PN

As validações realizadas nessa atividade devem considerar o contexto específico do processo de negócio refinado, ou seja, a aplicação específica criada durante esse processo "Engenharia de Aplicação", já que o processo de negócio elaborado aqui tem o objetivo de ser usado para resolver um problema em específico.

Testes de integração e de sistema não eram factíveis na "Engenharia de Domínio" uma vez que a tentativa de se testar diferentes combinações dos componentes do domínio leva a um crescimento exponencial das configurações de teste (TEVANLINNA; TAINA; KAUPPINEN, 2004). Sendo assim, uma estratégia adequada para a atividade $\underline{\text { Refinamento do }}$

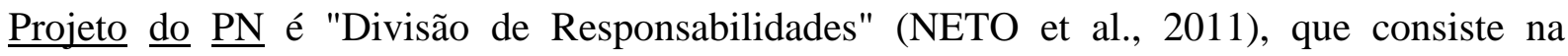
especificação de níveis de testes para cada ciclo de vida do processo de negócio, ou seja, as composições de serviços podem ser testadas unitariamente no ciclo "Engenharia de Domínio", enquanto que testes de integração, sistemas e aceitação podem ocorrer durante a instanciação dos processos no ciclo "Engenharia de Aplicação". 


\section{Tratamento dos Aspectos Dinâmicos}

Quando uma composição de serviço em WS-BPEL identifica um serviço e começa a usá-lo, periodicamente é necessário (re)testá-lo para garantir que o serviço entrega os requisitos necessários desejados e, ao mesmo tempo, se o serviço é capaz de atender aos requisitos de QoS contratados. Casos de testes podem ser usados como uma forma de contrato entre o provedor e a composição de serviços (PENTA et al., 2007).

Vários tipos de mudanças podem ocorrer que podem levar o serviço contratado a não cumprir com a entrega do que foi previamente acordado. Quando uma atividade (que pode ser vista como um serviço web) evolui sem a necessidade de modificar a sua interface e/ou especificação - pois o provedor acredita que foi realizada apenas uma pequena atualização tais mudanças podem ocultar problemas para os usuários daqueles serviços. Assim, uma estratégia capaz de lidar com esse tipo de problema é teste de regressão (PENTA et al., 2007).

Existem abordagens que aplicam teste de regressão em LP direcionadas ao desenvolvimento de software convencional, como por exemplo, a abordagem proposta por Machado et al. (2010), que aplicam a estratégia de teste de regressão à arquitetura da LP. O objetivo é garantir que nenhum novo defeito será introduzido na arquitetura anterior já testada. Para ter certeza de que a arquitetura está funcionando corretamente, sua especificação pode ser usada como oráculo de teste para identificar quando os casos de testes passam ou falham (MACHADO et al., 2010).

Tendo em vista o uso de tal estratégia em LP, torna-se adequado seu uso no processo DynPL4BPM, desde que seja adaptada, considerando que o produto a ser testado não é um software convencional, mas uma IPN - uma composição de serviços em WS-BPEL. Os passos da abordagem consistem em:

1) Planejamento e Análise: o planejamento é realizado para guiar a execução do ciclo de teste. Nesta fase, o plano de teste é criado coletando informações sobre os critérios adequados, medida de cobertura, recursos e riscos associados;

2) Projeto de teste e seleção: esta fase consiste em criar scripts de testes, suíte de testes e casos de testes adequados, considerando as diversas atividades que ocorrem na fase anterior;

3) Execução: durante a fase de execução do teste, os conjuntos de testes são executados contra a versão modificada de um ciclo de testes de regressão;

4) Comunicação: todas as informações serão reunidas para compor um relatório de teste. Este relatório é extremamente importante para a construção de outros planos de testes. 


\subsubsection{Gestão da LP}

Nas subseções a seguir, são apresentadas informações referentes ao processo "Gestão da LP" do processo DynPL4BPM.

\subsubsection{Atividade "5 - Execução e Administração da IPN"}

A atividade "5 - Execução e Administração da IPN" é responsável pela manutenção e geração de dados (Log de Execução) para análises futuras. Para cada processo de negócio criado, espera-se que ele entre em execução para atender uma determinada demanda organizacional ou mesmo interorganizacional. Considerando a natureza conceitual de processos de negócio, um mesmo processo pode ser executado várias vezes, para um conjunto de dados de entrada diferentes enquanto o processo de negócio usado como base satisfizer as necessidades organizacionais ou o ambiente ser flexível o suficiente para permitir ajustes dinâmicos no processo durante suas execuções. Essa atividade corresponde à fase Execução do ciclo de vida de BPM (conforme Figura 2).

Execução de IPN pode ser traduzido como a invocação dos serviços web que compõe o Modelo de Processos de Negócio Executável em WS-BPEL, considerando os níveis de QoS estabelecidos nos Acordos em Nível de Serviços. Há duas possibilidades para essa invocação: invocação estática de serviço web, considerando os casos em que o serviço web já foi definido em tempo de projeto, ou seja, durante as atividades Implementação do $\underline{\text { PN ou }}$ Refinamento da Implementação do PN; ou invocação dinâmica do serviço web, considerando os casos em que o serviço web não foi definido em tempo de projeto, mas apenas a indicação de que o mesmo deve ser selecionado em tempo de execução - nesse caso, a atividade Seleção Dinâmica de Serviços Web deverá ser executada.

Sistemas de Gestão de Processos de Negócio (BPMS - Business Process Management Systems) podem ser usados para administrar a execução de IPNs e garantir que as atividades do processo de negócio sejam realizadas de acordo com as restrições de execução especificadas no Modelo de Processo de Negócio Executável. BPMS permitem também a manutenção do histórico das versões das IPNs, sendo considerada uma atividade essencial para o controle de evolução da LP. Mas no caso de LP, é necessário levar em consideração os artefatos da plataforma e dos produtos de maneira integrada. Além disso, as características, regras de composição, metamodelos, modelos, especificações de transformação e ligações de rastreabilidade devem evoluir de forma consistente, o que significa que a co-evolução desses 
artefatos deve ser uma preocupação das abordagens de LP de maneira geral. Assim, sistemas de controle de versão devem ser usados com esta finalidade (CORRÊA, 2011).

\section{Tratamento de Aspectos Dinâmicos}

Devido à complexa relação de interdependência envolvendo metamodelos, modelos, especificações de transformação e ligações de rastreabilidade, a evolução consistente não é trivial (CORRÊA, 2011). As modificações em modelos da plataforma devem ser propagadas para os respectivos modelos dos produtos. Com o passar do tempo, a sincronização de plataforma e produtos pode se tornar inviável.

Há várias abordagens que propõem a evolução da plataforma reusável de uma LP. Corrêa (2011) apresenta uma série de trabalhos relacionados à sua proposta que podem ser usadas no processo DynPL4BPM.

\subsubsection{Atividade "6 - Monitoramento da IPN"}

Levando em consideração o ambiente dinâmico dos processos de negócio, as etapas de validação clássicas, como a verificação estática e testes, não são suficientes para constatar se os requistos organizacionais estão sendo alcançados. Por isso, nos últimos anos diversas abordagens foram propostas com soluções para garantir os níveis de QoS em cenários dinâmicos. Em particular, o monitoramento de composições de serviços em tempo de execução tem sido o alvo de muitas discussões (BARESI; GUINEA, PASQUALE, 2008).

A atividade "6 - Monitoramento da IPN" é um importante mecanismo para fornecer informações precisas sobre o status das IPNs. É uma atividade dinâmica por natureza, pois a sua realização só é possível a partir da instanciação do processo de negócio. Essa atividade corresponde à subfase Monitoramento do ciclo de vida de BPM (conforme Figura 2).

O principal objetivo do Monitoramento da $\underline{\text { IPN }}$ é a verificação do cumprimento dos Acordos de Nível de Serviços associados ao respectivo processo de negócio. Em caso de não conformidades detectadas uma estratégia de recuperação deve ser aplicada, o que pode levar a

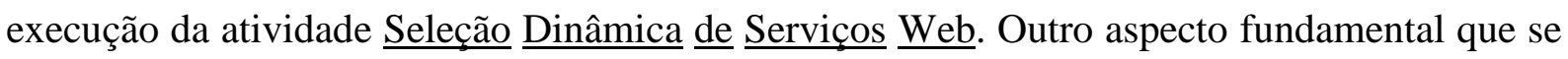
deve considerar nessa atividade está relacionado ao Log de Monitoramento para cada IPN em execução. Este artefato é usado como entrada na atividade $\underline{\text { Avaliação }} \underline{\text { do }} \underline{\text { PN. }}$.

Estratégias eficientes de monitoramento e recuperação para composições de serviços em WS-BPEL devem ter um modelo de dados comum, infraestrutura para a gestão do monitoramento comum, além de um framework de recuperação comum. O Framework 
Unificado proposto por Baresi, Guinea e Pasquale (2008), apresentado na Figura 35, é adequado à atividade Monitoramento da $\underline{\text { IPN }}$, pois permite acomodar vários conjuntos de abordagem de monitoramento que podem ser adicionadas como plugins. Neste trabalho não são discutidas as abordagens de monitoramento e recuperação apresentadas no Framework Unificado (Figura 35).

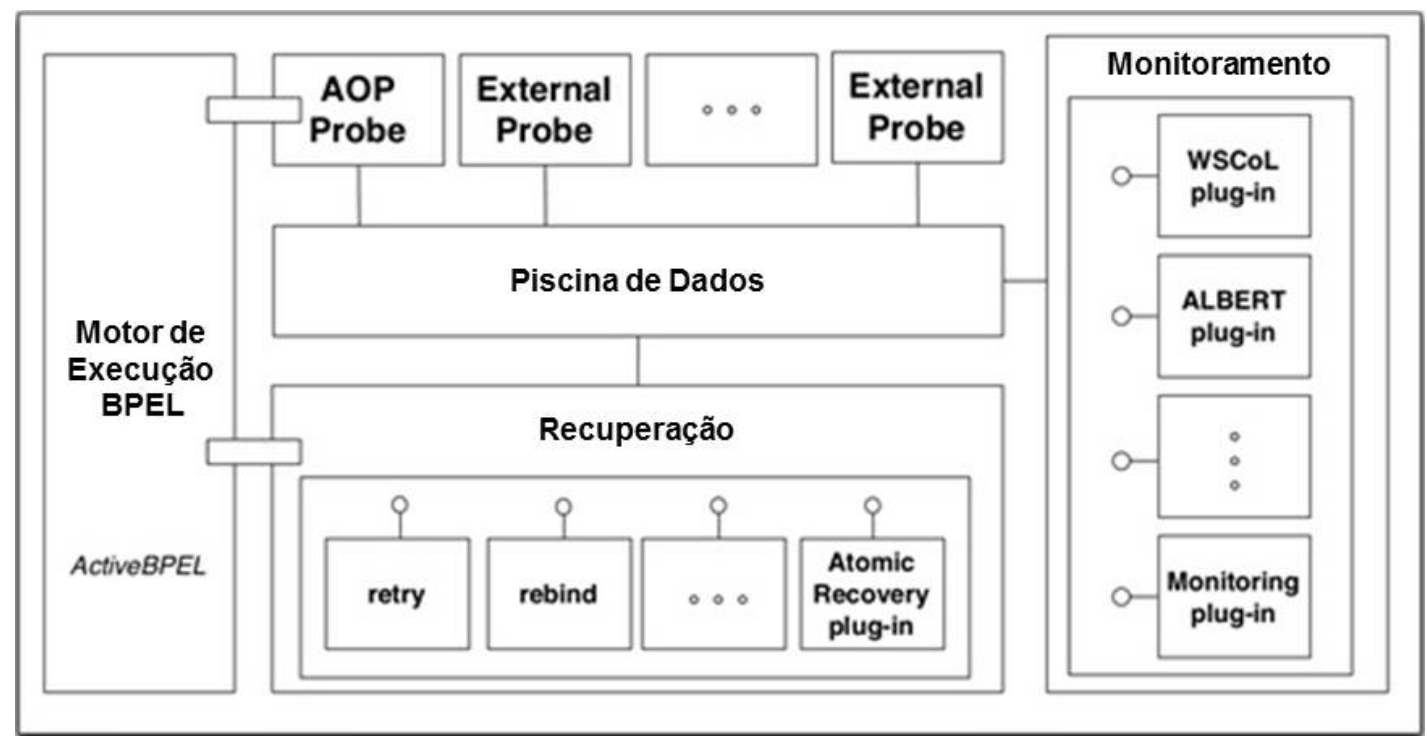

Figura 35 - Framework Unificado proposto

Fonte: Traduzido de Baresi, Guinea e Pasquale (2008)

De uma forma geral, frameworks e padrões também são importantes recursos para o enfoque de linha de produto. Para se conceber uma linha de produto é necessário partir de conceitos que levem à generalização de aplicações e que permitam instanciações para aplicações específicas (GIMENES; TRAVASSOS, 2002). A aplicação, do Framework Unificado (BARESI; GUINEA; PASQUALE, 2008) é aderente ao processo DynPL4BPM, pois diferentes técnicas podem ser usadas considerando que estas podem ser adicionadas como plug-ins e a para cada plug-in usado um histórico deve ser armazenado. No caso de futuras IPNs a serem colocadas em execução, deve-se consultar o histórico para identificar as técnicas que tiveram melhor aderência para aquele domínio específico.

\subsubsection{Atividade "7 - Seleção Dinâmica de Serviços Web"}

A atividade "7 - Seleção Dinâmica de Serviços Web" consiste em buscar e selecionar serviços web em tempo de execução, para os casos em que essa ação tenha sido prevista, que podem ser de dois tipos principalmente: serviços web para que implementem atividades de processo de negócio não definidos em tempo de projeto propositalmente para que as organizações responsáveis possam ter flexibilidade de realizar essa escolha de forma dinâmica 
em tempo de execução; e serviços web alternativos para substituir outros serviços web que estejam falhando em cumprir os níveis de serviços dos atributos de QoS que foram contratados nos Acordos de Nível de Serviço definidos entre as organizações envolvidas.

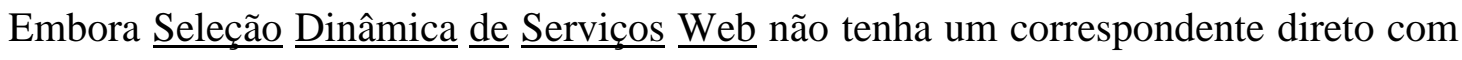
o ciclo de BPM apresentado na Figura 2 ela foi mantida de forma adaptada no processo DynPL4BPM por ser um conceito inerente à SOA, considerando sua grande importância.

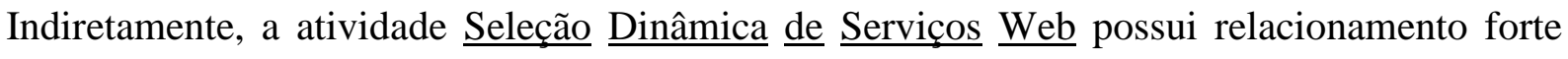
com a fase Execução do ciclo de vida de BPM.

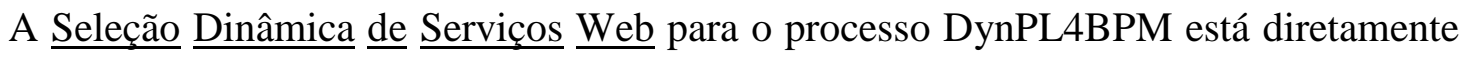
relacionada à composição automática de serviços baseada em workflow, que foi tratada nas

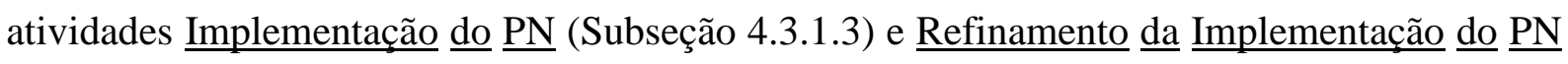
(Subseção 4.3.2.3). Técnicas baseadas em workflow são utilizadas, principalmente, em situações em que o consumidor já possui modelo de processo definido. Embora a técnica proposta por Tizzo, Coello e Cardozo (2011) seja baseada em workflow, a seleção de serviços daquela abordagem não é adequada ao processo DynPL4BPM pois apenas considera os requisitos funcionais. Uma técnica adequada deve considerar também os requisitos não funcionais.

Há diversos trabalhos na literatura que tratam de seleção dinâmica de serviços. Estes

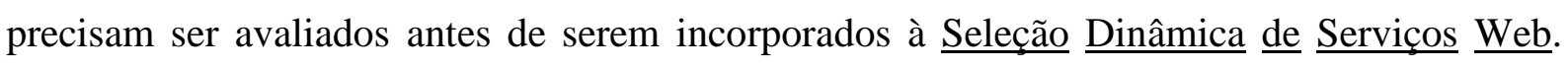
Um ponto de partida seria considerar os trabalhos relacionados citados em Tizzo, Coello e Cardozo (2011) para chegar a uma proposta mais adequada ao processo DynPL4BPM.

\subsubsection{Atividade "8 - Análise da IPN"}

A atividade "8 - Análise da IPN" consiste em realizar uma análise de uma IPN em particular, ou de um conjunto de IPNs, visando uma possível otimização do processo de negócio em execução. A intenção é que se tenha a oportunidade de otimizar ou a plataforma reusável no nível de domínio ou, pelo menos, o processo de negócio sendo usado como base para a geração de instâncias no nível de aplicação. Como produto final dessa atividade tem-se o Relatório da Avaliação. Este pode indicar novas versões do processo de negócio, que produzirão impacto no processo de negócio inteiro, ou apenas uma nova IPN baseada em um mesmo processo de negócio já em uso. Essa atividade corresponde à fase Avaliação do ciclo de vida de BPM (conforme Figura 2). Em muitas organizações a fase Avaliação ainda não é realizada de maneira sistemática e de forma contínua (AALST, 2011). 
No processo DynPL4BPM propõe-se a realização dessa atividade de forma sistemática, por inseri-la no contexto de LP, e também de forma continua oferecendo a possibilidade de fechar todo o ciclo de vida de BPM. Até então, as abordagens de LP no domínio de BPM apenas realizam parcialmente o ciclo de BPM, chegando apenas à fase de Execução.

Para avaliação das IPNs, pode se aplicar, por exemplo, técnicas de mineração de dados em processos, buscando por pontos de gargalo ou outras tendências identificáveis nas IPNs, com base nos históricos do Log de Execução e Log de Monitoramento. Mineração de processos é uma disciplina de pesquisa recente que cobre tanto aspectos da área de Inteligência Artificial - tais como aprendizagem de máquina e mineração de dados - quanto aspectos da área de Análise e Modelagem de Processos. A ideia de mineração de processos é descobrir, monitorar e melhorar os processos reais pela extração de conhecimento a partir de logs de eventos gerados pelos sistemas (sistema pode ser entendido como uma workflow engine) (AALST, 2011).

No processo DynPL4BPM a aplicação de técnicas de mineração de processo, tais como o framework proposto por Aalst (2011), é aderente pois se pode obter: (i) descoberta do processo: extração de modelos de processo, a partir de um log de eventos; (ii) verificação de conformidade: monitorar desvios a partir de comparações estabelecidas entre um modelo $a$ priori e o $\log$ da IPN; (iii) mineração de rede social ou organizacional: uma rede social consiste de nós que representam entidades organizacionais e arcos que representa os relacionamentos, sendo relevante para análise dos relacionamentos organizacionais que são estabelecidos; (iv) construção automatizada de modelos de simulação; (v) predição de caso e (vi) recomendações baseadas na história.

Considerando os itens obtidos por meio da aplicação da mineração de processo, o

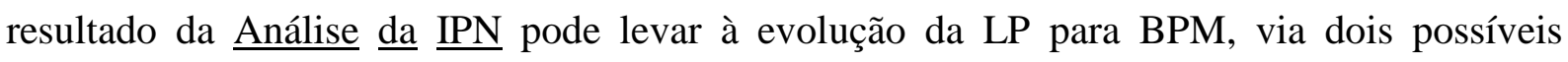
caminhos: a manutenção e consequente evolução da plataforma reusável de uma forma geral, no processo "Engenharia de Domínio"; ou uma nova aplicação de uma plataforma reusável da LP para BPM, no processo "Engenharia de Aplicação", por meio de um novo conjunto de configurações no Refinamento do Modelo de Domínio do PN.

\section{Tratamento dos Aspectos Dinâmicos}

Tradicionalmente, a mineração de processos tem sido usada de um modo off line, ou seja, ela considera apenas os dados coletados das IPNs que já foram finalizadas. Isto significa que somente casos concluídos estão sendo considerados, ou seja, os registros de eventos são 
traços completos correspondentes a casos que foram totalmente manipulados no passado. Estes dados influenciarão apenas as futuras IPNs.

Considerando o ambiente dinâmico em que as organizações estão inseridas, é fundamental que essas técnicas ofereçam alguma flexibilidade para poder lidar com situações imprevistas. No contexto de LPD é importante assegurar que as mudanças realizadas estejam em conformidade com a arquitetura da LPD. Nesse contexto, técnicas de avaliação devem tanto influenciar futuras IPNs ou a plataforma reusável, definida no processo "Engenharia de Domínio", quanto as IPNs em tempo de execução.

Conforme proposto por Aalst (2011), técnicas de mineração de processos podem ser aplicadas também em tempo de execução, principalmente as técnicas relacionadas ao suporte. Para tanto, devem considerar os logs parciais gerados pelos eventos, aqui denotado por traço parcial e formalmente representado por $\sigma_{\mathrm{p}}$. Assim, considerando que as atividades $a$ e $b$ foram executadas, o traço parcial $\sigma_{\mathrm{p}}=<\mathrm{a}, \mathrm{b}>$ descreve o caso de um passado conhecido. Apenas observando traço parcial o futuro é ainda desconhecido. Um futuro possível completo poderia ser $\sigma_{\mathrm{c}}=<\mathrm{a}, \mathrm{b}, \mathrm{c}, \mathrm{d}>$. Assim, três atividades de mineração de processos poderiam fornecer suporte a IPN em execução. A Figura 36 apresenta as atividades que são: Detect, Predict, Recommend.

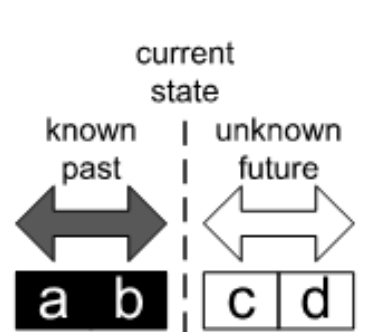

Figura 36 - Três atividade de mineração de processos relacionadas ao suporte operacional

\subsection{Considerações Finais}

Neste capítulo foi apresentada a proposta de uma abordagem de LPD para o domínio de BPM, descrevendo em um nível alto todas as atividades da LPD proposta. Como principal contribuição à área de BPM, a DynPL4BPM incorpora ao processo definido uma série de aspectos dinâmicos, além da realização do tratamento de tais aspectos na LPD para BPM definida, considerando principalmente os aspectos do paradigma SOA para realização de BPM. Na sequência, Capítulo 5, é apresentada uma avaliação da abordagem. 


\section{Exemplo Consolidado de Aplicação}

Este capítulo tem como objetivo apresentar exemplos mais detalhados dos artefatos produzidos durante a execução dos processos "Engenharia de Domínio" e "Engenharia de Aplicação", em relação àqueles apresentados junto com a abordagem proposta no Capítulo 4.

O capítulo está dividido em duas partes: na Seção 5.1 são apresentados os exemplos dos artefatos gerados nas atividades do processo "Engenharia de Domínio"; na Seção 5.2 são apresentados os exemplos dos artefatos gerados nas atividades do processo "Engenharia de Aplicação".

\subsection{Engenharia de Domínio}

Nas subseções a seguir, são apresentados os exemplos dos artefatos gerados pelas atividades que compõem o processo "Engenharia de Domínio".

\subsubsection{Atividade "1.A - Análise do Domínio do PN"}

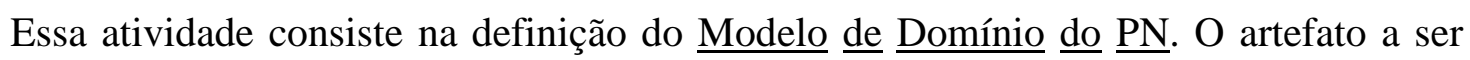
usado para essa atividade é um Modelo de Características. No processo DynPL4BPM, a construção do Modelo de Características pode ser resumida em dois passos:

1. Criação de um modelo de características inicial que possibilita definir as propriedades obrigatórias, opcionais e alternativas para um determinado domínio;

2. Tratamento dos aspectos dinâmicos, através da aplicação de uma técnica que estabelece a diferenciação entre propriedades - funcionais e não funcionais - que podem ser realizadas por serviços web daquelas que apenas definem $o$ comportamento dos processos de negócio.

A Figura 37 representa o Modelo de Características inicial. De acordo esse modelo, "Oportunidade de Negócio" e "Marketing Promocional" são exemplos de características Obrigatórias. "Mídia" é um exemplo de característica Opcional. Além disso, "Eventos Promocionais" e "Ofertas" são exemplos de característica "Alternativa" e característica "Ou", respectivamente. A área sombreada representa as características principais do Domínio de Marketing apresentado no Exemplo Motivacional (Capítulo 1). 


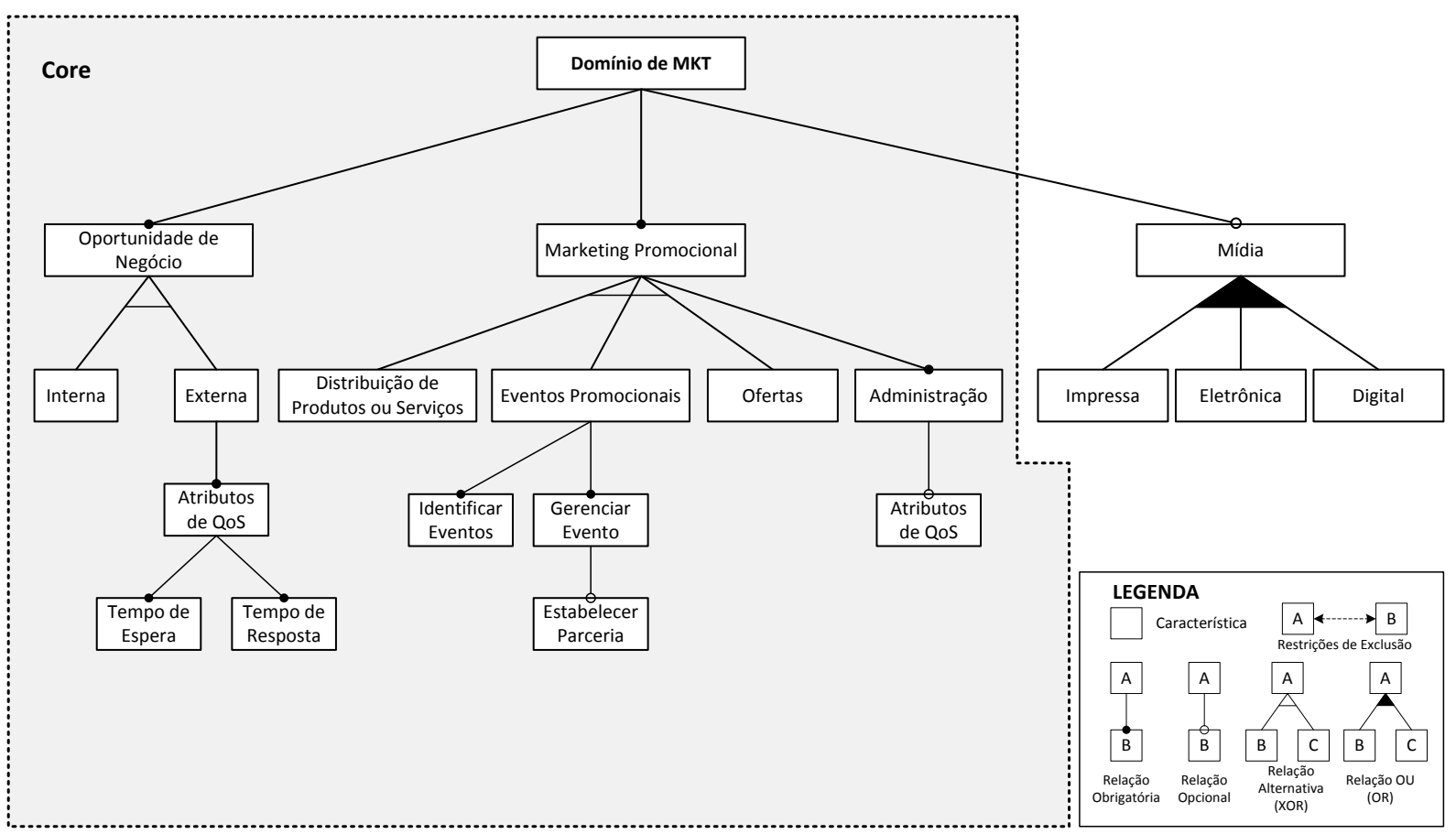

Figura 37 - Exemplo do Modelo de Características do Domínio de Marketing

A Figura 38 representa o artefato final gerado pela Atividade "1.A - Análise do Domínio do PN", através da aplicação da técnica de Lee, Muthig e Naab (2010) ao Modelo de Característica inicial (Figura 37). Detalhes sobre a aplicação da técnica foram apresentados na Subseção 4.3.1.1.

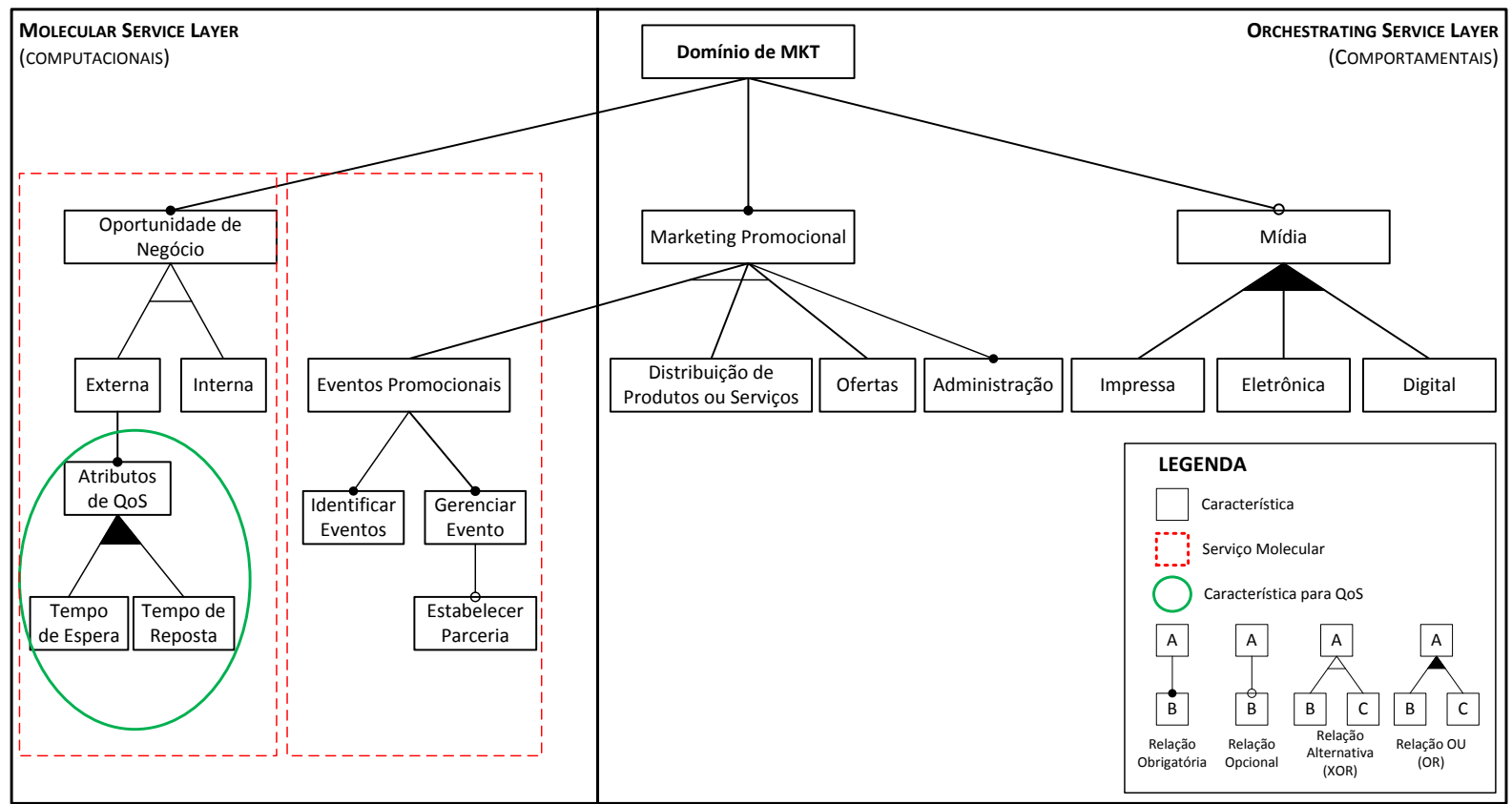

Figura 38 - Exemplo do Modelo de Características do Domínio de Marketing após aplicação da técnica de Lee, Muthig e Naab (2010) 


\subsubsection{Atividade "2.A - Projeto do PN"}

Essa atividade consiste na elaboração do Modelo de Processo de Negócio em BPMN e especificação dos Acordos em Nível de Negócio. Para a elaboração do Modelo de Processo de Negócio aplica-se a BFE (MONTERO; PEÑA; RUIZ-CORTÉS, 2008b): abordagem que define como usar as informações do Modelo de Características para a geração do Modelo de Processos de Negócio em BPMN.

O catálogo de equivalência apresentado na Figura 16 (página 32) foi utilizado para o mapeamento entre o Modelo de Características (Figura 38, página 84) e uma estrutura do BPMN. A Figura 39, a seguir, apresenta o resultado deste mapeamento:

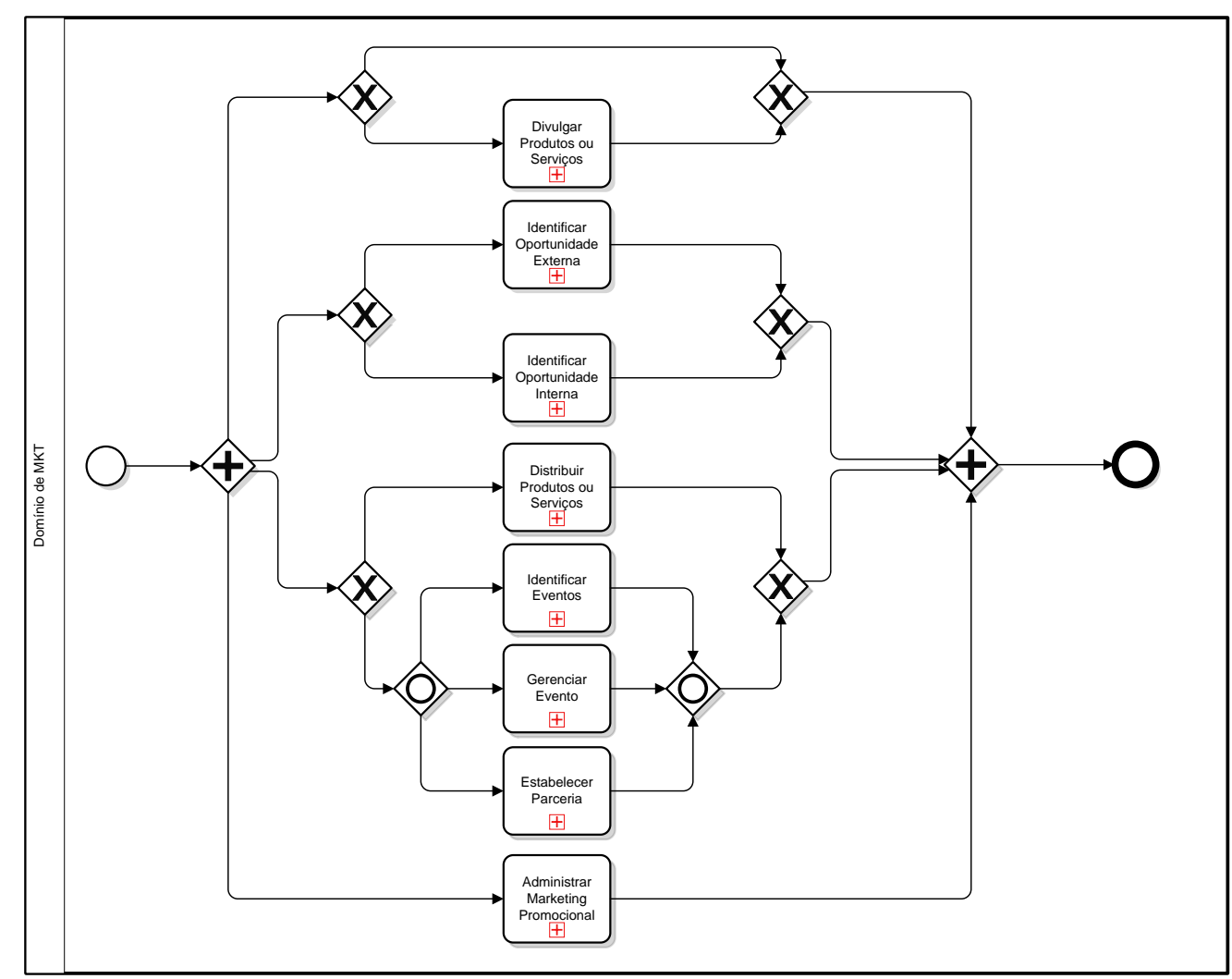

Figura 39 - Modelo de Processo de Negócio gerado a partir da aplicação da técnica proposta na abordagem BFE

A Figura 39 é um modelo de "Composição sem Sobreposição", ou seja, o modelo de processo de negócio não consome ou fornece artefatos para as atividades subsequentes, podendo ser realizado de forma independente. Ajustes manuais foram realizados, reordenando as atividades que são dependentes, a fim de atender aos requisitos funcionais do domínio em questão, conforme apresentado na Figura 40. 


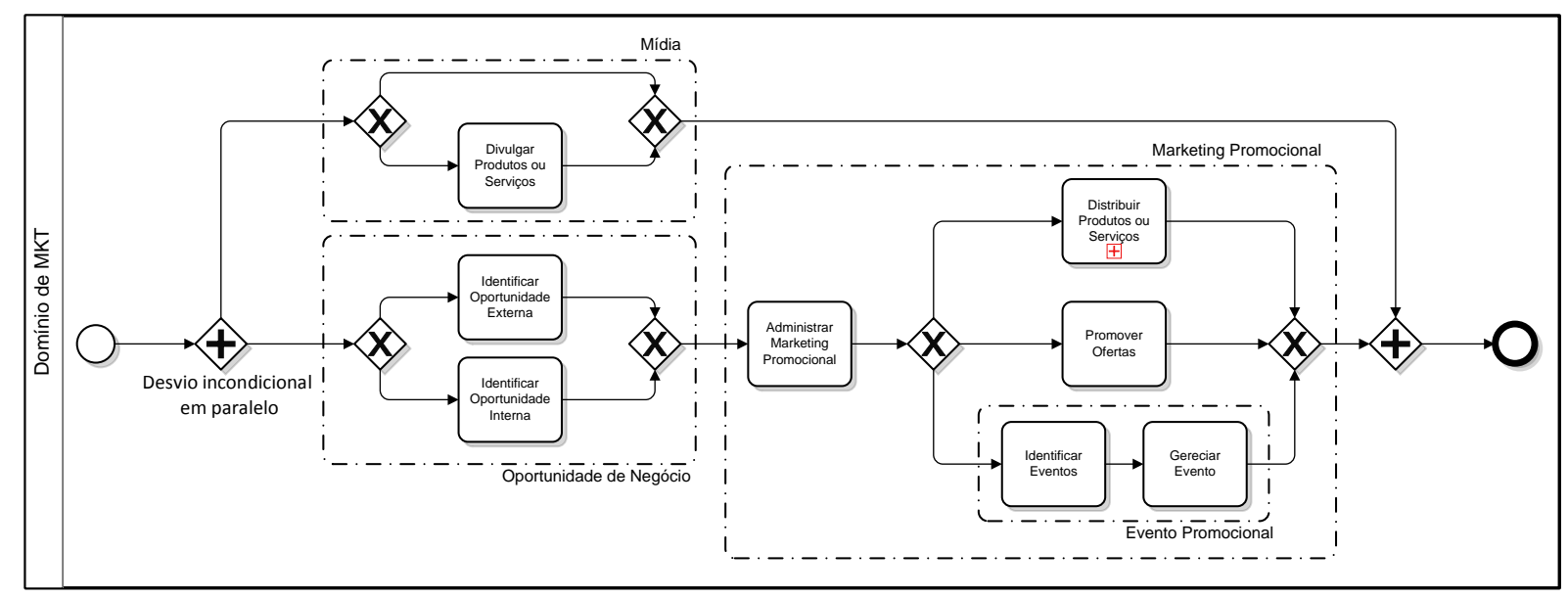

Figura 40 - Modelo de Processo de Negócio gerado a partir da aplicação da técnica proposta na abordagem BFE com adaptações

Como destacado na Subseção 4.3.1.3 ainda não existe uma técnica adequada para a especificação do Acordo em Nível de Serviço.

\subsubsection{Atividade "3.A - Implementação do PN"}

Essa atividade consiste na transformação dos artefatos gerados na atividade anterior em artefatos que permitam a execução do processo de negócio. Existem regras para o mapeamento do Modelo de Processo de Negócio para sua versão executável em WS-BPEL, incluindo ferramentas que automatizam tal transformação. O Código 02 e a Figura 41 ilustram esse mapeamento.

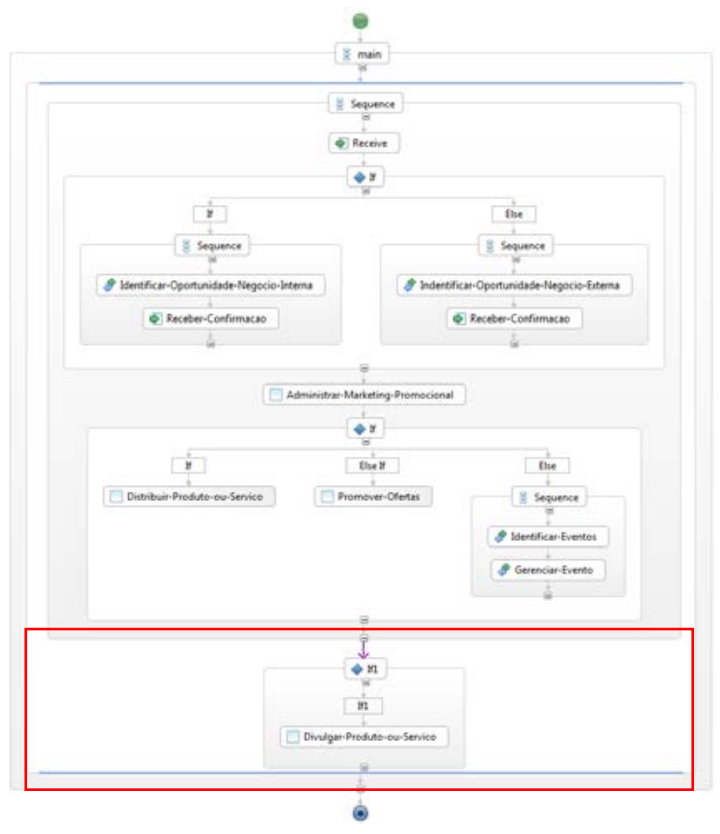

Figura 41 - Exemplo de Processo de Negócio Executável em WS-BPEL 


\section{Código 02: Exemplo de Processo de Negócio Executável em WS-BPEL}

\section{$(\ldots)$}

$<$ bpel: sequence name="main">

$<$ bpel:flow name="Flow"><bpel: sequence name="Sequence">

$<$ bpel:receive name="Receive" $></$ bpel: receive $>$

(...)

<! - - Feature_ID = Oportunidade de Negocio <<core〉> - - >

$<$ bpel: if name="If">

$<$ bpel: sequence>

<bpel:invoke name="Identificar-Oportunidade-Negocio-Interna" $></$ bpel: invoke $>$

$<$ bpel: receive name="Receber - Confirmacao" $></$ bpel: receive $>$

$<$ /bpel: sequence>

$<$ bpel:else>

$<$ bpel: sequence>

<bpel: invoke name="Identificar-Oportunidade-Negocio-Interna" $></$ bpel: invoke $>$

$<$ bpel: receive name="Receber - Confirmacao" $></$ bpel: receive $>$

$</$ bpel: sequence $>$

$</$ bpel:else $>$

$</$ bpel:if $>$

$<$ ! - - Feature_ID = Marketing Promocional $<<$ core $>>~-~->$

$<$ bpel:empty name="Administrar-MKT-Promocional"/> </bpel:empty> $<$ bpel: if name="If">

$<$ bpel: empty name="Distribuir-Produto-ou-Servico" $></$ bpel: empty $>$

$<$ bpel:elseif>

$<$ bpel: empty name="Promover - ofertas" $></$ bpel: empty $>$

$</$ bpel:elseif $>$

$<$ bpel:else>

$<$ bpel: sequence name="Sequence" >

<bpel: invoke name="Identificar -Eventos"></bpel: invoke>

$<$ bpel: invoke name="Gerenciar - Evento" $></$ bpel: invoke $>$

$</$ bpel: sequence $>$

$</$ bpel:else $>$

$</$ bpel:if $>$

<bpel: sources>

<bpel: source linkName="link1" ></bpel: source>

$</$ bpel: sources $>$

$</$ bpel: sequence $>$

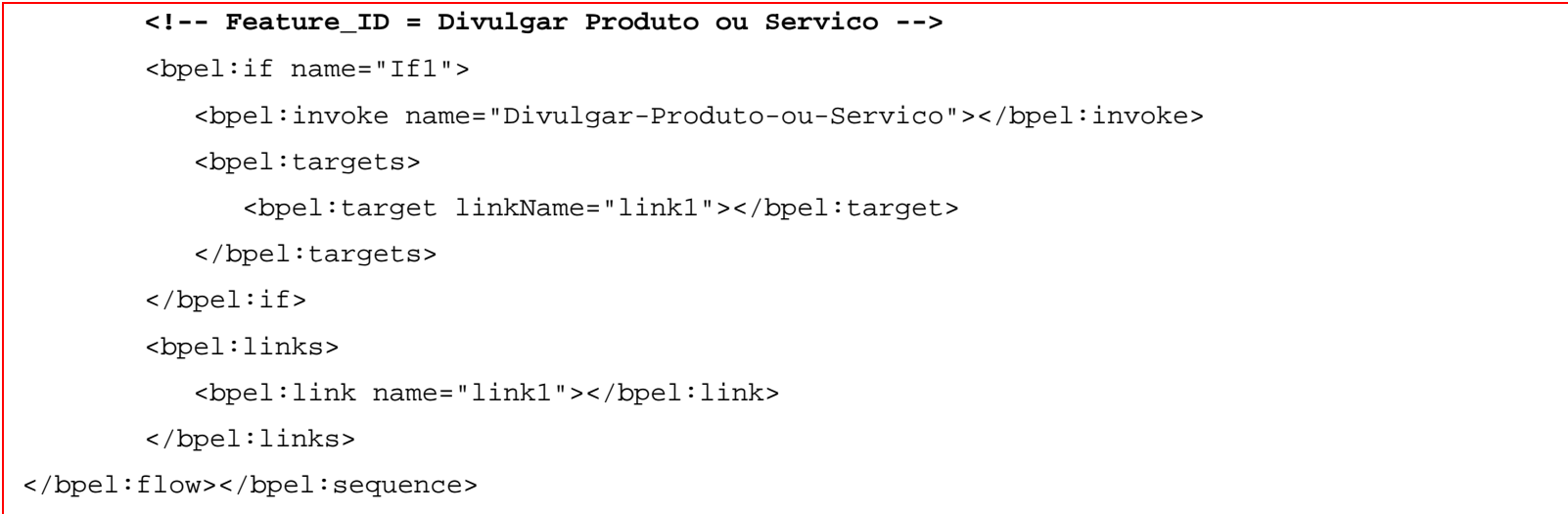


A área destacada na Figura 41 e Código 02 representa o desvio incondicional em paralelo do Modelo de Processo de Negócio em BPMN (Figura 40).

Os requisitos funcionais identificados no Projeto do $\underline{\mathrm{PN}}$ devem ser transformados em um SLA. Para essa formalização, utilizou-se a linguagem WS-Policy, conforme apresentado no Código 04.

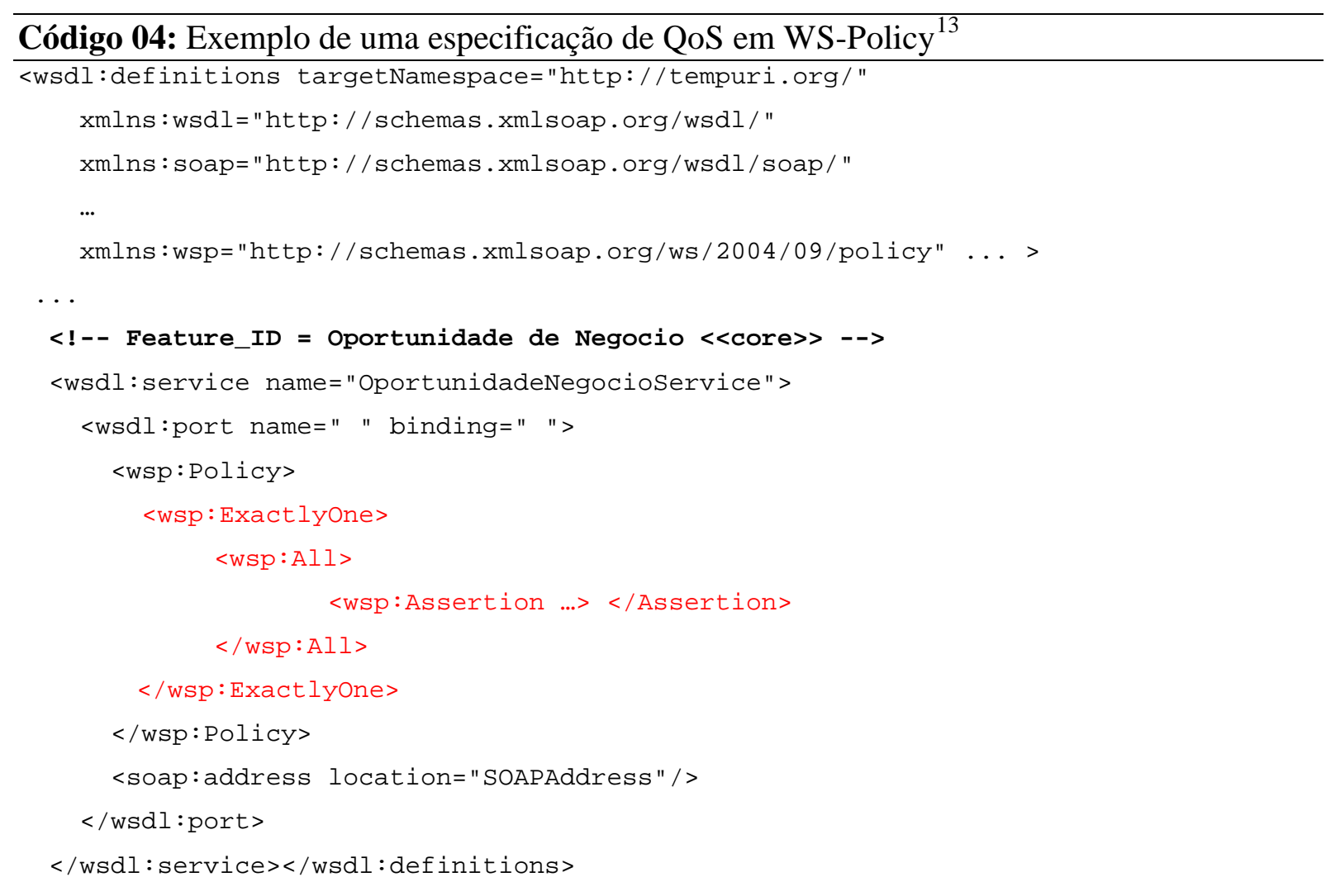

\subsubsection{Atividade "4.A - Validação do PN"}

Essa atividade consiste na validação dos artefatos gerados durante a atividade $\underline{\text { Implementação }} \underline{\text { do }} \underline{\mathrm{PN}}$, visando garantir que eles estão de acordo com os requisitos estabelecidos na atividade Projeto $\underline{\text { do }} \underline{\mathrm{PN}}$.

Tendo em vista que teste de software em LP ainda não é uma etapa tão madura quanto às demais etapas de LP, não é utilizada uma abordagem específica no processo DynPL4BPM e, portanto, não será apresentado um exemplo ilustrativo nesta seção.

\footnotetext{
${ }^{13}$ Prefixos e Namespaces usados no exemplo foram baseados em Vedamuthu et al. (2006).
} 


\subsection{Engenharia de Aplicação}

Nas subseções a seguir, são apresentados os exemplos referentes ao processo "Engenharia de Aplicação" do processo DynPL4BPM.

\subsubsection{Atividade "1.B - Refinamento do Modelo de Domínio do PN"}

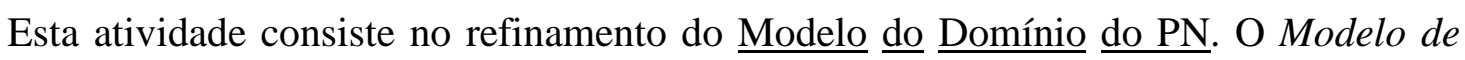
Característica criado na "Engenharia de Domínio" deve ser configurado para que o mesmo represente, em alto nível, as propriedades específicas do processo de negócio a ser criado para uma organização específica

Um exemplo de Modelo de Característica Configurado é apresentado na Figura 42. As características opcionais não selecionadas são apagadas do template. Como exemplo, temse as seguintes características: "Mídia", "Distribuição de Produtos e Serviços","Ofertas", "Interna" e "Tempo de Espera". A empresa específica aqui representada é AllSport, citada no exemplo motivacional (Subseção 1.1). 


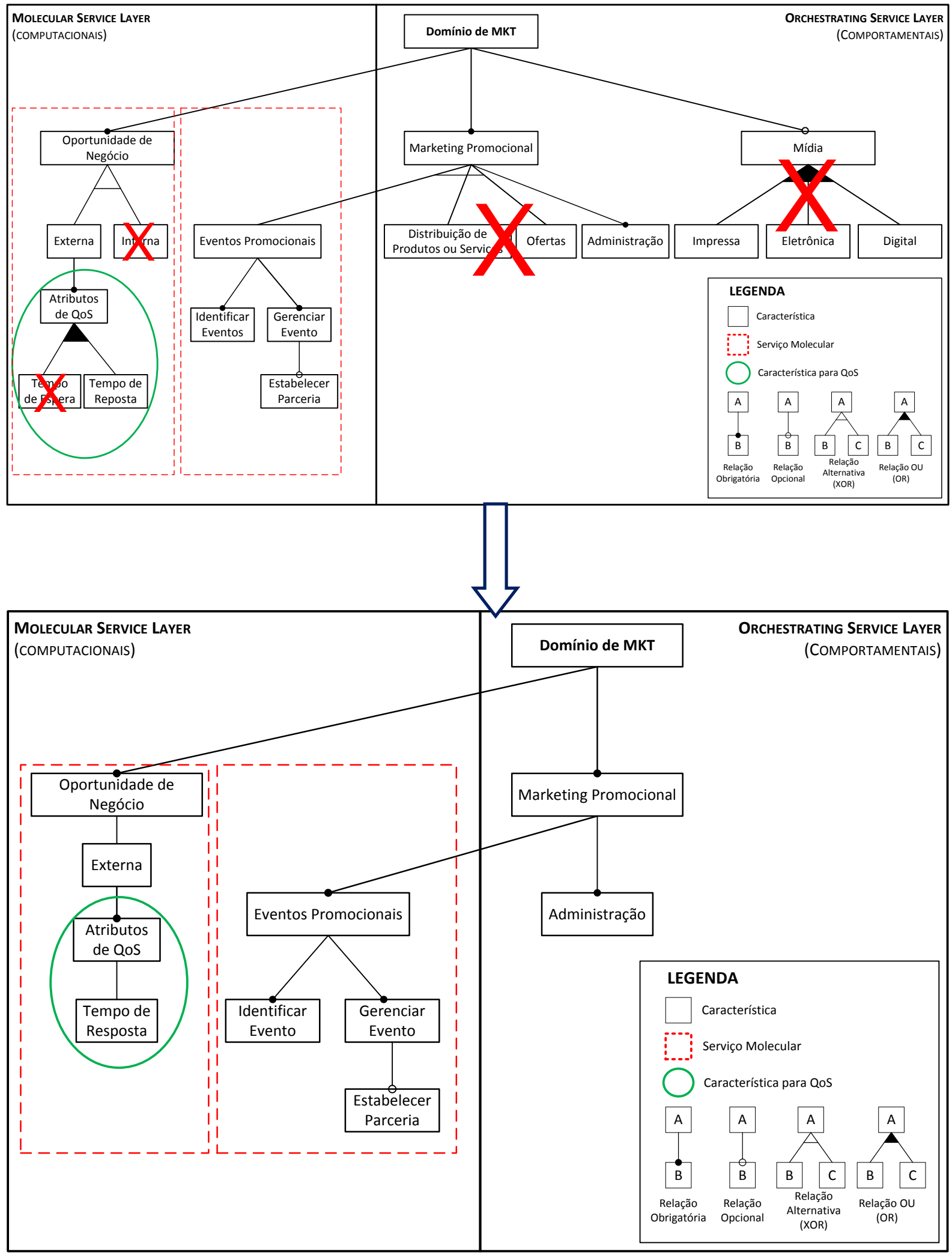

Figura 42 - Exemplo do Modelo de Características Configurado para uma organização específica 


\subsubsection{Atividade "2.B - Refinamento do Projeto do PN"}

Esta atividade consiste no refinamento dos artefatos relacionados ao Projeto do $\underline{\text { PN. }}$ Assim, os dois artefatos inter-relacionados - Modelo de Processo de Negócio e Acordos em Nível de Negócio - são derivados considerando as características selecionadas no Modelo de Característica Configurado.

A Figura 43 ilustra o processo de geração do Modelo de Processo de Negócio Configurado. Nota-se que são mantidos no Modelo de Processo de Negócio Configurado todos os elementos associados às características obrigatórias ou as características opcionais e/ou alternativas selecionadas durante a configuração do modelo de características. As características opcionais e/ou alternativas não selecionadas no Modelo de Características Configurado foram removidas do template.

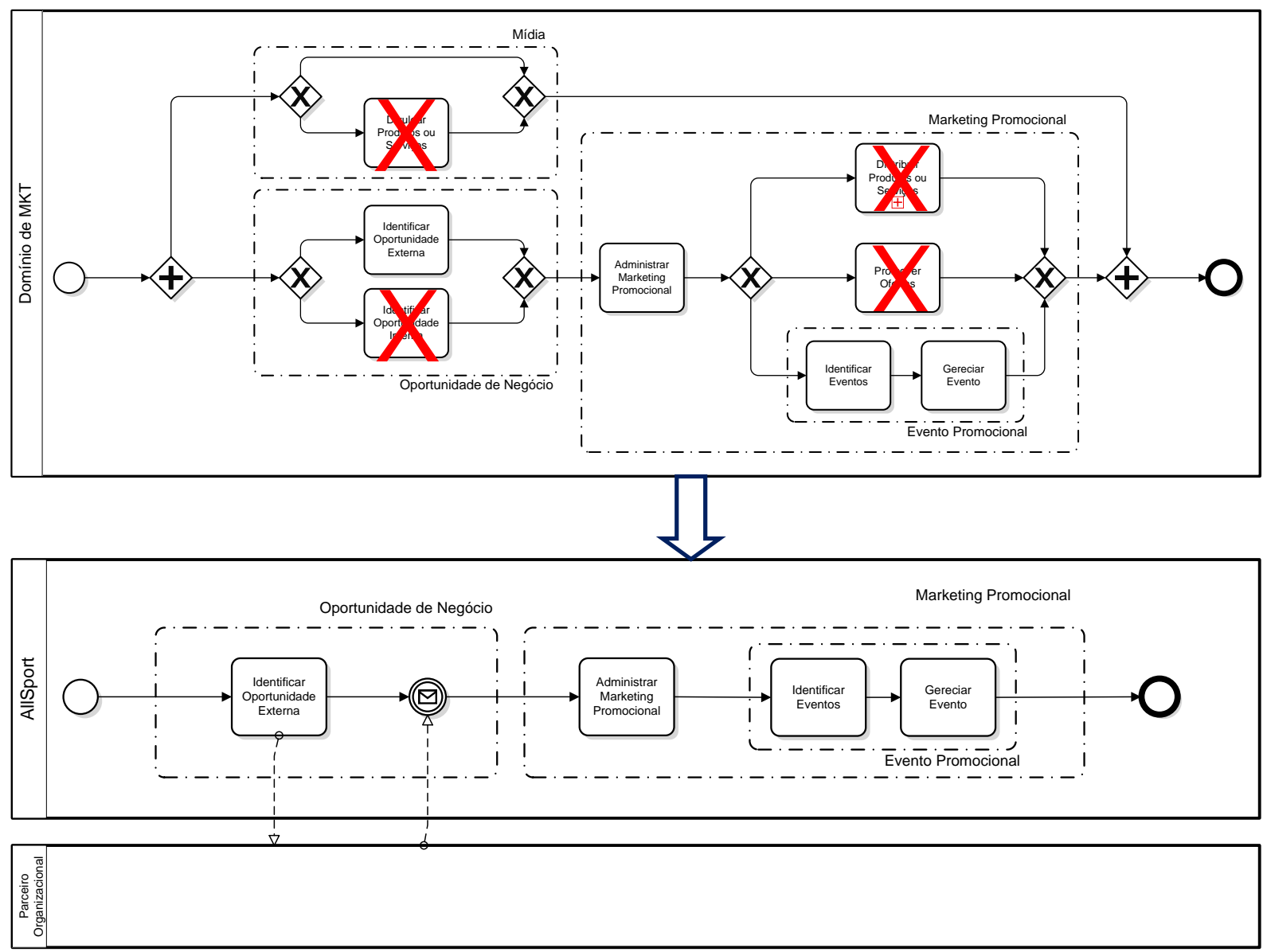

Figura 43 - Modelo de Processo de Negócio Configurado 


\subsubsection{Atividade "3.B - Refinamento da Implementação do PN"}

Essa atividade consiste na transformação dos artefatos gerados na atividade anterior em artefatos que permitam a execução do processo de negócio. Os artefatos inter-relacionados - Processo de Negócio Executável e Acordos em Nível de Serviço - são utilizados como templates, conforme ilustração da Figura 44.
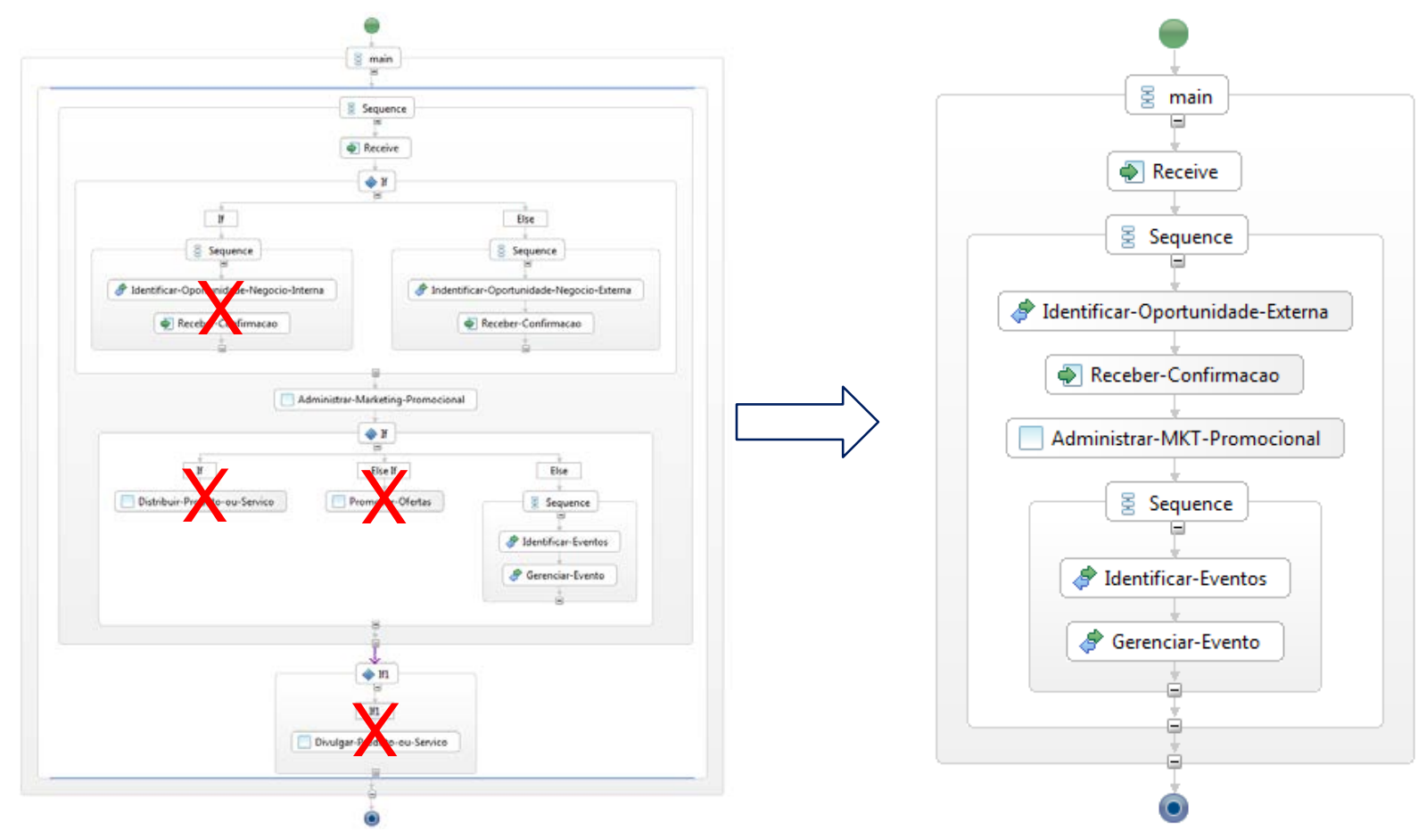

Figura 44 - Representação Gráfica do Processo de Negócio Executável Configurado em WSBPEL para uma organização específica

Conforme apresentado na Figura 44, são mantidos no Processo de Negócio Executável Configurado todos os elementos associados às características obrigatórias ou as características opcionais e/ou alternativas selecionadas durante a configuração do modelo de características. As características opcionais e/ou alternativas não selecionadas no Modelo de Características Configurado foram removidas do template, o que resulta no Processo de Negócio Executável Configurado. 


\subsubsection{Atividade "4.B - Refinamento da Validação do PN"}

Essa atividade consiste na validação dos artefatos Processo de Negócio Executável Configurado e Acordos em Nível de Serviço Configurados, visando garantir que eles estão de acordo com os requisitos estabelecidos na atividade Refinamento do Projeto Domínio do PN.

Tendo em vista que teste de software em LP ainda não é uma etapa tão madura quanto às demais etapas de LP, não é utilizada uma abordagem específica no processo DynPL4BPM e, portanto, não será apresentado um exemplo ilustrativo nesta seção. 


\section{Comparação da Abordagem DynPL4BPM}

Experimentação é sempre necessária e útil para avaliar a introdução de novas tecnologias, processos ou ferramentas na indústria. O método experimental tem sido amplamente usado para avaliação de novas abordagens da área de Engenharia de Software. Travassos et al. (2002) afirmam que novos métodos, técnicas, ferramentas, processos não deveriam ser colocados em produção sem experimentação e validação.

Frequentemente, experimentação em Engenharia de Software é feita por meio de estudos de caso (BASILI, 1996; KITCHENHAM; PICKARD; PFEEGLER, 1995), pois eles auxiliam na mensuração dos potenciais benefícios no uso das tecnologias, processos e/ou ferramentas sendo propostos ou avaliados. Para a realização de um estudo de caso experimental de forma sistemática, as seguintes etapas devem ser realizadas (YIN, 2008): (i) identificação de contexto; (ii) definição das hipóteses; (iii) seleção de projeto piloto; (iv) identificação de método de comparação; (v) redução de efeitos de fatores de distorção; (vi) planejamento; (vii) execução; (viii) análise dos resultados.

Analisando as etapas envolvidas na realização sistemática de um estudo de caso, a avaliação da abordagem proposta neste trabalho nesses moldes se mostrou inviável dentro do escopo deste projeto de mestrado. O processo da abordagem DynPL4BPM aqui proposta é bastante amplo, levando em consideração três processos e um conjunto de 12 atividades, cada um deles com um conjunto de artefatos sendo consumido e produzido. Portanto, a realização de um experimento que avalie tanto a viabilidade da abordagem proposta, quanto seus possíveis benefícios ou vantagens e suas possíveis limitações ou desvantagens, em um ambiente organizacional real ou mesmo em um ambiente simulado, produzindo artefatos mais próximos do real além do que os produzidos como exemplo e apresentados nessa dissertação, mostrou-se de escopo muito amplo para ser realizado juntamente com este projeto. Embora seja perfeitamente entendível a necessidade de uma experimentação mais aprofundada do processo DynPL4BPM, entende-se também que a mesma deveria ser realizada dentro do escopo de um novo projeto, o que será apresentado como sugestões de trabalhos futuros nas conclusões desta dissertação.

No entanto, assim é ainda necessário realizar uma avaliação sistemática para a abordagem sendo proposta aqui, pois ainda resta o compromisso de que nenhuma técnica, ferramenta e/ou processo - relacionados ao desenvolvimento de software - podem ser apenas sugeridos ou publicados sem qualquer tipo de avaliação (TRAVASSOS et al., 2002). 
Considerando essa diretriz, e para avaliar os potenciais benefícios da abordagem proposta foi realizada uma comparação sistemática da abordagem DynPL4BPM com outras abordagens já propostas na literatura para fins similares. Nesta comparação realizou-se uma análise dos trabalhos com a finalidade de se chegar a conclusões práticas, por meio dos atributos de comparação estabelecidos.

Nas seções a seguir são apresentados os mecanismos usados para essa avaliação e seus resultados. Mais especificamente, as seguintes seções são apresentadas: Seção 5.1 apresenta o método da avaliação; a Seção 5.2 apresenta os resultados da avaliação; e na Seção 5.3 é realizada a análise dos resultados.

\subsection{Método de Avaliação}

O método consiste em avaliar sistematicamente a abordagem DynPL4BPM a partir de um esquema de classificação, criado por meio de uma série de atributos específicos, que possibilita a categorização e comparação da abordagem proposta com trabalhos relacionados.

Trata-se de uma Avaliação Sistemática, pois a seleção das publicações similares abordagens de LPS para BPM - foi realizada por meio de uma Revisão Sistemática da Literatura (RS), usando as diretrizes propostas por Kitchenham (2007). A RS não foi criada com o objetivo de avaliar a abordagem DynPL4BPM, mas foi considerada útil considerando os objetivos apresentados no início desta Seção.

Uma RS é um método bastante rigoroso e é indicado para capturar estudos primários sobre determinado assunto ou área (KITCHENHAM, 2007). Uma RS envolve vários passos, os quais podem ser agrupados em três fases principais: (i) planejamento da revisão; (ii) condução da revisão e (iii) publicação dos resultados.

No planejamento da RS, elaborou-se o protocolo de pesquisa, que organiza e possibilita a reprodução dos seus passos (BIOLCHINI et al., 2005). A partir desse protocolo, foram criadas strings de busca na língua inglesa, buscando cercar o tema em estudo com o máximo possível de termos. Essas strings foram adaptadas e aplicadas em duas bases eletrônicas indexadas: Scopus ${ }^{14}$ e Web of Science $(\mathrm{WoS})^{15}$ que incluem registros das principais conferências e dos principais periódicos publicados em bibliotecas digitais tais como Springer, ACM e IEEE e para outros importantes veículos indexados.

\footnotetext{
${ }^{14}$ http://www.scopus.com

${ }^{15}$ http://apps.isiknowledge.com
} 
Na fase de condução da RS, as strings de busca adaptadas foram submetidas às bases de dados eletrônicas para identificação de estudos relevantes. Após a identificação foram aplicados os critérios de inclusão e exclusão para selecionar os estudos primários, considerando as questões de pesquisas definidas na fase de planejamento. Também foi realizada uma avaliação da qualidade desses estudos primários; por fim, para a extração e síntese dos dados, todos os trabalhos passaram por uma leitura mais aprofundada, buscando principalmente responder às questões de pesquisa levantadas na fase de planejamento.

Como resultado dessa revisão, 34 trabalhos foram selecionados como estudos primários conforme os critérios estabelecidos. Desses estudos primários, apenas seis tratam os aspectos dinâmicos específicos no contexto avaliado.

Ainda relacionado ao método de avaliação, trata-se de uma Avaliação Comparativa, pois foi estabelecida uma série de critérios objetivos, a fim de criar um esquema de classificação para então comparar os estudos primários com a abordagem proposta nesta dissertação. O esquema de classificação foi inspirado na metodologia incorporada ao Mapeamento Sistemático (MS) realizado para identificar trabalhos de LP para SOA (ROCHA; FANTINATO; BARROS, 2012). A metodologia usada para a criação do esquema de classificação consiste em (PETERSEN et al., 2008): (i) analisar o resumo dos artigos relevantes para extrair um “esquema de classificação” para os trabalhos, possibilitando o início dos agrupamentos; (ii) iniciar a classificação dos artigos dentro desse esquema, que pode evoluir - aumentando ou diminuindo os critérios - em função de uma leitura mais aprofundada de tais trabalhos.

Considerando o domínio para o qual a RS foi realizada - domínio de LP para BPM foi necessário criar um esquema de classificação que cobrisse tanto os aspectos de BPM, quanto os aspectos de LP, além dos aspectos dinâmicos. Para BPM foram estabelecidos como critérios as fases do ciclo de vida de BPM (Figura 2), que são (WESKE, 2007): Projeto e Análise; Configuração; Execução e Avaliação. Em relação aos critérios de LP, foram considerados os seguintes princípios: "Engenharia de Domínio"; "Engenharia de Aplicação"; Arquitetura da LP e Gestão de Variabilidades, além da técnica para gestão de variabilidades em LP: Modelo de Características.

Na RS não foi previsto o detalhamento dos aspectos dinâmicos da LPD. A RS estava preocupada apenas em verificar se os estudos primários fazia algum tipo de referência explícita a LPD, ou seja, se os termos “runtime” ou “dynamic” apareciam nos estudos primários selecionados. Tendo em vista esta limitação, foi necessário estabelecer algum tipo de critério para esta avaliação, com o objetivo de definir os critérios para que os trabalhos 
selecionados pudessem ser avaliados em relação às conceitos e/ou propriedades de LPD. Assim, as nove propriedades propostas por Hallsteinsen et al. (2008) foram adequadas a esse propósito e, portanto, incorporadas no esquema de classificação. O resultado desse esquema de classificação está apresentado na Tabela 1. A partir desse esquema de classificação proposto, foi possível estabelecer comparações entre as publicações e a abordagem DynPL4BPM. Os resultados da avaliação serão apresentados na Subseção 5.2.

\subsubsection{Seleção dos Trabalhos}

Como apresentado na Seção 5.1, na RS de LP para BPM foram selecionados um total de 34 estudos primários. No entanto, na mesma RS estabeleceu-se uma classificação adicional em termos de “Grupo de Autores”. Considerando essa classificação adicional e após uma análise mais aprofundada desses 34 trabalhos identificados inicialmente, chegou-se ao total de 23 trabalhos independentes.

Um dos resultados da RS é que ainda não foram propostas abordagens de LP no domínio de BPM que contempla as quatro fases do ciclo de vida de BPM, e dos 23 trabalhos, nenhum incorpora a fase "Avaliação" na LP para BPM proposta. Considerando essa limitação das abordagens, para essa avaliação comparativa com a abordagem DynPL4BPM sendo proposta aqui, foram selecionados apenas estudos primários que cobriam parcialmente o ciclo de BPM, ou seja, deveria pelo menos cobrir as três fases do ciclo de BPM - Projeto e Análise, Configuração e Execução. Assim, chegou-se a um conjunto de 12 trabalhos, que são as abordagens que mais se aproximam da abordagem DynPL4BPM e, portanto, seria uma comparação adequada.

Uma exceção à regra estabelecida é que se o estudo primário tratasse de aspecto dinâmico ele poderia ser incluído, mesmo não tratando daquelas três fases iniciais do ciclo de vida de BPM. Por fim, considerando todos os critérios apresentados, chegou-se a um total de 14 trabalhos que serão apresentados na Tabela 1. 
Tabela 1 - Comparação entre abordagens similares à abordagem DynPL4BPM

\begin{tabular}{|c|c|c|c|c|c|c|c|c|c|c|c|c|c|c|c|c|c|c|}
\hline \multirow{2}{*}{ Estudos Primários } & \multicolumn{4}{|c|}{$\begin{array}{c}\text { Ciclo de } \\
\text { Vida de BPM }\end{array}$} & \multicolumn{5}{|c|}{$\begin{array}{c}\text { Princípios e } \\
\text { Técnicas de LPS }\end{array}$} & \multicolumn{9}{|c|}{$\begin{array}{c}\text { Aspectos Dinâmicos } \\
\text { (Hallsteinsen et al., 2008) }\end{array}$} \\
\hline & F01 & F02 & F03 & F04 & $P 01$ & P02 & $P 03$ & P04 & T01 & A01 & A02 & A03 & A04 & $A 05$ & A06 & A07 & A08 & $A 09$ \\
\hline Altintas e Cetin (2006) & $\mathrm{x}$ & & & & & & $\mathrm{x}$ & & & & & & $\mathrm{x}$ & $\mathrm{x}$ & & $\mathrm{x}$ & $\mathrm{x}$ & $\mathrm{x}$ \\
\hline Bae e Kang (2007) & $\mathrm{x}$ & $\mathrm{x}$ & $\mathrm{x}$ & & $\mathrm{x}$ & $\mathrm{x}$ & $\mathrm{x}$ & $\mathrm{x}$ & $\mathrm{x}$ & & & & & & & & & \\
\hline Bayer, Kose e Ocampo (2006) & $\mathrm{x}$ & $\mathrm{x}$ & $\mathrm{X}$ & & $\mathrm{x}$ & $\mathrm{X}$ & & & & & & & & & & & & \\
\hline Gimenes, Fantinato e Toledo (2008) & $\mathrm{x}$ & $\mathrm{x}$ & $\mathrm{X}$ & & $\mathrm{x}$ & $\mathrm{X}$ & $\mathrm{x}$ & $\mathrm{x}$ & $\mathrm{x}$ & & & & & & & & & \\
\hline Gimenes et al. (2003) & $\mathrm{x}$ & $\mathrm{x}$ & $\mathrm{x}$ & & $\mathrm{x}$ & $\mathrm{x}$ & $\mathrm{x}$ & $\mathrm{x}$ & & & & & & & & & & \\
\hline Keuler et al. (2005) & $\mathrm{x}$ & $\mathrm{x}$ & $\mathrm{x}$ & & & & & $\mathrm{x}$ & & & & & & & & & & \\
\hline Leitner e Kreiner (2010) & $\mathrm{x}$ & $\mathrm{x}$ & $\mathrm{x}$ & & $\mathrm{x}$ & $\mathrm{x}$ & $\mathrm{x}$ & $\mathrm{x}$ & $\mathrm{x}$ & & & & & & & & & \\
\hline Montero, Pena e Ruiz-Cortés (2008a) & $\mathrm{x}$ & $\mathrm{x}$ & $\mathrm{x}$ & & & & & $\mathrm{x}$ & $\mathrm{x}$ & $\mathrm{x}$ & & $\mathrm{x}$ & & & & & & \\
\hline Nguyen e Colman (2010) & $\mathrm{x}$ & $\mathrm{X}$ & & & $\mathrm{x}$ & $\mathrm{x}$ & $\mathrm{x}$ & $\mathrm{x}$ & $\mathrm{x}$ & $\mathrm{x}$ & & $\mathrm{x}$ & & & & & & \\
\hline Schulz-Hofen e Golega (2006) & $\mathrm{x}$ & $\mathrm{x}$ & $\mathrm{x}$ & & $\mathrm{x}$ & $\mathrm{x}$ & $\mathrm{x}$ & $\mathrm{x}$ & $\mathrm{x}$ & $\mathrm{x}$ & & & & & & & & \\
\hline Siy, Wolfson e Zand (2011) & $\mathrm{x}$ & $\mathrm{x}$ & $\mathrm{x}$ & & $\mathrm{x}$ & $\mathrm{x}$ & $\mathrm{x}$ & $\mathrm{x}$ & $\mathrm{x}$ & & & & & & & & & \\
\hline Xu et al. (2009) & $\mathrm{x}$ & $\mathrm{x}$ & $\mathrm{x}$ & & & & $\mathrm{x}$ & & & & & & & & & & & \\
\hline Ye et al. (2007) & $\mathrm{x}$ & $\mathrm{x}$ & $\mathrm{x}$ & & $\mathrm{x}$ & $\mathrm{x}$ & $\mathrm{x}$ & $\mathrm{x}$ & & & & & & & & & & \\
\hline Zaupa et al. (2008) & $\mathrm{x}$ & $\mathrm{x}$ & $\mathrm{x}$ & & $\mathrm{x}$ & $\mathrm{x}$ & $\mathrm{x}$ & $\mathrm{x}$ & $\mathrm{x}$ & & & & & & & & & \\
\hline DynPL4BPM & $\mathbf{x}$ & $\mathbf{x}$ & $\bar{x}$ & $\mathbf{x}$ & $\mathbf{x}$ & $\mathbf{x}$ & $\mathbf{x}$ & $\bar{x}$ & $\mathbf{x}$ & $\mathbf{x}$ & $\mathbf{x}$ & $\mathbf{x}$ & $\mathbf{x}$ & $\mathbf{x}$ & & $\mathbf{x}$ & $\mathbf{x}$ & \\
\hline
\end{tabular}

\begin{tabular}{|c|c|c|c|}
\hline $\begin{array}{l}\text { LEGENDA: } \\
\text { F01 - Projeto e Análise } \\
\text { F02 - Configuração } \\
\text { F03 - Execução } \\
\text { F04 - Avaliação }\end{array}$ & $\begin{array}{l}\text { P01 - Engenharia de Domínio } \\
\text { P02 - Engenharia de Aplicação } \\
\text { P03 - Arquitetura da LP } \\
\text { P04 - Gestão de Variabilidades } \\
\text { T01 - Modelo de Características }\end{array}$ & $\begin{array}{l}\text { A01 - Variabilidade Dinâmica } \\
\text { A02 - Mudança de Vínculo } \\
\text { A03 - Mudança de Pontos de Variação } \\
\text { A04 - Tratamento de Mudanças Inesperadas } \\
\text { A05 - Tratamento de Mudanças dos Usuários }\end{array}$ & $\begin{array}{l}\text { A06 - Sensibilidade ao Contexto e Percepção da Situação } \\
\text { A07 - Propriedades Autônomas ou Autoadaptativas } \\
\text { A08 - Tomada de Decisão Automática } \\
\text { A09 - Ambiente / Situação de Contexto }\end{array}$ \\
\hline
\end{tabular}




\subsection{Resultados da Avaliação}

$\mathrm{Na}$ sequência serão apresentados os resultados da avaliação da abordagem DynPL4BPM. Mais especificamente, as seguintes subseções são apresentadas: Subseção 5.2.1 apresenta os resultados relacionados ao critério "Ciclo de BPM"; a Subseção 5.2.2 apresenta os resultados relacionados ao critério "Princípios e Técnicas de LP"; a Subseção 5.2.3 apresenta os resultados relacionados ao critério "Aspectos dinâmicos da LP".

\subsubsection{Ciclo de Vida de BPM}

De acordo com os dados apresentados na Tabela 1 e Figura 45, a fase "Avaliação" (F04) mostrou-se completamente fora do escopo das abordagens atuais. Para as outras fases do ciclo de vida de BPM, "Projeto e Análise" (F01), está presente em 100\% dos estudos primários, "Configuração" (F02) em 93\% e "Execução" (F03) em 86\% dos estudos primários.

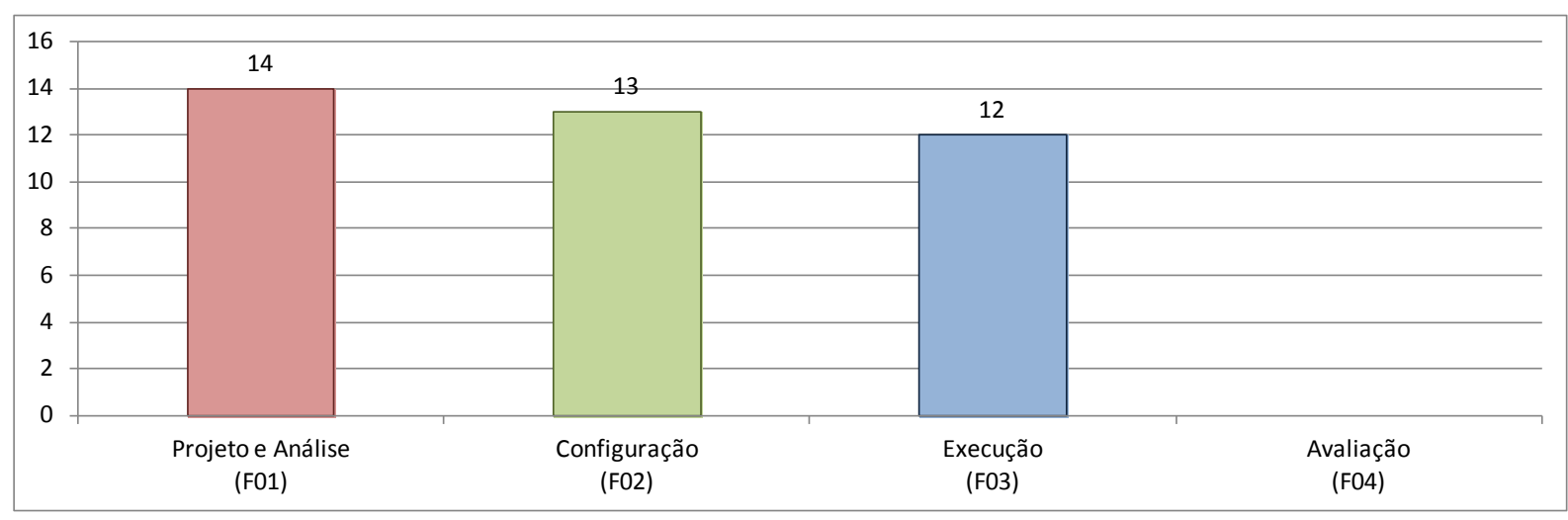

Figura 45 - Fases do ciclo de vida de BPM alcançadas quando princípios e técnicas de LP são aplicados neste domínio nos estudos primários

\subsubsection{Princípios e Técnicas de LP}

De acordo com os dados apresentados na Tabela 1 e Figura 46, a extração de dados e síntese encontrou evidências de aplicação nos estudos primários selecionados para os cinco princípios e a técnica de gestão de variabilidade de LP. 


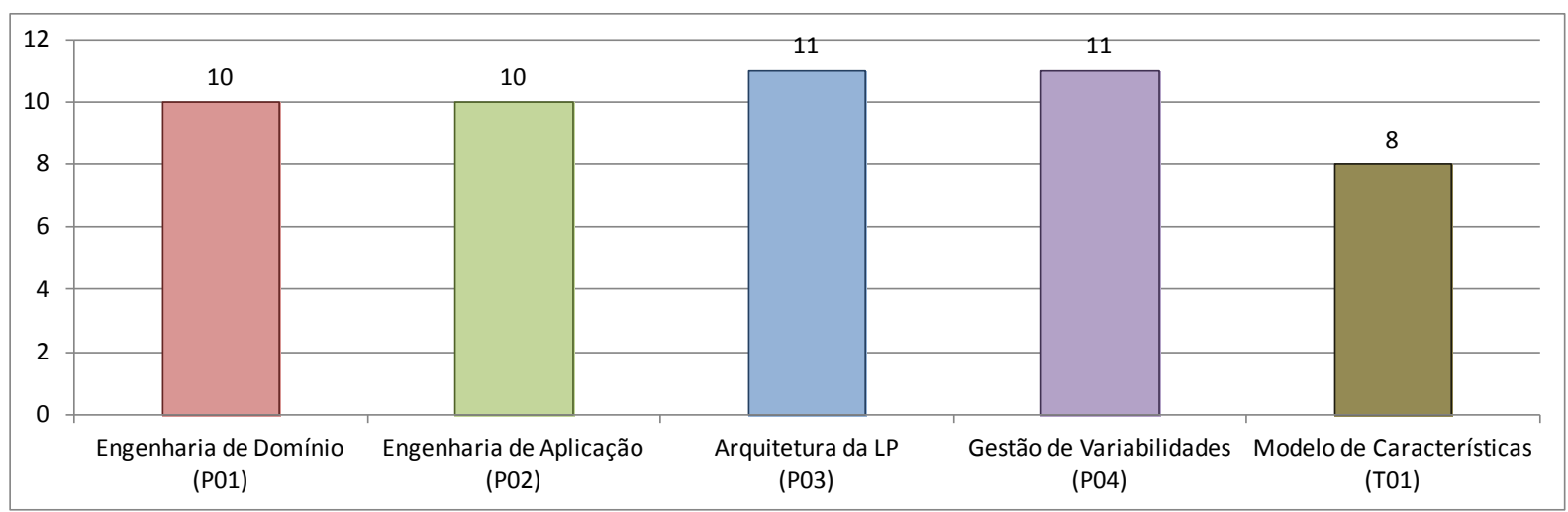

Figura 46 - Princípios e técnicas de LP aplicados ao domínio BPM nos estudos primários

"Arquitetura PL" (P03) e "Gestão de Variabilidade" (P04) foram os itens mais frequentes, ambos encontrados em 79\% dos estudos primários. Os segundo e terceiro itens mais frequentes foram "Engenharia de Domínio" (P01) e "Engenharia de Aplicação" (P02), ambos encontrados em $71 \%$ dos estudos primários. Por fim, apenas $57 \%$ do total usam a técnica "Modelos de Características" (T01).

\subsubsection{Aspectos Dinâmicos}

De acordo com os dados apresentados na Tabela 1 e Figura 47, "Variabilidade Dinâmica" (A01) foi o aspecto mais encontrado, porém com apenas 21\% do total dos estudos primários. O segundo item mais encontrado foi "Mudança de Pontos de Variação" (A03), com apenas $14 \%$ do total.

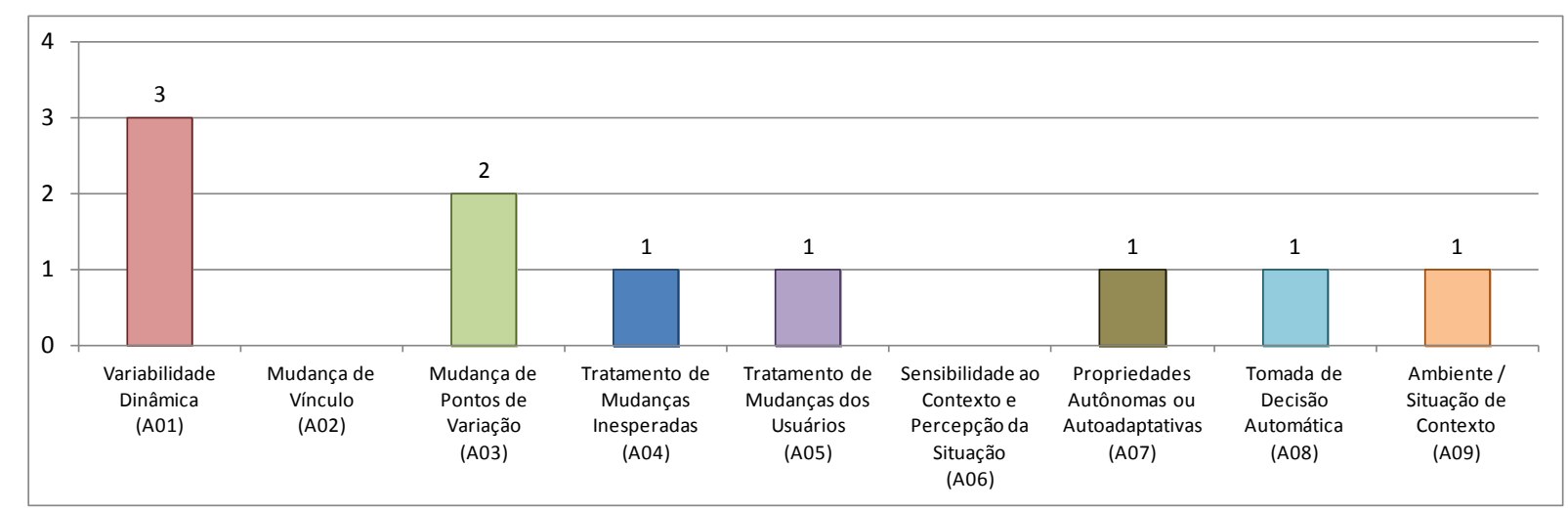

Figura 47 - Aspectos Dinâmicos de LP aplicados ao domínio de BPM nos estudos primários

Apenas um único estudo primário, que corresponde a 7\% do total de 14 trabalhos sendo avaliados nessa comparação, apresenta uma cobertura em diversos desses aspectos dinâmicos, incluindo "Tratamento de Mudanças Inesperadas" (A04), "Tratamento de 
Mudanças dos Usuários" (A05), "Propriedades Autônomas ou Autoadaptativas" (A07), "Tomada de Decisão Automática" (A08) e "Ambiente / Situação de Contexto" (A09).

Os aspectos dinâmicos "Mudança de Vínculo" (A02) e "Sensibilidade ao Contexto e Percepção da Situação" (A06) não foram tratados nos estudos primários selecionados.

\subsection{Análise dos Resultados}

Na sequência é apresentada a análise dos resultados apresentados na Subseção 5.2. Mais especificamente, as seguintes seções são apresentadas: Subseção 5.3 .1 apresenta uma análise dos resultados relacionados ao critério "Ciclo de BPM"; a Subseção 5.3.2 apresenta a análise dos resultados relacionados ao critério "Princípios e Técnicas de LP"; a Subseção 5.3.3 apresenta a análise dos resultados relacionados ao critério "Aspectos Dinâmicos".

\subsubsection{Ciclo de Vida de BPM}

Em relação ao critério "Ciclo de Vida de BPM", os resultados apresentados na Tabela 1 e Figura 45 indicam que as primeiras três fases do ciclo de vida de BPM - "Projeto e Análise", "Configuração" e "Execução" - são considerados nos estudos primários.

Não foram identificadas abordagens que tratam de "Avaliação" das IPNs. Uma possível justificativa para isso ainda não ser tratado nas abordagens atuais é que evolução em LP é complicada, pois a alteração de um único ativo pode afetar outros ativos e múltiplos produtos (MCGREGOR, 2003).

A abordagem DynPL4BPM propõe-se a realização da "Avaliação" ao mapeá-la para o

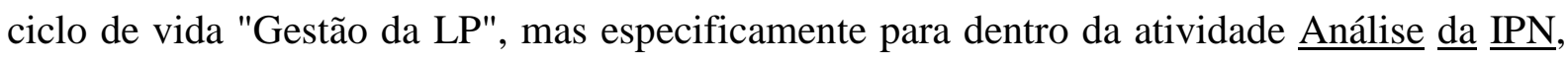
permitindo a sua realização de forma sistemática, por inseri-la no contexto de LP, e também de forma continua oferecendo a possibilidade de fechar todo o ciclo de vida de BPM. Até então, as abordagens de LP no domínio de BPM apenas realizam parcialmente o ciclo de BPM, chegando apenas à fase de "Execução".

\subsubsection{Princípios e Técnicas de LP}

Em relação ao critério "Princípios e Técnicas de LP", os resultados apresentados na Tabela 1 e Figura 46 indicam que os quatro princípios gerais de LP - Engenharia de Domínio; Engenharia de Aplicação, Arquitetura da LP e Gestão de Variabilidades - e a técnica para 
gestão de variabilidades em LP - Modelo de Características - são aplicadas ao domínio de BPM, considerando os 14 estudos primários selecionados nesta avaliação.

Os resultados mostram que a maioria dos trabalhos encontrados aplica princípios e técnicas relacionadas com a "Arquitetura da LP" e "Gestão de variabilidade", ambos os conceitos encontrados em 79\% dos estudos primários. Considerando os demais princípios ("Engenharia de Domínio", "Engenharia de Aplicação") e técnica de gestão de variabilidades ("Modelo de Características"), estes foram encontrados em um pouco mais da metade dos estudos primários - os dois princípios em $71 \%$ do total e técnica em 57\% do total dos estudos primários. Os estudos primários que apresentaram "Engenharia de Aplicação" também apresentaram "Engenharia de Domínio", conforme mostrado na Tabela 1. A cobertura, de acordo com os dados apresentados na Tabela 1, leva à conclusão de que os quatro princípios e técnica de gestão de variabilidades são comumente aplicados, em conjunto, nas abordagens LP para BPM. Apenas 43\% dos trabalhos cobrem todos os princípios - Engenharia de Domínio, Engenharia de Aplicação, Arquitetura da LP e Gestão de Variabilidades - e a técnica de gestão de variabilidades - Modelo de Características.

Como contribuição a este cenário, a abordagem DynPL4BPM incorpora os quatro princípios nos dois primeiro processos da abordagem - "Engenharia de Domínio" e "Engenharia de Aplicação".

\subsubsection{Análise Comparativa entre PL e BPM}

A Figura 48 apresenta a distribuição cruzada dos estudos primários levando em consideração “Fases do Ciclo de Vida de BPM Melhoradas pelos Princípios de LP” (no eixo horizontal) e "Princípios de LP Aplicados nos Estudos Primários” (no eixo vertical). O número dentro de cada círculo nas interseções representa o número de trabalhos que se enquadram em cada classificação bidimensional e o tamanho do círculo representa proporcionalmente o número de trabalho em cada interseção.

Com exceção da fase "Avaliação" do ciclo de vida de BPM, para qual não foi encontrado nenhum estudo primário que cobrisse tal fase, outros atributos estão distribuídos homogeneamente entre as interseções. Em média, há 10 estudos que cobrem ao mesmo tempo cada par de atributos definido em cada uma das possíveis interseções. 


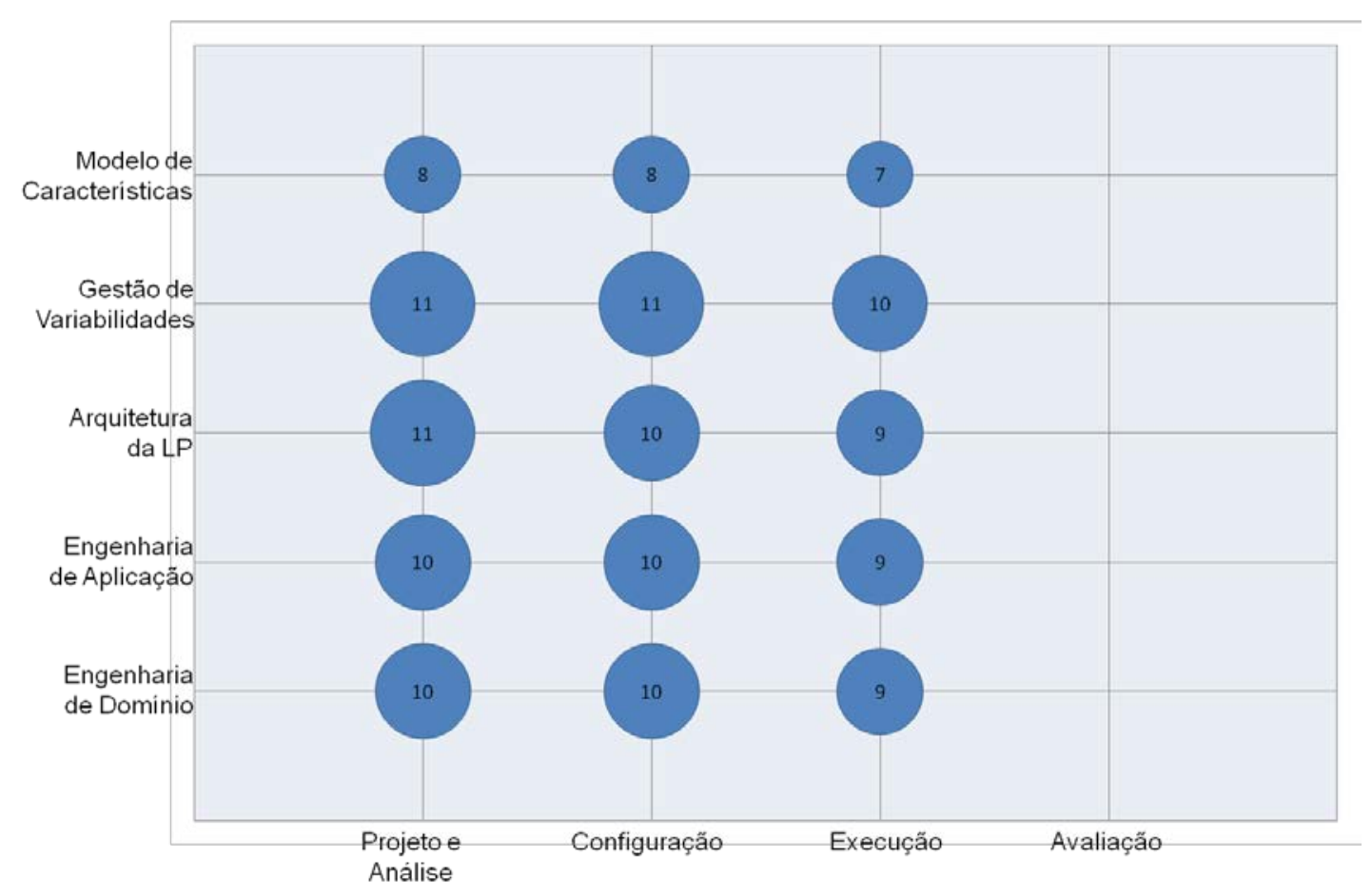

Figura 48 - Distribuição cruzada entre fases do ciclo de vida de BPM e princípios e técnicas de LP nos estudos primários

Desses estudos primários, 11 deles (o que representa 79\% do total) cobrem a interseção "Projeto e Análise" e "Gestão de Variabilidades", seguido por "Configuração" e "Gestão de Variabilidades" também com a mesma taxa de cobertura. A segunda interseção mais importante é a fase do ciclo de BPM "Execução" também usando a técnica de LP "Gestão de Variabilidades".

\subsubsection{Aspectos Dinâmicos}

Em relação ao critério "Aspectos Dinâmicos", os resultados apresentados na Tabela 1 e Figura 47 mostram que poucas abordagens apresentaram aspectos dinâmicos. Apenas três estudos primários identificados apresentam algum nível de aplicação de tais princípios ou técnicas, o que corresponde apenas $21 \%$ do total dos estudos primários.

Mais especificamente, apenas 21\% do total dos estudos primários identificados apresentaram o aspecto "Variabilidade Dinâmica" e, somente 14\% dos estudos primários apresentaram o aspecto "Mudanças de Ponto de Variação".

Considerando a afirmação de Hallsteinsen et al. (2008) que para ser considerada dinâmica, a LP deve possuir a maioria, senão todas, das propriedades apresentadas na Seção 4.2; pode-se, portanto, considerar que a DynPL4BPM é a que mais se aproxima de uma LPD, 
comparando com as outras abordagens apresentadas aqui, pois incorpora, pelo menos parcialmente, a maioria dos aspectos dinâmicos propostos por Hallsteinsen et al. (2008).

\subsection{Considerações Finais}

Neste capítulo foi apresentada uma comparação da abordagem DynPL4BPM. As principais contribuições desta abordagem foram: (i) definição de uma abordagem de LP para BPM, em alto nível, que contempla todo o ciclo de vida de BPM, principalmente, a fase "Avaliação" que não é coberta pelas outras abordagens; (ii) tratamento da maioria dos aspectos dinâmicos, propostos por Hallsteisen et al. (2008) em diferentes fases do ciclo de vida de BPM.

Um número esperado, contudo decepcionante foi o número de estudos primários que tratam de aspectos dinâmicos nos estudos primários analisados. Apenas três estudos primários dos 14 , representando $21 \%$ do total, foram classificados nesta categoria. Além de serem poucos estudos, os existentes são bastante limitadas, cobrindo apenas alguns aspectos dinâmicos de LP e apenas algumas etapas do ciclo de vida de BPM, conforme apresentado na Tabela 1 neste capítulo.

Como contribuição à área de pesquisa, a abordagem DynPL4BPM tenta cobrir a maioria dos aspectos apresentados, no entanto, é necessário o amadurecimento de conceitos e técnicas propostos pelas comunidades científicas de LP e BPM. Um exemplo é a fase "Avaliação" que ainda é pouco explorada, em ambas as áreas, e que necessita de investigações adicionais considerando, principalmente, a sua inserção no contexto de reúso sistemático.

No próximo capítulo são apresentadas as conclusões desta dissertação, incluindo um conjunto de lições aprendidas, bem como uma lista de trabalhos futuros. 


\section{Conclusões}

Para apoiar a adaptação dinâmica de processos de negócio, várias abordagens são propostas, inclusive o reúso sistemático, por meio dos princípios e técnicas de Linha de Produto de Software (LP) e Linha de Produto de Software Dinâmica (LPD). LP tem proporcionado redução de tempo e aumento da qualidade dos produtos, e quando aplicada no domínio de BPM torna possível, para alguns domínios de aplicação, a tão almejada flexibilidade na realização dos processos organizacionais.

Flexibilidade na realização dos processos organizacionais é o principal desafio que a abordagem DynPL4BPM buscou resolver. Assim, propriedades de LPD foram incorporadas, pelo menos parcialmente, nas atividades do processo DynPL4BPM, buscando alinhamento entre os paradigmas de BPM e SOA.

As principais contribuições desta abordagem foram: (i) definição de uma abordagem de LP para BPM, em alto nível, que contempla todo o ciclo de vida de BPM, principalmente, a fase "Avaliação" que não é coberta pelas outras abordagens; (ii) tratamento da maioria dos aspectos dinâmicos, propostos por Hallsteisen et al. (2008) em diferentes fases do ciclo de vida de BPM.

Relacionado à definição de um processo completo de LP para BPM, pode-se considerar que as abordagens relacionadas à DynPL4BPM, apresentadas no Capitulo 6 (Tabela 1), são consideradas LP para Workflow, levando em consideração que não foram identificadas, no contexto de LP, abordagens que tratam de "Avaliação" das IPNs; e, levando em consideração, de acordo com van der Aalst (2003), que a diferença estabelecida entre os conceitos de Workflow é BPM é a fase "Avaliação", ou seja, BPM estende as abordagens clássicas de Workflows, por meio da fase Avaliação. Assim, pode-se concluir que, a abordagem DynPL4BPM é um passo em direção à proposta de uma completa LP para BPM de fato.

Além disso, considerando que a inovação diz respeito à introdução de novidade ou aperfeiçoamento no ambiente produtivo ou social que resulte em novos produtos, processos ou serviços (BRASIL, 2004), pode-se também considerar que a abordagem DynPL4BPM trata-se de um processo de inovação, uma vez que propõe o aperfeiçoamento de uma abordagem de LP para BPM - processo PL4BPM - redefinindo-o para permitir uma gestão dinâmica completa dos processos de negócios. 


\subsection{Trabalhos Futuros}

Esta seção apresenta os principais trabalhos futuros a serem desenvolvidos como continuação do trabalho desenvolvido nesta dissertação:

- Avaliação da abordagem por meio de técnicas da Engenharia de Software Experimental: visando avaliar a viabilidade do processo DynPL4BPM, sugere-se usar técnicas de Engenharia de Software Experimental. Uma das abordagens que mais tem sido aplicada e que poderá ser usada neste projeto é o estudo de caso (KITCHENHAM; PICKARD; PFLEEGER, 1995; YIN, 2008). Assim, propõe-se a aplicação de um estudo de caso para obter resultados que possam ser analisados qualitativamente e, se possível, quantitativamente, como foi o projeto experimental de avaliação da abordagem PL4BPM realizada por Gonçalves et al. (2011). Para sua realização, as seguintes etapas devem ser realizadas: (i) identificação de contexto; definição das hipóteses; seleção de projeto piloto; identificação de método de comparação; redução de efeitos de fatores de distorção; planejamento; execução; análise dos resultados.

- Investigações adicionais: como trabalhos adicionais, uma área relacionada ao que está sendo proposto nesta dissertação é a reengenharia de processos de negócio, também conhecida como Business Process Redesign. Haveria, portanto, a necessidade de investigar trabalhos que tratam sobre este tema com o objetivo de melhorar os aspectos incorporados nas atividades do processo DynPL4BPM. Outra área é a fase "Avaliação" do ciclo de vida de BPM que ainda é pouco explorada nas abordagens de LP para BPM e, portanto, necessita de investigações adicionais considerando, principalmente, a sua inserção nesse contexto de reúso sistemático. As propriedades de LPD - "Sensibilidade ao Contexto" e "Ambiente/Situação de Contexto" também deverão ser investigadas, pois estão relacionadas à adaptação dinâmica dos processos de negócio.

- Desenvolvimento de conjunto de ferramentas: uma proposta para trabalhos futuros seria o desenvolvimento de um conjunto de ferramentas que permita o 
apoio automatizado aos diversos artefatos produzidos e consumidos pelo processo DynPL4BPM. 


\section{Referências}

AALST, W. M. P van der. Process-Aware Information Systems: Lessons to Be Learned from Process Mining. In: JENSEN, K.; AALST, W. M. P. van der (Eds.). Transactions on Petri Nets and Other Models of Concurrency II, Springer-Verlag, 2009, p. 1-26.

AALST, W. M. P. van der. Process Modeling and Analysis: Process Mining. Springer Berlin Heidelberg, 2011.

AALST, W. M. P. van der; HOFSTEDE, A. H. M. ter; WESKE, M. Business process management: A survey. In: INT. CONFERENCE ON BUSINESS PROCESS MANAGEMENT, 1, 2003. Proceedings... [S. l.]: Springer, 2003. v. 2678 of LNCS. p. 10191019.

AALST, W. M. P. van der; PESIC, M. Specifying and Monitoring Service Flows: Making Web Services Process-Aware In: BARESI, L.; NITTO, E. D. (ed.) Test and Analysis of Web Services. Springer, 2007, p. 11-55.

ADAM, S.; DOERR, J. How to better align BPM \& SOA-Ideas on improving the transition between process design and deployment. In: WORKSHOP ON BUSINESS PROCESS MODELING, DEVELOPMENT AND SUPPORT, 9, 2008, Montpellier, France. Proceedings... [S. 1.]: 2008, v. 335, 2008. p. 49-51.

ALONSO, G.; CASATI, F.; KUNO, H.; MACHIRAJU, V. Web Services: Concepts, Architectures and Applications. 1. ed. Springer, 2004.

ALTINTAS, N. I.; CETIN, S. Integrating a software product line with rule-based business process modeling In: VLDB Workshop Trends in Enterprise Application Architecture, Springer-Verlag, 2008. Proceedings... [S.l]: 2008, p. 15-28.

ANDRIEUX, A. et al. Web Services Agreement Specification (WS-Agreement). 2007. Disponível em: <http://www.ogf.org/documents/GFD.192.pdf>. Acesso em: dez. 2011.

BACHMANN, F.; BASS, L. Managing variability in software architectures. In: SYMPOSIUM ON SOFTWARE REUSABILITY, 2001, New York. Proceedings... [S. 1.]: ACM, 2001. p.126-132.

BAE, J.; KANG, S. A method to generate a feature model from a business process model for business applications In: International Conference on Computer and Information Technology, 2007. Proceedings... [S.l.]: IEEE Computer Society, 2007, p. 879-884.

BALDAM, R.; VALLE, R.; PEREIRA, H. et al. Gestão de processos de negócio: BPM Business process management. 2. ed. São Paulo: Érica, 2007.

BARESI, L., GUINEA, S. AND PLEBANI, P. WS-Policy for service monitoring. In: 6th VLDB INT. WORKSHOP ON TECHNOLOGIES FOR E-SERVICES, Proceedings... [S.l]: Springer, 2006, v. 3811 of LNCS, p. 72-83. 
BARESI, L.; GUINEA, S. \& PASQUALE, L. Towards a unified framework for the monitoring and recovery of BPEL processes. In: Workshop on Testing, analysis, and verification of web services and applications, 2008. Proceedings... New York: ACM, 2008, p. 15-19.

BASILI, V. R. The role of experimentation in software engineering: past, current, and future In: International Conference on Software Engineering, 18, 1996. Proceedings... [S.l]: IEEE Computer Society, 1996, p. 442-449.

BAYER et al. Process Family Engineering: Modeling variant-rich processes. BMBF-Project, 2005 (TR 18/2005).

BAYER, J.; FLEGE, O.; KNAUBER, P. et al. PuLSE: a methodology to develop software product lines. In: SYMPOSIUM ON SOFTWARE REUSABILITY, 1999, Los Angeles. Proceedings... [S. 1.]: ACM, 1999. p.122-131.

BAYER, J.; KOSE, M.; OCAMPO, A. Improving the development of e-business systems by introducing process-based software product lines In: International Conference on ProductFocused Software Process Improvement, 7, 2006. Proceedings... Springer-Verlag, 2006, 348-361

BIOLCHINI, J.; MIAN, P. G.; NATALI, A. C. C.; TRAVASSOS, G. H. Systematic Review in Software Engineering. Technical Report RT-ES 679/05, System Engineering and Computer Science Dept., COOPE/UFRJ, 2005. 30 p.

BRASIL. Lei n. ${ }^{\circ}$ 10.973, de 2 de dezembro de 2004. Dispõe sobre incentivos à inovação e à pesquisa científica e tecnológica no ambiente produtivo e dá outras providências. Diário Oficial da União, Brasília , DF, 03 nov. 2004. Seção 1, p. 2.

BURÉGIO, V. A.; ALMEIDA, E. S.; DE LEMOS MEIRA, S. R. Characterizing Dynamic Software Product Lines A Preliminary Mapping Study. In: INT. WORKSHOP ON DYNAMIC SOFTWARE PRODUCT LINES, 4, 2010, Jeju Island. Proceedings... [S. l.]: Springer, 2010. p.53-60.

BUTLER, P., HALL, T. W., HANNA, A. M., MENDONCA, L., AUGUSTE, B., MANYIKA, J. AND SAHAY, A. A Revolution in Interaction. McKinseyQ, 1997(1), p. 4-23.

CHANG, S. H.; KIM, S. D. A Variability Modeling Method for Adaptable Services in Service-Oriented Computing. In: INT. SOFTWARE PRODUCT LINE CONFERENCE, 11, 2007, Kyoto, Japan. Proceedings... Los Alamitos, CA, USA: IEEE Computer Society, 2007. p. 261-268.

CLEMENTS, P.; NORTHROP, L. Software Product Lines: Practices and Patterns. 3. ed. Addison-Wesley Professional, 2001.

CORRÊA; C. K. F. EvolManager: Uma Abordagem para o Controle de Evolução Consistente de Linhas de Produtos de Software Dirigidas por Modelos. Universidade Federal do Rio de Janeiro (Relatório Técnico), 2011. Disponível em: <http://reuse.cos.ufrj.br/files/publicacoes/ qualificacao/QF_Chessman.pdf>. Acesso em: jul. 2012. 
DIKMANS, L. Transforming BPMN into BPEL: Why and How. 2008. Disponível em: <http://www.oracle.com/technetwork/articles/dikmans-bpm-101437.html>. Acesso em: jul. 2012.

FANTINATO, M. Linha de produto dinâmica para gestão de processos de negócio baseados em serviços. 2009. Disponível em: <http://www.bv.fapesp.br/pt/projetos-jovenspesquisadores/5764/linha-produto-dinamica-gestao-processos/>. Acesso em: jan. 2012.

FANTINATO, M. Uma abordagem baseada em características para o estabelecimento de contratos eletrônicos para serviços web. 2007, 214 f. Tese (Doutorado em Computação) Instituto de Computação, Universidade Estadual de Campinas, Campinas, 2007.

FANTINATO, M.; GIMENES, I. M. de S.; TOLEDO, M. B. F. Product Line in the Business Process Management Domain. In: KANG, K. C.; SUGUMARAN, V.; PARK, S. (Orgs.); Applied Software Product Line Engineering. 1st ed. Boca Raton, FL: Auerbach Publications, 2010, p.497-530.

FANTINATO, M.; TOLEDO, M. B. F.; GIMENES, I. M. de S. A Feature-based Approach to Electronic Contracts. In: IEEE INT. CONF. ON E-COMMERCE TECHNOLOGY AND IEEE INT. CONF. ON ENTERPRISE COMPUTING, E-COMMERCE, AND E-SERVICES, 2006, San Francisco, California. Proceedings... Washington, DC, USA: IEEE Computer Society, 2006. p.34.

FLUEGGE, M.; SANTOS, I. J. G.; TIZZO, N. P.; MADEIRA, E. R. M. Challenges and techniques on the road to dynamically compose web services In: 6th international conference on Web engineering, 2006. Proceedings... New York: ACM, 2006, p. 40-47.

FUCHSLOCH, A. AND HOYER, V. Implementing Cross-Organizational Business Processes with Enterprise Mashups: Hype or Reality?. In: AMCIS, 2010. Proceedings... [S.l.]: Association for Information Systems, 2010. p. 165.

GALSTER, M. Describing variability in service-oriented software product lines. In: EUROPEAN CONFERENCE ON SOFTWARE ARCHITECTURE, 4, 2010, Copenhagen, Denmark. Proceedings... New York: ACM, 2010. p.344-350.

GHEZZI, C.; GUINEA, S. Run-Time Monitoring in Service-Oriented Architectures. In: BARESI, L.; NITTO, E. D. (ed.). Test and Analysis of Web Services. Springer, 2007, p. 237-264.

GIMENES, I. M. de S.; TRAVASSOS, G. H. O enfoque de Linha de Produto para Desenvolvimento de Software. In: XXI JAI. Livro Texto. Florianópolis: Sociedade Brasileira de Computação, 2002.

GIMENES, I.; FANTINATO, M.; TOLEDO, M. A Product Line for Business Process Management. In: Int. Software Product Line Conference, 12, 2008, Limerick, Ireland. Proceedings... Washington, DC, USA: IEEE Computer Society, 2008. p.265-274.

GIMENES, I.; JUNIOR, E.; LAZILHA, F.; BARROCA, L. A product line architecture for workflow management systems with component-based development. In: IEEE International Conference on Information Reuse and Integration, 2003. Proceedings... [S.l]: IEEE Computer Society, 2003, p. 112 - 119. 
GOMAA, H.; SALEH, M. Software product line engineering for Web services and UML. In: INT. CONFERENCE ON COMPUTER SYSTEMS AND APPLICATIONS, 2005, Cairo, Egypt. Proceedings... Washington, DC, USA: IEEE Computer Society, 2005. p.110.

GONÇALVES, T. L.; GIMENES, I.M. de S.; FANTINATO, M.; TRAVASSOS, G. H.; TOLEDO, M. B. F. Experimental studies of e-contract establishment in the PL4BPM context. Int. Journal of Web Engineering and Technology, v. 6, n. 3, p. 243-265, 2011.

GRONER, G.; WENDE, C.; BOSKOVIC, M.; SILVA PARREIRAS, F.; WALTER, T.; HEIDENREICH, F.; GASEVIC, D.; STAAB, S. Validation of Families of Business Processes In: MOURATIDIS, H.; ROLLAND, C. (Eds.). Advanced Information Systems Engineering, Springer, 2011, v. 6741, p. 551-565.

GUDGIN, M.; HADLEY, M.; MENDELSOHN, N. et al. SOAP Version 1.2 Part 1: Messaging Framework (Second Edition). W3C Recommendation, W3C, 2007. Disponível em: <http://www.w3.org/TR/soap12-part1/>. Acesso em: dez. 2011.

HALLSTEINSEN, S.; HINCHEY, M.; PARK, S.; SCHMID, K. Dynamic software product lines. Computer, v. 41, n. 4, p. 93-95, 2008.

JURIC, M. B.; PANT, K. Business Process Driven SOA using BPMN and WS-BPEL: From Business Process Modeling to Orchestration and Service Oriented Architecture. Birmingham: Packt Publishing, 2008.

KANG, D.; BAIK, D. K. Bridging Software Product Lines and Service-Oriented Architectures for Service Identification Using BPM and FM. In: INT. CONFERENCE ON COMPUTER AND INFORMATION SCIENCE, 9, 2010, Kaminoyama (Yamagata), Japan. Proceedings... Washington, DC, USA: IEEE Computer Society, 2010. p.755-759.

KANG, K. C. et al. FORM: A feature-oriented reuse method with domain-specific reference architectures. Annals of Software Engineering, v. 5, n. 1, p. 143-168, 1998.

KEULER, T.; LEHNER, T.; DECKER, B. \& MUTHIG, D. Efficient implementation of intelligent office appliances with software product lines. In: Biennial Conference on Professional Knowledge Management, 3, 2005. Proceedings... [S.l]: Springer-Verlag, 2005, p. 60-69.

KITCHENHAM, B. Guidelines for Performing Systematic Reviews in Software Engineering. Keele University, EBSE Technical Report-2007-01., 2007.

KITCHENHAM, B.; PICKARD, L.; PFLEEGER, S. L. Case studies for method and tool evaluation. IEEE Software, 1995, 12, 52-62.

LEE, J.; KOTONYA, G. Combining Service-Orientation with Product Line Engineering. IEEE Software, v. 27, n. 3, p. 35-41, 2010.

LEE, J.; MUTHIG, D.; NAAB, M. An Approach for Developing Service Oriented Product Lines. In: INT. SOFTWARE PRODUCT LINE CONFERENCE, 12, 2008, Limerick, Ireland. Proceedings... Washington, DC, USA: IEEE Computer Society, 2008. p.275-284. 
LEITNER, A.; KREINER, C. Managing ERP configuration variants: An experience report In: Workshop on Knowledge-Oriented Product Line Engineering, 2010. Proceedings... New York: ACM, 2010, p.2:1-2:6.

LÜBKE, D. Unit Testing WS-BPEL Compositions. In: BARESI, L.; NITTO, E. D. (ed.). Test and Analysis of Web Services. Springer, 2007, p. 149-171.

MCCABE, F. et al. Web Services Architecture. W3C Note, W3C, 2004. Disponível em: <http://www.w3.org/TR/ws-arch/>. Acesso em: jan. 2012.

MCGREgOR, J. D. The Evolution of Product Line Assets. Technical Report, SEI, 2003. Disponível em: <http://www.sei.cmu.edu/library/abstracts/reports/03tr005.cfm>. Acesso em: jan. 2012.

MEDEIROS, F.; DE ALMEIDA, E.; MEIRA, S. SOPLE-DE: An Approach to Design Service-Oriented Product Line Architectures. In: INT. SOFTWARE PRODUCT LINE CONFERENCE, 14, 2010, Jeju Island. Proceedings... [S. l.]: Springer, 2010. v. 6287. p. 456460.

MEJIA BERNAL, J. F.; FALCARIN, P.; MORISIO, M.; DAI, J. Dynamic context-aware business process: a rule-based approach supported by pattern identification In: ACM Symposium on Applied Computing, 2010, Sierre, Switzerland. Proceedings... New York, NY, USA: ACM, 2010, 470-474.

MENDONÇA, M.; BRANCO, M. \& COWAN, D. D. S.P.L.O.T.: software product lines online tools. In: Companion to the 24th Annual ACM SIGPLAN Conference on ObjectOriented Programming, Systems, Languages, and Applications, OOPSLA, 2009, Orlando, Florida. Proceedings... New York: ACM, 2009, p. 761-762.

MONTERO, I. A Methodology Fragment for Developing Families of Business Information Systems: Improving the Design of Business Families for Service Oriented University of Seville, Technical Report, 2009.

MONTERO, I.; PENA, J. \& RUIZ-CORTÉS, A. Representing runtime variability in business-driven development systems. In: 7th International Conference on CompositionBased Software Systems, 2008. Proceedings... [S.l]: IEEE Computer Society, 2008a, p. 228231.

MONTERO, I.; PENA, J.; RUIZ-CORTES, A. From Feature Models to Business Processes. In: IEEE International Conference on Services Computing. Proceedings... v. 2, IEEE Computer Society, 2008b, 605-608.

MOREIRA, A. M. P.; LEÃO, F. B. C.; LOPES, S. P.; FARIA, F.; AZEVEDO, L. G. WSBPEL: Principais Conceitos e Uso Prático. Universidade Federal do Estado do Rio de Janeiro (UNIRIO), Relatório Técnico Nº 0011/2011, 2011.

NEIGHBORS, J. M. The Evolution from Software Components to Domain Analysis International Journal of Software Engineering and Knowledge Engineering (SEKE), 1992, 02, p. 325-354. 
NETO, P. M. S.; MACHADO, I. C.; CAVALCANTI, Y.; ALMEIDA, E.; GARCIA, V.; MEIRA, S. R. de L. A Regression Testing Approach for Software Product Lines In: Symposium on Architectures Software Components, Architectures and Reuse (SBCARS), 4, 2010. Proceedings... [S.l]: IEEE, 2010, p. 41 -50.

NETO, P. M. S.; RUNESON, P.; MACHADO, I. M.; ALMEIDA, E.; MEIRA, S. R. L.; ENGSTROM, E. Testing Software Product Lines Software. IEEE, 2011, 28, 16 -20

NGUYEN, T.; COLMAN, A. A feature-oriented approach for Web service customization. In: INT. CONFERENCE ON WEB SERVICES, 8, 2010, Miami, FL, USA. Proceedings... Los Alamitos, CA, USA: IEEE Computer Society, 2010. p.393-400.

NGUYEN, T.; COLMAN, A.; TALIB, M. A.; HAN, J. Managing service variability: State of the art and open issues. In: Workshop on Variability Modeling of Software-Intensive Systems, 5, 2011, Namur, Belgium. Proceedings... New York: ACM, 2011. p.165-173.

NORTHROP, L. et al. A Framework for Software Product Line Practice, Version 5.0. Disponível em: <http://www.sei.cmu.edu/productlines/framework.html, 2012>. Acesso em: jan. 2012.

NUNES, V. T.; WERNER, C. M. L.; SANTORO, F. M. Dynamic process adaptation: A context-aware approach. In: International Conference on Computer Supported Cooperative Work in Design (CSCWD), 15, 2011, Lausanne, Switzerland. Proceedings... [S.l]: IEEE Computer Society, 2011, 97-104

OASIS. Web Services Business Process Execution Language (WSWS-BPEL). 2007. Disponível em: <http://www.oasis-open.org/committees/tc_home.php?wg_abbrev=wsWSBPEL>. Acesso em: jan. 2012.

OMG. Business Process Model and Notation (BPMN) Version 2.0. 2011. Disponível em: $<$ http://www.bpmn.org/>. Acesso em: jan. 2012.

OMG. Unified Modeling Language (UML) Version 2.0. 2005. Disponível em: $<$ http://www.bpmn.org/>. Acesso em: jan. 2012.

OUYANG, C.; DUMAS, M.; VAN DER AALST, W. M. P.; HOFSTEDE, A. H. M. T.; MENDLING, J. From business process models to process-oriented software systems. ACM Trans. Softw. Eng. Methodol., ACM, 2009, v. 19(1), p. 2:1-2:37.

PAPAZOGLOU, M. P.; TRAVERSO, P.; DUSTDAR, S.; LEYMANN, F. Service-oriented computing: A research roadmap International. Journal of Cooperative Information Systems (IJCIS), 2008, 17, p. 223-255.

PENTA, M.; BRUNO, M.; ESPOSITO, G.; MAZZA, V.; CANFORA, G. Web Services Regression Testing. In: BARESI, L.; NITTO, E. D. (ed.) Test and Analysis of Web Services. Springer, 2007, p. 205-234.

PETERSEN, K., FELDT, R., MUJTABA, S. AND MATTSSON, M. Systematic mapping studies in software engineering. In: Int. Conf. on Evaluation and Assessment in Software Engineering, 12, 2008. [S.1,]: , 2008, p. 1-10. 
POHL, K.; BÖCKLE, G.; LINDEN, F. J. van der. Software Product Line Engineering: Foundations, Principles and Techniques. Springer, 2005.

PUHLMANN, F.; SCHNIEDERS, A.; WEILAND, J.; WESKE, M. Variability Mechanisms for Process Models. BMBF-Project, 2005 (TR 17/2005).

ROCHA, R. dos S., FANTINATO, M., BARROS, V. A. Contribuições de Linha de Produto e Orientação a Serviços no Desenvolvimento de Sistemas de Informação. In: VIII Simpósio Brasileiro de Sistemas de Informação (SBSI), São Paulo: 2012. Anais... Porto Alegre: Sociedade Brasileira de Computação, v. 1. São Paulo, 2012, p. 91-102.

ROSEMANN, M.; AALST, W. M. P. van der. A configurable reference modeling language. Inf. Syst., Elsevier Science Ltd., 2007, 32, 1-23.

SALLES, G. B. M.; FANTINATO, M. Análise da Incorporação de Requisitos não Funcionais na Modelagem de Processos de Negócio. In: VIII Simpósio Brasileiro de Sistemas de Informação (SBSI), São Paulo: 2012. Anais... Porto Alegre: Sociedade Brasileira de Computação, 2012, v. 1, p. 79-90.

SCHNIEDERS, A.; PUHLMANN, F. Variability Mechanisms in E-Business Process Families. In: International Conference on Business Information Systems (BIS 2006). Proceedings... [S.l.]: 2006, p. 583-601.

SCHULZ-HOFEN, J.; GOLEGA, S. Generating web applications from process models. In: International Workshop on Model Driven Web Engineering, 2, 2006. Proceedings... New York: ACM, 2006, 6 p.

SEGURA, S.; BENAVIDES, D.; RUIZ-CORTÉS, A.; TRINIDAD, P. A Taxonomy of Variability in Web Service Flows. In: WORKSHOP ON SERVICE-ORIENTED ARCHITECTURES AND SOFTWARE PRODUCT LINES, 1, 2007, Kyoto, Japan. Proceedings... Hanscom AFB, MA: SEI, 2007. p. B1-B7.

SILVA, D. M.; SANTOS, F. J. N.; AZEVEDO, L. G. WS-Policy: conceitos e propostas de uso. Universidade Federal do Rio de Janeiro, 2011(0010/2011).

SIY, H.; WOLFSON, A.; ZAND, M. Ontology-based product line modeling and generation. In: International Workshop on Product Line Approaches in Software Engineering, 2, 2011. Proceedings... New York: ACM, 2011, p. 50-54.

TEVANLINNA, A.; TAINA, J. \& KAUPPINEN, R. Product family testing: a survey SIGSOFT Softw. Eng. Notes, ACM, 2004, 29, p. 12-12.

THOM, L. H.; IOCHPE, Cirano. BPMN 2.0 - Notação e Modelo de Processo de Negócio, 2010. Disponível em: <http://www.bpmb.de/images/BPMN2_0_Poster_PT.pdf>. Acesso em: nov. 2012.

TIZZO, N. P.; COELLO, J.; CARDOZO, E. Improving dynamic Web service selection in WS-BPEL using SPARQL. In: IEEE International Conference on Systems, Man, and Cybernetics (SMC), 2011. Proceedings... [S.l.]: IEEE, 2011, p. 864 -871.

TRAVASSOS, G. H. Introdução à Engenharia de Software Experimental. Relatório Técnico - COPPE, UFRJ, Rio de Janeiro, 2002. 
TRUJILLO, S.; KÄSTNER, C.; APEL, S. Product Lines that Supply Other Product Lines: A Service-Oriented Approach. Proceedings - In: WORKSHOP ON SERVICE-ORIENTED ARCHITECTURES AND SOFTWARE PRODUCT LINES, 1, 2007, Kyoto, Japan. Proceedings... Hanscom AFB, MA: SEI, 2007. p. E1-E6.

VEDAMUTHU, A. S.; ORCHARD, D.; HIRSCH, F.; HONDO; M.; YENDLURI; P.; BOUBEZ, T.; YALÇINALP, Ü. Web Services Policy 1.5 - Primer. W3C Standard, 2006. Disponível em: <http://www.w3.org/TR/2006/WD-ws-policy-primer-20061221/>. Acesso em: jun. 2012.

WEBER, B.; SADIQ, S. W.; REICHERT, M. Beyond rigidity - dynamic process lifecycle support. Computer Science - R\&D, 2009, v. 23(2), p. 47-65.

WEERAWARANA, S.; CURBERA, F.; LEYMANN, F.; STOREY, T.; FERGUSON, D. F. Web Services Platform Architecture: SOAP, WSDL, WS-Policy, WS-Addressing, WSBPEL, WS-Reliable Messaging, and More. 1. ed. Prentice Hall, 2005.

WESKE, MATHIAS. Business Process Management: Concepts, Languages, Architectures. 1. ed. Springer, 2007.

XU, X.; SUN, H.; LI, X.; ZHOU, C. A basing on model-driven framework of service-oriented software production line. In: Proceedings of the 2nd International Symposium on Computational Intelligence and Design, 2, 2009. Proceedings... [S.1]: IEEE Computer Society, 2009, 2, p. 139-145.

YE, E.; MOON, M.; KIM, Y.; YEOM, K. An approach to designing service-oriented productline architecture for business process families. In: INT. CONFERENCE ON ADVANCED COMMUNICATION TECHNOLOGY, 11, 2007, Phoenix Park, Republic of Korea. Proceedings... [S. 1.]: IEEE, 2007. v. 2. p. 999-1002.

YIN, R. K. Case Study Research: Design and Methods. 4. ed., Sage Publications, 2008.

ZAUPA, F.; GIMENES, I. M. S.; COWAN, D.; ALENCAR, P.; LUCENA, C. J. P. A service-oriented process to develop web applications. Journal of Universal Computer Science (J.UCS), 2008, 14, p.1368-1387. 


\section{ANEXO A - Artigos Publicados e em Avaliação}

Este anexo apresenta os artigos relacionados à proposta apresentada nesta dissertação que foram publicados ou que estão em processo de avaliação para posterior publicação.

\section{A.1 Artigos Publicados}

\begin{tabular}{|l|l|}
\hline Título & $\begin{array}{l}\text { Uma Abordagem Dinâmica de Linha de Produto para Gestão de Processos de } \\
\text { Negócio }\end{array}$ \\
\hline Autores & Roberto dos Santos Rocha, Marcelo Fantinato \\
\hline Evento & V Workshop de Teses e Dissertações em Sistemas de Informação - WTDSI \\
\hline Local & São Paulo - SP \\
\hline Data & Maio de 2012 \\
\hline Publicação & SBC - Sociedade Brasileira de Computação \\
\hline
\end{tabular}

\begin{tabular}{|l|l|}
\hline Título & $\begin{array}{l}\text { Contribuições de Linha de Produto e Orientação a Serviços no } \\
\text { Desenvolvimento de Sistemas de Informação }\end{array}$ \\
\hline Autores & Roberto dos Santos Rocha, Marcelo Fantinato, Vitor Almeida Barros \\
\hline Evento & VIII Simpósio Brasileiro de Sistemas de Informação - SBSI 2012 \\
\hline Local & São Paulo - SP \\
\hline Data & Maio de 2012 \\
\hline Publicação & SBC - Sociedade Brasileira de Computação \\
\hline
\end{tabular}

\section{A.2 Artigo em Avaliação}

\begin{tabular}{|l|l|}
\hline Título & $\begin{array}{l}\text { The use of software product lines for business process management: A } \\
\text { systematic literature review }\end{array}$ \\
\hline Autores & Roberto dos Santos Rocha, Marcelo Fantinato \\
\hline Periódico & Information and Software Technology \\
\hline Publicação & Elsevier \\
\hline Situação & Revisado e submetido para segunda avaliação em 20 de setembro de 2012 \\
\hline
\end{tabular}

